\title{
IUCN
}

\section{IUCN Guidelines for gathering of fishers' knowledge for policy development and applied use}

Winston Cowie, Dr. Shaikha Al Dhaheri, Ahmed Al Hashmi, Vivienne Solis-Rivera, Claudio Baigun, Kevin Chang, Dr. Rosie Cooney, Shaelene Kamaka'ala, Dr. Ken Lindeman, Christiana Louwa, Dr. Dilys Roe, Kristen Walker-Painemilla, Reem Al Baharna, Mohsin Al Ameri, Shamsa Al Hameli, Kholood Al Jaberi, Nessrine Alzahlawi, Rajeyah Binkulaib, Yassir Al Kharusi

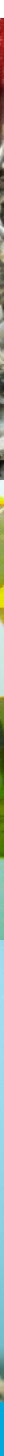
ESSSC 

IUCN is a membership Union uniquely composed of both government and civil society organisations. It provides public, private and non-governmental organisations with the knowledge and tools that enable human progress, economic development and nature conservation to take place together.

Created in 1948, IUCN is now the world's largest and most diverse environmental network, harnessing the knowledge, resources and reach of more than 1,400 Member organisations and more than 15,000 experts. It is a leading provider of conservation data, assessments and analysis. Its broad membership enables IUCN to fill the role of incubator and trusted repository of best practices, tools and international standards.

IUCN provides a neutral space in which diverse stakeholders including governments, NGOs, scientists, businesses, local communities, indigenous peoples organisations and others can work together to forge and implement solutions to environmental challenges and achieve sustainable development.

Working with many partners and supporters, IUCN implements a large and diverse portfolio of conservation projects worldwide. Combining the latest science with the traditional knowledge of local communities, these projects work to reverse habitat loss, restore ecosystems and improve people's well-being.

www.iucn.org

https://twitter.com/IUCN/

\section{IUCN Sustainable Use and Livelihoods Group (SULi)}

IUCN's Sustainable Use and Livelihoods Specialist Group (SULi) is a global expert network formed by IUCN as a joint initiative of the Species Survival Commission (SSC) and the Commission on Environmental, Economic and Social Policy (CEESP). Bridging the social and biological science strengths of SSC and CEESP, it is uniquely placed to provide credible, sound technical advice on sustainable use

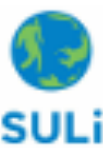
and livelihoods. SULi includes almost 300 experts from the intergovernmental, government, academic, private and NGO sectors, who bring a diverse array of relevant expertise: from technical management of forestry, fisheries, medicinal plants and wildlife, to traditional knowledge, community based natural resource management, and rural development. It operates in a manner inclusive of diverse opinions, encouraging debate based on evidence, and seeking to develop and provide knowledge-based and objective positions and advice. It is led by a Chair appointed by the Commission Chairs, Deputy Chairs for regions in which active groups focusing on regional issues have been formed, and a Steering Committee. SULi's mission is to promote both conservation and livelihoods through enhancing equitable and sustainable use of wild species and their associated ecosystems.

https://iucnsuli.org/

\section{IUCN Species Survival Commission (SSC)}

The IUCN SSC is a science-based network of more than 9,000 volunteer experts from almost every country of the world, all working together towards achieving the vision of, "A just world that values and conserves nature through positive action to reduce the loss of diversity of life on

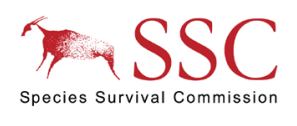
earth". Working in close association with IUCN's Global Species Programme, SSC's major role is to provide information to IUCN on biodiversity conservation, the inherent value of species, their role in ecosystem health and functioning, the provision of ecosystem services, and their support to human livelihoods. This information is fed into the IUCN Red List of Threatened Species ${ }^{\mathrm{TM}}$. SSC members also provide scientific advice to conservation organisations, government agencies and other IUCN members, and support the implementation of multilateral environmental agreements. The Policies, Guidelines \& Standards produced by the SSC provide guidance to specialized conservation projects and initiatives, such as re-introducing animals into their former ranges, handling confiscated specimens, and halting the spread of invasive species.

\section{https://www.iucn.org/commissions/species-survival-commission/about}

\section{IUCN Commission on Environmental, Economic and Social Policy (CEESP)}

CEESP is a unique IUCN network of approximately 1,500 volunteers representing disciplines from biology and anthropology, economics and law, to culture and indigenous peoples - among many others.

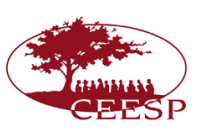
Our work represents the crossroads of conservation and development. CEESP contributes to the IUCN Mission by providing insights and expertise and promoting policies and action to harmonize the conservation of nature with the crucial socio-economic and cultural concerns of human communities-such as livelihoods, human rights and responsibilities, human development, security, equity, and the fair and effective governance of natural resources. CEESP's natural and social scientists, environmental and economic policy experts, and practitioners in communitybased conservation provide IUCN with critical resources to meet the challenges of twenty-first century nature and natural resource conservation and the goal of shaping a sustainable future. 
IUCN Snapper Grunt and Seabream Specialist Group (SSG SG)

The IUCN SSG SG works to achieve global conservation and sustainable use of snappers, seabreams, grunts, and associated reef-fish species through the application of improved scientific knowledge and community engagement to management decision-making.Underpinning these efforts are the following foundational attributes of the biology and management of SSG SG species.

1. The fishes in this Specialist Group can inhabit nearly every hardbottom, softbottom, estuarine and marine habitat in tropical through temperate regions globally.

2. Some of the most valuable fishes on the planet are in this SG. Many species are sold as "red snapper" and hundreds of other species, ubiquitous protein sources, occur across tropical through temperate coastal regions.

3. Data is typically very limited; when available, fishery, ecological, and Red List assessments suggest that almost all species are subject to heavy fishing pressure, habitat loss, and climate change threats that are not decreasing.

https://www.iucn.org/commissions/ssc-groups/fishes/snapper-seabream-and-grunt-specialist-group

\section{World Forum of Fisher Peoples}

The World Forum of Fisher Peoples (WFFP) has 29 member organisations from 23 countries and represents over 10 million fisher people from all over the world. WFFP supports its members to strengthen their organisational capacities, and it advocates

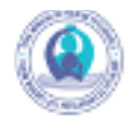

FOAD WJNaIL te FuteLOS PESCADOHES WORLD FORUN OF FISHER PEOPLES

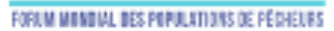
for the rights of fisher people to access and manage fisheries resources, for human rights and for the protection of natural biodiversity. WFFP also represents the interests of its constituencies at regional and international levels. Founded on 21 November 1997 in New Delhi, India, by a number of mass-based organisations from the Global South, WFFP was established in response to the increasing pressure being placed on small-scale fisheries, including habitat destruction, anthropogenic pollution, encroachment on small-scale fishing territories by the large scale fishing fleets, illegal fishing and overfishing. Years later climate change was added to the list of threats that WFFP addresses in its work.

https://worldfishers.org/

\section{Environment Agency - Abu Dhabi (EAD)}

Established in 1996, the Environment Agency - Abu Dhabi (EAD) based in the United Arab Emirates is committed to protecting and enhancing air quality, groundwater as well as the biodiversity of our desert and marine ecosystem. By partnering with other government

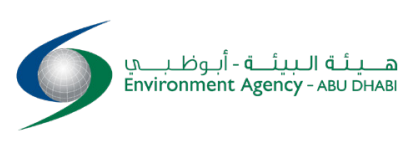
entities, the private sector, NGOs and global environmental agencies, we embrace international best practice, innovation and hard work to institute effective policy measures. We seek to raise environmental awareness, facilitate sustainable development and ensure environmental issues remain one of the top priorities of our national agenda.

www.ead.gov.ae

\section{International Planning Committee Working Group on Fisheries}

The International Planning Committee Working Group on Fisheries organizes internal meetings, workshops, trainings and consultations on different issues. These meetings are fundamental to: build the capacities of the grassroots organizations; receive feedbacks from the ground; raise the awareness on global issues and negotiations; strengthen the struggles at national and regional levels; raise the voice of small scale producers to the decision-making spaces; strengthen the exchange from farmer to farmer from the North to the South and from the East to the West. The

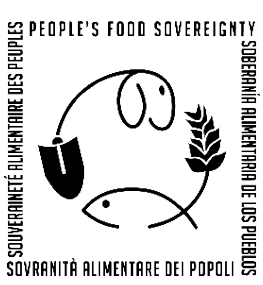
Group was fundamental to the development of the Voluntary Guidelines for Securing Sustainable Small-Scale Fisheries in the Context of Food Security and Poverty Eradication (SSF-Guidelines) (2015).

https://www.foodsovereignty.org/working_groups/fisheries/ 


\section{IUCN Guidelines for gathering of fishers' knowledge for policy development and applied use}

Winston Cowie, Dr. Shaikha Al Dhaheri, Ahmed Al Hashmi, Vivienne Solis-Rivera, Claudio Baigun, Kevin Chang, Dr. Rosie Cooney, Shaelene Kamaka'ala, Dr. Ken Lindeman, Christiana Louwa, Dr. Dilys Roe, Kristen Walker-Painemilla, Reem Al Baharna, Mohsin Al Ameri, Shamsa Al Hameli, Kholood Al Jaberi, Nessrine Alzahlawi, Rajeyah Binkulaib, Yassir Al Kharusi 
The designation of geographical entities in these Guidelines, and the presentation of the material, do not imply the expression of any opinion whatsoever on the part of IUCN, the Environment Agency - Abu Dhabi or other participating organisations concerning the legal status of any country, territory, or area, or of its authorities, or concerning the delimitation of its frontiers or boundaries.

The views expressed in this publication do not necessarily reflect those of IUCN, the Environment Agency - Abu Dhabi, or other participating organisations.

IUCN is pleased to acknowledge the support of its Framework Partners who provide core funding: Ministry for Foreign Affairs of Finland; Government of France and the French Development Agency (AFD); the Ministry of Environment, Republic of Korea; the Norwegian Agency for Development Cooperation (Norad); the Swedish International Development Cooperation Agency (Sida); the Swiss Agency for Development and Cooperation (SDC) and the United States Department of State.

This publication has been made possible in part by funding from the Environment Agency - Abu Dhabi.

Published by: IUCN, Gland, Switzerland in collaboration with the Environment Agency - Abu Dhabi

Copyright: ( 2020 IUCN, International Union for Conservation of Nature and Natural Resources, and the Environment Agency - Abu Dhabi

Reproduction of this publication for educational or other non-commercial purposes is authorised without prior written permission from the copyright holder provided the source is fully acknowledged.

Reproduction of this publication for resale or other commercial purposes is prohibited without prior written permission of the copyright holder.

Citation: Cowie, W., Al Dhaheri, S., Al Hashmi, A., Solis-Rivera, V., Baigun, C., Chang, K., Cooney, R., Kamaka'ala, S., Lindeman, K., Louwa, C., Roe, D., Walker-Painemilla, K., Al Baharna, R., Al Ameri, M., Al Hameli, S., Al Jaberi, K., Alzahlawi, N, Binkulaib, R., Al Kharusi, Y. (2020). IUCN Guidelines for gathering of fishers' knowledge for policy development and applied use. IUCN, Gland, Switzerland; and Environment Agency Abu Dhabi, United Arab Emirates.

ISBN: $\quad$ 978-2-8317-2074-6 (PDF)

DOI: $\quad$ https://doi.org/10.2305/IUCN.CH.2020.11.en

Cover photo: Top left: Christiana Louwa. Elmolo Tribal Elder. Lake Turkana. Kenya Source: Christiana Louwa. Top Middle: Fujairah Fishers utilising the dhagwa technique. United Arab Emirates. Source: Environment Agency - Abu Dhabi. Top right: Juvenile pelagics caught utilising the dhagwa technique. Source: Environment Agency Abu Dhabi. Middle Left: Fishers using a cast net in the Pilcomato River, Bolivia. Source: Claudio Baigun. Middle: Fishing boat off Sok San village, Koh Rong. Source: Jeremy Holden / Flora and Fauna International. Middle right: Schooling Zuraidi / Golden Trevally. Abu Dhabi. United Arab Emirates. Source: Environment Agency - Abu Dhabi. Bottom left: Fisherwomen preparing fish for the market. Cabuya, Marine Management Area. Costa Rica. Source: CoopeSoliDar R.L, 2019. Bottom middle: Traditional Knowledge Interview. Abu Dhabi. United Arab Emirates. Source: Environment Agency - Abu Dhabi. Bottom right: Hamour / Orange Spotted Grouper. Source: Environment Agency - Abu Dhabi.

Layout by: Environment Agency - Abu Dhabi and IUCN. Design by Nouf AI Qemzi, Senior designer.

\section{Available from:}

IUCN, International Union for Conservation of Nature

Sustainable Use and Livelihoods Group

Rue Mauverney 28

1196 Gland

Switzerland

Tel +41229990000

Fax +41229990002

Email: suli.iucn@gmail.org

www.iucn.org/resources/publications

\author{
Environment Agency - Abu Dhabi \\ Al Mamoura Building \\ Murour Road \\ Abu Dhabi \\ United Arab Emirates \\ Tel: +971 (2) 6934444 \\ Email: customerservice@ead.gov.ae \\ www.ead.ae/resources
}




\section{Contents}

Foreword

\section{Introduction}

1.1. Purpose

1.2. Who do these Guidelines apply to?

1.3. Which fisheries are these Guidelines applicable to?

1.4. Why are these Guidelines needed?

1.5. Objectives

1.6. How were these Guidelines developed?

2 What is fishers' knowledge?

2.1 Fishers' knowledge definition

2.2 What is traditional knowledge?

2.3 What is traditional fishing knowledge?

2.3.1 Traditional fishing knowledge definition

3.1.1 Convention on Biological Diversity (1992) 7

3.1.2 Aichi Targets (2011-2020)

3.1.3 UN Code of Conduct for Responsible Fisheries (1995)

3.1.4 UN Declaration on the Rights of Indigenous Peoples (2007)

3.1.5 Nagoya Protocol (2010)

3.1.6 UN FAO Voluntary Guidelines for Securing Sustainable Small-Scale Fisheries

in the Context of Food Security and Poverty Eradication (2015)

3.1.7 UN Sustainable Development Goals (2015)

3.1.8 CBD Training Manual on the incorporation of Traditional Knowledge into the description and identification of Ecologically or Biologically Significant Marine Areas (2016)

3.1.9 Mataatua Declaration on Cultural and Intellectual Property Rights of Indigenous Peoples (1993) 10

4 How do we gather fishers' knowledge?

4.1 Phase 1: setting objectives, gathering and recording FK

4.1.1 Setting FK research objectives

4.1.2 International framework review

4.1.3 Locality FK literature review

4.1.4 FK - identifying what information to gather

4.1.5 Developing questions

4.1.6 Consent and ethical considerations

4.1.7 Who should be engaged?

4.1.8 Survey sample size

4.1.9 Facilitator / interviewer briefing

4.1.10 Method of gathering traditional knowledge $\quad 15$

4.1.11 Videoing the engagement 16

4.1.12 Recorded baseline $\quad 16$

4.1.13 Data analysis $\quad 16$

$\begin{array}{ll}\text { 4.1.14 Feedback to fishers } & 16\end{array}$

5 How can we apply fishers' knowledge in fisheries policy and today's society? 19

5.1 Phase 2: Fishers' knowledge - applied use framework 19

$\begin{array}{ll}5.1 .1 \text { Fisheries policy } & 21\end{array}$

5.1.2 FK and the Aichi Targets $\quad 24$ 
Bibliography

Appendix: Resources and case studies

Africa 35

Regional experts

Case study - Lake Turkana, Kenya, Africa

Case study - Lake Victoria, Tanzania, Africa

Asia 40

Regional experts

Case study - Koh Rong Archipelago, Cambodia 41

Case study - Tonle Sap Great Lake, Cambodia 43

Case study - Aceh Province, Indonesia $\quad 46$

Case study - United Arab Emirates, Middle East $\quad 48$

\section{Caribbean}

Regional experts

Case study - Greater Caribbean $\quad 51$

$\begin{array}{ll}\text { Central and South America } & 53\end{array}$

Regional experts

Case study - Parana River Basin, Argentina $\quad 54$

Case study - Tárcoles, Pógeres, and La Pita, Costa Rica, Central America $\quad 57$

Case study - Chomes, Puntarenas, Costa Rica, Central America $\quad 59$

$\begin{array}{ll}\text { Pacific } & 61\end{array}$

Regional experts 61

Case study - Mo'omomi, Moloka'i, Hawai'i, United States of America 62

Case study - Local Managed Marine Areas Guidelines, Melanesia $\quad 65$

Case study - Aotearoa / New Zealand $\quad 68$

Case study - Aotearoa / New Zealand $\quad 70$

Case study - Aotearoa / New Zealand

Case study - Solomon Islands $\quad 74$ 


\section{Foreword}

In the Arabian Gulf, the sea is a fundamental part of our heritage, and has always been our gateway to the world. In day's past, the sea and its fisheries sustained and maintained us; it enabled us to survive. Around the world and now days it is no different - globally fish accounts for about 17 percent of the global population's intake of animal protein and provides about 3.2 billion people on the planet with nearly 20 percent of their animal protein. Yet around $90 \%$ of global fish stocks are either fully exploited or in decline.

Achieving sustainable fisheries and seeking to maintain traditional links in society today is a challenge and one that the International Union for Conservation of Nature (IUCN) and Environment Agency - Abu Dhabi (EAD) is proud to be working with the

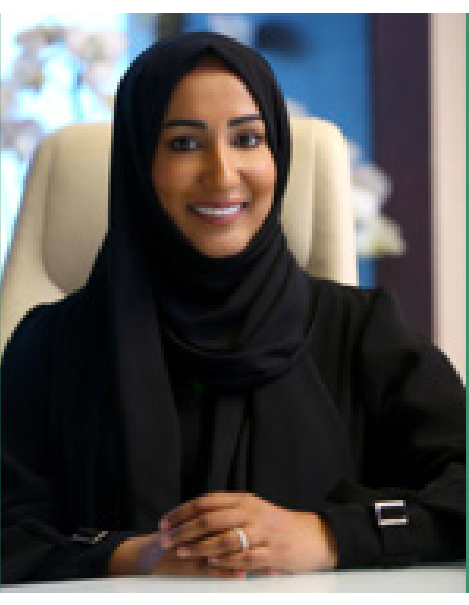
international community to solve. By looking to the past and drawing lessons from what worked and what didn't, what our beliefs were and how we interacted with the natural world, we are able to draw inspiration and develop contemporary uses for this knowledge.

These voluntary IUCN Guidelines for gathering of fishers' knowledge for policy development and applied use (the “Fishers' Knowledge Policy Development Guidelines") provide much needed practical and theoretical guidance on what and how gathering Fishers' Knowledge can be utilised in policy development and in society today. Fishers' Knowledge includes indigenous and traditional knowledge and experienced persons who have been involved in a fishery and community over an extended period of time.

These Guidelines are complimentary to international instruments and guidelines including the Convention of Biological Diversity, Aichi Targets, to the United Nations (UN) Code of Conduct on Responsible Fisheries to the UN Small-Scale Fisheries Guidelines all of which highlight the importance of integrating traditional fishing knowledge in resource management decision making. These are the first internationally agreed guidelines that focus specifically on 'what' Fishers' Knowledge can be gathered', 'why' it should be gathered, 'how' it can be gathered, and 'how' it can be applied today, in partnership.

The development of these Guidelines followed a robust participatory process, led by the IUCN Sustainable Use and Livelihoods Group (SULi), with the partnership of EAD and consulted with stakeholders from subject matter experts to governments, small-scale fisher organisations, indigenous fisher organisations, civil society organisations, research and academia, and the private sector.

I would like to personally thank the 50 experts who gave their time and provided case studies of excellence in Fisheries Knowledge resource management in Argentina; Cambodia; the Caribbean; Costa Rica; Indonesia; Kenya; Melanesia; New Zealand; Solomon Islands; Tanzania; the United Arab Emirates; and the United States of America.

As IUCN Councillor for West Asia, I am proud to have contributed to these Guidelines and know that they will help fisheries resource managers, (both marine and freshwater) at the community, local, regional and national levels in countries in fulfilling international traditional knowledge and sustainable fisheries targets.

\section{Dr. Shaikha Al Dhaheri IUCN Councillor West Asia \\ Secretary General, Environment Agency - Abu Dhabi}




\section{Abstract}

Small-scale fisheries provide food security, livelihoods and income to millions of people but their management still presents a challenge to managers and other stakeholders due to problems in gathering suitable information and its incorporation in fisheries policy. Fishers are a key source of knowledge for assessment of both extractive capacity and value in small-scale fisheries, in addition to providing a broad array of cultural knowledge. However, they have often been excluded from processes of data collection, analysis, interpretation and management. The increasing recognition of the value of incorporating traditional fishing knowledge in freshwater, riverine, lacustrine and coastal and marine fisheries management is now evident in international conventions and published literature. The purpose of these Guidelines is to make it easier for users to recognise and include fishers' knowledge as an important data stream in resource management. We present details on the breadth of knowledge that can be gathered, how it can be gathered, and how this information can be applied to support sustainable fisheries policy and broader applications in society. These are voluntary guidelines that are intended to be used by fisheries resource managers at the local, regional and national levels; by communities, non-governmental organisations (NGOs) and researchers.

\section{Key messages:}

1. Fishers' knowledge can provide valuable information to apply in support of assessments of extractive capacity and value in small scale fisheries, in addition to providing a broad array of cultural knowledge.

2. Fishers' knowledge is defined in these guidelines as: "The cumulative body of knowledge, practice and belief, evolving by adaptive processes and handed down through generations by cultural transmission, about the relationship of living beings (including humans) with one another, their environment and specifically fisheries resources. In the fishing context it includes contribution to societal living; the types of species caught and not caught - why and when; the methods of fishing; and knowledge of species and seasons. This knowledge may be manifested in myths and legends and in folk taxonomics."

3. The Guidelines are intended to make it easier for users to recognise and include Fishers' knowledge as an important data stream in resource management in small scale fisheries, by presenting details on the breadth of knowledge that can be gathered, how it can be gathered, and how this information can be applied to support sustainable fisheries policy and broader applications in society today.

4. The Guidelines are intended to:

a. Promote the recognition, gathering and recording of a baseline of fishers' knowledge.

b. Value, recognise and encourage the transfer and preservation of this knowledge.

c. Involve fishers in enhancing and applying this knowledge in the modern context in one of five 'applied use' categories:

i. Fisheries policy;

ii. Supporting IUCN Species and Ecosystem Red Listing;

iii. Co-management;

iv. Enhancing transmission and perpetuation of knowledge (books / film) and /or

v. Genetic utilization of biodiversity resource - a Nagoya Protocol use.

5. These Guidelines support the achievement of international conventions including the Convention on Biological Diversity (1992) (CBD) Aichi Targets and particularly Targets 6 and 18; and Goals 2 and 14 of the Sustainable Development Goals; the UN Code of Conduct on Responsible Fisheries and related instruments. 


\section{Acknowledgements}

This publication was made possible thanks to the support of IUCN, specifically the IUCN Species Survival Commission; IUCN Commission on Environmental, Economic and Social Policy (CEESP); IUCN Sustainable Use and Livelihoods Specialist Group (SULi); IUCN Snapper, Seabream and Grunt Specialist Group; Environment Agency - Abu Dhabi (EAD); and World Forum of Fisher Peoples.

Lead Author: Winston Cowie. IUCN SULi. IUCN Snapper Seabream and Grunt Specialist Group. IUCN CEESP. Marine Policy Manager, Environment Agency - Abu Dhabi.

Email: winston.cowie@ead.gov.ae

Working Group: Thanks to the following working group members who coordinated the development of these guidelines:

- H.E. Dr. Shaikha AI Dhaheri, IUCN Councilor for West Asia. Secretary General, Environment Agency - Abu Dhabi.

- Ahmed Al Hashmi, Acting Executive Director, Terrestrial and Marine Biodiversity, Environment Agency - Abu Dhabi.

- Vivienne Solis-Rivera. IUCN SULi, IUCN CEESP, CoopeSoliDar R.L., Costa Rica.

- Claudio Baigún, CONICET-Universidad Nacional de San Martin, Buenos Aires, Argentina.

- Dr. Rosie Cooney, Honorary Senior Fellow, Fenner School of Environment and Society, Australian National University. Former Chair of IUCN SULi.

- Kevin Chang, Co-Director, Kua'āina Ulu 'Auamo, Hawai'i, United States of America.

- Shaelene Kamaka'ala, Community Based Subsistence Fisheries Coordinator, State of Hawai'i, Department of Land and Natural Resources, Division of Aquatic Resources, United States of America (Previous).

- Dr. Ken Lindeman, Co-chair, IUCN Snapper, Seabream and Grunt Specialist Group. Program in Sustainability, Florida Institute of Technology, United States of America.

- Christiana Louwa, United Nations Food and Agriculture Organization International Planning Committee for Food Sovereignty Fisheries Working Group, Kenya. Chair, World Forum for Fisher Peoples.

- Dr. Dilys Roe. Chair. IUCN SULi. International Institute for Environment and Development, United Kingdom.

- Kristen Walker-Painemilla. Chair. IUCN CEESP. Centre for Communities and Conservation. Conservation International, United States of America.

- Mohsin Al Ameri, Assistant Fisheries Scientist, Environment Agency - Abu Dhabi.

- Reem Al Baharna, Section Manager - Fisheries, Environment Agency - Abu Dhabi.

- Shamsa Al Hameli, Assistant Fisheries Scientist, Environment Agency - Abu Dhabi.

- Kholood Al Jaberi, Marine Policy Analyst, Environment Agency - Abu Dhabi.

- Nessrine Alzahlawi. Unit Head, Terrestrial Policy, Environment Agency - Abu Dhabi, United Arab Emirates.

- Rajeyah Binkulaib. Senior Analyst, Terrestrial Policy, Environment Agency - Abu Dhabi, United Arab Emirates.

- Yassir Al Kharusi. Analyst, Terrestrial Policy, Environment Agency - Abu Dhabi, United Arab Emirates.

We would like to thank the 50 different international experts who have contributed to and reviewed this publication.

\section{Contributors:}

\section{Environment Agency - Abu Dhabi}

- H.E. Razan Khalifa Al Mubarak, Managing Director, Environment Agency - Abu Dhabi.

- H.E. Dr Shaikha Al Dhaheri, IUCN Councilor for West Asia. Secretary General, Environment Agency - Abu Dhabi.

- Ahmed Al Hashmi, Executive Director, Terrestrial and Marine Biodiversity, Environment Agency - Abu Dhabi.

- Winston Cowie. Marine Policy Manager, Environment Agency - Abu Dhabi.

- Reem Al Baharna, Fisheries Manager, Environment Agency - Abu Dhabi.

- Mohsin Al Ameri, Assistant Fisheries Scientist, Environment Agency - Abu Dhabi.

- Shamsa Al Hameli, Assistant Fisheries Scientist, Environment Agency - Abu Dhabi.

- Kholood Al Jaberi, Policy Analyst, Environment Agency - Abu Dhabi.

- Nessrine Alzahlawi, Terrestrial Policy Unit Head, Environment Agency - Abu Dhabi.

- Rajeyah Binkulaib, Senior Terrestrial Policy, Environment Agency - Abu Dhabi.

- Mohamed Al Marzooqi, Aquaculture Manager, Environment Agency - Abu Dhabi.

- Yassir Al Kharusi, Analyst, Terrestrial Biodiversity Policy, Environment Agency - Abu Dhabi.

- Amna Al Mansoori, Assistant Scientist Marine Habitats, Environment Agency - Abu Dhabi.

- Mohamed Zaabi, Lead Specialist, Fisheries, Environment Agency - Abu Dhabi.

- Sultan Al Ali, Lead Fisheries enumerator, Environment Agency - Abu Dhabi.

- Khalfan Al Suwaidi, Senior Fisheries enumerator, Environment Agency - Abu Dhabi.

- Noora Albalooshi, Assistant Fisheries Scientist, Environment Agency - Abu Dhabi. 


\section{Specialist contributors}

\section{African region:}

- Christiana Louwa, United Nations Food and Agriculture Organization International Planning Committee for Food Sovereignty Fisheries Working Group, Kenya. Chair, World Forum for Fisher Peoples.

- Juvenary E.A. Matagelli, Fishers Union Organization, Tanzania.

\section{Asian region}

- Phallin Chea, Project Officer, Cambodia Marine Coastal Programme, Flora \& Fauna International, Cambodia.

-Winston Cowie, Marine Policy Manager, Environment Agency - Abu Dhabi.

- Henry Duffy, Marine Technical Specialist, Asia-Pacific. Flora \& Fauna International, United Kingdom.

- Dewa Gumay, Aceh Programme Manager, Flora and Flora International, Indonesia

- Soen Pheakday, Water and Wetlands Coordinator. IUCN Cambodia.

\section{Caribbean region}

- Dr. Ken Lindeman, Program in Sustainability, Florida Institute of Technology, United States of America. Co-chair, IUCN Snapper, Seabream and Grunt Specialist Group.

- Dr. Barry Russell, Co-chair, IUCN Snapper, Seabream and Grunt Specialist Group.

\section{Central and South Americas region}

- Claudio Baigún, CONICET-Universidad Nacional de San Martin, Buenos Aires, Argentina.

- Vivienne Solis-Rivera. IUCN SULi, IUCN CEESP, CoopeSoliDar R.L., Costa Rica.

- Trilce Irupé Castillo, CONICET-Universidad Nacional de Rosario, Rosario, Santa Fe, Argentina.

- Aracelly Jiménez, CoopeMolusChomes R.L, Costa Rica.

- Marvin Fonseca Borrás, CoopeSoliDar R.L, Costa Rica

- David Chacón Rojas, CoopeTárcoles R.L., Costa Rica.

\section{Pacific region}

- Kevin Chang, Co-Director, Kua'āina Ulu ‘Auamo, Hawai'i, United States of America.

- Dr Rosie Cooney, Honorary Senior Fellow, Fenner School of Environment and Society, Australian National University Former Chair of IUCN SULI.

- Winston Cowie, Marine Policy Manager, Environment Agency - Abu Dhabi.

- Simon Foale, Associate Professor, James Cook University, Australia.

- Hugh Govan, Senior Fellow, University of the South Pacific, Fiji.

- Doug Jones, Environment Protection Authority, Aotearoa / New Zealand.

- Shaelene Kamaka'ala, Community Based Subsistence Fisheries Coordinator, State of Hawai'i, Department of Land and Natural Resources, Division of Aquatic Resources, United States of America (Previous).

- Solomon Kaho'ohalahala, Maunalei Ahupua'a Restoration Project, E Alu Pū Council Member, Kua‘āina Ulu 'Auamo, Hawai'i, United States of America.

- Jeff Kinch, Principal of the National Fisheries Authority, Papua New Guinea.

- Te Taiawatea Moko-Mead, Senior Policy Analyst, Te Ohu Kaimoana, Aotearoa / New Zealand

- Mehana Vaughan, Associate Professor, University of Hawai'i

- Charles Young, Kama'āna United to Protect the 'Āina (KUPA), E Alu Pū Council Member, Hawai'i, United States of America.

- Mac Poepoe, Hui Mālama o Mo'omomi, E Alu Pū Council Member, Hawai'i, United States of America.

\section{Peer review}

We would like to thank the following international experts for their peer review:

- Doug Jones. General Manager - Kaupapa Kura Taiao Manaautū, Environment Protection Authority, Aotearoa / New Zealand.

- John Kurien. Visiting Professor, Azim Premji University, Bengaluru, India \& Honorary Fellow, WorldFish Centre, Penang.

- Te Taiawatea Moko-Mead, Tai Moana, Senior Policy Analyst, Te Ohu Kaimoana (The Māori Fisheries Trust).

- Kim Drummond, Kurae Moana, Fisheries and Aquaculture Policy Manager, Te Ohu Kaimoana, The Māori Fisheries Trust, New Zealand.

- The wider Te Ohu Kaimoana / The Māori Fisheries Trust whanau: Monique Holmes; Kirsty Woods; Peter van Kampen; Graeme Hastilow; and Dion Tuuta.

We would like to thank staff of the Food and Agriculture Organization (FAO) of the United Nations for their review of an early draft:

- John Jorgensen, Fisheries and Aquaculture Department, Food and Agriculture Organization of the United Nations.

- Daniela Kalikoski, Fisheries and Aquaculture Department, Food and Agriculture Organization of the United Nations.

- Lena Westlund, Fisheries and Aquaculture Department, Food and Agriculture Organization of the United Nations. 


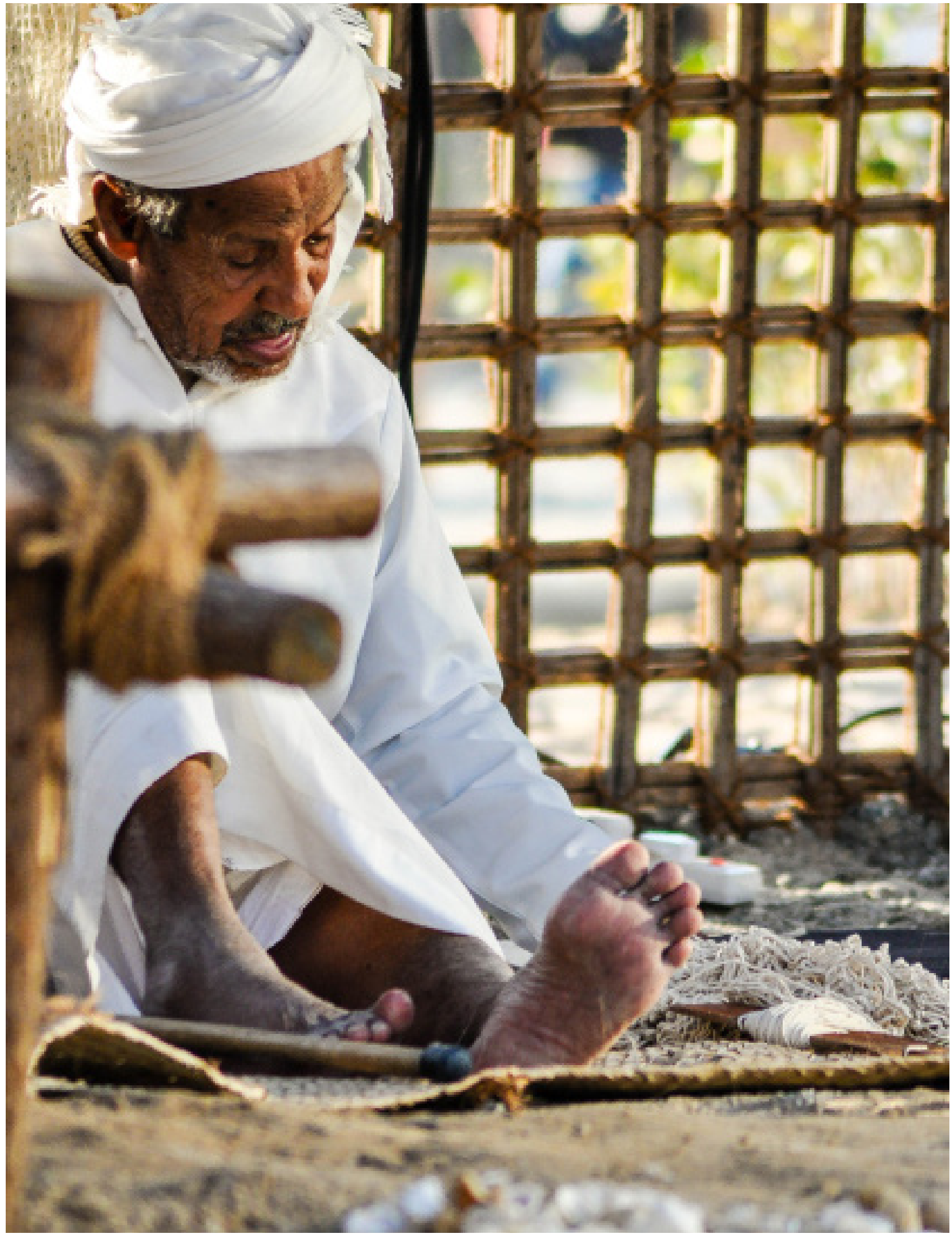

Traditional Net making. Qasr Al Hosn. United Arab Emirates. (c) Environment Agency - Abu Dhabi. 


\section{Introduction}

These International Union for Conservation of Nature (IUCN) Guidelines for the Gathering of Fishers' Knowledge for Policy Development and Applied Use recognise the importance of both indigenous, local marine-coastal community knowledge, and experienced fishers' knowledge (FK) to the development of Fisheries Policy and seeks to provide guidance on 'how to' utilise this rich cultural knowledge in resource management in a range of contexts, in pursuit of an ecosystem approach to fisheries management.

In every community where fishing occurs in coastal, marine and freshwater ecosystems, there are people that can support and partner with fisheries policy makers and managers because they hold situated knowledge based on time tested wisdom and practices that can bolster scientific studies on how fisheries and ecosystems have changed over time. Fishing in these Guidelines includes pre and post fishing activities, the activity of fishing, in addition to sustainable practices and uses in the coastal zone (e.g. mollusc and shell gathering).

There are many terms used to describe this knowledge - in these guidelines we refer to 'fishers' as men and women - both indigenous peoples and long established fishers. The main distinguishing characteristic of FK is that it is experience-based. Fishers thus include experienced persons who have been involved in a fishery and community over an extended period of time, including several generations.

These Guidelines are complimentary and consistent with existing Convention on Biological Diversity (CBD), IUCN and United Nations (UN) Food and Agriculture Organization (FAO) Guidelines that highlight the importance of Traditional Knowledge in broader contexts including pursuit of an ecosystem approach, protected area management, the description and identification of ecologically or biologically significant marine areas, supporting IUCN red listing and small scale fisheries governance and development. The Guidelines encourage policy makers and fisheries managers to develop ongoing relationships with fishermen and women, engage in knowledge partnership to support in policy making and fisheries management across marine and freshwater systems and commercial, recreational, subsistence and small-scale fisheries.

\section{Purpose}

The purpose of these Guidelines is to make it easier for users to recognise and include FK as an important data stream in resource management, by presenting details on the breadth of knowledge that can be gathered, how it can be gathered, and how this information can be applied to support sustainable fisheries policy and in broader application, in society today.

\section{Who do these Guidelines apply to?}

These are voluntary Guidelines that are intended to be used by fisheries resource managers at the community, local, regional and national levels in countries where there are coastal, marine and freshwater fisheries. They can also be used by communities, non-governmental
Organizations (NGOs) and researchers who wish to study and recognise traditional fishing knowledge in coastal, marine and freshwater systems.

\section{Which fisheries are these Guidelines applicable to?}

These Guidelines are applicable in small-scale freshwater, riverine, lacustrine and near-shore coastal fisheries where there is a community associated with and relying on fishing for sustenance, recreation, or a source of income. The Guidelines can be used in fisheries, which are overexploited, to support fisheries change management, those that have limited data management, and in sustainably utilised fisheries.

\section{Why are these Guidelines needed?}

Small-scale fisheries (commerical, recreational and subsistence) provide food security, livelihoods and income to millions of people but their management still presents a challenge to managers and other stakeholders due to problems in gathering suitable information and defining management strategies. This is the case even with international conventions and guidelines promoting the application of traditional knowledge in resource use decision making. As fishers are the principal actors of fishery systems, both traditional knowledge and more broadly FK, (which includes experienced fishers), is an essential component of the social, cultural and ecological context of small-scale fisheries, and relates directly to the environment, species and resources where fisheries take place.

FK includes women's knowledge too. Women strongly participate in the pre and post fishing activities of small-scale fishing - women gather important information concerning the management of resources and ecosystems, harvest fish and are a repository of knowledge and technologies.

Given FK is also closely linked with fisheries performance it can provide valuable information that, in most of cases, is applied to support an assessment of extractive capacity and value. In this context, however, fishers are often viewed as a source of potential knowledge for assessment, but are often excluded from subsequent processes of data analysis, interpretation and management. FK is used to assimilate reliable information, mostly based on fish abundance, distribution and bioecological information, but it can be collected to increase fisher support and participation to provide a governance perspective in which fishers and their knowledge are involved in management decisions and in identifying and avoiding territorial conflicts. The improvement and reinforcement of the application of FK and promoting a more empowering fishers' engagement has been identified as an international priority for the management of fisheries under an ecosystem-based approach in marine and freshwater systems.

These Guidelines respond to this pressing international need for theoretical frameworks and guidance on what FK encompasses and how this knowledge and experience can be be valorised, encouraged, strengthened and applied to assist in achieving targets in international instruments, and in broader applied uses in society. 


\section{Objectives}

The objectives of these guidelines are:

\section{Objective 1: Promote}

1. Objective 1: Promote the recognition, gathering and recording of a baseline of FK.

\section{Objective 2: Value, Encourage and Preserve}

2. Objective 2: Value, recognise and encourage the transfer and preservation of this knowledge.

\section{Objective 3: Involve, Enhance, Apply}

3. Objective 3: Involve fishers in enhancing and applying this knowledge to shape:

- 3.1 Fisheries Policy;

- 3.2 Supporting IUCN Species and Ecosystem Red Listing;

- 3.3 Co-management;

- 3.4 Enhancing transmission and perpetuation of knowledge (books / film); and /or

- 3.5 Genetic utilization of biodiversity resource - a Nagoya Protocol use.

\section{Objective 4: Support and Achieve}

4. Objective 4: Through these Guidelines support the achievement of the Convention on Biological Diversity (CBD) Aichi Targets and particularly Targets 6 and 18; and Goals 2 and 14 of the Sustainable Development Goals; the UN Code of Conduct on Responsible Fisheries and related instruments. Goals 6 and 18 of the Aichi Targets are relevant to sustainable fisheries and FK:

- CBD AICHITARGET 6: By 2020 all fish and invertebrate stocks and aquatic plants are managed and harvested sustainably, legally and applying ecosystem based approaches, so that overfishing is avoided, recovery plans and measures are in place for all depleted species, fisheries have no significant adverse impacts on threatened species and vulnerable ecosystems and the impacts of fisheries on stocks, species and ecosystems are within safe ecological limits.

- CBD AICHI TARGET 18: By 2020, the traditional knowledge, innovations and practices of indigenous and local communities relevant for the conservation and sustainable use of biodiversity, and their customary use of biological resources, are respected, subject to national legislation and relevant international obligations, and fully integrated and reflected in the implementation of the Convention with the full and effective participation of indigenous and local communities, at all relevant levels.

The Guidelines will also support the achievement of post Aichi 2020 targets with respect to FK.

\section{How were these Guidelines developed?}

These guidelines have been developed by a multidisciplinary team of experts led by the IUCN Sustainable Use and Livelihoods Group, with support from the Environment Agency - Abu Dhabi, United Arab Emirates, and specialists from the IUCN Species Survival Commission, IUCN Commission on Environmental, Economic and Social Policy, IUCN Snapper, Seabream and Grunt Specialist Group, and World Forum of Fisher Peoples. They have been workshopped with experts at the IUCN Communities, Conservation and Livelihoods Conference, held 28-30 May 2018 in Halifax, Nova Scotia, Canada, and have been circulated widely for review and comment to representatives of governments, small-scale fisher organisations, indigenous fisher organisations, fish workers and their organizations, researchers, development partners and other relevant stakeholders.

The result is an internationally developed set of practical guidelines and tools to support sustainable fisheries and traditional knowledge transfer in small-scale fisheries. These guidelines will support the development of fisheries policy and management planning in both marine and freshwater ecosystems and in both developed and developing countries.

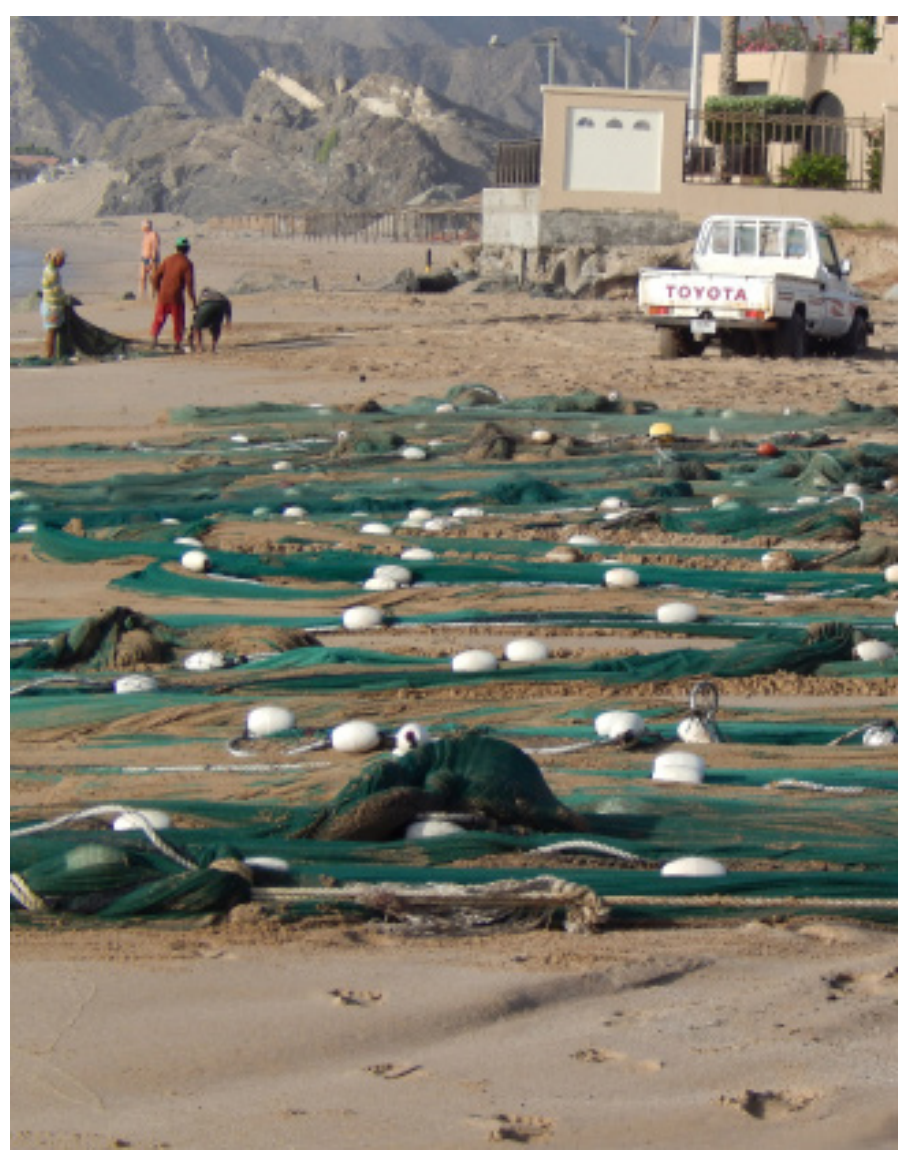

Dhagwa (seine netting from the beach). Fujairah, United Arab Emirates. The dhagwa traditonal fishing technique being conducted with modern materials. (c) Environment Agency-Abu Dhabi. 


\section{What is fishers' knowledge?}

This section of the Guidelines presents the breadth of FK in the wider context of Traditional Knowledge; and identifies the range of rich cultural and resource management data it can provide in support of fisheries policy and management.

There is no uniform term to describe knowledge held by indigenous peoples and local communities, with terms and acronyms including: Aboriginal traditional knowledge (ATK), traditional knowledge (TK), Traditional Ecological Knowledge (TEK), Indigenous Knowledge (IK), Indigenous Ecological Knowledge (IEK), Indigenous and Local Knowledge (ILK), Local Ecological Knowledge (LEK), Fishers' Ecological Knowledge (FEK), Tradition-Based Knowledge, Aboriginal or Indigenous Science, Community Knowledge and Local Knowledge.

These Guidelines have wide application and are aimed at both indigenous and experienced fishers, men and women, young and elder. Accordingly we follow the UN FAO definition of fishers' knowledge (FK) as stated in the UN FAO 'Fishers' Knowledge and the Ecosystem Approach to Fisheries Technical Paper (2015).

\subsection{Fishers' knowledge definition}

\section{Fishers' knowledge}

Fishers' knowledge (FK) comprises the body of experiential knowledge including ecological, resource-based, ecosystem, fishing practices, fishing communities and livelihoods, governance and markets, and their dynamic relationships. This knowledge is developed in a socialcultural and geographical context. The working definition of FK is broader in scope than traditional, local or indigenous ecological knowledge (TEK/LEK/IEK), but includes these types of knowledge. The main distinguishing characteristic of $\mathrm{FK}$ is that it is experience-based.

Source: UN FAO. 'Fishers' Knowledge and the Ecosystem Approach to Fisheries Technical Paper. Applications, experiences and lessons in Latin America. Technical Paper No. 591. (2015).

\subsection{What is traditional knowledge?}

Traditional knowledge is historically applicable to indigenous peoples and is a complex term that represents the accumulated knowledge of a culture in respect of their nature-society interactions. It may include knowledge about species, environments and encompass resource use such as hunting, fishing, medicinal products collection, household economy and trade, and spiritual divination. It may also be as wide as the learned values that guide interactions between the people and their environment.

Definitions of traditional knowledge vary in respect of the focus of international traditional knowledge initiatives, with the most relevant definitions presented in Figure 1.

Given the various definitions presented, for the purposes of these Guidelines, we will adopt the Traditional Knowledge definition proposed by the United Nations Environment Programme (UNEP) Intergovernmental Platform on
Biodiversity and Ecosystem Services (IPBES), taking into account Berkes definition as promoted by the IPBES.

\section{Traditional knowledge definition}

"Indigenous and local knowledge refers to the multifaceted arrays of knowledge, know-how, practices and representations that guide societies in their innumerable interactions with their natural surroundings. This interplay between people and place has given rise to a diversity of knowledge systems that are at once empirical and symbolic, pragmatic and intellectual, and traditional and adaptive. It is a cumulative body of knowledge, practice and belief, evolving by adaptive processes and handed down through generations by cultural transmission, about the relationship of living beings (including humans) with one another and with their environment."

\section{Source: UNEP IPBES and Berkes (2012).}

The CBD Guidance cautions that "traditional" does not only relate to the past, but that all knowledge evolves and develops over time, and thus can have a real impact on today's environmental, social and cultural problems. Ruddle (1991) also states that modern influences do not necessarily make contemporary local knowledge less "traditional," as they are incorporated into a framework of existing knowledge. While some of the past generations' knowledge is replaced through the present's experience, the knowledge core remains intact. Ruddle contends that this core derives from the observations and experiences of generations of fishermen and fisherwomen working in environments with which they are intimately familiar. By virtue of both this continuity and flexibility, contemporary knowledge of the coastal marine environment retains its local character.

A core concept is that FK is arrived at by a process of reasoning which is different from the mainstream Western scientific tradition. This is that FK is largely based on 'abductive reasoning' which is unlike the 'deductive' or 'inductive' reasoning of our current (largely Western) scientific practice. Abductive reasoning is logical inference which starts with an observation or set of observations and then seeks to find the simplest and most likely explanation for the observations. It is an evolving iterative process and does not yield any 'definitive' cause-effect relationships (Kurien, 2019).

\section{Traditional knowledge and science}

In a recent IUCN draft guideline on incorporating traditional knowledge into Red List assessments (2017), an important differentiation was made between Traditional Knowledge and 'formal science'. This was in recognition that Traditional Knowledge and formal science can be understood as different ways of understanding and interpreting the world (laccarino, 2003). As stated in that Guideline, "While Indigenous Local Knowledge (ILK) is understood by some as a form of science (Alessa et al., 2016; Snively \& Williams, 2016; Whyte et al., 2016), here we use the term formal science (or just "science"), to 
refer to knowledge underpinned by a focus on analytical and reductionist methods, resulting in positivist and materialistic understandings (Nakashima \& Roué, 2002; Mazzocchi, 2006). ILK may also be underpinned by analytical methods and positivist understandings, but may also include holistic, intuitive and spiritual knowledge and does not differentiate between secular and sacred (Nakashima \& Roué, 2002; Mazzacchi, 2006)."

Both Traditional Knowledge and Science are thus important streams of information to be taken into account when developing policy, whether environmental or fisheries.

\subsection{What is traditional fishing knowledge?}

Traditional fishing knowledge is a broad basket of knowledge that fits within the wider 'traditional ecological knowledge' framework. It generally refers to the information necessary for cultural survival, accumulated through trial and error over many years (Drew, 2005). For example, if a fisher was consistently able to maximize return on catches (the optimal completion of the task of fishing), that individual would pass his or her method along to the next generations of fishers. Techniques or fishing grounds that were not fruitful would fade out of memory. The knowledge that was useful was learned over centuries by the people completing tasks optimally in the environment in which they have been living (Berkes et al. 2000; Davis \& Wagner 2003). The ecosystem approach developed from the holistic practices and approaches of environmental management by indigenous peoples and local communities (Kahui \& Richards 2014).

Traditional Fishing Knowledge falls into three major subcategories that pertain to ecological research.

- Population-level knowledge;

- Ecological relationships and ecosystem functioning; and

- Folk taxonomy and systematics.

The principle behind these proposed categories is that by learning from traditional peoples with alternative world views, researchers may gain insight from areas outside their primary scientific discipline. As an example, 'folk taxonomy' assesses the ways in which different cultures organize their world. Investigating these systems of classification is useful in delineating the views of indigenous and local peoples about how organisms are grouped and how important that species is to their culture (Boster \& Johnson 1989; Ruddle 1991; Berlin 1992). Lobel (1978) gives an example of Fanning Island in the Pacific, where indigenous peoples had different names for different size classes of tiger shark and three names for a species of jack (Caranx melampygus). The higher level of specificity identifies the importance of these species to indigenous peoples. For freshwater systems, Castillo et al (2018) found that fishers in the Parana River were able to correctly identified 87 species that were grouped in 322 folk names.

Traditional ecological knowledge can also provide information on historic population-level issues, such as behavioural ecology, population genetics, and populationlevel biology (Drew 2005). The principle is that persons who harvest from their environment through cultivation or hunting are more aware of their impacts on populations, particularly in oceanic islands where the eternal frontier philosophy does not exist (Flannery 2001; Hickey \& Johannes 2002).

Ecological relationships can also be reflected in the knowledge of multitaxa interactions. For example, in the agricultural domain, Polynesian peoples spread the risk of cyclones throughout agricultural systems (Colding et al. 2003), and in Cameroon, the Ntumu leave particular species in place to facilitate the ecological restoration of their forests (Carriere 2002). Ecosystem functioning is a relevant issue in freshwater systems, particularly in large floodplain rivers as fishers develop fishing strategies associated to flood pulses and changing habitats (Castello et al. 2015).

Knowledge can be recognized along the whole value chain of the different fisheries and fish products, mollusks and others where women participate. They also input the generation of knowledge concerning the resources and ecosystems.

Smyth et al. (2006) provides an alternative framework in a study of the cultural values ascribed by Aboriginals to Torres Strait marine species, Australia. These include nine cultural domains and cultural elements that can support the gaining of traditional fishing and ecological knowledge (Table 1).

Table 1: Traditional ecological knowledge framework

\begin{tabular}{|c|c|}
\hline Cultural Domain & Cultural Element \\
\hline $\begin{array}{l}\text { Subsistence food } \\
\text { source }\end{array}$ & $\begin{array}{l}\text { Dietary preferences, desired, } \\
\text { required (consumed and not con- } \\
\text { sumed). }\end{array}$ \\
\hline Material application & $\begin{array}{l}\text { Use as bait, pet, container, tool or } \\
\text { trade item, use of feathers, shell, } \\
\text { bone, tooth, skin for ornamentation, } \\
\text { body jewellery, masks, dancing } \\
\text { paraphernalia, head gear, fish traps, } \\
\text { sacred sites. }\end{array}$ \\
\hline Subsistence skills & $\begin{array}{l}\text { Procurement, preparation, exchange } \\
\text { and trade, e.g., hunting, fishing, } \\
\text { collecting techniques, butchering, } \\
\text { distribution, cooking, presentation. }\end{array}$ \\
\hline Wisdom & $\begin{array}{l}\text { Environmental knowledge about } \\
\text { behaviour, habitat, place locality, sea- } \\
\text { son, moon phase, tide, current, wind. }\end{array}$ \\
\hline $\begin{array}{l}\text { Socio-political repre- } \\
\text { sentation }\end{array}$ & $\begin{array}{l}\text { Totem and identity, e.g., connected to } \\
\text { social groups, clans, and tribes; nam- } \\
\text { ing of cultural sites, e.g., seascape } \\
\text { and territory. }\end{array}$ \\
\hline $\begin{array}{l}\text { Mythological repre- } \\
\text { sentation }\end{array}$ & Story, myth, legend, folktale. \\
\hline Ritual representation & Ceremony, ritual, magic, beliefs. \\
\hline $\begin{array}{l}\text { Symbolic represen- } \\
\text { tation }\end{array}$ & $\begin{array}{l}\text { Constellations, rock art, music, song, } \\
\text { story, dance, technical arts. }\end{array}$ \\
\hline $\begin{array}{l}\text { Contemporary repre- } \\
\text { sentation }\end{array}$ & $\begin{array}{l}\text { Utilization by institutions, e.g., fish- } \\
\text { eries, Torres Strait Treaty, schools, } \\
\text { teams; politics, e.g., flags; commer- } \\
\text { cial utilization. }\end{array}$ \\
\hline
\end{tabular}

Source: Smyth (2006) 
Both Drew (2005) and Smyth's (2006) cultural elements and domains are useful frameworks for understanding the types of traditional information that should be gathered.

In addition, following 40 years of research in small-scale fishing communities in Kerala, Indonesia and Cambodia, Kurien (2019) gave the following insights into what Traditional Fishing Knowledge entails. The insights will give the reader an indication of the extent of Traditional Fishing Knowledge. These include:

- FK is scientific. However, it is holistic and therefore may not be amenable to providing simple 'axioms' which are verifiable in the manner of current scientific practice.

- FK is not science (knowledge) for the sake of science (knowledge). It is science (knowledge) for the purpose of survival and livelihood.

- FK is not narrowly focussed on fish and water, but also on other larger relationships which affect the fishwater interplay - such as wind, tides, flows, currents, sun and moonlight effects, and bird behaviour among others.

- FK is arrived at using all human senses of sight, sound, smell, taste, touch, and additionally -- intuition.

-FK results in creation of convivial artefacts which mediate between the fisher and his aquatic milieu in order to (mainly) harvest aquatic resources.

- FK is joyfully gendered in that it is created both by men and women, as they interact with the aquatic ecosystem and the natural resources obtained from it, in order to pursue their respective livelihoods.

- FK is intuitive and qualitative and therefore transmitted mainly through mentorship undertaken through live occupational experience.

- FK is rooted in a social context that sees the world in terms of social and spiritual relations between all lifeforms.

- FK is based on reciprocity and obligations toward both community members and other life-forms.

- FK is acquired by individuals but becomes collective wealth of the community through measures such as development of convivial artefacts and creation of communal resource management institutions (rules and norms) based on shared knowledge and meaning.

Traditional knowledge also has strong links with archaeology - and in this Guideline's context - the heritage of fishing artefacts. Kurien (2019) states that these innovations were always 'in-process' or 'evolutionary' and the result of continuous interaction with nature -- wind, waves, currents, and the prey itself. There did not seem to be any culmination in the form of a 'final product'. They were always being perfected by an incremental process of trial and error over a considerable period of time. The materials used were either from the locality or at least within the country. Being socio-economically marginalised and isolated did not imply a lack of creativity. On the contrary, it acutely enhanced one's genius and creative mind because of the compulsion for survival. The hallmark of the resulting vessels and artefacts - particularly the fishing gear - was that they imbibed the qualities of smallness of size, selectivity in form, passivity in operation and seasonality in use. The diffusion of their innovations was the result of an open source and collective sharing process. There was a great degree of interactive learning and technological democracy. The process was historically 'designs and innovations without borders.' Hornell (1920) provides more information as does the contemporary Gillet (2002) with his work with small craft for artisanal smallscale fishers of south India.

\subsubsection{Traditional fishing knowledge definition}

Applying Drew (2005),Smith (2006) and Kurien (2019), in respect of what traditional ecological knowledge (or in this context - fisheries knowledge) should be gathered, common elements include:

- Subsistence and Folk Taxonomy - what species were consumed and what were not consumed and why, with folk taxonomy identified as a method of key fish species and biodiversity identification and recognition;

- Methods - what were the methods and tools of fishing, and the ways to process and conserve the fish products?;

- Species Population and Ecological Knowledge about fish behaviour; and

- Underlying values guiding respectful, reciprocal interactions and relationships with fish and their surrounding environments.

In taking a holistic approach and these frameworks, for the purposes of understanding FK, Traditional Fishing Knowledge' can be defined as below.

\section{Traditional fishing knowledge}

"The cumulative body of knowledge, practice and belief, evolving by adaptive processes and handed down through generations by cultural transmission, about the relationship of living beings (including humans) with one another, their environment and specifically fisheries resources. In the fishing context it includes contribution to societal living; the types of species caught and not caught - why and when; the methods of fishing; and knowledge of species and seasons. This knowledge may be manifested in myths and legends and in folk taxonomics." IUCN and Environment Agency - Abu Dhabi. (2020). IUCN Guidelines for gathering of fishers' knowledge for policy development and applied use.

As per the FK definition outlined earlier in this Section, the working definition of $\mathrm{FK}$ is broader in scope than traditional, local or indigenous ecological knowledge but includes these types of knowledge. To reiterate, the main distinguishing characteristic of $\mathrm{FK}$ is that it is experiencebased. 


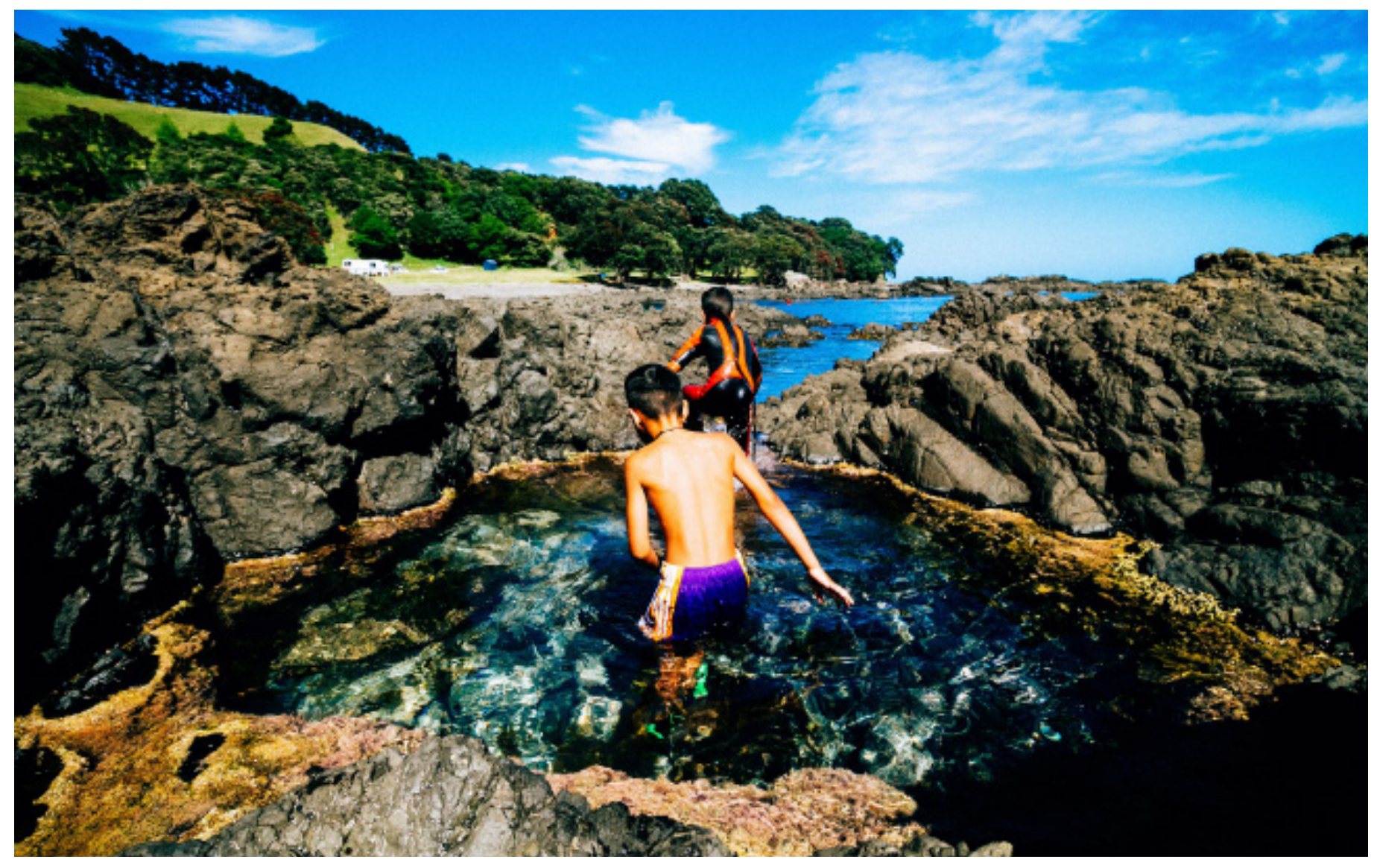

Indigenous knowledge is integral to the fisheries partnership in Aotearoa / New Zealand. (c) Erica Sinclair.

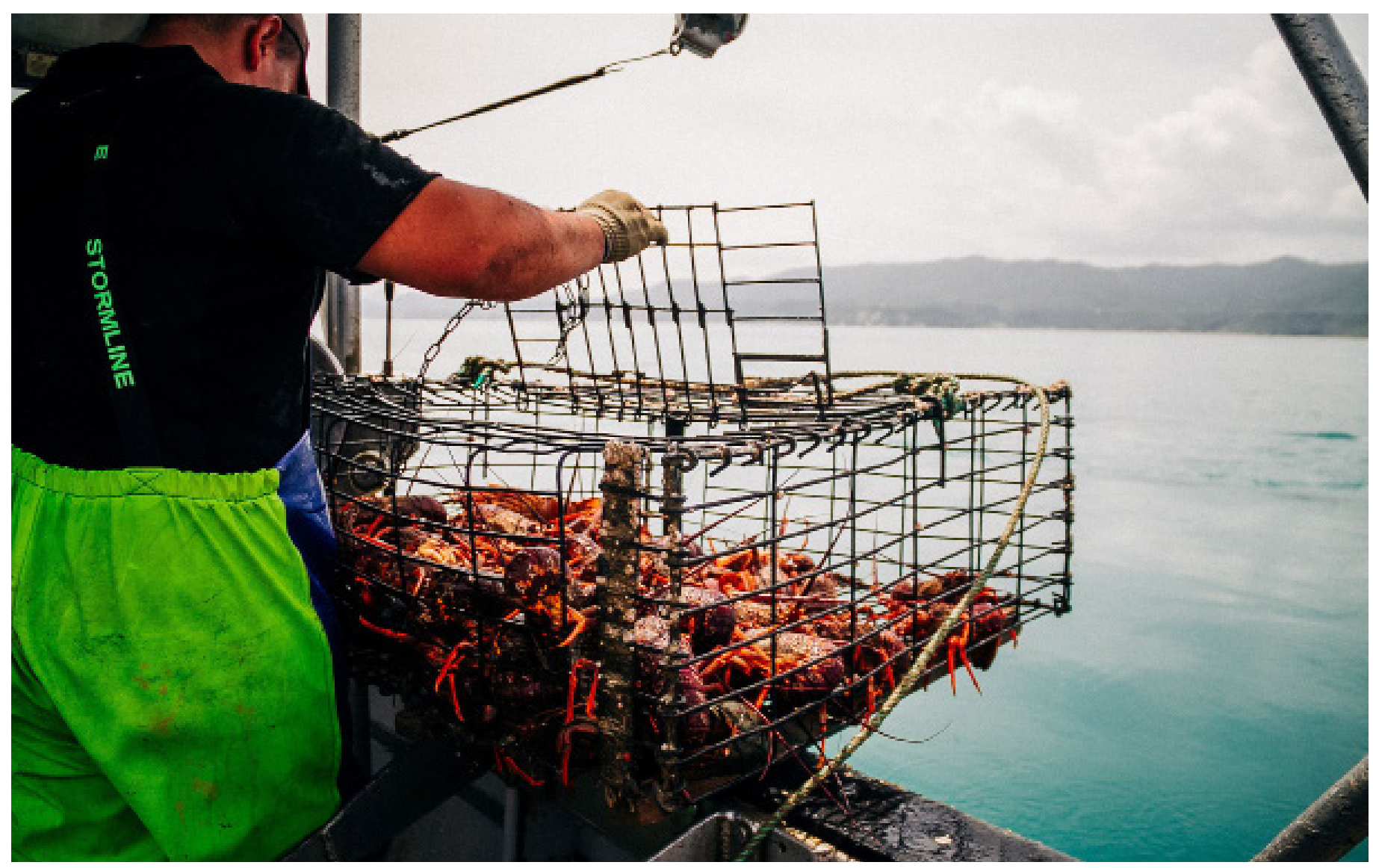

Community partnership has been integral to the changing of crayfish quota in the Hawkes Bay region. (c) Erica Sinclair 


\section{International framework}

International conventions and guidelines promote the modern application of traditional and fishers' knowledge in resource use decision-making, sustainable fisheries, and in education to promote historic nature-society interactions. In applying these Guidelines, users referencing the international conventions and guidelines contained within this section, and their achievement through the likes of National Biodiversity and Strategic Action Plans (NBSAPs) and Fisheries Management Plans, will support the achievement of the targets contained within, taking into account a user's priorities.

\subsection{International priority}

The significance of community-based action for biodiversity, ecosystems and sustainable livelihoods was captured in the CBD, the preamble recognising the:

"close and traditional dependence of indigenous and local communities ... on biological resources and the desirability of sharing in the benefits derived from the use of traditional knowledge, innovations and practices."

Since the CBD, the following international legal instruments, guidance documents and technical papers also provide international guidance, direction and targets on the incorporation of traditional knowledge (and specifically traditional fishing knowledge) in environmental decisionmaking. Those instruments with a provision specific to Traditional Fishing Knowledge have been included in this Section:

- Aichi Targets (2010);

- Nagoya Protocol (2010);

- United Nations (UN) Code of Conduct of Responsible Fisheries (1995);

- UN Declaration on the Rights of Indigenous Peoples (2007);

- UN Sustainable Development Goals (2015);

- UN Voluntary Guidelines for Securing Sustainable Small-Scale Fisheries in the Context of Food Security and Poverty Eradication (2015);

- UN 'Fishers' Knowledge and the Ecosystem Approach to Fisheries. Application, experiences, and lessons in Latin America. Technical Paper (2015);

- UN Marine Protected Areas: Interactions with Fishery Livelihoods and Food Security (2016); and

- CBD Training Manual on the incorporation of Traditional Knowledge into the description and identification of Ecologically or Biologically Significant Marine Areas (2016).

In addition the following organisations are relevant to the guideline for assessment for the following genres:

- United Nations Educational, Scientific and Cultural Organisation - the mandated and leading global organisation building peace through international cooperation in Education, the Sciences and Culture.

o https://en.unesco.org/about-us/introducingunesco

- United Nations Environment Programme - the mandated and leading global environmental authority that sets the global environmental agenda, promotes the coherent implementation of the environmental dimension of sustainable development within the United Nations system, and serves as an authoritative advocate for the global environment.

o https://www.unenvironment.org/

-World Trade Organisation - the only global international organization dealing with the rules of trade between nations with a goal of helping producers of goods and services, exporters, and importers conduct their business.

o https://www.wto.org/

-World Intellectual Property Organisation - the global forum for intellectual property services, policy, information and cooperation.

o https://www.wipo.int/portal/en/index.html

The following section provides details on the international framework for Traditional Knowledge, specific to Traditional Fishing Knowledge with relevant provisions of the key conventions and guidelines summarised below.

\subsubsection{Convention on Biological Diversity (1992)}

The significance of community-based action for biodiversity, ecosystems and sustainable livelihoods was captured in the $\mathrm{CBD}$, the preamble recognising the:

"close and traditional dependence of indigenous and local communities ... on biological resources and the desirability of sharing in the benefits derived from the use of traditional knowledge, innovations and practices."

Additional traditional knowledge articles within the CBD include Article 8 (In-situ Conservation), Article 10 (Sustainable Use of Components of Biodiversity), Article 17 (Exchange of Information), and Article 18 (Technical and Scientific Cooperation) (UNEP 1992). The most relevant of these articles is Article 8 (j) which states that signatories shall:

"Subject to its national legislation, respect, preserve and maintain knowledge, innovations and practices of indigenous and local communities embodying traditional lifestyles relevant for the conservation and sustainable use of biological diversity and promote their wider application with the approval and involvement of the holders of such knowledge, innovations and practices and encourage the equitable sharing of the benefits arising from the utilization of such knowledge, innovations and practices."

This article encourages countries to incorporate into national legislation mechanisms to preserve and maintain this knowledge, and promote its equitable sharing of this knowledge.

The CBD Training Manual on the incorporation of Traditional Knowledge into the description and identification of Ecologically or Biologically Significant Marine Areas (2016), detailed below is a step towards achieving these articles. 


\subsubsection{Aichi Targets (2011-2020)}

The 2020 Aichi Targets under the framework of the CBD, provide further detail to that in the CBD including in Aichi Target 6 (sustainable fisheries); Aichi Target 11 (which focuses on protected areas, including "other effective areabased forms of conservation"); Target 14 (which focuses on ecosystem services), and Target 18 (which focuses specifically on Traditional Knowledge). Targets 6 and 18 of the Aichi Targets are most relevant to FK:

- CBD AICHI TARGET 6: By 2020 all fish and invertebrate stocks and aquatic plants are managed and harvested sustainably, legally and applying ecosystem based approaches, so that overfishing is avoided, recovery plans and measures are in place for all depleted species, fisheries have no significant adverse impacts on threatened species and vulnerable ecosystems and the impacts of fisheries on stocks, species and ecosystems are within safe ecological limits.

- CBD AICHI TARGET 18: By 2020, the traditional knowledge, innovations and practices of indigenous and local communities relevant for the conservation and sustainable use of biodiversity, and their customary use of biological resources, are respected, subject to national legislation and relevant international obligations, and fully integrated and reflected in the implementation of the Convention with the full and effective participation of indigenous and local communities, at all relevant levels.

Post Aichi, the recent publication 'CBD 2020 and Beyond, Future Directions under the Convention' proposes that post 2020, the Aichi goals and targets will be maintained or adjusted. These Guidelines, particularly in respect of 'gathering and utilising FK,' will remain a valuable resource in achieving these goals.

\subsubsection{UN Code of Conduct for Responsible Fisheries (1995)}

Following the CBD (1992) and calls from the International Conference on Responsible Fishing (1992) to strengthen the international legal framework for more effective conservation, management and sustainable exploitation and production of living aquatic resources, the UN FAO Code of Conduct for Responsible Fisheries was developed in 1995. Over two decades since its adoption, the Code continues to be a reference framework for national and international fisheries best management. The Code of Conduct sets out a series of principles that are voluntary, but are the best practise international guide for fisheries management. The key principles of relevance to incorporating traditional fishing knowledge in fisheries management planning are:

\section{- General Principles: Article 6.4:}

o Conservation and management decisions for fisheries should be based on the best scientific evidence available, also taking into account traditional knowledge of the resources and their habitat, as well as relevant environmental, economic and social factors. States should assign priority to undertake research and data collection in order to improve scientific and technical knowledge of fisheries including their interaction with the ecosystem. In recognizing the trans-boundary nature of many aquatic ecosystems, States should encourage bilateral and multilateral cooperation in research, as appropriate.

- Fisheries Management: Article 7.6.6:

o When deciding on the use, conservation and management of fisheries resources, due recognition should be given, as appropriate, in accordance with national laws and regulations, to the traditional practices, needs and interests of indigenous people and local fishing communities which are highly dependent on fishery resources for their livelihood.

- Fisheries Research: Article 12.12:

o States should investigate and document experienced fisheries knowledge and technologies, in particular those applied to small-scale fisheries, in order to assess their application to sustainable fisheries conservation, management and development.

It is clear from the UN Code of Conduct for Responsible Fisheries (1995) that traditional fishing knowledge and FK, as with best available scientific, economic and social factors, is a key consideration that should be assessed when developing informed responses to fisheries management.

\subsubsection{UN Declaration on the Rights of Indigenous Peoples (2007)}

In 2007 the UN adopted the Declaration on the Rights of Indigenous Peoples. The Declaration recognizes the equal human rights of indigenous peoples to all other peoples against any forms of discrimination and seeks to promote mutual respect and harmonious relations between indigenous peoples and States. Article 31 states: that Indigenous peoples "have the right to maintain, control, protect and develop their Intellectual Property over such cultural heritage, traditional knowledge and traditional cultural expressions."

This Declaration is particularly relevant to a Nagoya Protocol applied use for FK.

\subsubsection{Nagoya Protocol (2010)}

The Nagoya Protocol on Access to Genetic Resources and the Fair and Equitable Sharing of Benefits Arising from their Utilization (2010) to the CBD was adopted on 29 October 2010 in Nagoya, Japan and entered into force on 12 October 2014. The objective is the fair and equitable sharing of benefits arising from the utilization of genetic resources, thereby contributing to the conservation and sustainable use of biodiversity.

The Nagoya Protocol has a number of provisions relevant to traditional knowledge associated with genetic resources including provisions on access, benefit-sharing and compliance. Parties to the convention are to take measures to ensure these communities' prior informed consent, and fair and equitable benefit-sharing, taking into account community laws, procedures and customary use and exchange.

The Nagoya Protocol is relevant to these Guidelines as one of the proposed applied uses for traditional knowledge, where applicable, specifically the use of marine flora or fauna for their genetic resources. Traditional Knowledge 
provisions are located throughout the Protocol - as an example the Preamble contains seven paragraphs relevant to Traditional Knowledge. The authors will not complete an exhaustive list of these provisions here, but if a Nagoya Protocol use is recommended, the relevant provisions of the protocol should be followed.

\subsubsection{UN FAO Voluntary Guidelines for Securing Sustainable Small-Scale Fisheries in the Context of Food Security and Poverty Eradication (2015)}

Given the identified need for voluntary guidelines for small-scale fisheries, in 2015 the UN FAO published the Voluntary Guidelines for Securing Sustainable Small-Scale Fisheries in the Context of Food Security and Poverty Eradication. It is the first internationally agreed instrument dedicated to the small-scale fisheries sector. What a small 'scale fisheries sector' comprises, is context specific, with the Code providing the following guidance:

- What is a small-scale fishery?

"The small-scale fisheries sector tends to be firmly rooted in local communities, traditions and values. Many smallscale fishers are self-employed and usually provide fish for direct consumption within their households or communities. Women are significant participants in the sector, particularly in postharvest and processing activities. It is estimated that about 90 percent of all people directly dependent on capture fisheries work in the small-scale fisheries sector. As such, small-scale fisheries serve as an economic and social engine, providing food and nutrition security, employment and other multiplier effects to local economies while underpinning the livelihoods of riparian communities...

Small-scale fisheries represent a diverse and dynamic subsector, often characterized by seasonal migration. The precise characteristics of the subsector vary depending on the location; indeed, smallscale fisheries tend to be strongly anchored in local communities, reflecting often historic links to adjacent fishery resources, traditions and values, and supporting social cohesion. For many small-scale fishers and fish workers, fisheries represent a way of life and the subsector embodies a diverse and cultural richness that is of global significance. Many small-scale fishers, fish workers and their communities - including vulnerable and marginalized groups - are directly dependent on access to fishery resources and land..."

Similar to the Code of Conduct for Responsible Fisheries, the UN FAO Voluntary Guidelines for Securing Sustainable Small-Scale Fisheries provides a series of principles that are voluntary, the key principles of relevance to incorporating traditional fishing knowledge in fisheries management planning are:

- Part 1: Introduction: Guiding Principle: 2. Respect of cultures:

o Recognizing and respecting existing forms of organization, traditional and local knowledge and practices of small-scale fishing communities, including indigenous peoples and ethnic minorities encouraging women leadership and taking into account Art. 5 of the Convention on the Elimination of All Forms of
Discrimination Against Women.

- Part 2: Responsible Fisheries and Sustainable Development: Governance of tenure in small-scale fisheries and resource management. Article 5. 5: o States should recognize the role of small scale fishing communities and indigenous peoples to restore, conserve, protect and co-manage local aquatic and coastal ecosystems.

- Part 3: Ensuring an enabling environment and supporting implementation: Policy coherence, institutional coordination and collaboration:

\begin{abstract}
- Article 10.1:
o States should recognize the need for and work towards policy coherence with regard to, inter alia: national legislation; international human rights law; other international instruments, including those related to indigenous peoples; economic development policies; energy, education, health and rural policies; environmental protection; food security and nutrition policies; labour and employment policies; trade policies; disaster risk management (DRM) and climate change adaptation (CCA) policies; fisheries access arrangements; and other fisheries sector policies, plans, actions and investments in order to promote holistic development in small-scale fishing communities. Special attention should be paid to ensuring gender equity and equality.
\end{abstract}

- Article 11: Information, research and communication 11.1 States should establish systems of collecting fisheries data, including bioecological, social, cultural and economic data relevant for decision-making on sustainable management of small-scale fisheries with a view to ensuring sustainability of ecosystems, including fish stocks, in a transparent manner. Efforts should be made to also produce gender-disaggregated data in official statistics, as well as data allowing for an improved understanding and visibility of the importance of small-scale fisheries and its different components, including socioeconomic aspects. Articles 11.2-11.11 provide further guidance.

It is clear from the UN Voluntary Guidelines for Securing Sustainable Small-Scale Fisheries that best practise fisheries management involves the participation of communities in fisheries management planning, with recognition given to the ability of indigenous peoples to restore, conserve, protect and co-manage local aquatic and coastal ecosystems.

\subsubsection{UN Sustainable Development Goals (2015)}

Building upon the achievements of the Millennium Development Goals, in 2015, 17 new global sustainable development goals were set with a 2030 time horizon. The global plan of action sets the agenda for people, planet and prosperity, seeks to strengthen universal peace, and eradicate poverty. These Guidelines will support with the achievement of Goals 2, 5 and 14 of the Sustainable Development Goals.

- Goal 2: End hunger, achieve food security and improved 
nutrition and promote sustainable agriculture:

o Goal 2.3: By 2030, double the agricultural productivity and incomes of small-scale food producers, in particular women, indigenous peoples, family farmers, pastoralists and fishers, including through secure and equal access to land, other productive resources and inputs, knowledge, financial services, markets and opportunities for value addition and non-farm employment.

- Goal 5: Achieve gender equality and empower all women and girls

o Goal 5.1: End all forms of discrimination against all women and girls everywhere.

o Goal 5.4: Recognize and value unpaid care and domestic work through the provision of public services, infrastructure and social protection policies and the promotion of shared responsibility within the household and the family as nationally appropriate.

o Goal 5.5: Ensure women's full and effective participation and equal opportunities for leadership at all levels of decision making in political, economic and public life.

o Goal 5.A: Undertake reforms to give women equal rights to economic resources, as well as access to ownership and control over land and other forms of property, financial services, inheritance and natural resources, in accordance with national laws

o Goal 5.C: Adopt and strengthen sound policies and enforceable legislation for the promotion of gender equality and the empowerment of all women and girls at all levels

- Goal 14: Conserve and sustainably use the oceans, seas and marine resources for sustainable development:

o Goal 14.2: By 2020, sustainably manage and protect marine and coastal ecosystems to avoid significant adverse impacts, including by strengthening their resilience, and take action for their restoration in order to achieve healthy and productive oceans.

o Goal 14.4: By 2020, effectively regulate harvesting and end overfishing, illegal, unreported and unregulated fishing and destructive fishing practices and implement science-based management plans, in order to restore fish stocks in the shortest time feasible, at least to levels that can produce maximum sustainable yield as determined by their biological characteristics.

o Goal 14.7: By 2030, increase the economic benefits to Small Island developing States and least developed countries from the sustainable use of marine resources, including through sustainable management of fisheries, aquaculture and tourism.

o Goal 14.B: Provide access for small-scale artisanal fishers to marine resources and markets.

\subsubsection{CBD Training Manual on the incorporation of Traditional Knowledge into the description and identification of Ecologically or Biologically Significant Marine Areas (2016)}

These Guidelines are complimentary to the CBD Guideline on integrating traditional knowledge into the description of ecologically or biologically significant marine areas (EBSA). EBSA's are special areas in the oceans that support the healthy functioning of the oceans and the many services that they provide. The EBSA process is an effort by CBD Parties to locate those areas that are significant ecologically or biologically, and that may become priorities for future management.

The CBD training manual states that it has two principal audiences:

(i) Indigenous peoples and local communities and organizations working with them;

(ii) Scientists and policymakers.

The stated purpose of the training manual is:

1) To improve the participation of indigenous peoples and local communities in the process of describing areas meeting the CBD scientific criteria for ecologically or biologically significant marine areas (EBSAs) and to ensure that their knowledge is incorporated to the greatest extent possible, with their full and effective participation.

2) To provide information about how traditional knowledge can, through participatory methodologies, be integrated into the EBSA process

Two-way learning between cultures is stated as an important pre-condition for those using the manual.

The objectives of the manual are:

1) Describe some of the challenges for indigenous and local community participation in the EBSA process, and possible ways to overcome these challenges;

2) Develop an understanding of the nature of traditional knowledge, its applications in the EBSA process, and some of the methods through which this can be achieved; 3) Consider ethical issues related to the application of traditional knowledge, and access available guidance on designing a research project working with indigenous peoples and local communities;

4) Plan how to facilitate the incorporation of traditional knowledge, and the full and effective participation of indigenous peoples and local communities in the EBSA process in your country.

The manual should be read in conjunction with the CBD training manual that covers the scientific assessment of developing an EBSA:

https://www.cbd.int/ebsa/resources?tab=trainingmaterials.

\subsubsection{Mataatua Declaration on Cultural and Intellectual Property Rights of Indigenous Peoples (1993)}

This international declaration was made at the First International Conference on the Cultural \& Intellectual Property Rights of Indigenous Peoples, held in Whakatane, Aotearoa / New Zealand, 1993. Over 150 delegates from fourteen countries attended, with the Declaration identifying that indigenous people were the owners of their cultural and intellectual property. The Declaration includes a number of recommendations to indigenous peoples; to states, national and international agencies; and to the United Nations, in addition to ethical considerations to take into account when considering FK. 


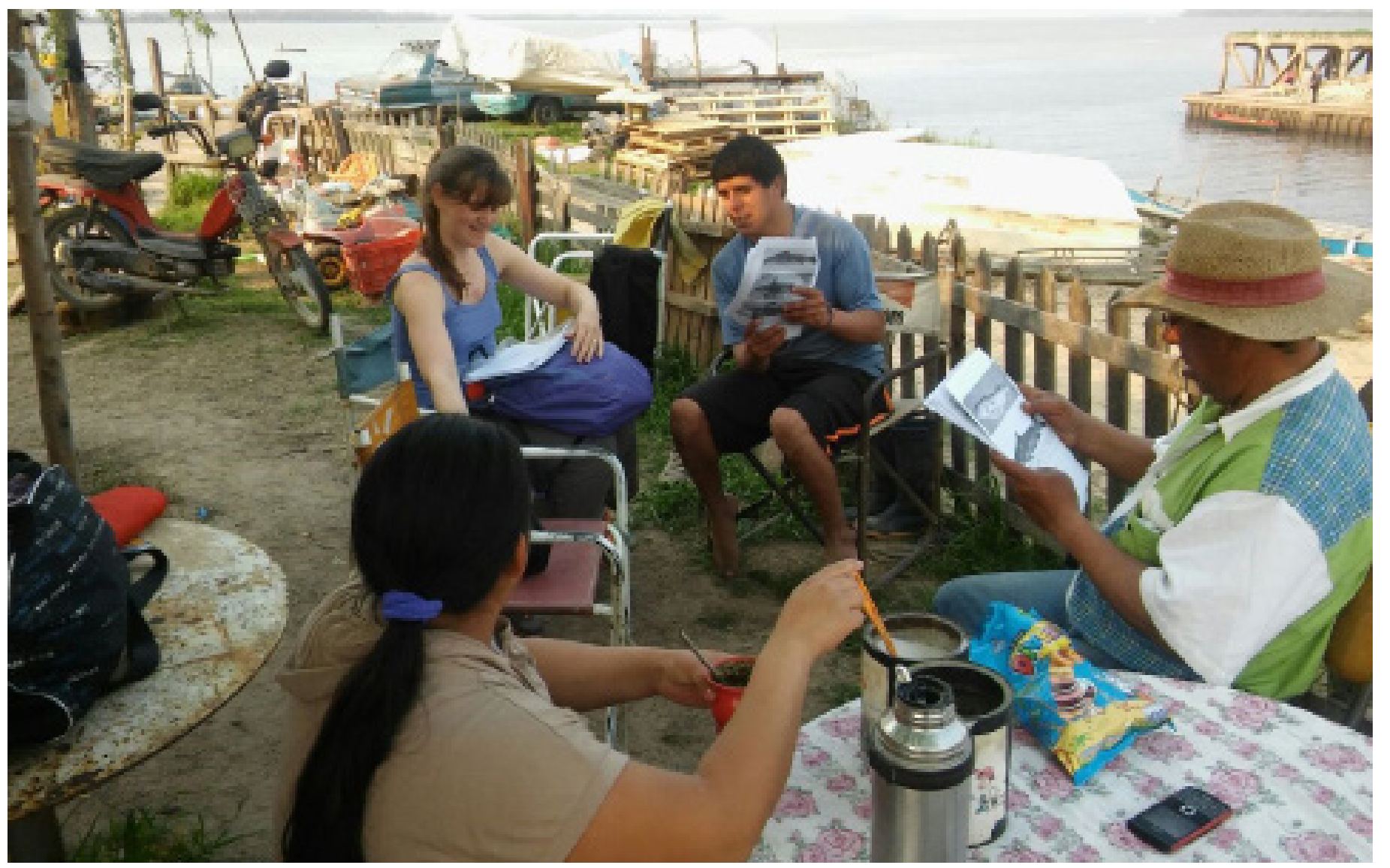

Gathering fishers' knowledge via interview, Parana River, Argentina. (c) Claudio Baigun

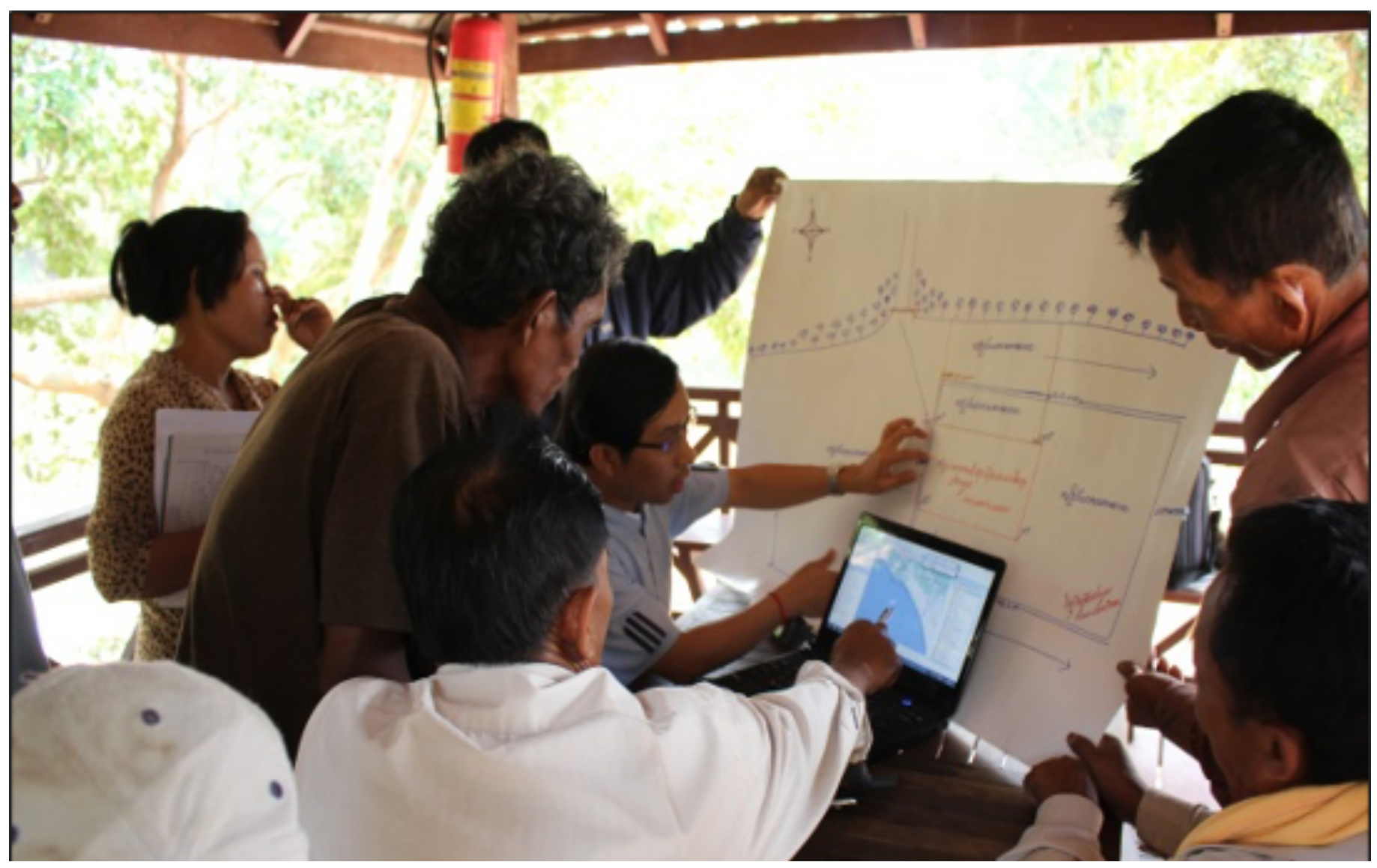

Developing a community led approach. 'EU-NSA' project, Great Tonle Sap, Cambodia. (c) Sorn Pheakday 


\section{How do we gather fishers' knowledge?}

There is a pressing need for theoretical frameworks and guidance on how to gather FK and apply this knowledge in fisheries policy, planning and wider application. It is a two-phase process:

- Phase 1: Setting objectives, gathering and recording FK; and

- Phase 2: Developing fisheries policy and plans and wider "applied use" recommendations for this knowledge in society today.

This Section provides practical guidance on how this knowledge can be gathered, with the following section (Section 5) identifying how FK may be applied in the modern context.

\subsection{Phase 1: Setting objectives, gathering and recording FK}

This section gives guidance on the methodology for Phase 1 - setting objectives establishing the FK theoretical framework; the literature review; and how to gather and record FK in the field.

\subsubsection{Setting FK research objectives}

The initial step why the FK study is being completed, what fishers aim to achieve through their participation and partnership, and to identify study objectives. These will vary by study and may be in line with the purpose of these Guidelines: for users to include FK to guide fisheries policy and fisheries management.

Objectives may include:

- Objective 1: Obtaining fishers' views on the state of a fishery, biology, biodiversity, ecosystems and habitats and fisheries management issues to support development of fisheries policy and plans.

- Objective 2: Gathering a baseline of FK; and

- Objective 3: Identifying applied uses for FK today.

\subsubsection{International framework review}

The user should conduct a desktop review of relevant international instruments to FK and sustainable fisheries management. This review, already broadly completed for the user in Section 3, assists in establishing the why - why incorporate FK in fisheries policy and plans. In respect of the methodology in choosing these international instruments, the review of documents should include international conventions that are applicable to the country of the user (i.e. signed and or ratified) and also the guidelines recommended by international organisations (e.g. IUCN) working on recording traditional knowledge and incorporating it into decision making. International treaties, conventions and guidelines that were considered relevant to these Guidelines review included those that had a provision in respect of protection and applied use of traditional knowledge generally, with a lens on traditional fishing knowledge, sustainable fisheries, and FK more widely.

\subsubsection{Locality FK literature review}

A literature review will need to be completed of FK in the locality where the project is based - this may be a regional area (e.g. the Arabian Gulf, Pacific Ocean or Amazon River), a country, or a specific locality. The review should be completed in national languages and indigenous written languages where applicable (e.g. Arabic and English in the United Arab Emirates or English and Māori in Aotearoa / New Zealand). The review may find that while studies have been completed on issues like marine archaeological sites, a comprehensive study gathering traditional fishing knowledge and the cultural elements associated with it, may not have been completed.

\subsubsection{FK - Identifying what information to gather}

FK can broadly be categorised into two streams of information:

- Information Stream 1: FK on the state of the fishery, biology, biodiversity, ecosystems, habitats and fisheries management;

- Information Stream 2: FK on cultural elements.

Information Stream 1-obtaining fishers' views on the state of a fishery, biology or fisheries, ecosystems and habitats and how they have changed over a period of time, the key pre-requisite to FK being experience. Fishers' perspective on the state of ecosystems or habitats where they fish and how such areas could have changed is of paramount relevance in freshwater systems where land and water uses along the basins can produce changes in riverscape and affect fisheries sustainability. These are fundamental data inputs to developing informed fisheries policy and fisheries management plans.

Information Stream 2 - FK of historic societal living; myths and folk systematics and species and ecological knowledge, is also a fundamental data input and should be gathered to support development of a record of traditional fishing knowledge.

The key point is that these informational streams are linked - fishing and a relationship with the sea or rivers is an emotional subject matter - thus elements of both these informational streams will need to be included in the development of questionnaires.

Phase 2 identifies for both these information streams how this information may be applied today.

\subsubsection{Developing questions}

Questions will vary on the context, with the following subjects to be covered, and could include:

- Explore what fishing means and meant to attendees as individuals, families, communities and tribes - both today and in historical terms;

- Explore beliefs and views about the current and past state of the fisheries (broad and specific);

- Explore views on existing fishing methods and fisheries 
management measures, if applicable, and obtain opinions on how management can be improved;

- Explore what traditional aspects of fishing may be incorporated into fisheries management; and

- Explore aspects of traditional and contemporary culture that would help secure buy-in to any changes that may occur (e.g. parables, songs, stories, quotations, sayings, etc.).

- Explore views and perceptions about ecological changes in the areas where people fish and possible causes.

It is suggested that the facilitator have Smyth et al's (2006) FK guideline Table (Table 1, above) included within their questionnaire as a guide of the Informational Stream 2 FK on cultural elements, that can be collected.

\subsubsection{Consent and ethical considerations}

A crucial element of obtaining and recording FK is ensuring that:

- FK holders obtain a fair and equitable share of benefits from the use and application of their FK; and

- Persons interested in using FK (institutions or scientists) obtain the prior, informed approval of FK holders.

The World Intellectual Property Organization (WIPO) developed a checklist that researchers will need to check prior to commencing and documenting traditional knowledge.

World Intellectual Property Organization (WIPO). Checklist to apply before documenting traditional knowledge:

- Plan carefully.

- Consult as widely as possible among indigenous peoples, local communities and key stakeholders at an early stage.

- Consider and clarify the role of the different stakeholders involved (researchers, government agencies, communities, etc.).

- Ponder on indigenous peoples and local communities expectations and how best to respond to and reflect them.

- Identify customary laws applicable to sharing, collection and documentation of TK, as well as related to decision-making within indigenous peoples and local communities.

- Consider how to effectively apply prior informed consent (PIC) principles - take note of 'shared TK' issues.

- Set out documentation objectives, including intellectual property (IP) objectives and develop an IP strategy if and when needed.

- Consider the widest possible range of options to meet these objectives.

- Develop a monitoring and verification plan to provide assurances that documented TK will be used as determined in the documentation process.

- Consider that legal issues may arise in the contexts of existing access to genetic and biological resources policies, and legal frameworks and regulations (ABS).

- Distinguish between non-confidential TK and TK which may be secret (due perhaps to its sacredness) and which may require additional conditions and securities (if it were to be documented).

Source: WIPO. Available at https://www.wipo.int/edocs/ pubdocs/en/wipo_pub_1049.pdf

Three CBD Guidance documents provide more information on ethical considerations in recording FK:

- Mataatua Declaration on Cultural and Intellectual Property Rights of Indigenous Peoples (1993) (https:// www.wipo.int/tk/en/databases/creative_heritage/ indigenous/link0002.html)

- The Tkarihwaié:ri Code of Ethical Conduct to Ensure Respect for the Cultural and Intellectual Heritage of Indigenous and Local Communities Relevant to the Conservation and Sustainable Use of Biological Diversity (2013); (http://www.cbd.int/traditional/code/ ethicalconduct-brochure-en.pdf).

- The Akwé: Kon Voluntary Guidelines for the Conduct of Cultural, Environmental and Social Impact Assessments regarding Developments Proposed to Take Place on, or which are Likely to Impact on, Sacred Sites and on Lands and Waters Traditionally Occupied or Used by Indigenous and Local Communities (2004). (www.cbd.int/doc/publications/akwe-brochure-en.pdf).

These codes of conduct reflect the principle that the use of knowledge should be undertaken on mutually agreed terms.

\subsubsection{Who should be engaged?}

Identifying experienced fishers is the key pre-requisite and distinguishing feature in identifying knowledge holders to engage with. In some indigenous communities, what is known as the gatekeeper function applies, where the most experienced person, elder, or perhaps chief, is the gatekeeper to the knowledge and identifying prospective interviewees. In other communities and developed countries, the gatekeeper may be 'well known' and may be the president of, as an example, a commercial fishers' cooperative society or a recreational game fishing club. In both contexts, once the initial contact is made layers of contacts and interviewees can be built up.

\subsubsection{Survey sample size}

The survey sample size does not need to be predetermined and will vary by community. The number of interviews in each location is dependent on the number of experienced fishers within that locality who wishes to share knowledge. As Huntington (2000) and Davis and Wagner (2003) have warned - in an indigenous community context, often a researcher may not know who is in possession of the required knowledge because of cultural differences (including wariness on behalf of the informer, sexual division of knowledge, or concerns about intellectual property rights). By using the gatekeeper function, however, and being respectful layers of contacts will generally be built up. 


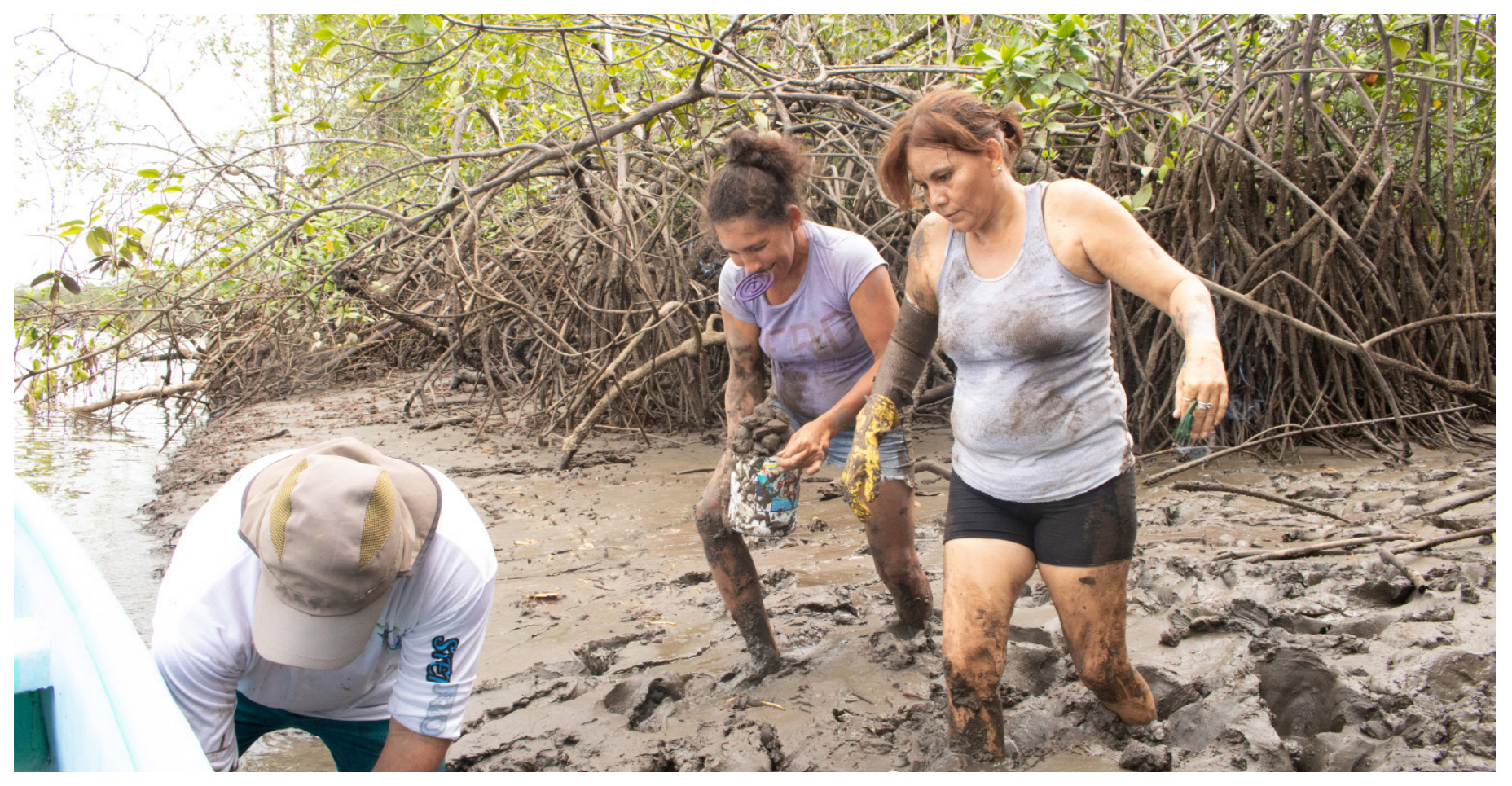

Women mollusc gathers in Chomes, Puntarenas, Costa Rica, Central America. Women mollusc gathers Fishers Knowledge was found to be key in gathering information about the wider ecosystem (mangroves, the beach and estuaries). (c) PoroStudio - CoopeSoliDar R.L, 2019.

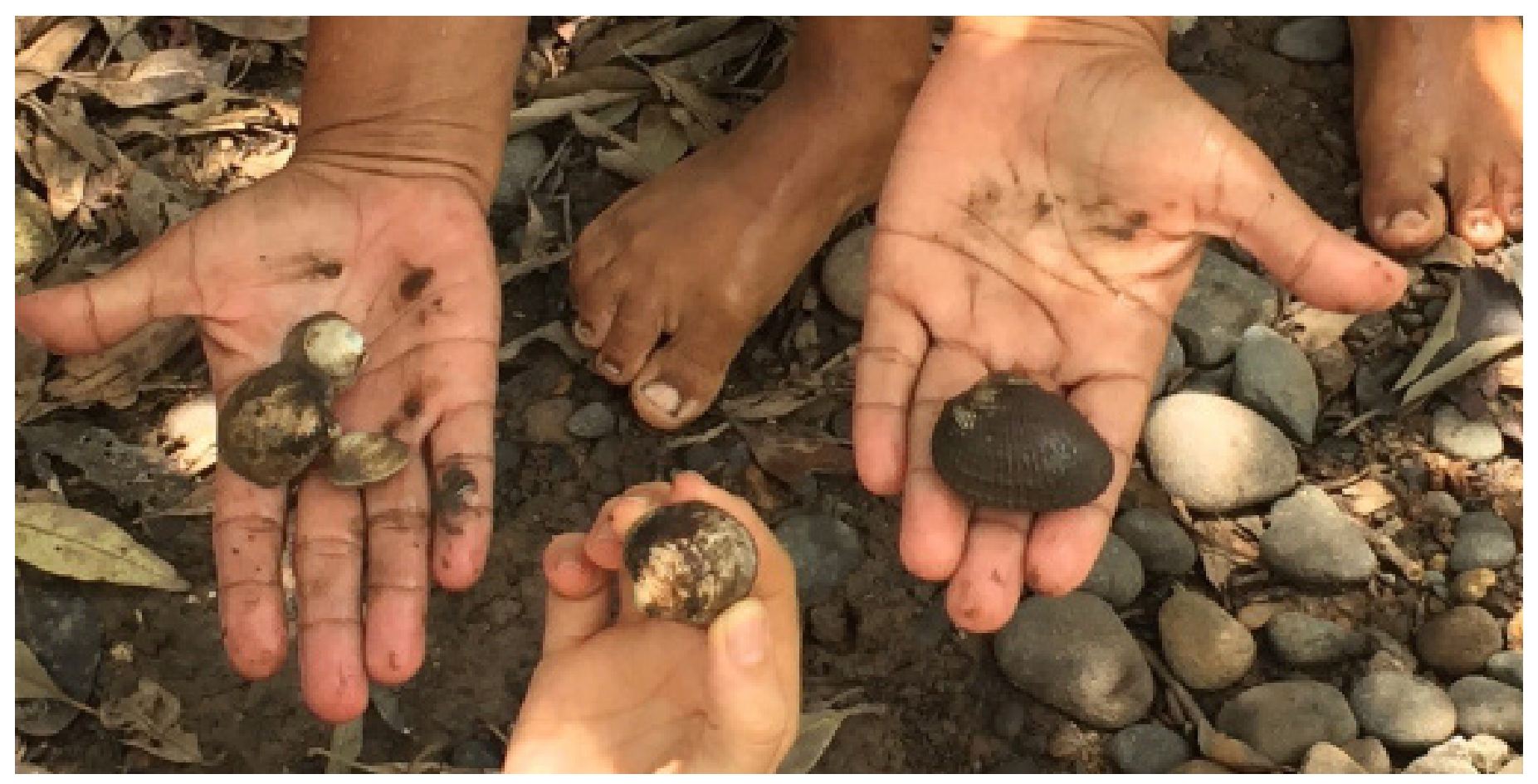

Molluscs gathered by women gathers from Terraba- Sierpe Mangrove, Golfo Dulce- Costa Rica. (c) Poro Studio-CoopeSoliDar R.L 


\subsubsection{Facilitator / interviewer briefing}

A detailed briefing on the purpose, objectives and desired outcomes of the engagement is recommended, when there is more than one facilitator / interviewer. This should include discussion on the following:

- Purpose and importance of gathering FK;

- Pre-interview preparation;

- Equipment and materials;

- How to conduct the interview: introduction, location, sample or subject questions;

- Important considerations during the interview (voice tone, body language, active listening, respect); and

- Confidentiality considerations and disclaimer.

4.1.10 Method of gathering traditional knowledge The method or way in which an interviewer engages with the community will be dependent on the cultural context of a specific community. The most common methods include:

- Questionnaires;

- Semi-directive interview;

- Workshop or Focus Group; or

- Collaborative fieldwork.

While all of the methods have their strengths and weaknesses, the detail below will assist the reader in deciding which method is the right method to use for the community being engaged.

The CBD Training Manual on the incorporation of Traditional Knowledge into the description and identification of Ecologically or Biologically Significant Marine Areas (2016) provides additional guidance on the suitability of these methods:

\subsubsection{Questionnaires}

Guidance on Questionnaires and when they may be appropriate include (Ref: CBD Traditional Knowledge EBSA Guidelines (2016)):

- Depending on the cultural context, this may be more comfortable to some respondents than the more freeform semi-directive interview.

- The approach is useful when an interviewer knows in advance what he or she is seeking.

- The approach simplifies comparisons between respondents.

- Quantification is sometimes simpler than a welldesigned questionnaire.

-When quantification is not necessary for all responses, some questions can be left open-ended, giving the respondent a chance to add more detail.

While Questionnaires are unlikely to produce as thorough a discussion as, for example, a semi-directive interview, it can be useful in providing new ideas and insights beyond the scope of the initial inquiry.

It is recommended that given potential cultural differences in perception and value systems, questionnaires should be developed or co-developed by a member of the indigenous and local community using local terminology and addressing issues from a local perspective.

\subsubsection{Semi-directive interview}

The interview method will vary on the context and will be dependent on the culture in which the interviews are occurring and time and resource constraints. In some contexts, interviews with experienced fishers may be more direct with a pre-determined list of questions. In others, including more traditional settings, and consistent with 'story telling' being a key part of many cultures, semi-direct interviews or focus groups may be more appropriate. In this situation the interviewer may have a list of subjects or questions as a guide (as per Section 4.1.5) and with the flexibility to move between questions rather than ask them in a pre-determined order (Huntington, 2000).

The following step by step process provides guidance to the interviewer:

- Determine interview location;

- Preparation of space (if applicable);

- Identify and greet interviewee;

- Introduce yourself and the team members (names, positions);

- Explain the topic and purpose of the meeting;

- Let the interviewee know how much of his time is needed;

- Let the interviewee know that their answers are confidential unless they are happy for them to be publicised;

- If applicable, ask for permission to record audio and video;

- Begin interview;

- Thank the interviewee for their time; and

- Ask the interviewee to sign for video and audio consent.

The CBD Traditional Knowledge EBSA Guidelines (2016) add the caution that even simple questions often include assumptions that may not be universally valid, such as equating "north" with "up". In a conversation about the fish species "herring," one might ask the question, "Where do the fish enter the bay?" In the local context, "fish" may mean "salmon" rather than "herring," - the answer may therefore appear valid but actually be referring to a different species than the researcher believes. Similar problems could arise in freshwater system where fishers recognize different species under the "catfish" category, it is important to check that participants are talking about the same species.

\subsubsection{Workshop or focus group}

In some situations a workshop or focus group may be appropriate because it brings together FK holders, scientists and policy makers. By having all knowledge holders in the same place, it is considered that it may be easier to find a common understanding and develop priorities for knowledge recording FK and future management. Facilitators will need to be clear and focused on the topics to be covered, language, power dynamics, local custom and even with the time allocation amongst different stakeholder groups. This method is promoted in 
the CBD Traditional Knowledge EBSA Guidelines (2016) as a platform to find common understanding in the analysis of data.

\subsubsection{Collaborative field work}

An alternative approach to gathering FK does not involve sitting and completing either questionnaires, semi direct interviews or focus groups. Attending the field and visiting sites and / or fishing grounds is also an interactive way of obtaining and documenting FK. It also ensures that the understanding of specific local species names and understandings are clearer, so the FK gatherer is clear on terms and local understanding.

\subsubsection{Videoing the engagement}

In addition to recording the answers of the knowledge holder, consideration should be given to videoing the engagement - whether the approach be questionnaires, semi direct interviews, workshops or collaborative field work, with the view that these videos will become and form the video record baseline of FK in respective communities. This approach has been used successfully in the United Arab Emirates with over 60 of the most experienced fishers interviewed across the emirates, the interviews supporting empirical scientific data, and assisting in developing a fisheries change management documentary. These Guidelines recommend the filming of engagements, after obtaining prior informed consent, with the view that a video record is obtained before this crucial information is lost.

\subsubsection{Recorded baseline}

Once engagements are completed, the information gathered (including the raw film footage (if applicable) in conjunction with existing literature) becomes the 'recorded baseline' of FK in a given locality. Questionnaires, notes and raw footage should be saved electronically and lodged with the relevant Competent Authority subject to confidentiality disclaimers.

At this stage of the process, the user will have completed Objective 2 - if that is the objective of their use of these Guidelines - 'Gather and record a baseline of FK.'

\subsubsection{Data analysis}

In respect of Informational Stream 1: FK on the state of the fishery, ecosystems, habitats and fisheries management; collated results should be compared against the most recent scientific stock assessment and ecosystem health data (if applicable) to either support with fisheries management decision making, or to support fish stock prioritisation assessment. More context on how this information can be used is provided in Section 5, below. For ecosystem data, this should be compared against past ecological studies performed by other scientists of related disciplines (hydrology, geomorphology, limnology, ecology, etc.) to assess on what extent the landscape and riverscape have changed.

In respect of the second informational stream - FK on cultural elements, historic societal living; myths and folk systematics and species and ecological knowledge, this information can be compared against Smyth et al.'s (2006) traditional knowledge framework to assess what traditional knowledge fishers held.

\subsubsection{Feedback to fishers}

Regardless of the method used to obtain the information, or the use (e.g. fisheries policy; supporting IUCN species and ecosystem red listing; co-management; enhancing transmission and perpetuation of knowledge; or genetic utilization of biodiversity resource-a Nagoya Protocol use), best practice requires returning the information gathered to fishers, getting their feedback on products created based on their knowledge and on how that knowledge is to be utilised, and continually involving fishers in that process. Section 5 provides more detail. 


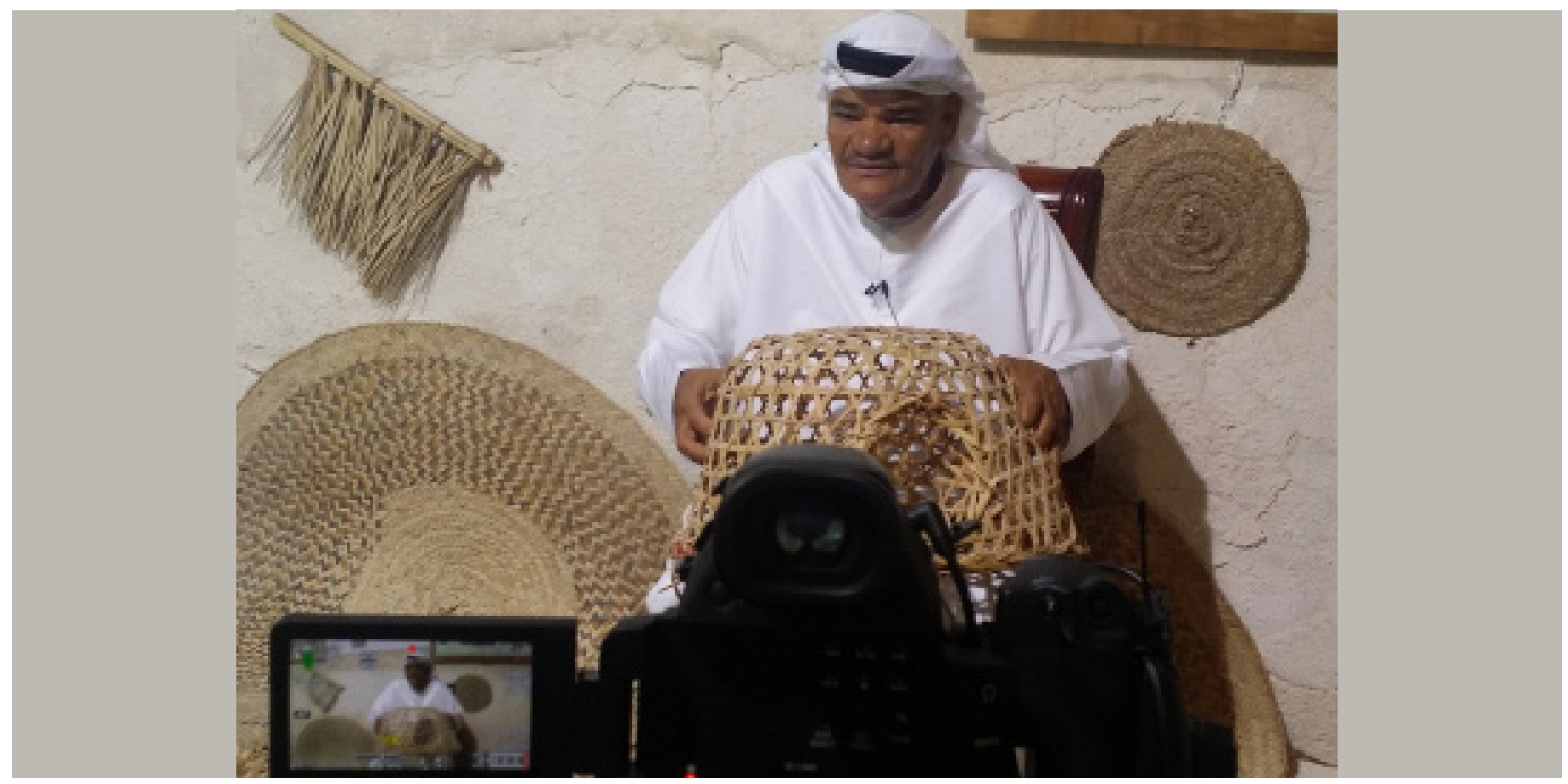

Gathering and videoing the Fishers Knowledge Baseline - how to create a gargoor / fish trap using palm fronds. Delma Isand. United Arab Emirates. (c) Environment Agency - Abu Dhabi.

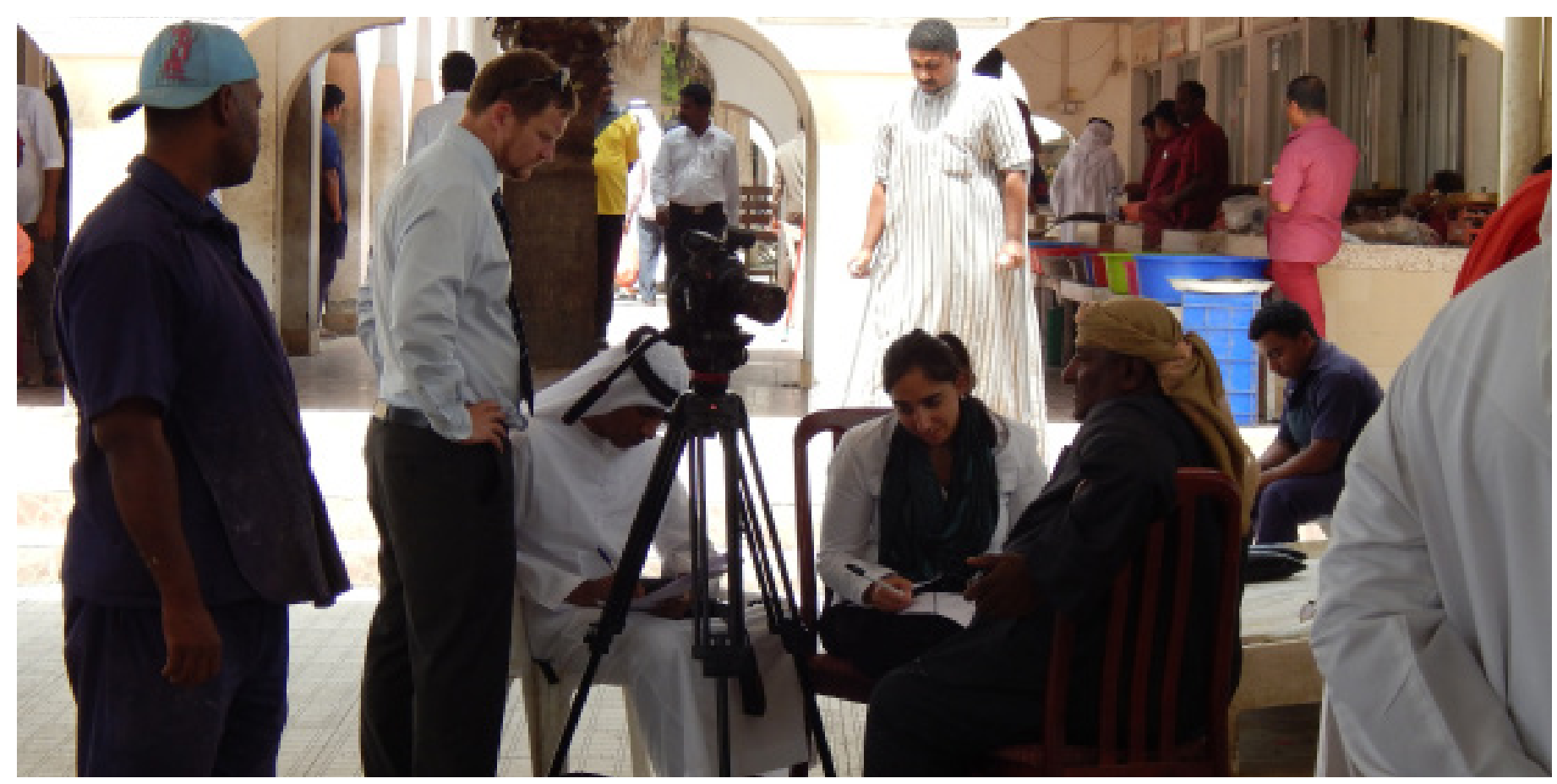

Gathering and videoing Fishers Knowledge in Umm Al Quwain fish market. Umm Al Quwain. United Arab Emirates. (c) Environment Agency - Abu Dhabi. 


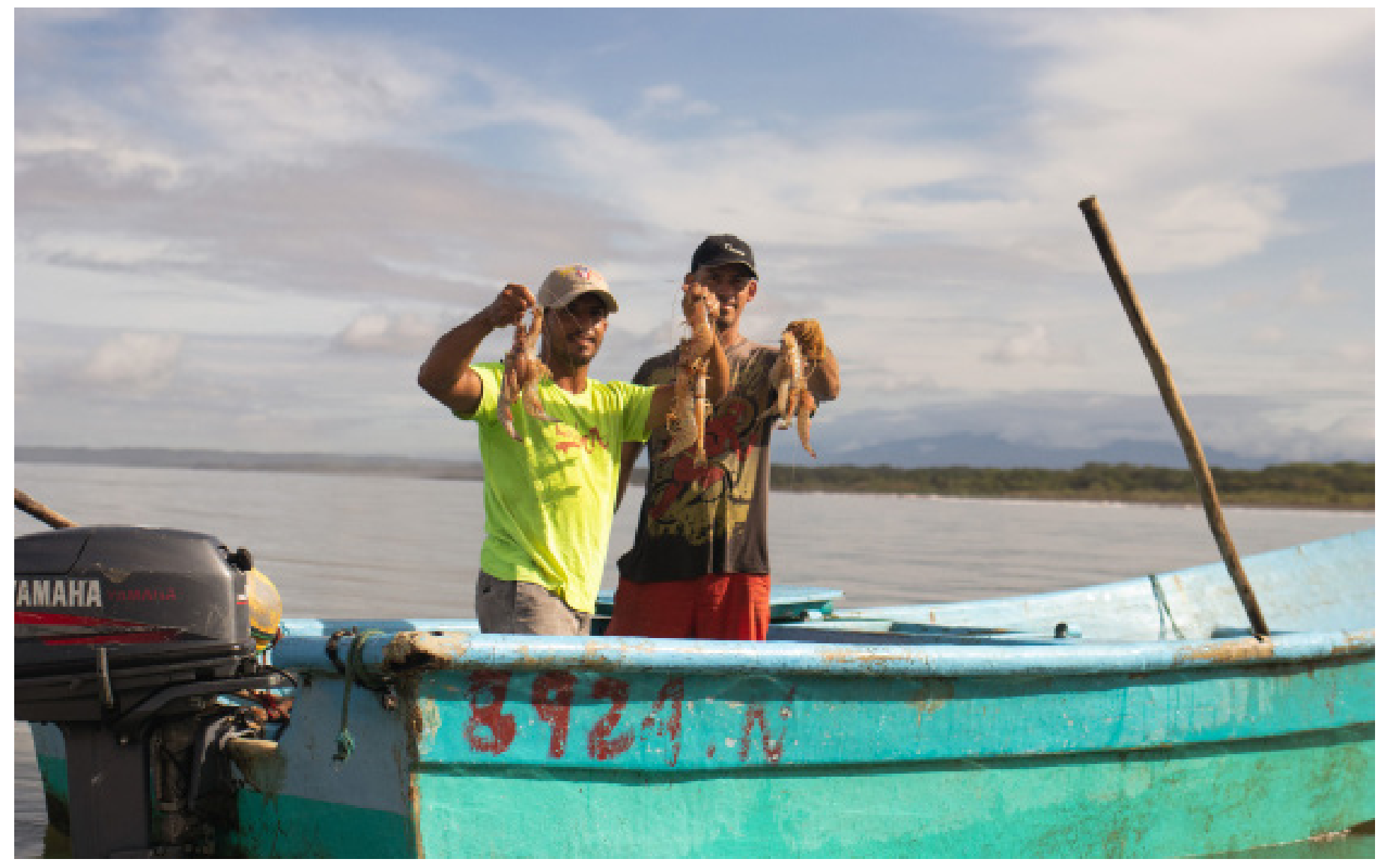

Fishers from the Marine Responsible Fishing Area in Tarcoles, Costa Rica, hold knowledge on the fluctuations in the shrimp fishery. (c) Poro Studio-CoopeSoliDar R.L, 2019

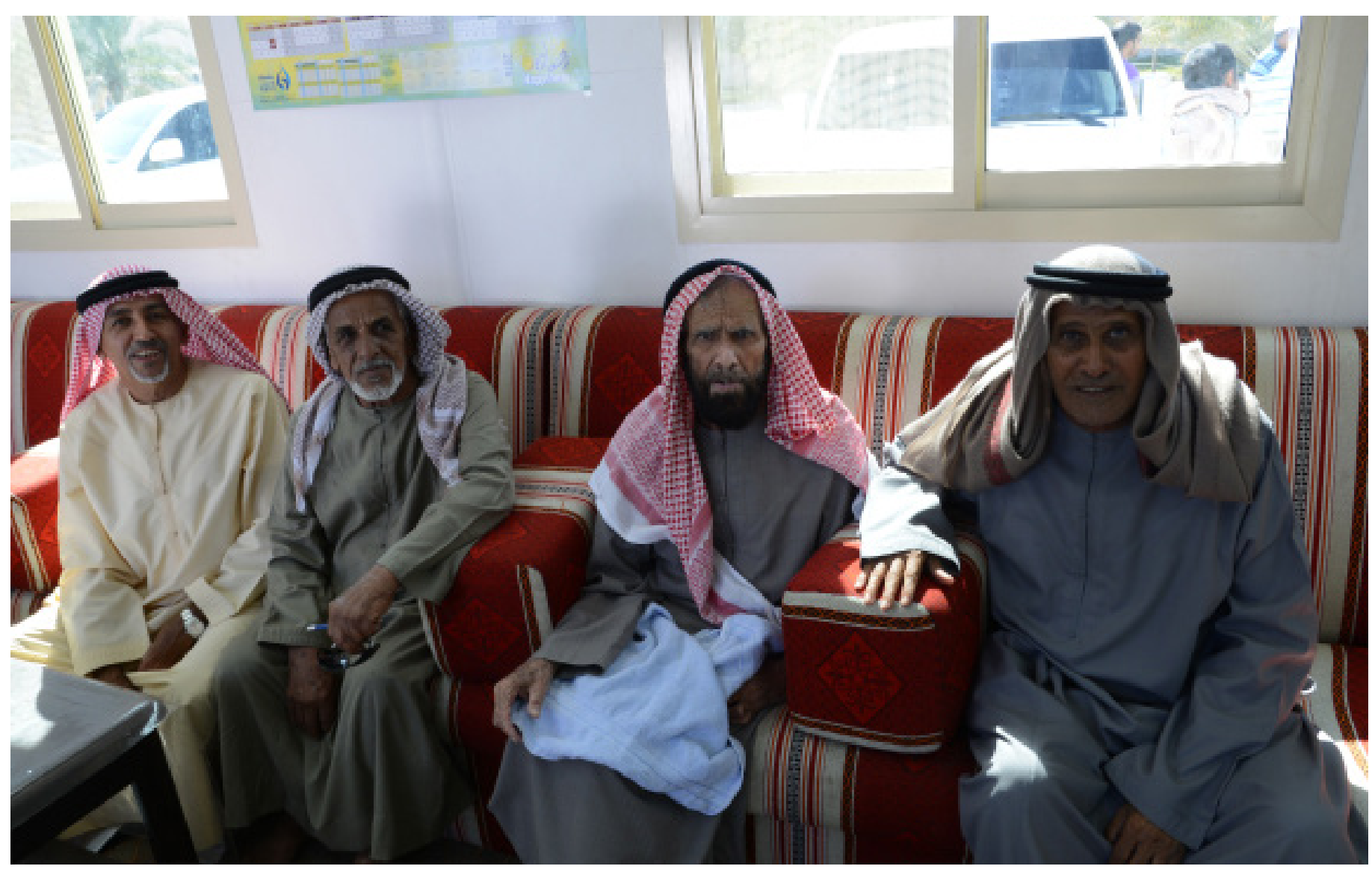

A focus group with traditional fishers at Al Bateen Majlis. Abu Dhabi. United Arab Emirates. (c) Environment Agency - Abu Dhabi. 


\section{How can we apply fishers' knowledge in fisheries policy and today's society?}

At this stage, the Guidelines have assisted the user in achieving Phase 1 - obtaining FK relevant to two broad informational streams - one on the state of a fishery and fisheries management and two, on FK cultural elements. This section presents Phase 2 of the process and intends to provide users guidance on how this information may be used in fisheries policy and other contemporary applications.

\subsection{Phase 2: Fishers' knowledge - applied use framework}

In respect of the key element - 'the how' to incorporate FK today, to date, most traditional fishing knowledge studies have focused on the inclusion of traditional peoples in governance and the integration of customary ecological management practices into conservation planning (Johannes, 1982; Zaan, 1985; King \& Faasili, 1999; Glaesel ,2000; Colding \& Folke, 2001; Davis \& Wagner, 2003). Traditional Knowledge has been viewed as integral to co-management conservation and resource use arrangements, particularly the long-term efficacy of those initiatives (Heyman \& Granados-Dieseldorff, 2012; Hamilton et al., 2012; King \& Faasili, 1999; Evans \& Birchenough, 2001; Johannes, 2002; Aswani \& Hamilton, 2004). In Aotearoa/New Zealand, as an example, partnership with Māori through recognition of the Treaty of Waitangi and the Māori Fisheries Act 2004 has been incorporated in fisheries legislation to develop rules and co-manage fisheries in respect of certain marine areas.

Engagement of experienced fishers in governance, co-management and conservation planning can be a core building block of a sustainable fishery. In addition we provide guidance on how else FK could be used in the wider societal context to enhance the public's nature-society connection and provide benefits to communities.

We also recognise that an applied use for FK in one societal context may be very different to an applied use in another. We have attempted to be as general as possible and consider that there are at least five key areas or uses we could apply to this knowledge:

-1. Fisheries policy;

-2. Supporting IUCN Species and Ecosystem Red Listing;

-3. Co-management;

- 4. Enhancing transmission and perpetuation of knowledge (books / film); and / or

-5. Genetic utilization of biodiversity resource - a Nagoya Protocol use.

Figure 2 presents a schematic of this framework and how and where the information streams support these applied uses, with detail on each applied use following. 


\section{UTILISING FISHERS’ KNOWLEDGE: APPLIED USE FRAMEWORK}

\begin{tabular}{|c|c|}
\hline $\begin{array}{c}\text { Fishers' } \\
\text { Knowledge }\end{array}$ & $\begin{array}{l}\text { 1. A Basket of Fisher Knowledge } \\
\text { Population-level knowledge; Ecological relationships; Ecosystem functioning; Folk } \\
\text { taxonomy and systematics; Subsistence food sources; Wisdom; Material Application; } \\
\text { Subsistence Skills; Socio-political representation ; Myths and Legends; Ritual } \\
\text { representation; Symbolic Representation; Contemporary representation. }\end{array}$ \\
\hline $\begin{array}{l}\text { Fishers' } \\
\text { Knowledge } \\
\text { Informational }\end{array}$ & $\begin{array}{l}\text { 1.1. Fishers' Knowledge Information Stream 1: Historic state of the } \\
\text { fishery, biology, biodiversity, ecosystem, habitat and change to today's state - } \\
\text { Observational information. } \\
\text { Purpose: Observational evidence can support empirical science and socioeconomic } \\
\text { studies in fisheries policy, red listing and management. }\end{array}$ \\
\hline $\begin{array}{c}\text { Streams } \\
\text { Categorisation }\end{array}$ & $\begin{array}{l}\text { 1.2. Fishers' Knowledge Information Stream 2: Cultural Elements - e.g. } \\
\text { Historic Societal Living; Wisdom; Myths \& Folk Systematics. } \\
\text { Purpose:Fishers' Knowledge can be applied in society to strengthen society's } \\
\text { nature-society relationship. }\end{array}$ \\
\hline & $\begin{array}{l}\text { 2. Analysis of Informational Streams and Applied Use } \\
\qquad \text { Recommendations }\end{array}$ \\
\hline
\end{tabular}

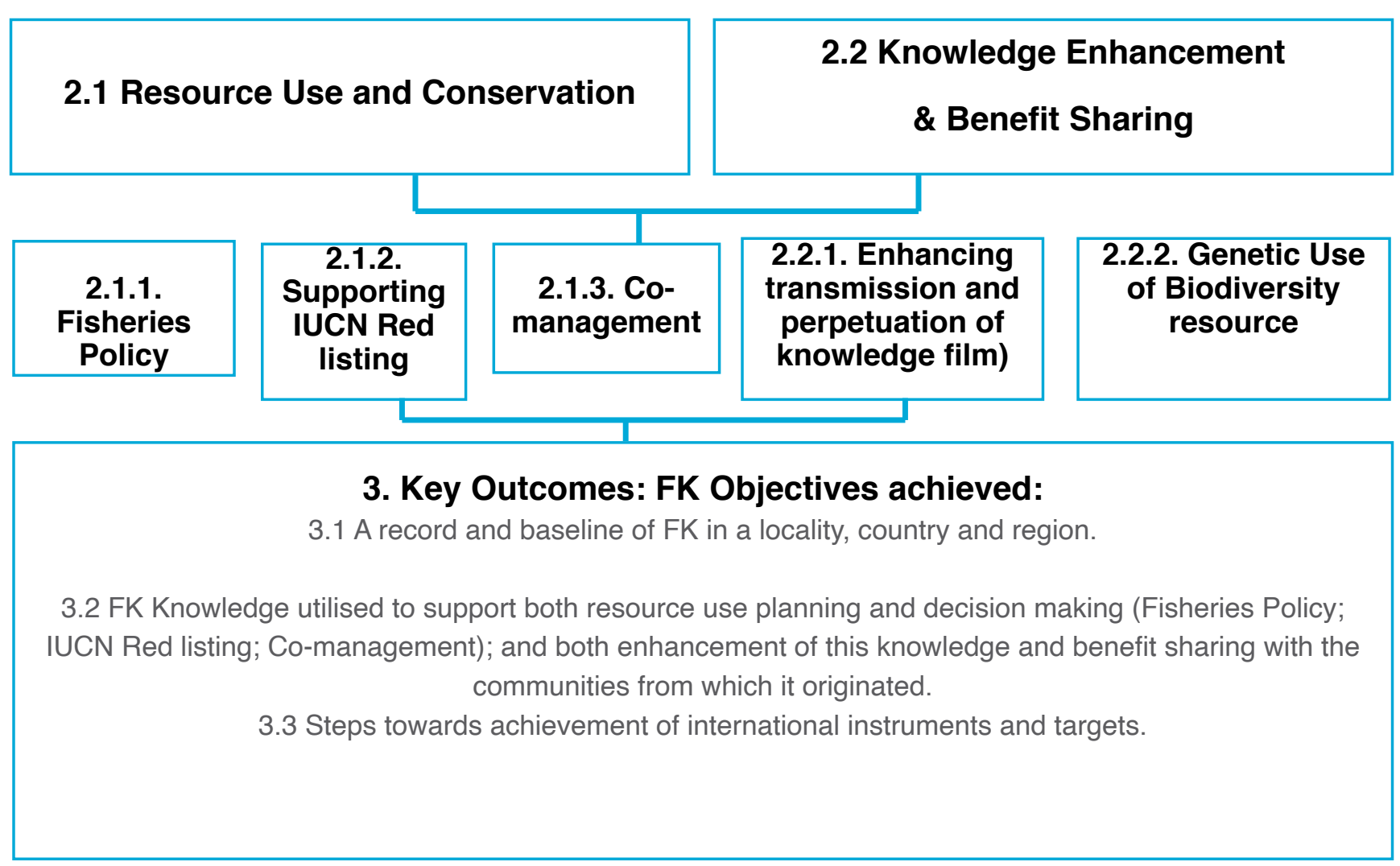




\subsubsection{Fisheries policy}

Achieving sustainable fisheries and integrating Traditional Knowledge and in this case Fishers' Knowledge in national legislation and policy are two key international targets under the Aichi agreement, in addition to being recognised as a priority in a number of other international instruments. The 2020 Aichi Target for fisheries (Target 6) includes a number of key elements when deconstructed:

1. All fish and invertebrate stocks and aquatic plants are managed and harvested sustainably, legally and applying ecosystem based approaches, so that overfishing is avoided;

2. Recovery plans and measures are in place for all depleted species;

3. Fisheries have no significant adverse impacts on threatened species and vulnerable ecosystems and the impacts of fisheries on stocks, species and ecosystems are within safe ecological limits.

Whilst every legislative system is different, and there is debate in respect of what comes first - a policy or a law, it is clear that a fisheries policy or fisheries policies are a necessity to set the direction for fisheries management.

There are many definitions of policy and flexibility with the term is needed in different contexts and legislative systems. For the purposes of these Guidelines, the following definition gives guidance on what a policy is.

\section{POLICY}

Policy is a defined course of government action or inaction, selected to guide present and future decisions, in order to achieve desired goals and outcomes. A policy precedes the development of policy instruments (such as Fisheries Management Plans), which are put in place to implement a policy.

Key considerations follow - how should it be developed? What should it include and how can FK be incorporated in it? The following sections provide guidance in answering these questions.

\subsubsection{How should the policy be developed?}

Policy development should set and seek to achieve a policy vision or statement. In the fisheries context this vision will have sustainability at its core which will involve seeking to reach the right balance between the environment, resources conservation, and social and economic considerations, taking into account stakeholders' interests and concerns. These Guidelines promote Fishers (indigenous, traditional and experienced) as a key stakeholder group to be engaged.

In developing the policy, while the approach will vary by country, the following principles, adopted from the Environment Agency - Abu Dhabi's Environmental Policy Development Guide, provide a guide on what should be taken into account:

- Policy shall be developed to fit the local context, taking into account international and regional approaches and guidelines;

- Policy shall be developed based on analysis of relevant environmental, social and economic aspects;

- Policy development shall involve appropriate engagement, internally and externally, with transparency throughout the process;

- Policy shall be defensible by means of following a clear process and identifying those accountable;

- Policy development shall lead to informed decision making; and

- Policy development shall build-in considerations to ensure commitment and implementation.

In applying these principles, and again recognising that policy development will vary by country and context, policy development should be based on a robust process of issue identification and characterization; analysis of key societal and environmental components; the proposition of a proposed solution(s); internal and external engagement with key stakeholders; followed by the drafting of a policy, regulation or plan, implementation and ongoing evaluation of the chosen solution.

Figure 3 provides an example of a commonly used policy development framework.

\section{Figure 3: Policy Development Framework}

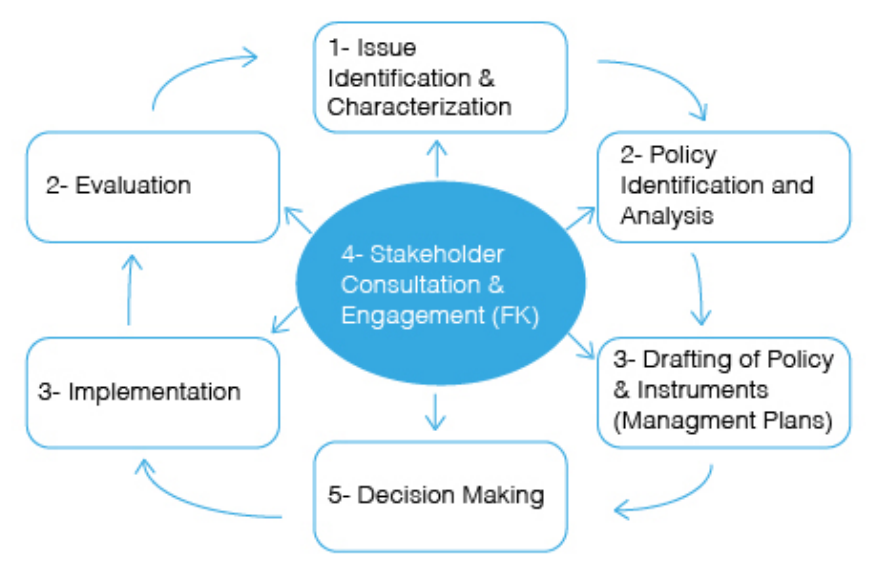

Additional guidance on how this process works is provided below including where gathering and including FK can be included in the process.

\section{Step 1 - Issue Identification and Characterization}

The step of issue identification and characterization aims to frame the fisheries issue being addressed and define the policy goals. This step is often called "policy agenda building", as it is the stage during which issues are identified and prioritized for policy development.

Frequently, fisheries policy is developed reactively when problems expand to a level that becomes visible to the public (e.g. a collapsed fishery or ecosystem shift), often at a great cost to the environment, society and the economy. However, many countries realize that developing fisheries policy proactively can support sustainable economic and social development in the medium and long terms and at lower costs than when using a reactive approach to environmental protection. 
In either case, there is an opportunity to raise the issue and create the necessary urgency for action. The issue may arise as a result of an environmental catastrophe, pressure from private/public interest groups, international or local media articles, or a large event that captures the public's and politicians' imagination. In many cases, because Fishers are generally well known and respected in their communities, they may be the ones raising the issue - which gives the issue added weight - because of the experience and position experienced fishers hold.

Once the issue has been identified, the Guideline user should then analyse the drivers, pressures, state, impact and proposed responses (DPSIR) to that issue.

\section{Figure 4: DPSIR Framework}

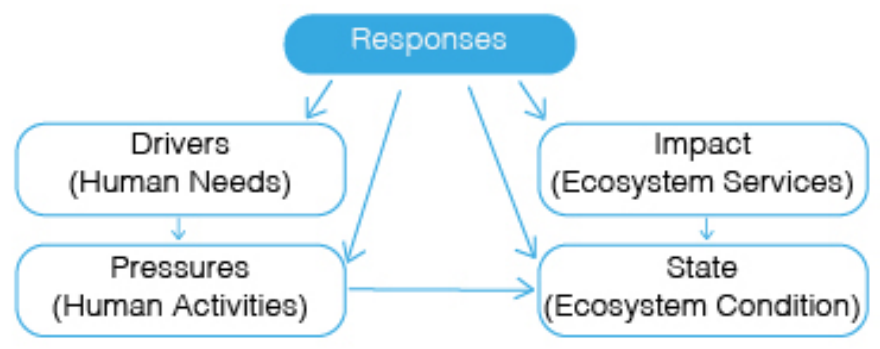

Source: European Environment Agency.

Definitions of the key components of this useful DPSIR framework, adopted to fit the fisheries context, are provided below:

- Drivers are demographic, social, and economic developments that affect fish stock levels, and are generally to satisfy human needs for food, water, shelter, health, security, and culture.

- Pressures are the stresses of human activities on the marine environment and these include land use changes, resource consumption, pollution, etc. Pressures vary with local conditions and technologies used with generally the largest pressure being the fisher exploitation.

- State of the environment includes the physical, chemical and biological variables of the marine ecosystems, and the available information on the state of a specific fishery - scientific stock assessments, and in their absence the results of socioeconomic, FK surveys and citizen science initiatives.

- Impacts are the resultant state of the fish stock, environment degradation, reduction in ecosystem services such as provision of food and water, and cultural and recreational value, etc. social and economic impacts.

- Responses are actions to prevent, adapt and recover to changes in the state of the fish stock and ecosystem. These can target drivers, pressures, the state of the environment, or impacts.

At this issue identification and characterization phase it is also important to: (a) identify the underlying causes and driving forces for policy formulation (e.g.: who is behind the agenda and why?); (b) identify potential concerned stakeholders; (c) which organisation has the mandate and capacity to address; and (d) whether a new policy or a policy revision is needed.

\section{Step 2 - Identification and Analysis of Policy and Instruments}

The policy identification and analysis step aims to identify policy options and to evaluate their effectiveness and costefficiency in achieving the policy goals. This step improves understanding of the impacts of alternative policies and policy instruments on stakeholders and on other policies. If there is an existing policy, policy identification and analysis result in recommendations to decision makers on whether the policy framework should be changed and what type of amendments or new policies need to be drafted and enacted.

To identify policies and policy instruments, one starts by reviewing existing and prior relevant policies in the locality, country and internationally and conducting benchmarking analyses. This should include analysis of the most relevant international approaches, regional agreements, as well as national and emirate approaches. Stakeholder engagement is also advised during the policy identification phase, to benefit from experience outside the policy analysis team, and identify on-going initiatives.

At this stage it is fundamental to include FK particularly if there is a paucity of information on a fishery or marine ecosystem available. The initial process of engaging with fishers to obtain this knowledge in a developing country context is different to situations where fisheries are well established. In the first situation, the process outlined in Section 4 should be followed for guidance. In a context where fisheries management is well established, the knowledge may still exist, but may not be being utilised. Special consideration should be given to engaging with 'Fishers' in this situation to supplement empirical studies.

Broadly, stakeholders can be consulted through bilateral meetings and focus groups and can use brainstorming and/or logic tree analysis to break down large problems into manageable questions and sub-questions.

Once alternative policy options and instruments are identified and validated with the relevant stakeholders, the policy analysis team can use several evaluation instruments, such as the Political, Economic, Social, Technological, Legal, Environmental (PESTLE) analysis (Table 2). 
Table 2: PESTLE Policy Analysis

\begin{tabular}{|c|c|c|c|}
\hline Areas & Key Questions & Sub Questions & Info Needed \\
\hline Political & $\begin{array}{l}\text {-What is the political context? } \\
\text { - Where does this problem fit within } \\
\text { the government strategic priorities? }\end{array}$ & $\begin{array}{l}\text {-Who are the leaders/change makers? } \\
\text {-Where is the pressure coming from? } \\
\text {-Which government entities need to be } \\
\text { involved in addressing the issue? } \\
\text { - What are Fishers' views? }\end{array}$ & \multirow{6}{*}{$\begin{array}{l}\text { - Stakeholder map (list } \\
\text { stakeholders, assess influ- } \\
\text { ence and interest of stake- } \\
\text { holders) } \\
\text { - Actions currently being } \\
\text { taken by other government } \\
\text { entities. } \\
\text { - International and local } \\
\text { benchmarking, evidence, } \\
\text { best practices and success } \\
\text { stories. } \\
\text { - Position of regional and } \\
\text { international community on } \\
\text { the issue. } \\
\text { - Assessment of potential } \\
\text { costs and benefits from } \\
\text { alternative solutions, and no } \\
\text { intervention. }\end{array}$} \\
\hline Economic & $\begin{array}{l}\text { - What are the economic impacts: } \\
\text { short versus long term; overall and } \\
\text { by stakeholder. } \\
\text { - What are the impacts on Fishers? }\end{array}$ & $\begin{array}{l}\text {-What are the market effects of problem } \\
\text { and solutions? (cost-benefit, opportunity } \\
\text { costs, effectiveness, economic impact) }\end{array}$ & \\
\hline Social & $\begin{array}{l}\text { - Which sectors of society are af- } \\
\text { fected by problem and solutions? } \\
\text { - What are the impacts on Fishers } \\
\text { and what are their views? } \\
\text { - Is there awareness of problem and } \\
\text { solutions? }\end{array}$ & $\begin{array}{l}\text { - What are the social issues of problem } \\
\text { and solutions? } \\
\text { - Social equality effected? } \\
\text { - Are there cultural, religious consider- } \\
\text { ations? } \\
\text { - Impact on regional, social equality, } \\
\text { community? }\end{array}$ & \\
\hline Technological & $\begin{array}{l}\text { - Are there technological tools to } \\
\text { help address issue? }\end{array}$ & $\begin{array}{l}\text { - What are the tools available from other } \\
\text { entities? } \\
\text { - What are the technologies evolved by } \\
\text { fishers based on their knowledge? }\end{array}$ & \\
\hline Legal & $\begin{array}{l}\text { - Is there a legal framework in } \\
\text { place? A new/improved legal frame- } \\
\text { work is required? }\end{array}$ & $\begin{array}{l}\text { - Are there legal barriers or enablers for } \\
\text { the problem and solutions? } \\
\text { - What is the regulatory impact of policy } \\
\text { and instruments? } \\
\text { - Is the policy and instruments constitu- } \\
\text { tional, feasible and enforceable? }\end{array}$ & \\
\hline $\begin{array}{l}\text { Fisheries and } \\
\text { Environmental }\end{array}$ & \multicolumn{2}{|c|}{$\begin{array}{l}\text { - What is the environment and fisheries impact of the problem and solutions? } \\
\text { - How can Fishers be part of the solution? }\end{array}$} & \\
\hline
\end{tabular}

The areas outlined in Table 2 are indicative only to ensure that all issues are covered in analysing the policy issue. Policy instruments should be evaluated in terms of alignment to overall policy direction, effectiveness in achieving outcomes, cost-efficiency, political and practical feasibility. Combinations of policy instruments should also be evaluated in terms of cost and benefits since synergies can be created. Trade-offs between policy objectives should be resolved and if this is not possible then the main policy objectives to be addressed should be identified.

A cost-benefit analysis is typically conducted once the policy proposed has been developed and detailed and helps inform the decision-making approval process. Costbenefit analyses typically cover direct and indirect costs and benefits of the proposed approach. Direct costs and benefits are those related to capital requirements, operating costs, and human resources costs. Indirect costs and benefits are those related to impacts on other sectors of the economy, society and environment and are frequently considered and discounted on a medium-term of, for example, 5-10 years' time horizon. A "without-policy" scenario should also be considered in the evaluation of the policy instruments.

\subsubsection{What should the policy include?}

In following through the policy development process, the following steps provide guidance on what the policy should include once options have been assessed.

\section{Step 3 - Drafting of Policy and Instruments}

The drafting process for a policy instrument includes a summary sector review to give the policy context on the issues the policy aims to address, and to incorporate local, regional and international best practices. A policy document can vary widely in structure and content depending on the policy instrument. However, a policy document typically includes the below, with the key information stream 'Fishers' Knowledge' added:

\section{FISHERIES POLICY TABLE OF CONTENTS}

1. Policy Vision

o 1.1 Introduction

o 1.2 Policy aim

o 1.3 Policy challenges

o 1.4 Policy objectives

o 1.5 Legal authority

o 1.6 Policy application

o 1.7 Policy effective date

-2. Policy Background

o 2.1 Fisheries and heritage

o 2.2 Drivers and Pressures on the fishery

o 2.3 Fisheries sector overview

o 2.4 Fisheries State

$\square$ Fisheries Science

$\square$ Fisheries Socioeconomics

口 Fishers' Knowledge

o 2.5 Planning and Policy Hierarchy

-3. Policy Statement

- 4. Policy Analysis 
o 4.1 Options Assessment

o 4.2 PESTLE Analysis

o 4.3 Policy Costs and Benefits

- 5. Policy Implementation and Review

o 5.1 Implementation mechanisms

o 5.2 Resources needed to support this policy

o 5.3 Review of policy: measurement

- 6. Bibliography

The above is a general guide for what to include in a fisheries policy, with it recognised that the contents will vary by the context. The Sections below give guidance on achieving Steps 4: Stakeholder Engagement; Step 5: Decision Making; Step 6: Implementation; and Step 7: Evaluation.

\section{Step 4 - Stakeholder engagement}

The stakeholder engagement step aims to ensure that all concerned stakeholders and interest groups agree and support the proposed policy and instruments. It also aims to identify challenges and risks, and define solutions for challenges and management plans for risks. Stakeholder consultation and engagement permeates the policy development cycle, meaning that it should occur at the various steps of the process map.

The objectives of stakeholder engagement include:

- Enable transparent and effective policy making;

- Seek information on the issue;

- Improve stakeholder understanding of the policy;

- Validate information and test the soundness of ideas;

- Identify potential challenges, solutions, risks and opportunities;

- Collect new ideas and expert opinions;

- Obtain buy-in and endorsement;

- Provide a mechanism for raising awareness of the policy issues;

- Make progress towards policy declaration and/ or implementation; and

- Seek feedback on the effectiveness of the policy.

Each country will differ on their process - what is important for the purposes of these Guidelines is that FK is identified as a key data stream and component and this group is consulted on fisheries state and proposed options.

\section{Step 5 - Decision making and approval}

A decision on policy will be as per a country's context, constitution and legislation.

\section{Step 6-Implementation of policy}

Policy and instrument implementation includes tracking and reporting on progress of implementation. This is a matter of tracking implementation actions against timeframes, which will be dependent on their nature.

\section{Step $7-$ Evaluation of policy}

Evaluation aims to ensure that policy and instruments meet their objectives. In addition, evaluation provides input for further policy and instrument development. The evaluation phase includes measuring performance and outcomes against implementation plans and pre-defined targets - e.g. for a fisheries policy being implemented at a small scale protected area in a seasonal sea with high variability in temperature and conditions - like the Arabian Gulf, scientific monitoring could take place biannually or quarterly. In other contexts, and dependent on resource constraints, monitoring may be annually, or in a situation where a fishery has been closed, every three to five years. Taking a broader perspective, evaluation can also be conducted based on policy impact on the environment. This is a longer timeframe, and is usually on a five year basis. This type of evaluation could be carried out, for example, based on the state of the environment reporting.

\subsubsection{FK and the Aichi targets}

The above section has outlined guidelines to follow for how to develop fisheries policy and what to include in it, in seeking to provide guidance to achieve the likes of Aichi Target 6 on sustainable fisheries. In assessing Aichi Target 18 on Traditional Knowledge and how it may be achieved, the target, when deconstructed, includes a number of key elements:

- Respect: Traditional knowledge, innovations and practices of indigenous and local communities relevant for the conservation and sustainable use of biodiversity, and their customary use of biological resources, are respected;

- Legislation: Traditional knowledge is subject to national legislation and relevant international obligations;

- Participation: Traditional knowledge is fully integrated and reflected in the implementation of the Convention with the full and effective participation of indigenous and local communities, at all relevant levels.

Applying the policy development process outlined above in either a developed or developing country context should generally result, if these Guidelines are followed correctly, in traditional fishers feeling respected and that they have participated and have the ongoing opportunity to participate in respect of resource management. All of the applied uses outlined in these Guidelines (e.g. Fisheries Policy development; IUCN Red Listing; and co-management) will support the achievement of the 'Respect' and 'Participation' components of Aichi Target 18.

In respect of the final element - including Traditional Knowledge in legislation, whilst every legislative system is different, and there is debate in respect of what comes first - a policy or a law, it is clear that direction to include Traditional Knowledge or Fishers' Knowledge in a participatory process when developing fisheries policy will achieve this key component of Aichi Target 18.

\subsubsection{Additional applied uses}

This section identifies additional applied uses where FK can be utilised. These include:

- Red Listing supporting empirical studies;

- Co-management;

- Enhancing transmission and perpetuation of knowledge 
(books / film); and

- Genetic Use: A Nagoya Protocol type Use.

\subsubsection{Supporting IUCN Red Listing}

A contemporary application for $\mathrm{FK}$ is inclusion as a supporting data stream for IUCN Red-listing. A forthcoming Guideline on incorporating FK in Red-Listing, will provide guidance on how FK can support the red listing process. The key messages and intent are:

- Integrating FK into species assessments for The IUCN Red List of Threatened Species and Ecosystems can improve assessments through ensuring these are informed by the best available information, including on distribution, abundance, seasonal patterns, behavioural ecology, drivers of change, and threats. In some cases FK may be the only source of information available.

- Integrating FK may also increase local acceptance of and engagement with conservation measures that may follow IUCN Red List assessments.

- Working with FK holders and integrating FK may pose novel challenges for IUCN Red List assessors, and involve a wide range of considerations to ensure respectful and appropriate interactions.

These Guidelines aim to support IUCN Red List assessors by providing a toolbox of practical considerations and approaches, to guide engagement with FK holders and use of FK.

\subsubsection{Co-management}

Fishers can also apply their knowledge in co-management within and outside of protected areas and in Indigenous Peoples and Local Communities Conserved areas Territories of life. Three additional guidelines are good reference points:

- Co-management within protected areas:

o UN FAO Marine Protected Areas: Interactions with Fishery Livelihoods and Food Security (2016).

Access: http://www.fao.org/3/a-i6742e.pdf

o Borrini-Feyerabend, G., N. Dudley, T. Jaeger, B. Lassen, N. Pathak Broome, A. Phillips and T. Sandwith (2013). Governance of Protected Areas: From understanding to action. Best Practice Protected Area Guidelines Series No. 20, Gland, Switzerland: IUCN. Access: https://www.iccaconsortium.org/wp-content/ uploads/2015/08/publication-iucn-best-practices-no202013-en.pdf

- Co-management more broadly:

o Govan, H., Aalbersberg, W., Tawake, A., and Parks, J. (2008). Locally-Managed Marine Areas: A guide for practitioners. The Locally-Managed Marine Area Network. Access:

http://Immanetwork.org/resources/tools/

http://www.reefresilience.org/wp-content/uploads/ LMMA-Guide-2008.pdf

\section{Co-management within protected areas}

Literature covering a variety of different co-management arrangements in Africa, Asia, Europe, North America and the Pacific, in both freshwater and marine habitats, suggests that cooperative, advisory and informative levels of engagement and subsequent management occurred in situations where user groups were able and willing to take up the responsibility (Sen and Nielsen 1996).

Within protected areas, both the IUCN Governance of Protected Areas: From understanding to action. Best Practice Protected Area Guidelines (2013) and the recent Technical Guideline by UN FAO (2016) provides guidance. The recent UN FAO Guideline is a Technical Paper entitled 'Marine Protected Areas: Interactions with Fishery Livelihoods and Food Security (2016).' It focuses on the interface of Marine Protected Areas (MPA) / Protected Areas (PA) and livelihoods-food security in coastal and inland water areas based on case studies in Africa, Asia, Latin America and Oceania. The case studies and analyses provides details on the different range of outcomes that can arise in terms of the interactions between communities and Protected Areas. As an example, some papers highlight the significant resistance of fishers towards the placement of MPAs in their traditional fishing grounds while others indicate benefits of MPAs, such as maintaining the quality of freshwater areas for decades in the Philippines or rebuilding eel-grass habitats in Japan.

The Guideline assesses whether managers can produce greater net benefits for food security and livelihoods, within PAs. It provides the following Guidance to improve the outcomes for fishing communities from using PAs, in respect of livelihoods and food security and is another fundamental application for FK:

- Adequate policies. There is an urgent need to refine marine conservation and fisheries policy-making so that food security and poverty alleviation are seen as integral and complementary to conservation objectives. This finding has been incorporated in the proposed fisheries policy development process, above. In the case of freshwater systems fishers can also play a critical role in supporting protected area definitions and management based on their knowledge.

- Clear objectives. If PAs are to have positive impacts on both ecological and human well-being at a local scale, their planning should integrate balanced objectives - i.e. ecological protection and livelihoods and food security. Engagement with fishers is critical to setting these objectives. In addition, clear objectives should also include a well-defined problem definition. We see too often that a tool is developed before the problem is defined.

- Participation. In all case studies in the Guideline, a high level of effective participation is considered as a clear condition of success - seen as depending on both the degree of involvement (relating as well to suitable empowerment) and the commitment and support of stakeholders (including communities) in planning, implementation, monitoring and enforcement. A good demonstration of effective participation, as an example, is the collaborative development of management plans which improves the "ownership" of the PA by the community.

- d. Capacity-building. Participation is necessary but 


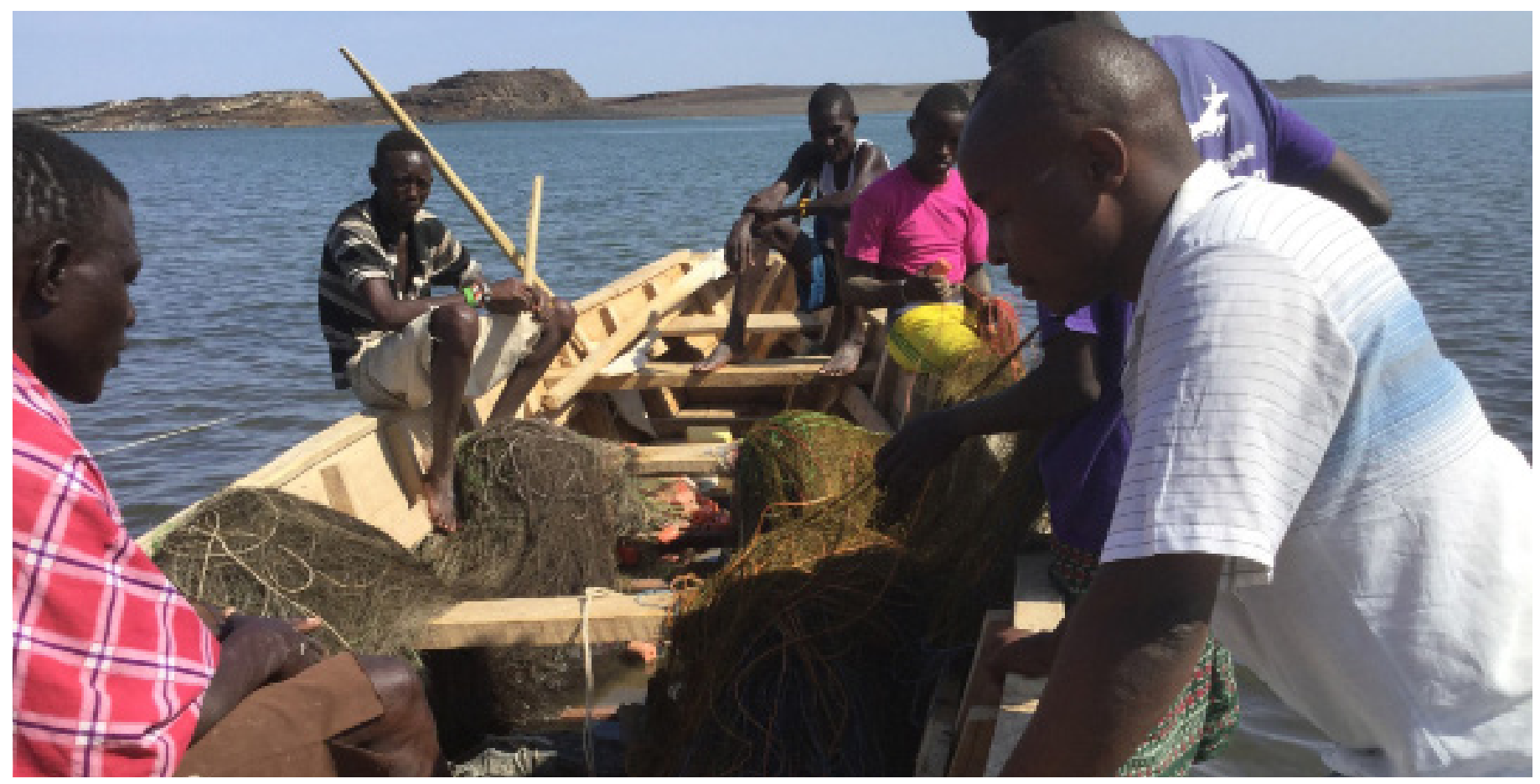

Integrating FK into fisheries assessments in scientific data deficient fisheries can support in fisheries like Lake Turkana, Kenya, where the Elmolo people hold Fishers Knowledge. (c) Christiana Louwa.

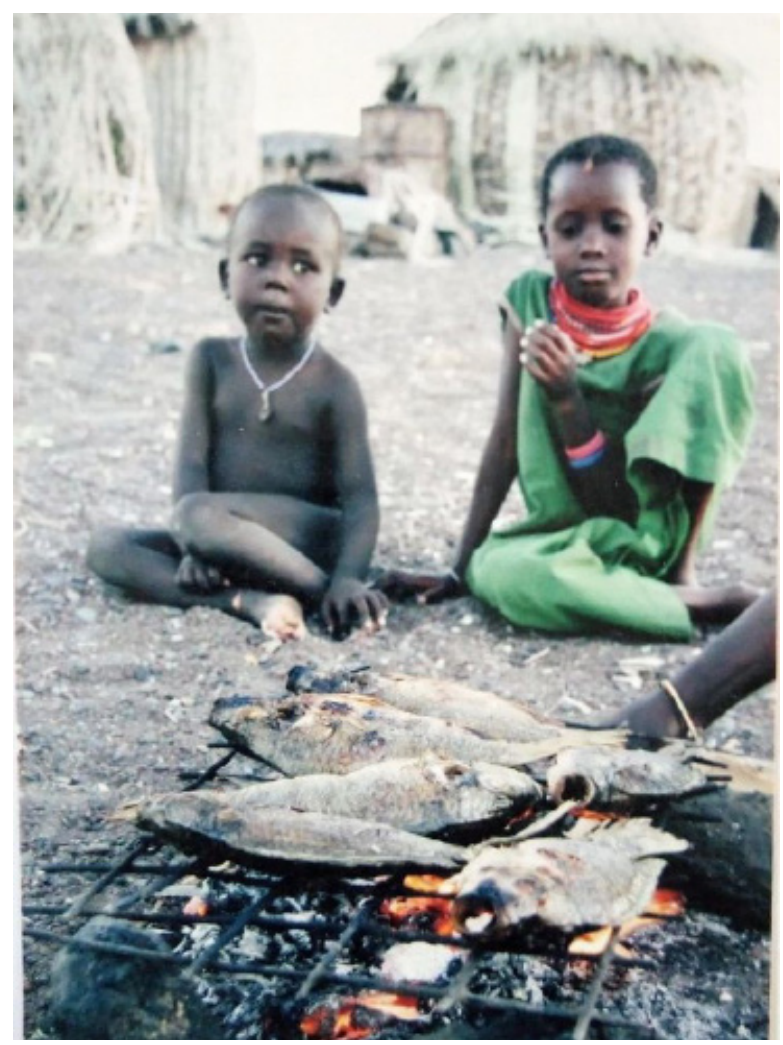

Elmolo people cooking fish traditionally - another cultural element of Fishers Knowledge, Lake Turkana, Kenya. (c) Christiana Louwa.

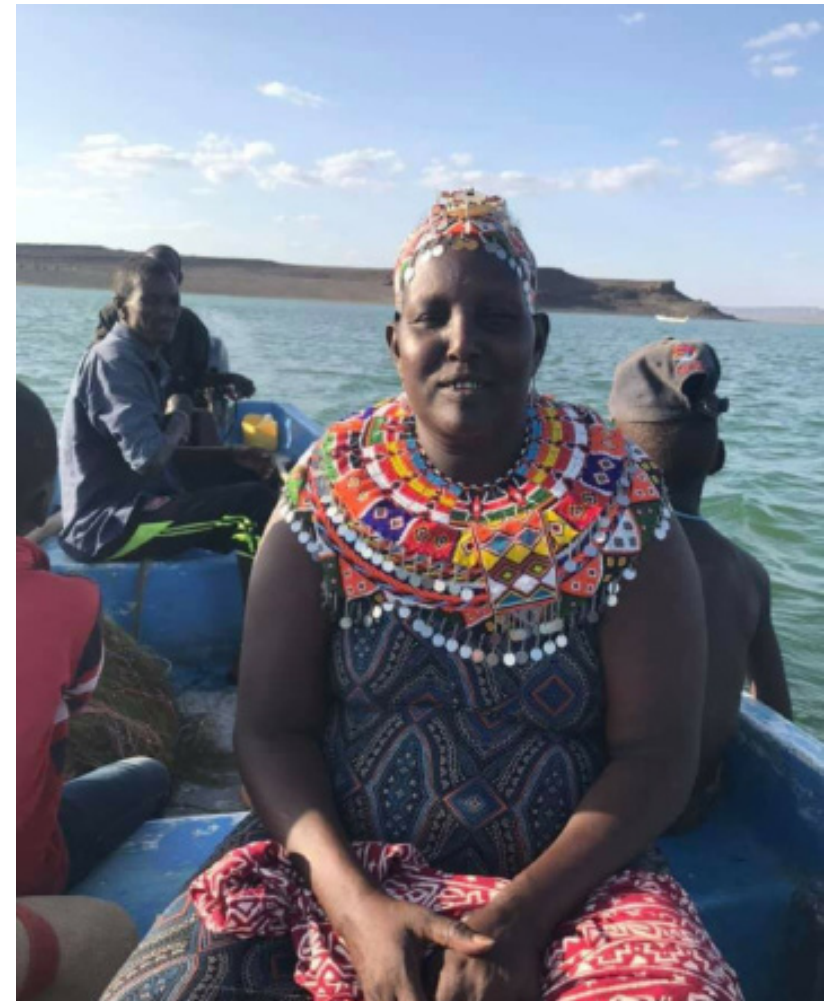

Christiana Louwa, Chief of the Elmolo people. Holder of Fishers' Knowledge on Lake Turkana. (c) Elomolo people. 
not sufficient if the capacity to effectively participate is not developed. Capacity-building is a fundamental requirement of PA design: co-management structures; monitoring, control and surveillance; and adaptive management.

- e. Management measures. The Guidelines promote the combination of PA management with fishery management (as previously promoted in UN FAO, 2011). Framing these measures in an agreed and cooperatively developed management plan would improve compliance and success.

- f. Traditional knowledge and the use of fishers' memories is identified as being able to make a substantial contribution to the success of PA design and implementation. The Guideline identifies that the development of an historical perspective of the communities and their functioning helps in developing better understanding and prediction of the effects of a PA.

- g. Communication and knowledge. A better understanding of how PAs interact with livelihoods and food security can be built through establishing clear communication channels between villagers, local leaders, local government and NGOs, national authorities and international donors.

- h. Compensation. The Guidelines provide guidance on whether compensation may be appropriate in the context where a PA has had an adverse effect on the livelihood of a fisher.

The UN FAO Marine Protected Areas: Interactions with Fishery Livelihoods and Food Security (2016) provide guidance and case studies on one of the key applied uses identified in these Guidelines - Protected Area CoManagement.

\section{Co-management more broadly}

The Locally-Managed Marine Areas: A guide for practitioners (2008) Guideline presents step-by-step guidelines for setting up a co-managed or locally managed marine area and provides simple and discrete community organizing activities and 'tools' that are used to facilitate and guide communities, local leaders, and their conservation partners through the process of creating and managing a co-managed or locally managed area.

Entitled Locally-Managed Marine Areas: A guide for practitioners (2008), It represents a joint undertaking by the following organizational members of the Locally-Managed Marine Area (LMMA) Network: the World Resources Institute, the Applied Science Institute of the University of the South Pacific, the Foundation of the Peoples of the South Pacific International Secretariat, and the World Wide Fund for Nature South Pacific Programme.

This Guideline presents step-by-step guidelines for setting up an LMMA and provides simple and discrete community organizing activities and 'tools' that are used to facilitate and guide communities, local leaders, and their conservation partners through the process of creating and managing an LMMA.
The guideline has been written principally with coastal community members and leaders in mind, as well as the partner organizations that support them and their local management efforts. Partners can include government agencies, non-government organizations, universities and other interested parties. This principle of partnership is explicit in Aotearoa/New Zealand in the mechanisms identified in the Fisheries Act (2004) which legally gives status to customary Māori fishing areas e.g. taipure and mataitai - these are areas where Māori can undertake management of fisheries resources (Stephenson et al 2014)

The guideline may also be useful for national decision makers who are considering using LMMAs, conservation scientists and researchers who are working to learn how to improve the practice of marine conservation, donor organizations who support LMMAs and marine conservation work, and students, professors or others in academia. There is also detailed and useful information on how to set up no-take areas, followed by information on biological monitoring. This manual is helpful to anyone wishing a better understanding of how to carry out effective community-based management of the coastal area and many of the activities could also be adapted for different situations.

The guideline is structured around four general phases taken along the path of LMMA establishment and use:

- Phase One - Initial Assessment;

- Phase Two - LMMA Design and Planning;

- Phase Three - Implementation of Community-Based Adaptive Management; and

- Phase Four - Ongoing Community Based Adaptive Management.

More detail is included in the Appendix on this Case Study.

\subsubsection{FK enhancement - transmission and perpetuation of knowledge}

Consideration should be given on how to enhance perpetuation, ongoing use and adaptation of FK. Books, films and education programmes are all of examples to how this knowledge can be applied to contemporary issues and concerns. FK and particularly traditional knowledge, provides inspiration when it is brought to life - books and films are key ways to bring to current and future generations knowledge on the tangible and intangible heritage of a locality and highlight the rich culture and history of an area through creative and interactive media. Social media also provides opportunities through the likes of interesting 'Did you know?' media feeds.

Similarly, dedicated traditional knowledge and marine education programs aiming to raise awareness of the value of biodiversity and heritage are also ways in which FK can be brought to life. EAD's award winning Sustainable Schools programme is an example - where the likes of 'colouring-in books' are included with images of fishers behaviour and how this can adversely and positively effect biodiversity - e.g. fishing nets and dugong. 


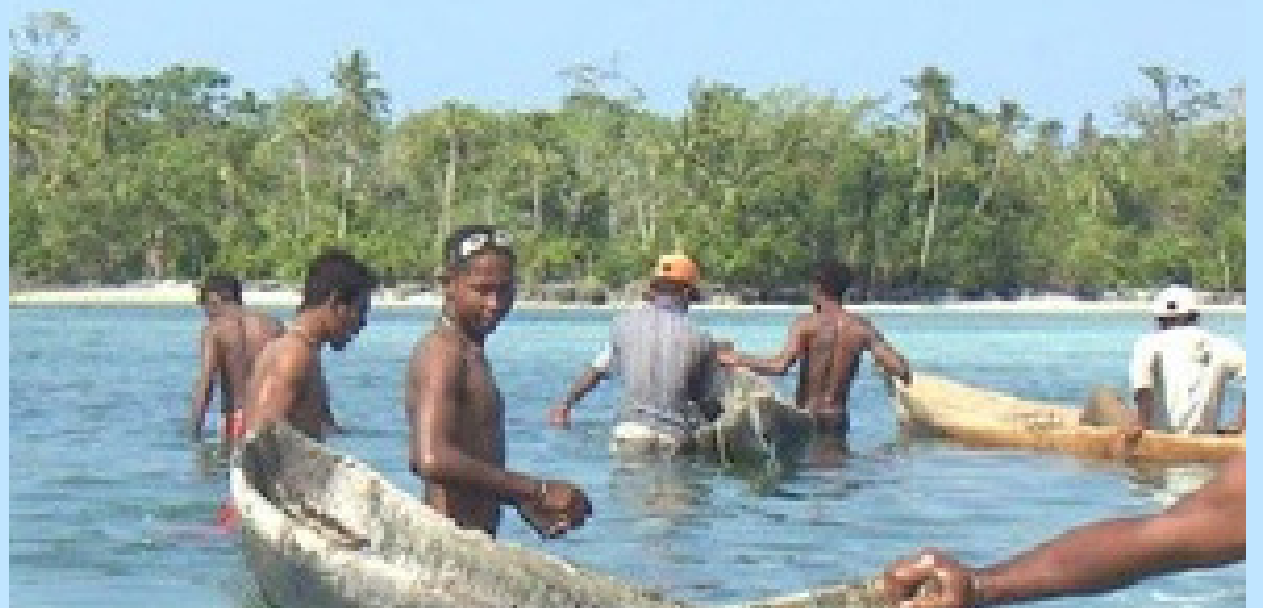

The Local Marine-Managed Areas Guideline has supported co-management in many Pacific communities. (c) Hugh Govan.

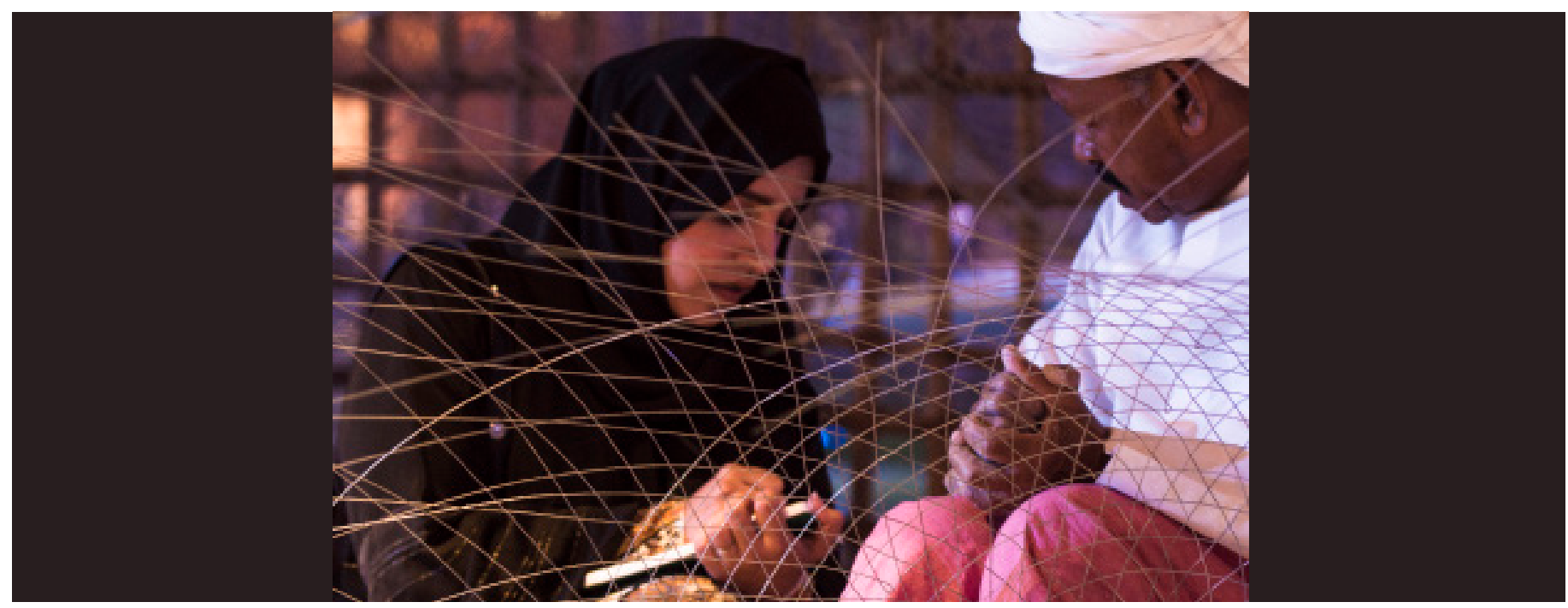

Abu Dhabi youth - learning how to weave a fish trap using palm fronds. (c) Environment Agency - Abu Dhabi.

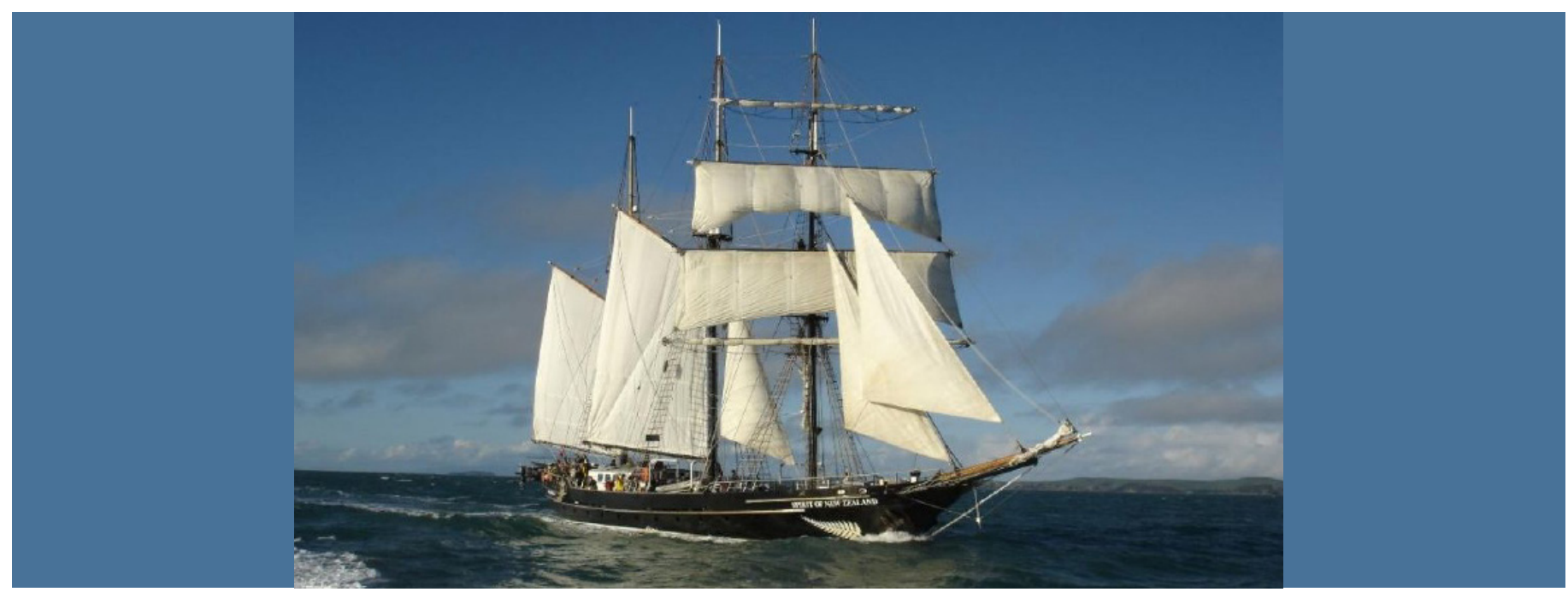

The Spirit of Adventure' ship based education programme is a practical method of passing on fishing and marine knowledge to youth. (c) Spirit of Adventure Trust. 
Educational programs which perpetuate fishing lifestyles and traditional practices can strengthen teaching and application of fishers knowledge across generations. 'Examples include multi-generational educational, fishing camps held in many rural Hawai'i communities.

Practical outdoor marine character development programmes are also examples of how FK can be brought to life. The Spirit of New Zealand vessel is an example of this, where children from age 15 have the opportunity to sail on a vessel, learn how to do so, and then sail it by themselves on the final day of their 10 day voyage.

In the Solomon Islands, a collaboration between local fishers, James Cook University and documentary makers developed a fisheries science education DVD, called "Fish and People". Its main target audience was high school students in Solomon Islands and Papua New Guinea, seeking to achieve environmental awareness. The program is divided into five 12-minute episodes, each dealing with a different topic and all cohesively aligned to achieving greater educational awareness. A Teacher's Guide for each episode is part of the package. More details are provided in the case study in Appendix A.

\subsubsection{Genetic use of biodiversity resource}

It is generally recognised that most of the information on how to extract benefits out of biodiversity and natural resources is held by indigenous people. The Nagoya Protocol and its implementation are inextricably linked with the compilation, documentation and protection of the traditional knowledge held by the native inhabitants of an area or country. The Protocol contains significant provisions relating to traditional knowledge and sets out clear requirements to obtain the prior consent of the local communities prior to sharing, communicating or using this traditional knowledge. These Guidelines support the implementation of the Protocol, setting out the process for building a record of experienced fisheries knowledge - with the Nagoya Protocol identifying the process for establishing how benefits arising from this knowledge may be shared.

\subsubsection{Fishers' knowledge case studies}

Case studies are fundamental to understanding how FK can be applied in Fisheries Policy and Management. Applying FK in fisheries management is an approach that has been applied globally with success, albeit not as widely or at the speed as the international conservation community would like, hence the development of these Guidelines. Selected Case Studies provided by experts by region are provided in Appendix 1 to support with readers' benchmarking. In the interests of sharing knowledge and building capacity we encourage readers to contact experts by region if they have additional queries.

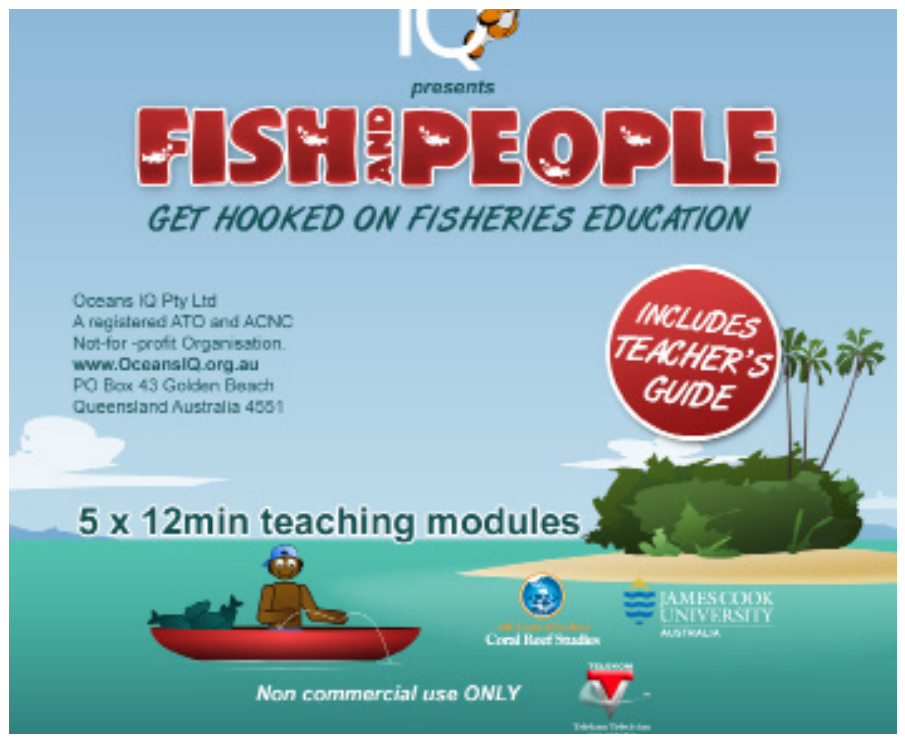

Fishers knowledge was enhanced into a DVD entitled 'Fish and People' in the Solomon Islands. (c) Simon Foale. James Cook University. 


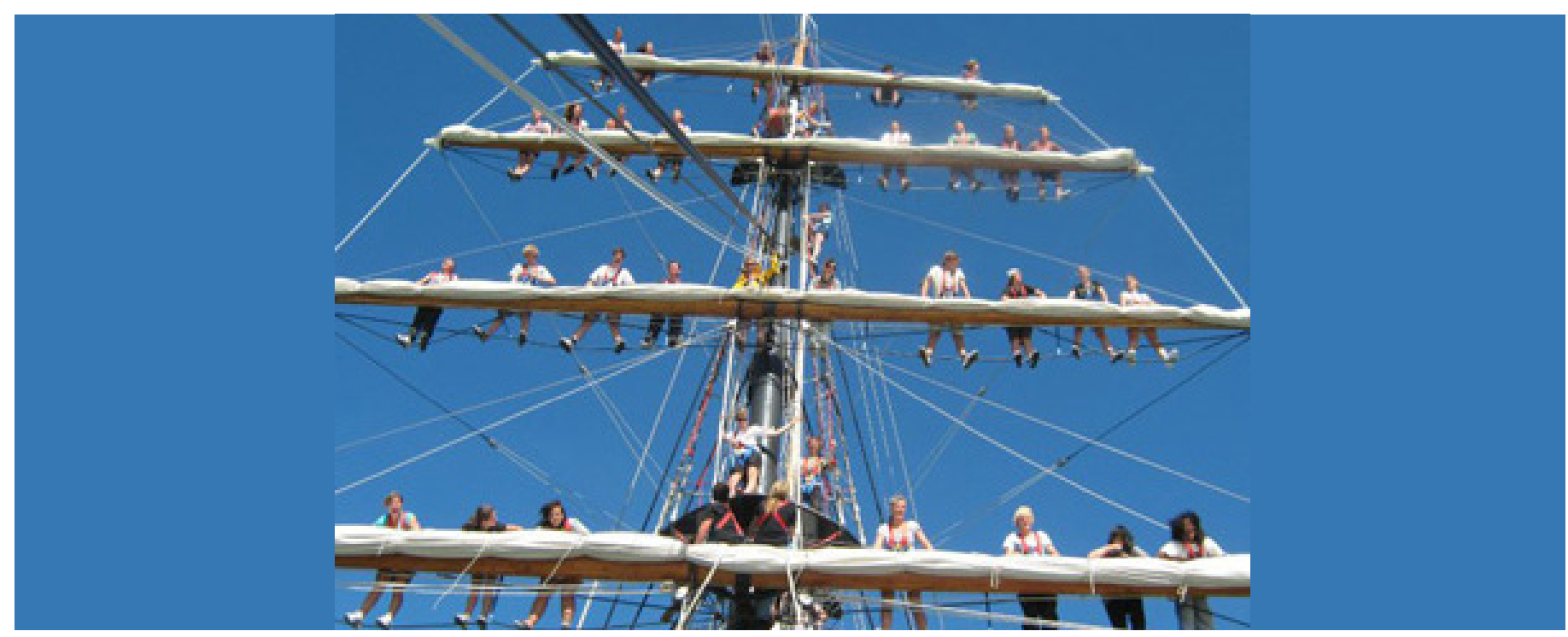

School age children learning marine education practically, up the ship mast. (c) Spirit of Adventure Trust.

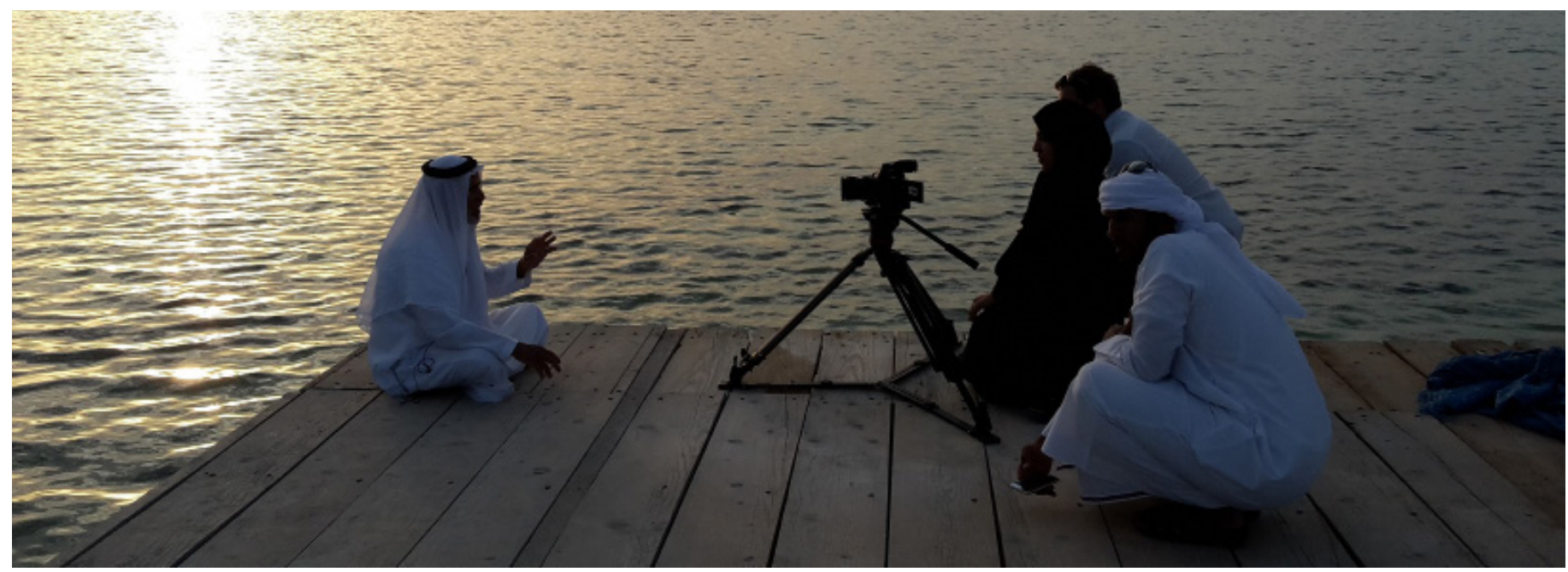

Fishers Knowledge in the United Arab Emirates was turned into a documentary - Our Sea Our Heritage. Traditional Fisher Jumaa Al Romaithi being interviewed. Marawah Island. (c) Environment Agency - Abu Dhabi.

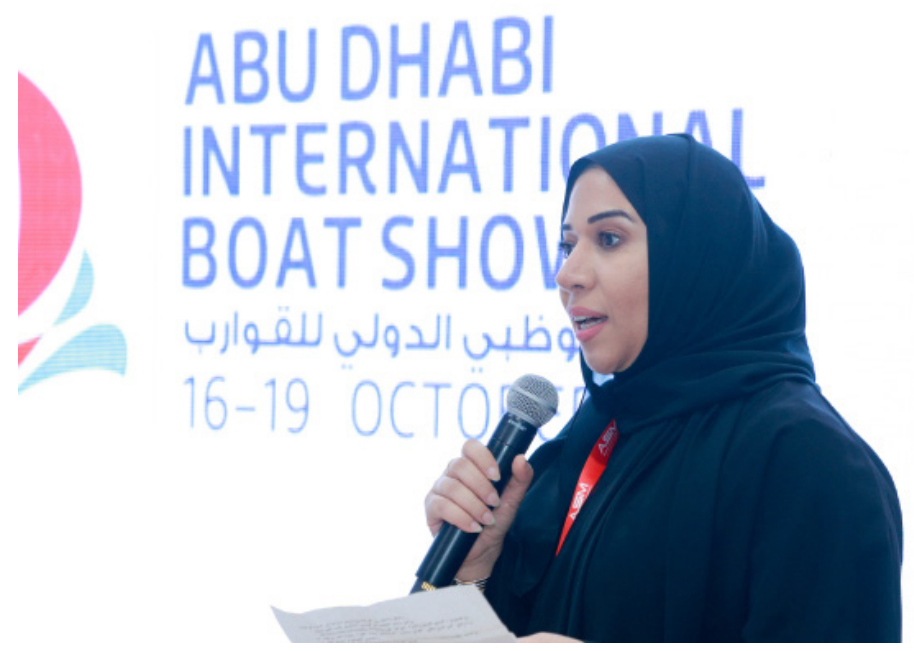

Reem Al Baharna, Section Manager Fisheries speaks at the premiere of Our Sea Our Heritage. (c) Environment Agency - Abu Dhabi. 


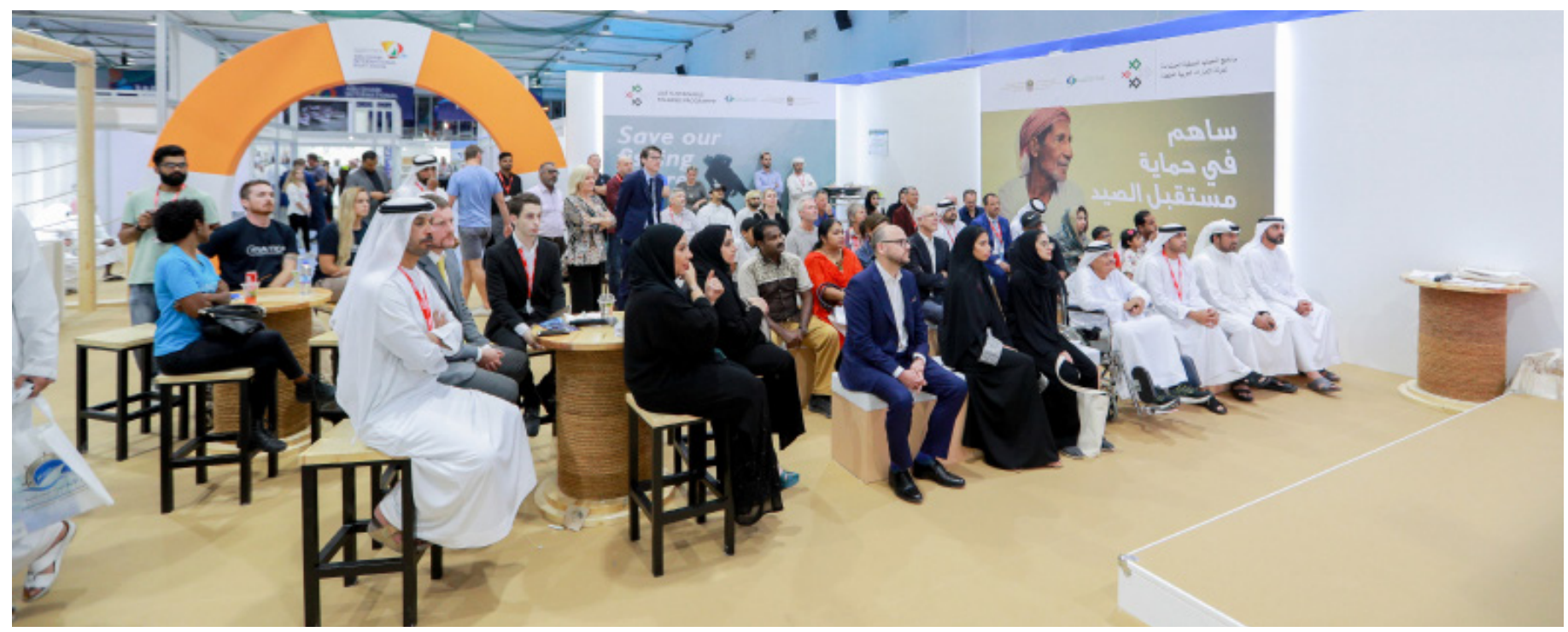

Premiere of Our Sea Our Heritage at the Abu Dhabi International Boat Show. (c) Environment Agency - Abu Dhabi.

Large-Scale

Sand Movements

Affect Fish Behavior

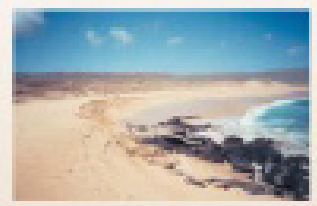

Largescale sand

movenents cause

seascnal ecosystem

shifts along the

Mo'onomi cosst.

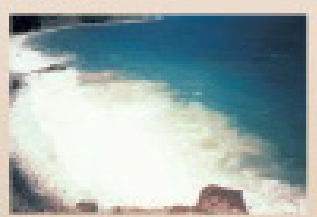

Marine species shift

bcations as their habitats

fil with sand.

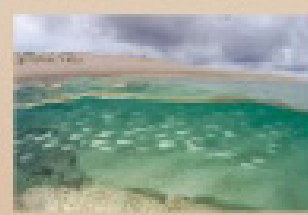

Change in habtat may trigger fish spawring

activily

Send may bury or expose

fish nursery habitat

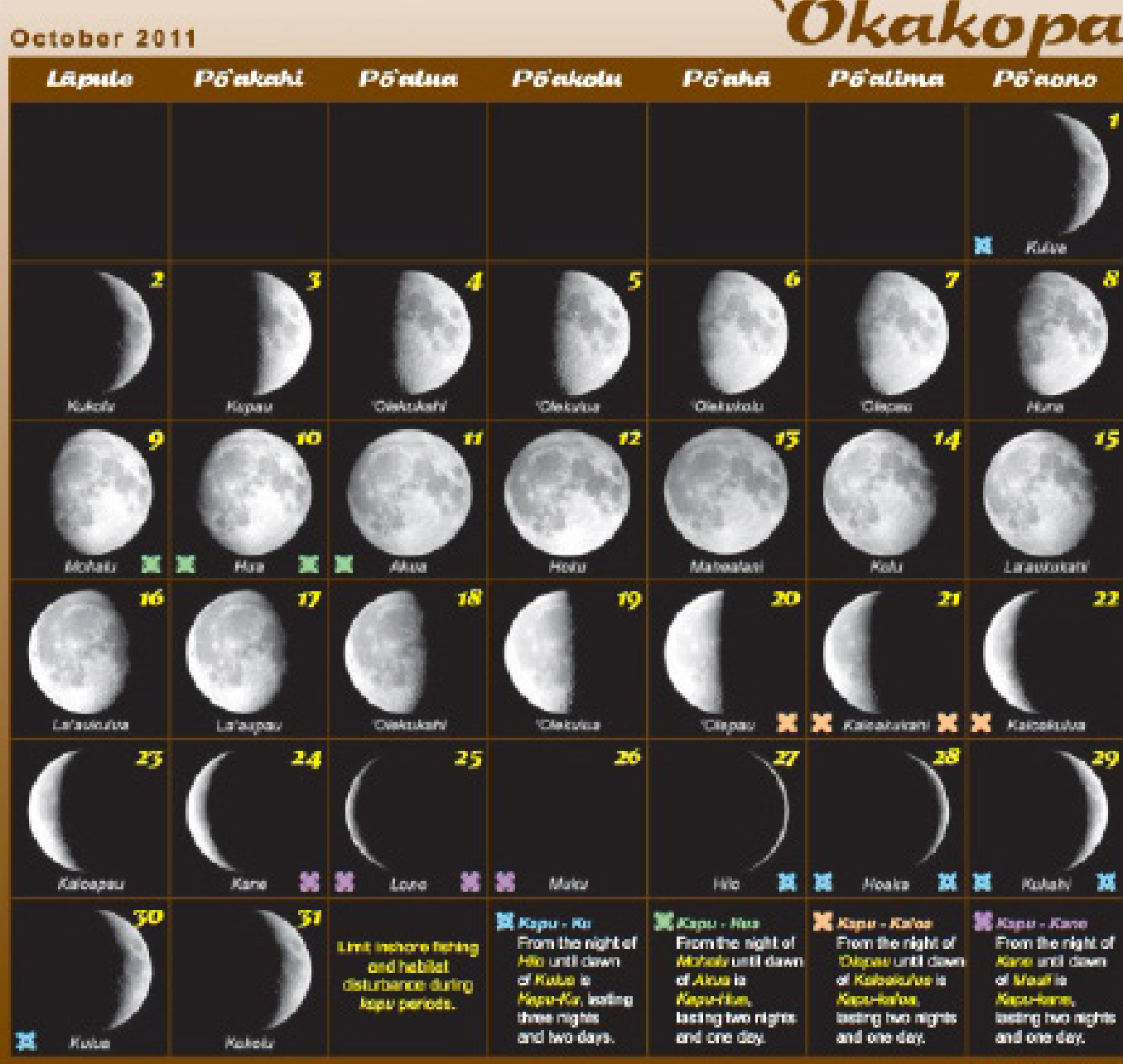

Kov - Drr Seaton

Fishers Knowledge was used to develop a lunar fishing and marine knowledge calendar. (c) Hui Malama o Mo'omomi. 
Aswani, S., and Hamilton, R.J. (2004). Integrating indigenous ecological knowledge and customary sea tenure with marine and social science for conservation of bumphead parrotfish (Bolbometopon muricatum) in the Roviana Lagoon, Solomon Islands. Foundation for Environmental Conservation. 10.1017/ S037689290400116X.

Anacleto, A., França, M.N., de Assunção Gomes, K., Junior, M. P. M., \& Surian, V. V. (2019). The Traditional Fishing in Parana Coast-Brazil, Implications, potentialities and Socioeconomics Aspects. International Journal of Advanced Engineering Research and Science, 6(1), 1-6.

Azzurro, E., Bolognini, L., Dragičević, B., Drakulović, D., Dulčić, J., Fanelli, E., Grati, F., Kolitari, J., Lipej, L., Magaletti, E. and Marković, O., (2019). Detecting the occurrence of indigenous and non-indigenous megafauna through fishermen knowledge: A complementary tool to coastal and port surveys. Marine Pollution Bulletin, 147, 229-236.

Baum, J.K., Myers, R.A., Kehler, D.G., Worm, B., Harley, S. J., \& Doherty, P.A. (2003). Collapse and conservation of shark populations in the Northwest Atlantic. Science, 299, 389-392.

Beauclair, R. de. (2008). La parure funéraire de la nécropole néolithique d'al-Buhais 18 (Émirats Arabes Unis). Pages 39-52 in Bailly, M. \& Plisson, $\mathrm{H}$. (eds.), La valeur fonctionnelle des objets sépulcraux (Aixen-Provence, Préhistoire Anthropologie méditerranéennes 14).

Berkes, F., Colding,J., and Folke,C. (2000). Rediscovery of traditional ecological knowledge as adaptive management. Ecological Applications 10:1251-1262.

Berlin, B. (1992). Ethnobiological classification: Principles of categorization of plants and animals in traditional societies. 9780691601267. Princeton, NJ: Princeton University Press.

Boster, J. S., \& Johnson, J. C. (1989). Form or function: A comparison of expert and novice judgments of similarity among fish. American Anthropologist. New Series, Vol. 91, No. 4 (Dec, 1989), pp. 866-889.

Brattland, C and Mustonen, T. (2018) How Traditional Knowledge Comes to Matter in Atlantic Salmon Governance in Norway and Finland. Arctic. Vol 71. No. 4. P 375-392. https://doi.org/10.14430/ $\operatorname{arcti} 4751$

Brown, M.I., Pearce, T., Leon, J., Sidle, R., \& Wilson, R. (2018). Using remote sensing and traditional ecological knowledge (TEK) to understand mangrove change on the Maroochy River, Queensland, Australia. Applied geography, 94, 71-83.

Carpenter, K.E., Krupp, F., Jones, D.A., Zajonz, U. (1997). FAO species identification guide for fishery purposes. The living marine resources of Kuwait, Eastern Saudi Arabia, Bahrain, Qatar, and the United Arab Emirates. Rome, FAO. 293. p., 17 colour plates.

Carriere, S. M. (2002). Orphan trees of the forest: why do Ntumu farmers of Southern Cameroon protect trees in their swidden fields? Journal of Ethnobiology 22:133-162.

Castello, L., Isaac, V.J., Thapa, R. (2015) Flood pulse effects on multispecies fishery yields in the Lower Amazon.R. Soc. open sci.2: 150299. http://dx.doi.org/10.1098/rsos.150299
Castillo, T.I., Brancolini, F., Saigo, M., Correa, J. R., \& Baigún, C. R. (2018). Ethnoichthyology of Artisanal Fisheries from the Lower La Plata River Basin (Argentina). Journal of ethnobiology, 38(3), 406-424.

Christensen, A.S., and Raakjær, J. (2006). Fishermen's tactical and strategic decisions - a case study of Danish demersal fisheries. Fisheries Research, Vol. 81, 2006, p. 258-267.

Colding, J., and Folke, C. (2001). Social taboos: "invisible" systems of local resource management and biological conservation. Ecological Applications 11:584-600.

Colding, J., Elmqvist, T, and Olsson, P. (2003). Living with disturbance: building resilience in social-ecological systems. Pages 163-185 in Berkes, F., J. Colding, J., and Folke, C. Editors. Navigating Social-Ecological Systems. Cambridge University Press, Cambridge, United Kingdom.

Davis, A., J. R. Wagner, J. R. (2003). Who knows? On the importance of identifying experts when researching local ecological knowledge. Human Ecology 31:463-489.

Drew, J.A. (2005). Use of traditional ecological knowledge in marine conservation. Conservation Biology 19(4):1286-1293. 10.1111/j.1523-1739.2005.00158.x.

EAD. (2015). Biodiversity Strategy for Abu Dhabi Emirate. Internal Technical Report. Environment Agency Abu Dhabi.

EAD. (2016). UAE Fisheries Socioeconomic Survey. Internal Technical Report. Environment Agency Abu Dhabi and Shallard and Associates.

EAD. (2017). Abu Dhabi State of the Environment Report. Environment Agency Abu Dhabi. Available at: www.soe.ae

Eckert, L.E., Ban, N.C., Frid, A., \& McGreer, M. (2018). Diving back in time: Extending historical baselines for yelloweye rockfish with Indigenous knowledge. Aquatic Conservation: Marine and Freshwater Ecosystems, 28(1), 158-166.

Evans, S.M., and Birchenough, A. C. (2001). Community-based management of the environment: lessons from the past and options for the future. Aquatic Conservation 11:137-147.

Finn, S., Herne, M., \& Castille, D. (2017). The value of traditional ecological knowledge for the environmental health sciences and biomedical research. Environmental health perspectives. 125(8), 085006.

Fischer, J., Jorgensen, J., Josupeit, H., Kalikoski, D. and Lucas, C.M., eds. (2015). Fishers' knowledge and the ecosystem approach to fisheries: applications, experiences and lessons in Latin America. FAO Fisheries and Aquaculture Technical Paper No. 591. Rome, FAO. 278 pp.FAO. (2018). The State of World Fisheries and Aquaculture 2018 - Meeting the sustainable development goals. Rome. Licence: CC BY-NC-SA 3.0 IGO.

Flannery, T. (2001). The eternal frontier: an ecological history of North America and its peoples. Atlantic Monthly Press, New York. 10: 0871137895. 
Gillet P, 1985: Small is Difficult: The Pangs and Success of Small Boat Technology Transfer in South India, ITDG, United Kingdom. http://www.siffs.org/Books/SmallisDifficult.pdf

Glaesel, H. (2000). Community level marine resource management and the spirit realm in coastal Kenya. Women in Natural Resources. 21:35-42.

Govan, H., Aalbersberg, W., Tawake, A., and Parks, J. (2008). Locally-Managed Marine Areas: A guide for practitioners. The Locally-Managed Marine Area Network.

Hamilton, R., de Mitcheson, Y.S. and Aguilar-Perera, A. (2012). The role of local ecological knowledge in the conservation and management of reef fish spawning aggregations. In Reef fish spawning aggregations: biology, research and management (pp. 331-369). Springer, Dordrecht.

Heyman, W.D. and Granados-Dieseldorff, P. (2012). The voice of the fishermen of the Gulf of Honduras: improving regional fisheries management through fisher participation. Fisheries Research, 125, pp.129-148.

Hellyer, P., and Aspinall, S. EAD. (2005). The Emirates - A Natural History. Peter Vine Publishers. Environment Agency Abu Dhabi.

Hickey, F.R., and Johannes, R.E. (2002). Recent evolution of village-based marine resource management in Vanuatu. SPC traditional marine resource management and knowledge information bulletin 14:8-21.

Huntington, H.P. (2000). Using traditional ecological knowledge in science: methods and applications. Ecological Applications, Vol. 10, No. 5, pp. 1270-1274.

Huntington, H.P. (2005). We dance around in a ring and suppose: academic engagement with traditional knowledge. 10.1353/ arc.2011.0101. Arctic Anthropology 42(1):29-32.

Hornell, J. (1920). The Origins and Ethnological Significance Of Indian Boat Designs. Memoirs of the Asiatic Society of Bengal Calcutta 1920. Re- issued in 2002 by South Indian Federation of Fishermen Societies, Trivandrum.

Jackson, J.B.C. (2008). Ecological extinction and evolution in the brave new ocean. Proceedings of the National Academy of Sciences of the United States of America, 105, 11458-11465.

Johannes, R.E. (1982). Traditional conservation methods and protected marine areas in Oceania. Ambio 11:258-261.

Johannes, R.E., Freeman, M.M.R., Hamilton. R.J. (2000). Ignore fishers' knowledge and miss the boat. Fish and Fisheries, 1: 257 271.

Johannes, R.E. (2002). Did indigenous conservation ethics exist? SPC Traditional Marine Resource Management and Knowledge Information Bulletin 14:3-7.

Kahui, V., \& Richards, A.C. (2014). Lessons from resource management by indigenous Maori in New Zealand: Governing the ecosystems as a commons. Ecological Economics, 102, 1-7.

King, M., and Faasili, U. (1999). Community-based management of subsistence fisheries in Samoa. Fisheries Management and Ecology 6:133-144.
Kurien, J. (2019). Valorising Subaltern History, Knowledge and Heritage for a Convivial Future: Some Personal Reflections from Trysts with Artisanal Fishers. Keynote Address at Social Sciences Winter School, French Institute of Pondicherry, Pondicherry, India.

Kurien, J. (1998) Traditional Ecological Knowledge and Ecosystem Sustainability: New Meaning to Asian Coastal Proverbs. Ecological Applications. Vol. 8, No. 1, Supplement: Ecosystem Management for Sustainable Marine Fisheries. pp. S2-S5

Kurien, J. (1990). Knowledge systems and fishery resource decline: a historical perspective in Lenz $W$ and E. Deacon, editors. Ocean sciences: their history and relations to man. Proceedings of the Fourth International Congress on the History of Oceanography (ICHO), Bundesamt fur Seeschiffahrt Und Hydrographic, Hamburg, Germany. pp 476-480

Lobel, P.S. (1978). Gilbertese and Ellice islands names for fish and other organisms. Micronesia 14: 177-197.

Lotze, H.K., \& Milewski, I. (2004). Two centuries of multiple human impacts and successive changes in a North Atlantic food web. Ecological Applications, 14, 1428-1447.

McClenachan, L., \& Cooper, A. B. (2008). Extinction rate, historical population structure and ecological role of the Caribbean monk seal. Proceedings of the Royal Society, B-Biological Sciences, $275,1351-1358$.

McMillen, H., Ticktin, T., \& Springer, H.K. (2017). The future is behind us: traditional ecological knowledge and resilience over time on Hawai 'i Island. Regional Environmental Change. 17(2). 579-592.

Myers, R.A., \& Worm, B. (2003). Rapid worldwide depletion of predatory fish communities. Nature, 423, 280-283.

O'Donnell, K.P., Pajaro, M.G. and Vincent, A.C.J. (2010). Improving conservation and fishery assessments with local knowledge: future directions. 539 - 540. Animal Conservation, 13: $539-540$.

Pauly, D. (1995). Anecdotes and shifting baseline syndrome of fisheries. Trends in Ecology and Evolution 10 (10:430).

Pinnegar J.K. \& Engelhard G.H. (2007). The 'shifting baseline' phenomenon: a global perspective. Fish Biology and Fisheries 18, 1-16. 10.1007/s11160-007-9058-6.

Pita, P., Fernández-Vidal, D., García-Galdo, J., \& Muíño, R. (2016). The use of the traditional ecological knowledge of fishermen, cost-effective tools and participatory models in artisanal fisheries: towards the co-management of common octopus in Galicia (NW Spain). Fisheries Research, 178, 4-12.

Raymond-Yakoubian, J., Raymond-Yakoubian, B., \& Moncrieff, C. (2017). The incorporation of traditional knowledge into Alaska federal fisheries management. Marine Policy, 78, 132-142.

Ruddle, K. (1991). The Transmission of Traditional Ecologlcal Knowledge. Paper presentee! at the Second International Conference of the Association for the Study of Common Property, University of Manitoba, Winnipeg, September.

Ruddle, K.(1988) Social Principles Underlying Traditional Inshore Fisheries Management Systems in the Pacific Basin. Marine Resource Economics 5(4): 351-363. 
Sáenz-Arroyo A., Roberts C.M., Torre J. \& Carino-Olvera M. (2005a). Using fisher's anecdotes, naturalist's observations, and grey literature to reassess marine species at risk: the case of the gulf grouper in the Gulf of California, Mexico. Fish \& Fisheries 6, 121-133. 10.1111/j.1467-2979.2005.00185.x.

Sáenz-Arroyo A., Roberts C.M., Torre J., Carino-Olvera M. \& Enríquez-Andrade R.R. (2005b). Rapidly shifting environmental baselines among fishers of the Gulf of California. Proceedings of the Royal Society b-Biological sciences, Vol. 272, No. 1575, 22.09.2005, p. 1957-1962.

Sáenz-Arroyo A., Roberts C.M., Torre J., Carino-Olvera M. \& Hawkins J.P. (2006). The value of evidence about past abundance: marine fauna of the Gulf of California through the eyes of 16 th to 19 th century travelers. Fish \& Fisheries 7,128 146. 10.1111/j.1467-2979.2006.00214.x.

Sandlos, J., \& Keeling, A. (2016). Aboriginal communities, traditional knowledge, and the environmental legacies of extractive development in Canada. The extractive industries and society. 3(2). 278-287.

Sen, S \& Nielsen, J.R. 1996. Fisheries co-management: a comparative analysis. Marine Policy, 20: 405-418.

Smyth, D., J. Fitzpatrick, and D. Kwan. (2006). Towards the development of cultural indicators for marine resource management in the Torres Strait. Torres Strait Cooperative Research Centre Report, Townsville, Australia.

Mataatua Declaration on Cultural and Intellectual Property Rights of Indigenous Peoples (1993).

Te Ohu Kaimoana (The Māori Fisheries Trust). Aotearoa / New Zealand. The Maori Fisheries Strategy (2017).

United Nations Intergovernmental Platform on Biodiversity and Ecosystem Services. (2012). Plenary of the Intergovernmental Science-Policy Platform on Biodiversity and Ecosystem Services First session. Consideration of initial elements: recognizing indigenous and local knowledge and building synergies with science. IPBES/1/INF/5. 12-60310 (E) 301112.

Zaan, L. P. (1985). Traditional management and conservation of fisheries in Kiribati and Tuvalu atolls. Pages 53-77 in Ruddle, K. \& Johannes, R.E - editors. The traditional knowledge and management of coastal systems in Asia and the Pacific. United Nations Educational, Scientific, and Cultural Organization, Jakarta, Indonesia.

\section{Laws, conventions and guidelines}

Aotearoa / New Zealand. The Fisheries Act (1996).

CBD. (2004) The Akwé: Kon Voluntary Guidelines for the Conduct of Cultural, Environmental and Social Impact Assessments regarding Developments Proposed to Take Place on, or which are Likely to Impact on, Sacred Sites and on Lands and Waters Traditionally Occupied or Used by Indigenous and Local Communities.

CBD. (2011). The Tkarihwaié:ri Code of Ethical Conduct to Ensure Respect for the Cultural and Intellectual Heritage of Indigenous and Local Communities Relevant to the Conservation and Sustainable Use of Biological Diversity.
CBD Training Manual on the incorporation of Traditional Knowledge into the description and identification of Ecologically or Biologically Significant Marine Areas (2016).

IUCN (2013). Governance of Protected Areas: From Understanding to Action. Best Practice Protected Area Guidelines No. 20. Gland, Switzerland: IUCN. https://portals.iucn.org/library/ node/29138

IUCN Draft Guidance for Integrating Indigenous and Local Knowledge in IUCN Red List Assessments. (2017).

Mataatua Declaration on Cultural and Intellectual Property Rights of Indigenous Peoples (1993).

United Nations Convention on Biological Diversity. (1992).

United Nations Code of Conduct for Responsible Fisheries. (1995).

United Nations Declaration on the Rights of Indigenous Peoples. (2007).

United Nations Convention on Biological Diversity Aichi Targets. (2010).

United Nations Sustainable Development Goals. (2015).

United Nations Voluntary Guidelines for Securing Sustainable Small-Scale Fisheries in the Context of Food Security and Poverty Eradication. (2015).

United Nations 'Fishers' Knowledge and the Ecosystem Approach to Fisheries. Application, experiences, and lessons in Latin America. Technical Paper. (2015).

United Nations Marine Protected Areas: Interactions with Fishery Livelihoods and Food Security. (2016). 


\section{Appendix: Resources and case studies}

\section{AFRICA}

\section{Regional experts}

IUCN SULi FK experts in the African region are considered to include the following:

\begin{tabular}{|l|l|l|l|}
\hline Name & Country & Organization & Contact Details \\
\hline Christiana Louwa & Kenya & $\begin{array}{l}\text { UN FAO International Plan- } \\
\text { ning Committee for Food } \\
\text { Sovereignty (IPC) } \\
\text { Fisheries Working Group }\end{array}$ & Email: louwachristiana@gmail.com \\
\hline $\begin{array}{l}\text { Juvenary E. A } \\
\text { Matagili }\end{array}$ & $\begin{array}{l}\text { Tanza- } \\
\text { nia }\end{array}$ & $\begin{array}{l}\text { Fishers Union Organization } \\
\text { P.O BOX 2969 } \\
\text { Mwanza Tanzania } \\
\text { Kirumba-Kabuhoro } \\
\text { Mlimani Street. }\end{array}$ & $\begin{array}{l}\text { Mobile:+255755876335 } \\
+255784876335 \\
\text { Tel;+255 25 2541369 } \\
\text { Email: fishersunion@gmail.com } \\
\text { Blog: fishersunion.Blogspot.com }\end{array}$ \\
\hline Lena Westlund & Italy \\
based & $\begin{array}{l}\text { Fisheries and Aquaculture } \\
\text { Department, Food and } \\
\text { Agriculture Organization of } \\
\text { the United Nations. }\end{array}$ & Email: Lena.Westlund@fao.org \\
\hline
\end{tabular}




\section{Case study - Lake Turkana, Kenya, Africa FK and co-management}

This case study is a good example of sustainable co-management of fisheries at the local community level.

Fishery type: Freshwater. Small-scale artisanal/commercial. Subsistence and local sale.

No. of fishing communities: The Elmolo people, also known as the Gurapau (people of the Lake), is the traditional fishing community of Lake Turkana. Elmolo is the smallest tribe in Kenya numbering around 4000 people, living on the south-east corner of the lake.

Vessel types: Wooden paddle powered canoes and fibreglass outboard powered vessels.

Fishing methods and species: Traditional / Artisinal (Beach Seine nets, Scoop and Lift nets; Gill nets, Long line, Hook \& Line), targeting 12 commercially important species, which can be grouped into:

- The tilapia fishery in the littoral zone, currently dominated by Nile tilapia (Oreochromis niloticus).

- The inshore demersal fishery, currently dominated by the Assuan labeo (Labeo horie).

- The offshore demersal fishery, which is dominated by Catfish (Bagrus bayad).

- The pelagic fishery, consisting mainly of Tigerfish (Hydrochnus forskalii), Alestes baremose, Alestes minutus, Nile perch (Lates niloticus) and the catfish (Synodonis schaal).

Method of obtaining FK: Oral Tradition is passed on intergenerationally within the tribe. Part of this oral tradition on fisheries is presented by Elmolo tribal leader, Christiana Louwa, at international conferences. The Elmolo have not yet documented the FK, but intend to.

Aichi Target achievement. Co-management of fisheries resources contributes to both Aichi Targets 6 and 18 .

\section{Key findings:}

-Within Kenya, a fisheries co-management system is in place through the establishment of Beach Management Units (BMUs). BMU's function as part of the local Government, but allow for decentralised fisheries management decisions to be made at community level. The community self-police their locality to prevent environmental degradation and illegal fishing.

-The community has always depended on their traditional knowledge on fishing and the natural resources in their territory for survival. For the Elmolo people, fishing is life.

- Conservation and environmental protection are key elements in Elmolo traditional knowledge. This is practiced through promotion of oral traditions and good practices that are not harmful to the lake, its ecosystem and the environment. As an example it is custom to return undersize fishes harvested back to the lake, and practice the rotational use of fishing grounds.

- FK is passed intergenerationally and is held by tribal elders. It has also supported the completion of local stock assessments.

- FK has been gathered in respect of the traditional studies of climatic and weather conditions, the winds, the brightness and darkness of the moon, position of particular stars, movement of waves and other phenomena.

- FK is considered to appease the ancestors - giving thanks to God, Mother earth and the waters (lake) for taking care of families and community with songs, blessings and rituals.

A key future challenge the community is facing is the damming of the Omo river in Ethiopia (a hydroelectric powerdam) -where $90 \%$ of the water entering Lake Turkana comes from.

- Future initiatives proposed is additional documentation of FK held by the Elmolo people.

\section{Key references:}

- Christiana Louwa. Presentation at IUCN, Communities, Conservation \& Livelihoods Conference, Halifax, Canada, 2018.

- FAO, Fishery and Aquaculture Country Profiles. Kenya. 2016. http://www.fao.org/fishery/facp/KEN/en

- Kenya Marine and Fisheries Research Institute. Turkana Station. Available: https://www.kmfri.co.ke/index.php/about-us/ research-centres/turkana-research-station

- Lake Turkana Fishery: Options for development of a sustainable trade. Netherlands Development Organisation. 2005. Available: https://www.oceandocs.org/bitstream/handle/1834/6925/ ktf0040.pdf? sequence $=1$ \&isAllowed $=y$

\section{FK programme contacts:}

- Christiana Louwa. Tribal elder and UN FAO International Planning Committee for Food Sovereignty (IPC) Fisheries Working Group. Kenya. Contact: louwachristiana@gmail.com - John Malala. Kenya Marine and Fisheries Research Institute. Lake Turkana Research Station. Contact: jmalala@kmfri.co.ke

Case study location: Lake Turkana is located in the eastern region of the Great Rift Valley, Kenya. It is approximately $30 \mathrm{~km}$ wide and extends $265 \mathrm{~km}$ in a north-south direction. It occupies an area of about $7,560 \mathrm{~km} 2$, almost twice that of Kenya's part of Lake Victoria. 


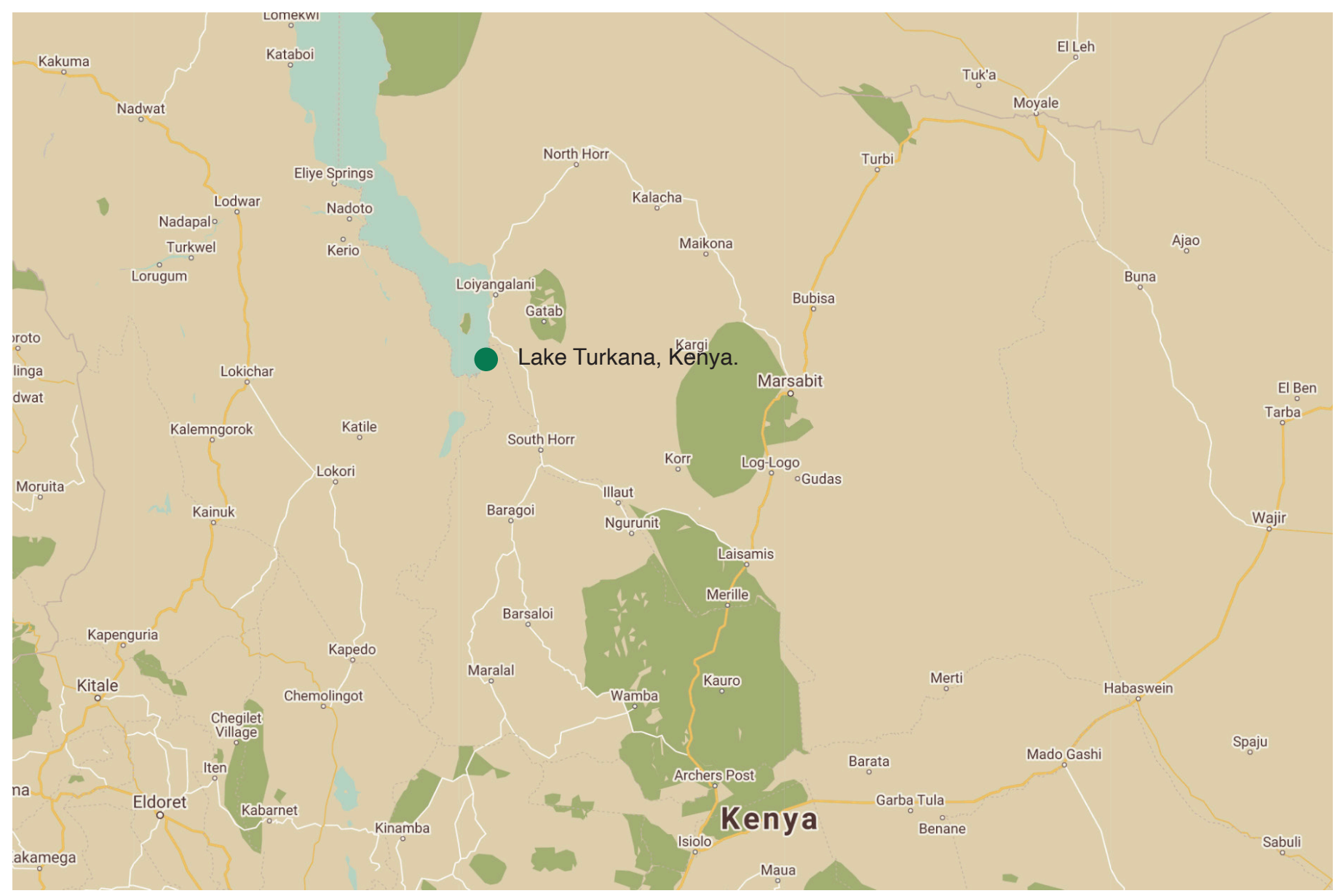

Figure 1: Case Study Location Map: Lake Turkana, Kenya. 


\section{Case study - Lake Victoria, Tanzania, Africa. FK and co-management}

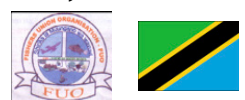

This case study is a good example of sustainable co-management of fisheries at the local community level, and representation through a Union.

Fishery type: Freshwater. Small-scale artisanal / commercial. Subsistence and local sale.

No. of fishing communities: 50 island communities with a population of over 500,000 people.

Representation: The Fishers Union Organisation (FUO) is a civil society organization that was established in 2005 by artisanal fishers along Lake Victoria. These included fishers, fish mongers and service providers within the fishing communities both on islands and the lake shore. The union has been registered since 2007 in the Vice President's Office, Dar es Salaam with a focus on empowerment of fishing communities and support in health, conservation and sustainable development.

Vessel types: Wooden canoes and catamarans (paddle, sail or outboard powered), and outboard powered collector vessels.

Fishing Methods and Species: Traditional / Artisinal (Beach Seine nets, Scoop and Lift nets; Gill nets, Long line, Hook \& Line), targeting Nile perch, (Lates niloticus), Nile tilapia (Oreochromis niloticus), and the freshwater sardine or Dagaa (Rastrineobola argentea).

Method of obtaining FK: Representation via Union.

Aichi Target achievement. Co-management of fisheries resources contributes to both Aichi Targets 6 and 18 .

Key findings:

- Like Kenya, inland fisheries are community managed through what is known locally as 'Beach Management Units' (BMU), a comanagement arrangement between local Government and the community. They are supported by the Department of Fisheries Development, via its field offices and under the BMUs initiative, fishing communities at landing sites, and the community at large, self-police their locality to prevent environmental degradation and illegal fishing.

- The FUO works with the BMUs (of which there are over 150 in the region), working to achieve a vision of empowering fishers and fishing communities to become prosperous and conserve environment for sustainable development.

- The FUO's mission is 'empowering all fishing communities to have just and prosperous society through capacity building, technical skills and support using participatory approach for suitable environment livelihood.'

- FUO's work in empowerment, education and good governance and includes both a social and environmental focus.

- The Union provides support through initiatives including: Social Accountability Monitoring (SAM); establishing a Public Expenditure Tracking System (PETS); healthy, maternal \& child clinics; health care provision including HIVIAIDS, malaria, awareness creation in helping children through death and grief,
TB, typhoid, bilharzia, malaria, fistula and other high-burden, communicable, poverty-linked diseases; gender violence, protection of fishers rights, drug abuse, mental illness support, prevention of illegal fishing activities, environment conservation and sustainable fish farming.

- The organization has been financed by the Environmental International Agency; Family Heath International; Sengerema District Council; Lake Victoria Basin Commission; Ministry of Water, AMREF for HIV/AIDS/TB; Right Light Company and the Hesperian Health Guide.

- FUO has a five year strategic plan $(2016$ - 2021), that it is working towards the implementation of. Implementation of initiatives is through capacity building, policy advocacy, and research.

- FK crucial to establishment of environmental management controls within BMU Plans. These have included minimum net sizes for Nile perch, Tilapia and Dagaa.

- FUO is also promoting the transfer of technologies regarding renewable energies in fishing communities. The aim is to spread renewable energy technology as the alternative way to fossil energy sources. Currently, in cooperation with BMU plans to implement the likes of a solar lights in fishing initiative in Lake Zone regions.

\section{Key references:}

- Breuil, Christophe. Grima, Damien (2014). Baseline Report Tanzania. SmartFish Programme of the Indian Ocean Commission, Fisheries Management FAO component, Ebene, Mauritius. http://www.fao.org/3/a-br800e.pdf

- FAO, Fishery and Aquaculture Country Profiles. Tanzania. 2007. http://www.fao.org/fishery/facp/TZA/en

- FUO. Overview. Available at 'Network for African Youths for Development.' http://nayd.org/fishers-union-organisationtanzania/

- FUO. Five Year Strategic Plan (2016-2021). Unavailable online. - Tanzanian Fisheries Sector. Challenges and Opportunities (2016).

\section{FK programme contacts:}

- Juvenary E. A Matagili. Fishers Union Organisation. Tanzania. Contact: fishersunion@gmail.com

Case study location: The FUO currently is registered to operate in the Lake Victoria Basin, including Mwanza, Geita, Kagera, Simiyu, Mara, Shinyanga and Tanzania mainland. Tanzania's territory includes $51 \%$ of Lake Victoria $(68,800 \mathrm{~km} 2)$, which is also shared with Uganda and Kenya). 


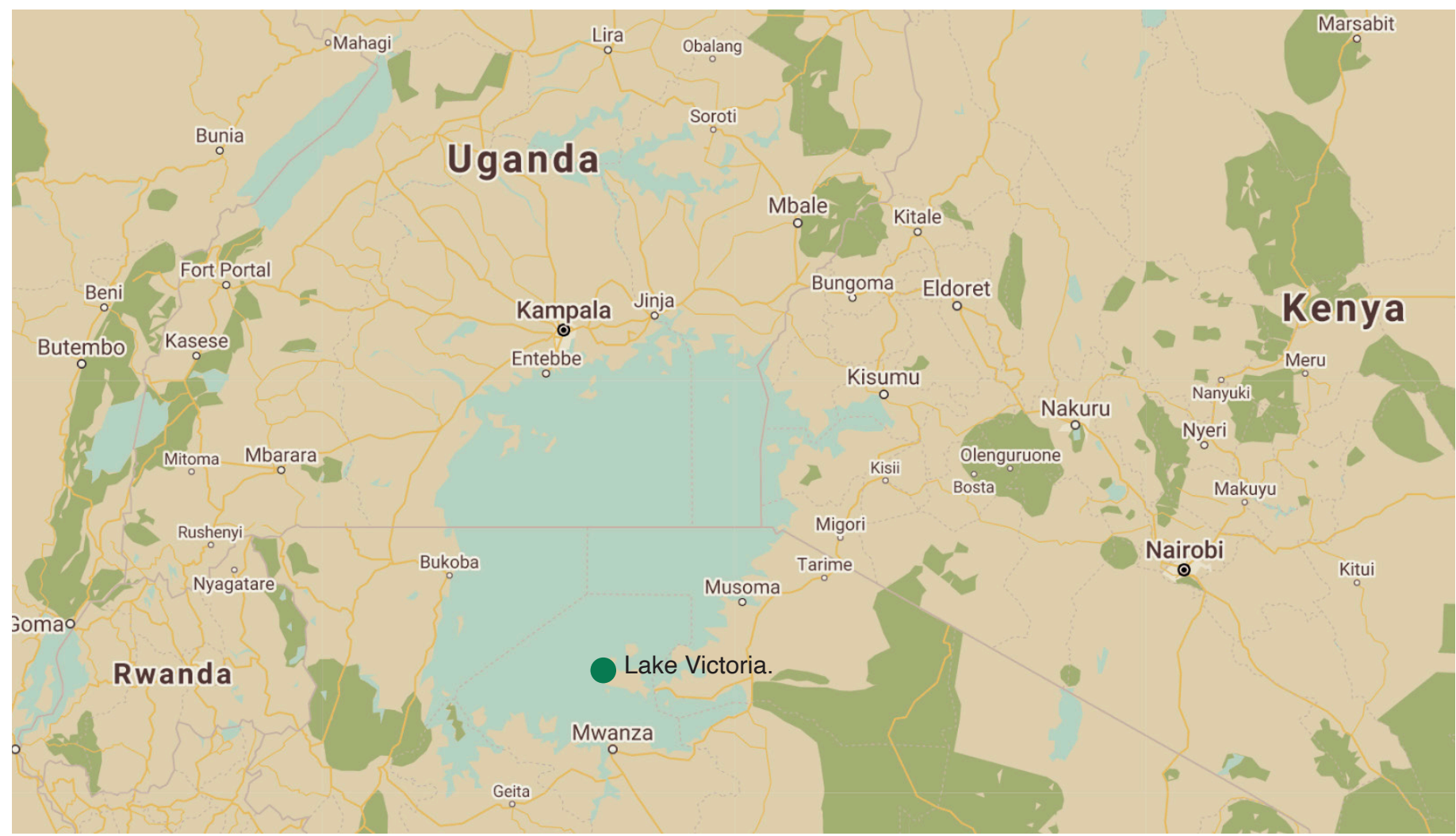

Figure 1: Case Study Location Map: Lake Victoria, Tanzanian territory.

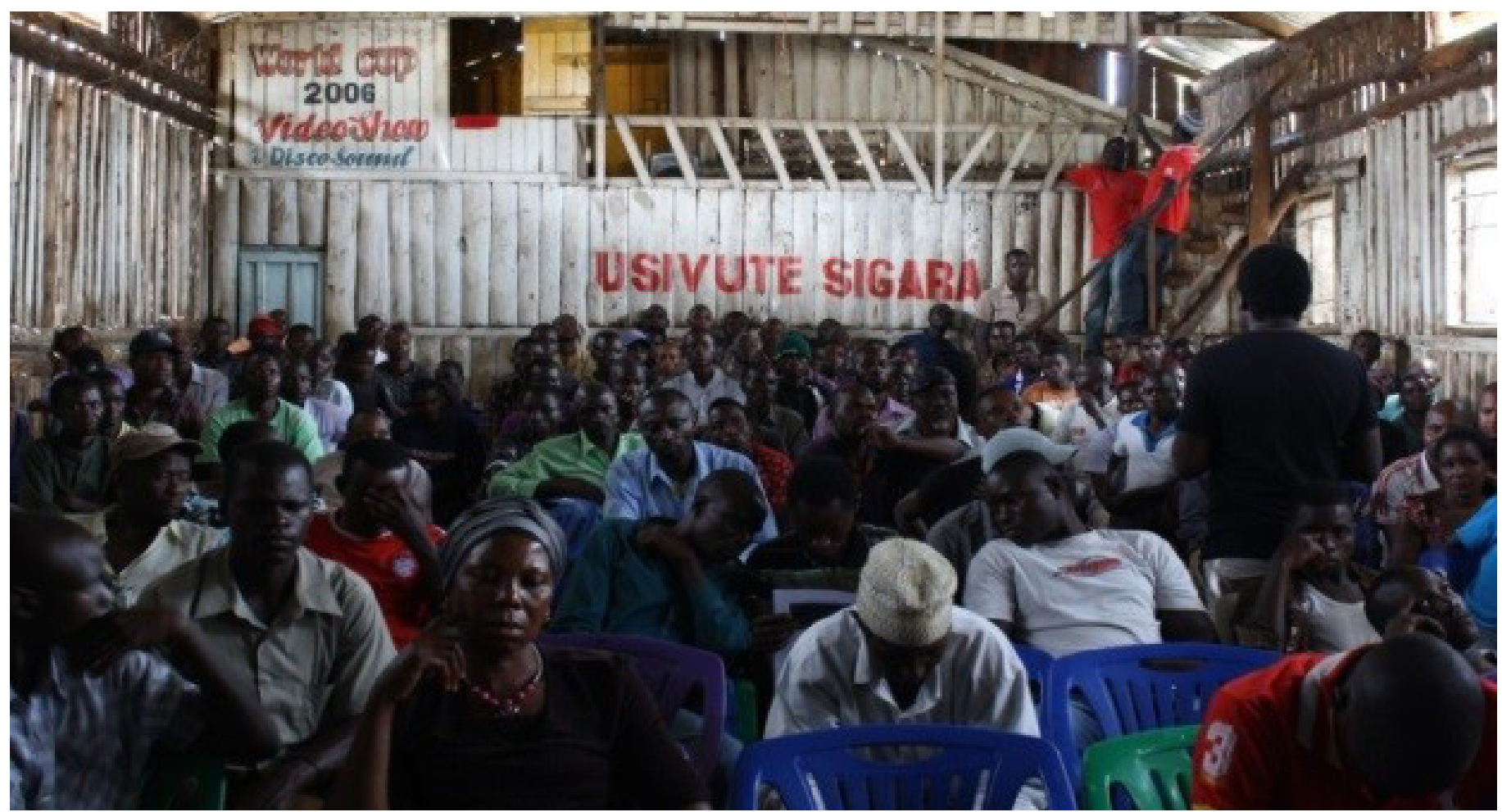

Figure 2: FUO Meetings, and fishers' utilising sustainable lighting sources rather than kerosene. Lake Victoria, Tanzania. 
ASIA

\section{Regional experts}

FK experts in the Asian region are considered to include the following:

\begin{tabular}{|l|l|l|l|}
\hline Name & Country & Organisation & Contact Details \\
\hline Ahmed Al Hashmi & United Arab Emirates & $\begin{array}{l}\text { Acting Executive Director, Terrestrial and } \\
\text { Marine Biodiversity Sector, } \\
\text { Environment Agency - Abu Dhabi, } \\
\text { United Arab Emirates }\end{array}$ & $\begin{array}{l}\text { Email: } \\
\text { ahmed.alhashmi@ead.gov.ae }\end{array}$ \\
\hline Salah Al Rayssi. & United Arab Emirates & $\begin{array}{l}\text { Acting Assistant Undersecretary for the } \\
\text { Biodiversity and Marine Life Sector. } \\
\text { Ministry of Climate Change and } \\
\text { Environment. }\end{array}$ & $\begin{array}{l}\text { Email: } \\
\text { saalrayssi@moccae.gov.ae }\end{array}$ \\
\hline Phallin Chea & Cambodia & $\begin{array}{l}\text { Project Officer, Cambodia Marine } \\
\text { Coastal Programme, Flora \& Fauna } \\
\text { International, Cambodia. }\end{array}$ & $\begin{array}{l}\text { Email: } \\
\text { phallin.chea@fauna-flora.org }\end{array}$ \\
\hline Winston Cowie & United Arab Emirates & $\begin{array}{l}\text { Marine Policy Manager } \\
\text { Environment Agency - Abu Dhabi, } \\
\text { United Arab Emirates }\end{array}$ & $\begin{array}{l}\text { Email: } \\
\text { winston.cowie@ead.gov.ae }\end{array}$ \\
\hline Henry Duffy & Asia-Pacific Region & $\begin{array}{l}\text { Marine Technical Specialist, Asia-Pacif- } \\
\text { ic. Flora \& Fauna International, United } \\
\text { Kingdom. }\end{array}$ & $\begin{array}{l}\text { Email: } \\
\text { henry.duffy@fauna-flora.org }\end{array}$ \\
\hline Dewa Gumay & Indonesia & $\begin{array}{l}\text { Aceh Programme Manager, FFI } \\
\text { Indonesia }\end{array}$ & $\begin{array}{l}\text { Email: } \\
\text { dwgumay@fauna-flora.org }\end{array}$ \\
\hline Soen Pheakday & Cambodia & $\begin{array}{l}\text { Water and Wetlands Coordinator. IUCN } \\
\text { Cambodia. }\end{array}$ & $\begin{array}{l}\text { Email: } \\
\text { pheakdey.sorn@iucn.org }\end{array}$ \\
\hline
\end{tabular}




\section{Case study - Koh Rong Archipelago, Cambodia FK in policy, spatial planning and co-management}

This case study is a good example of FK being integrated in policy, spatial planning, and sustainable co-management of fisheries at the local community level.

Fishery Type: Marine. Small-scale artisanal/commercial. Subsistence and local sale.

No. of fishing communities: Three Community Fisheries (CFi) are established and registered, with their combined fishing area of 18,672 ha comprising nearly half of the total area of the Koh Rong Archipelago (KRA) Marine Fisheries Management Area (MFMA) which was the first marine protected area to be designated in Cambodian waters.

Vessel types: Wooden paddle powered canoes and small motorised fishing vessels.

Fishing Methods and Species: Small-scale fishing gears (gillnet, trap, hook, line, and hand collection).

Method of obtaining FK: Semi-structured interviews and community consultation.

Aichi Target Achievement. Community fisheries organisations and associated management approaches integrated into marine spatial planning, conservation and decision-making in coral reef and seagrass fishery systems (Target 6 \& Target 10).

\section{Key findings:}

- Under national law, Cambodian citizens have the right to form a CFi in their respective fishing area on a voluntary basis, in order to actively participate in the sustainable management, conservation, development and use of fisheries resources (Law on Fisheries 2006). This case study focuses on three specific CFis operating in the KRA.

- The three CFis in KRA are aligned with specified targets and timings within Cambodia's national Strategic Planning Framework for Fisheries 2010-2019 (FiA, 2011).

- These CFis represent community fisheries interests within the Technical Working Group of KRA-MFMA, which meets on a quarterly basis and provides a platform for cross-sectoral engagement across multiple stakeholders including government, fishers, enforcement agencies and conservation organisations.

- Committee members and fishers associated with the three CFis actively provided inputs throughout the development of the MFMA zonation scheme, in addition to the creation and revision of $\mathrm{CFi}$ three-year management plans. This ensured that fisher knowledge was considered and incorporated into all management strategies for the area.

- The three CFis formed an enforcement team and received training in order to conduct SMART patrols as part of monitoring, control and surveillance activities within their own fishing areas. This empowered the fishers to play an active role in safeguarding their marine resources, increasing engagement with enforcement processes.

- As a result of the activities detailed above, KRA-MFMA has developed into an adaptively managed MPA in which locally collected evidence is used to support effective decision-making. For example, a 2017 analysis of MPA patrolling data and interviews with local communities highlighted gaps in communityled enforcement. This information was then used to support improved patrol planning, enabling new targeting of areas which were not being patrolled, but where illegal activities were likely to be occurring.

- In the KRA, the extensive consultation with CFis during MFMA planning, and the co-management approach utilised after its declaration, have led to high levels of perceived legitimacy and strong likelihood of compliance among local fishers.

- Knowledge, Attitude and Practices (KAP) surveys indicated high general awareness of the MFMA ( $87.7 \%$ of respondents being aware) and a positive attitude among local communities towards the management area.

- KAP survey responses also indicated that communities perceived high compliance by fishers from within the CFi but low compliance by outsiders. Low awareness levels were also identified in the marine tourism sector. Acceptance and support of the MFMA rules by resource users was perceived to be the main driver of compliance, whereas rule-breaking appears to be mainly unintended and associated with poor knowledge.

- Increasing recognition by Cambodian government bodies of the importance of community-based fisheries management practices is a key motivation for the ongoing empowerment of local people through their active involvement in management planning and implementation.

- The participatory designation process used in KRA-MFMA will be used as a model for further MPA designations in Cambodia, with the eventual aim of implementing a network of locallyendorsed and managed MPAs throughout Cambodian waters.

\section{References:}

- Chea P. (2015). Assessment of Community Fisheries Committees Perceptions in Fisheries Resources Management in Koh Rong Archipelago, Cambodia. Second Year Report. FFI/ Cambodia.

- Mulligan, B. \& Longhurst, K. (2014) Research and Recommendations for a Proposed Marine Fisheries Management Area in the Koh Rong Archipelago. Fauna \& Flora International Cambodia Programme, Phnom Penh, Cambodia \& Coral Cay Conservation, Surrey, UK.

- Paula R. B. et al. (2018) Using patrol records and local perceptions to inform management and enforcement in a marine protected area in Cambodia. Cambodian Journal of Natural History. 18/10. Phnom Penh, Cambodia.

\section{FK Programme Contacts:}

- Phallin Chea, Project Officer, Cambodia Marine Coastal Programme, Flora \& Fauna International, Cambodia.

Contact: phallin.chea@fauna-flora.org

- Henry Duffy, Marine Technical Specialist, Asia-Pacific. Flora \& Fauna International, United Kingdom.

Contact: henry.duffy@fauna-flora.org 


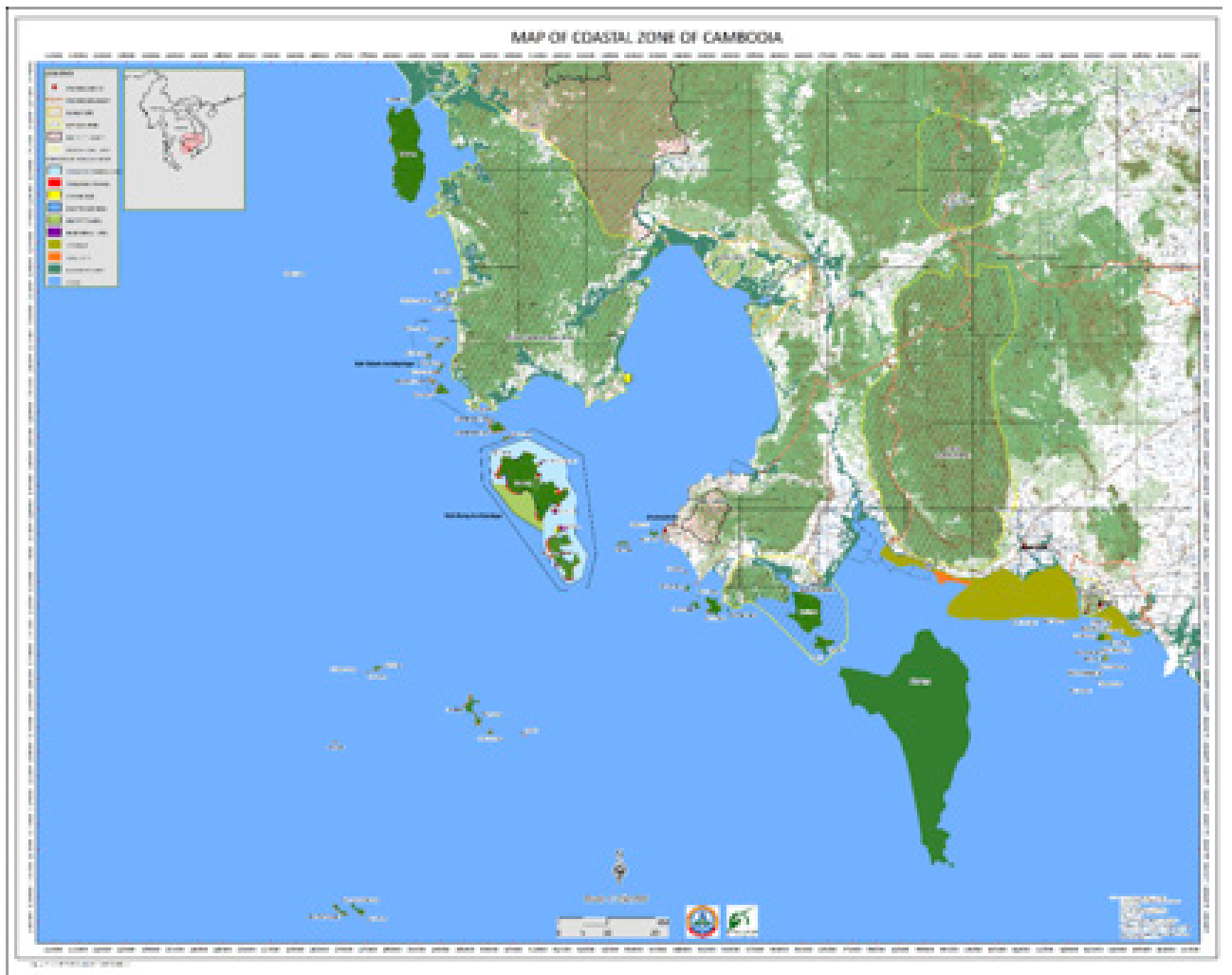

Figure 1: Map of Cambodian coastline showing the location and management zonation of the Koh Rong Marine Fisheries. Management Area.

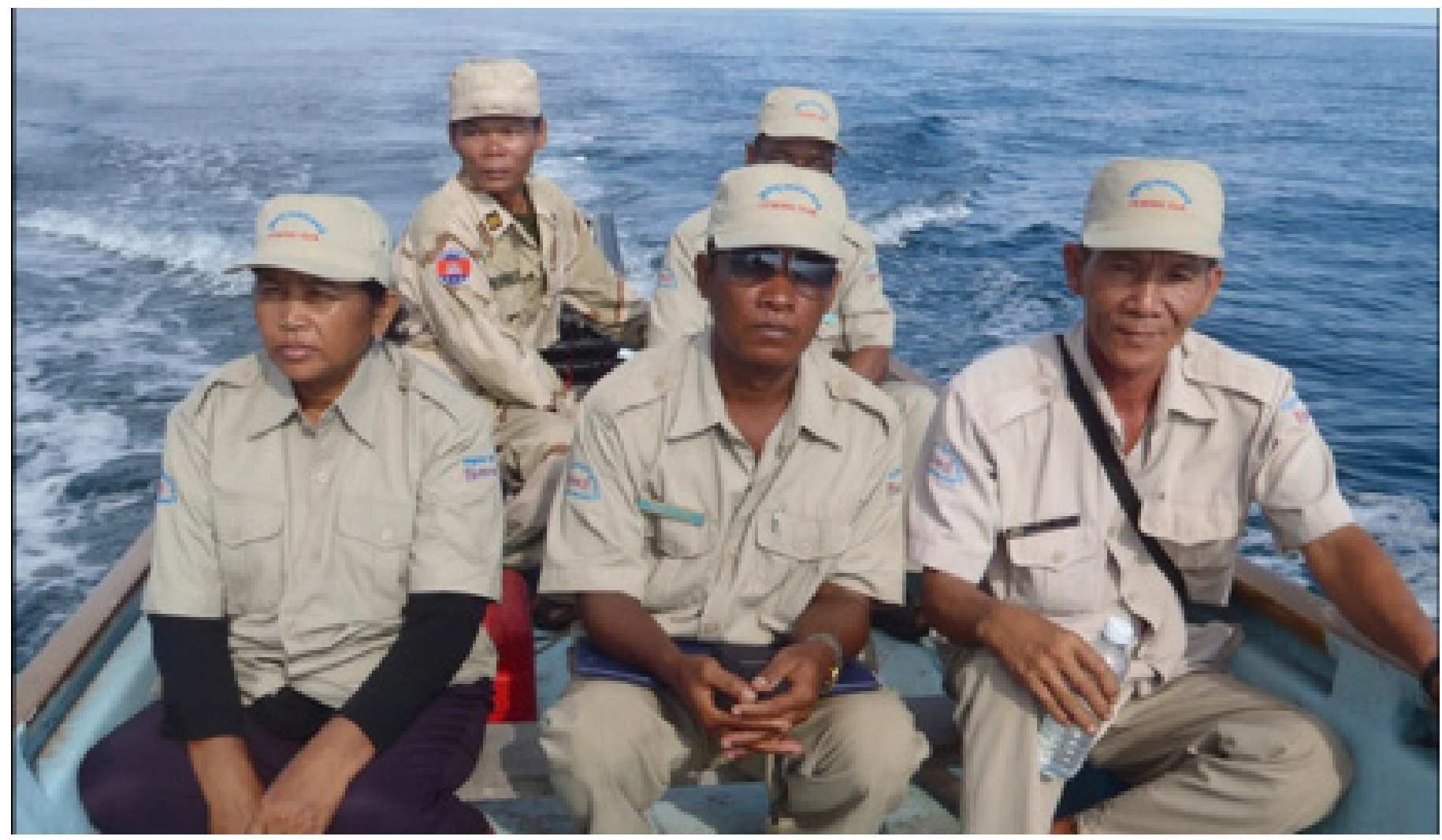

Figure 2: CFi members undertaking enforcement SMART patrols within Koh Rong MFMA. Credit: Phallin Chea/FFI. 


\section{Case study - Tonle Sap Great Lake, 는 FK in policy and co-management.}

This is case study is a good example of sustainable comanagement of fisheries at the local community level.

Fishery type: Freshwater. Small-scale artisanal/commercial. Subsistence and local sale.

No. of fishing communities: Three communities living on Tonle Sap Great Lake.

Vessel types: Wooden paddle powered canoes and small motorised fishing vessels.

Fishing methods and species: Fish bag nets, shrimp bag nets, and arrow shaped bamboo fence traps.

Method of obtaining FK: Focus groups with the local community.

Aichi Target achievement. Co-management of fisheries resources contributes to both Aichi Targets 6 and 18.

No. of fishing communities: Tonle Sap is home to over 1 million fishers, with three communities bordering the lake chosen to implement the project.

\section{Key findings:}

- Cambodia's Tonle Sap is the world's largest freshwater fishing ground. It produces $50 \%$ of the wild fish biomass of the Mekong and accounts for $75 \%$ of Cambodia's entire protein intake.

- It is also a system under threat by rapid environmental change and weak governance. Not only does this have implications for the wider Tonle Sap ecosystem, but for the livelihoods of millions of Cambodian citizens, who depend on the resources provided by this natural ecosystem.

- In recognition of the importance of Cambodia's Tonle Sap to the surrounding communities, a four year project (Jan 2013 - Dec 2016) funded by the European Union (EU) was implemented.

- Entitled the 'EU-NSA' project, it was completed by IUCN in partnership with the local Fisheries Action Coalition Team (FACT).

-The project applied an ecosystem-based management approach, combined with common pool resource management principles and a highly participatory approach to achieve sustainable conservation and livelihood benefits in these communities.

- It included development and implementation of Fish Conservation Area's (FCA) at three pilot sites where fishing was to be prohibited year round to protect key fish refugia.

- The criteria for zoning a FCA were:

o An ecologically important area;

o Small size $<100$ ha (100-200 ha, located in open space);

o As close as possible to a village centre;

o An area undisturbed from human activities.

- The process followed in establishing the FCA was:

o Step 1: Local consultation - introduction of the concept of zoning to the local community.

o Step 2: Provincial consultation - approval at subnational level to erect temporary boundary poles with participation from local key stakeholders. o Step 3: Submit for approval from the National Fisheries Administration / Ministry of Environment.

o Step 4: Commence building FCA boundary poles and post signboards.

- Some of the key interventions completed with success were:

o Successful establishment of 3 Fish Conservation Areas;

o FCA boundary demarcation and signboards; o Developed patrol plans for protecting the FCA; o Fish habitat improvement via Fish Attraction Devices;

o Training a Community Fisheries committee on Participatory engagement;

o Developed Community Fisheries by-laws and Management Plans.

- The key impacts from the project included:

o Increased awareness on benefits of FCA management for local community;

o Increased public awareness (both local and outsider) on FCA;

o Increased fish stock around and inside the FCA;

o Improved food security for local community;

o Improved livelihoods of local fisherfolks;

o Local capacity building.

- This project has demonstrated that in the complex socioecological system of the Tonle Sap, ecosystem based intervention through the establishment of co-management FCA's can result in the successful achievement of both ecosystem conservation objectives and livelihood development activities.

\section{References:}

- Presentation. Sorn Pheakday. Community-Based Small-Scale Fish Conservation Area (FCA) Management in the Tonle Sap Great Lake, Cambodia.

- IUCN Conference: Communities Conservation \& Livelihoods. Halifax, Canada.

- Project video link: https://www.youtube.com/ watch?v=ysSDWDTE1eo.

FK programme contacts:

- Sorn Pheakdey - Water and Wetlands Coordinator, IUCN. Cambodia. Contacts:pheakdey.sorn@iucn.org

Case study location: The Tonle Sap Great Lake is the largest freshwater lake in Southeast Asia, located almost in the middle of Cambodia. It is an ecological hot spot that was designated as a UNESCO biosphere reserve in 1997. Communities lived within 3 pilot sites of Tonle Sap Great Lake. 


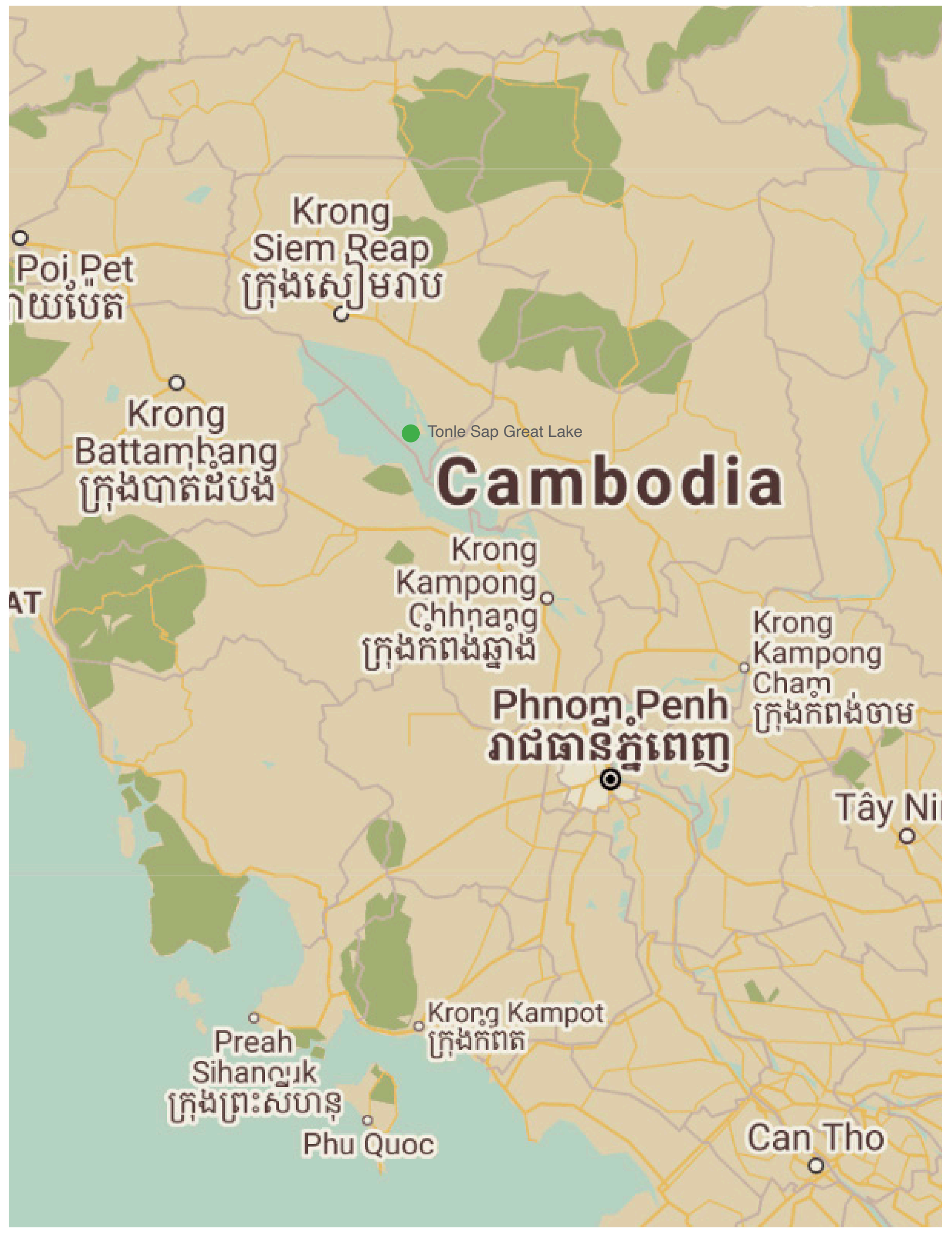

Figure 1. Case study location map: Tonle Sap Great Lake, Cambodia. 


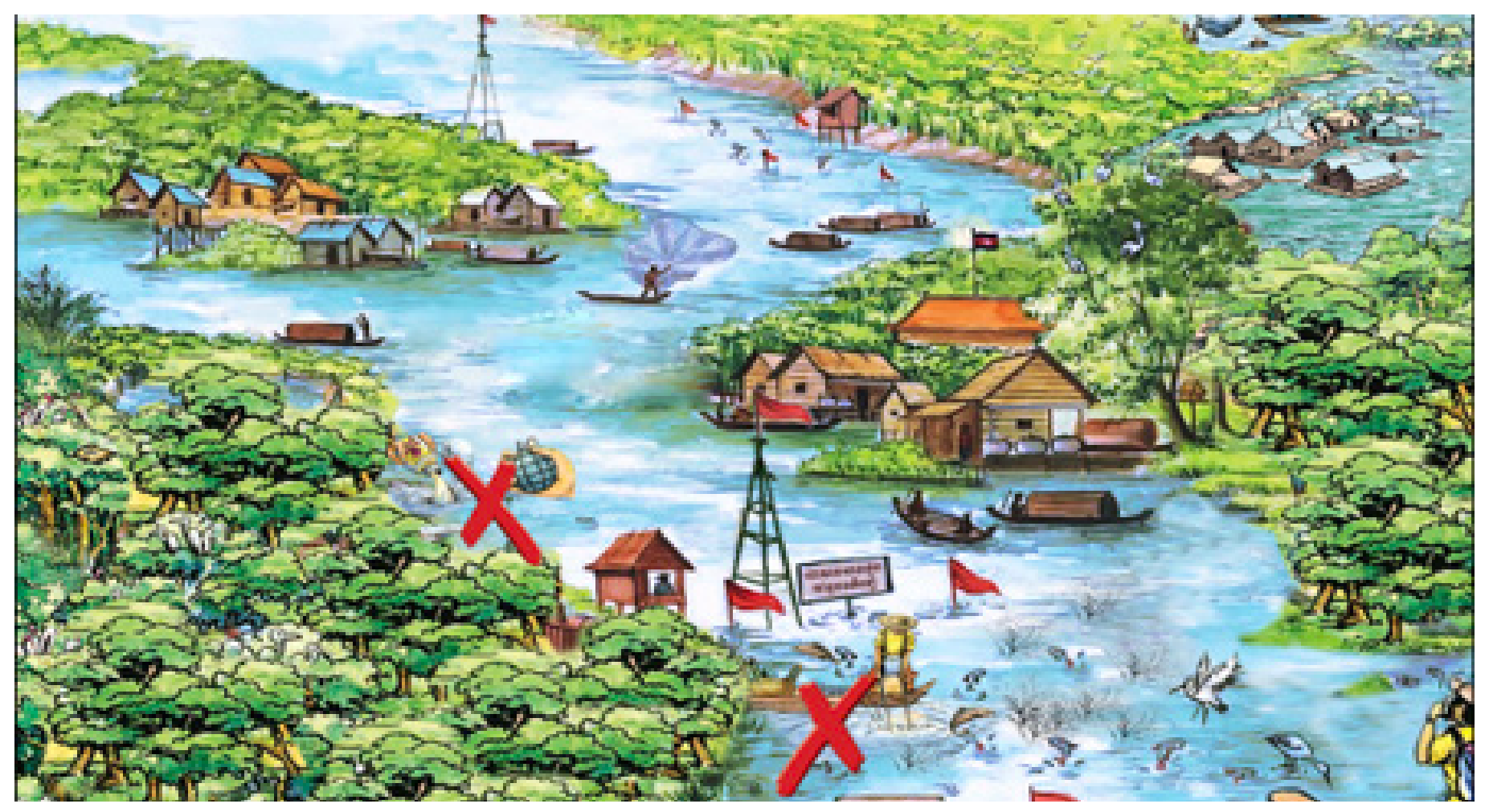

Figure 2: Project Implementation: Schematic outlining FCA boundary. 


\section{Case study - Aceh Province, Indonesia FK in policy, spatial planning and co- management}

This case study is a good example of integration of FK in policy, spatial planning and in co-management.

Fishery type: Marine. Small-scale subsistence and commercial.

No. of fishing communities: 71,064 fishers within 162 traditional fishing areas under Panglima Laot management systems.

Vessel types: Hand-powered \& motorised canoes, motorised wooden fishing vessels.

Fishing methods and species: Traditional \& artisanal mixed gears (handline, longline, purse seine, gill net, beach seines, lift nets, shore nets, spears and harpoons).

Method of obtaining FK: Community consultation for spatial planning, baseline surveys and participatory management.

Aichi Target achievement. Traditional fisher knowledge and management approaches integrated into marine spatial planning, conservation and decision-making in coral reef fishery systems (Target 6 \& Target 10).

\section{Key findings:}

- The Panglima Laot (Sea Commander) system of Aceh Province was established 400 years ago, during the reign of Sultan Iskandar Muda (1607-1636). After Indonesian independence in 1945 the Aceh Kingdom was integrated into the Indonesian Republic, and the Panglima Laot was transformed into an autonomous management system (customary institution) for fishers and, later, fisheries in the province. This institution regulates fish harvesting methods (meupayang), social culture, customary environmental management, customs of seagoing goods, and dispute resolution.

- The term Panglima Laot refers to both the management institution and to the institutional leader, who is elected by fishers within each traditional area. Fishing communities each hold customary management areas, known locally as 'Ihoks'.

- In 2002, the Indonesian government designated Aceh as a conflict area under military control. During this time, the Panglima Laot arrested illegally fishing foreign vessels and handed them over to authorities. These ships were auctioned off and the funds granted to the Panglima Laot.

- Traditional fisheries knowledge and management capacity in Aceh was severely affected by the 2004 Indian Ocean tsunami, which caused an estimated 167,000 deaths in the province including 14,000 fishers and over a quarter of traditional marine leaders.

- Losses in knowledge of - and physical changes in - fishing grounds post-tsunami were partially mitigated through participatory and bathymetric mapping of hazardous areas (eg. coral reefs and unknown seamounts which might entangle and damage expensive purse seine nets). This process supplemented traditional knowledge and reduced economic losses whilst safeguarding vulnerable habitats from overfishing.

- New Indonesian regulations in 2006 regarding the governance of Aceh created an opportunity to develop the Panglima Laot as autonomous customary fisheries management institutions.

- A subsequent marine spatial planning process, headed by
Aceh's Marine \& Fisheries Taskforce, incorporated traditional knowledge through participatory consultation. Following the consultation process, a total of 26 proposed MPAs covering 211,028 hectares were designated, in addition to 231,400 hectares previously confirmed in the Province.

- Local marine resource management capacity has been increased through support provided to the Panglima Laot in enforcing traditional fishing areas and tackling non-compliance through customary court proceedings for violators.

- Community-based management has been integrated within local fisheries governance and MPA management through the creation of locally managed marine area (LMMAs). These represent a vital step towards the clarification and state acknowledgement of traditional fishing area boundaries which lie within existing MPAs. This process also supports the integration of formal fisheries law into customary regulations.

- Panglima Laot members are participating in voluntary SMART patrols within traditional fishing areas, particularly aimed at detecting and deterring illegal fishing. This has increased monitoring, control and surveillance (MCS) capacity in areas without regular enforcement from maritime agencies, and boosted collaboration with government actors. Several violations have been prosecuted and sanctioned by the Panglima Laot customary courts, with patrol results also reported to government. - In a key protected site on Simeulue Island, improved management and community-led patrolling has seen a decrease of $70 \%$ in illegal and destructive compressor fishing on coral reefs since 2015 .

- The design process for an updated zoning plan covering Aceh's coastal areas and small islands is currently underway, with the customary management areas of the Panglima Laot recognised as extending up to four nautical miles from the coast.

\section{References:}

- Aceh Government (2018). Draft; Plan of coastal zoning and small islands: 2018-2038.

- Food and Agriculture Organization (2014). Strengthening organizations and collective action in fisheries: A way forward in implementing the international guidelines for securing sustainable small-scale fisheries. FAO Workshop Report 18-20 March 2013, Rome, Italy.

- International Collective in Support of Fishworkers (2009). Customary Institutions in Indonesia: Do They Have a Role in Fisheries and Coastal Area Management? Workshop Report 2-5 August 2009.

- Mansur, T.M. (2012) Tantangan Peradilan Adat Laot di Aceh, Kanun Jurnal IImu Hukum. No.57. Th XIV, pp.279-290.

- Syakur, A., Wibowo, J.T.,Firmansyah, I.A. \& Linkie, M. (2012). Ensuring local stakeholder support for marine conservation: establishing a locally-managed marine area network in Aceh. Oryx. 46(4), 516-24.

- Undang-Undang Republik Indonesia, No 11, Tahun 2006. Tentang Pemerintahan Aceh.

- Wilson, C. \& Linkie, M. (2012). The Panglima Laot of Aceh: a case study in large-scale community-based marine management after the 2004 Indian Ocean tsunami. Oryx. 46(4), 495-500.

\section{FK programme contacts:}

- Dewa Gumay. Aceh Programme Manager, FFI Indonesia.

dwgumay@fauna-flora.org

- Henry Duffy. Marine Technical Specialist, Asia-Pacific. FFI UK. henry.duffy@fauna-flora.org 


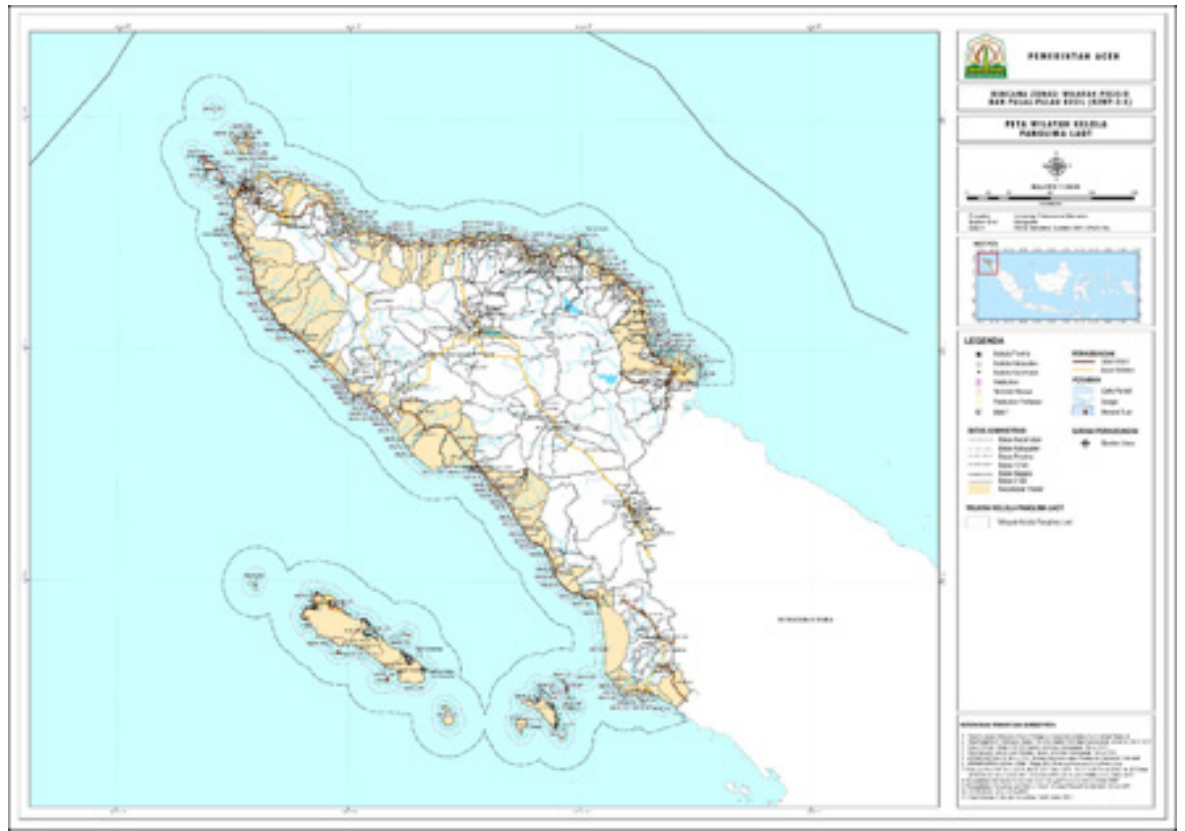

Figure 1: Map of Aceh Province, Indonesia.

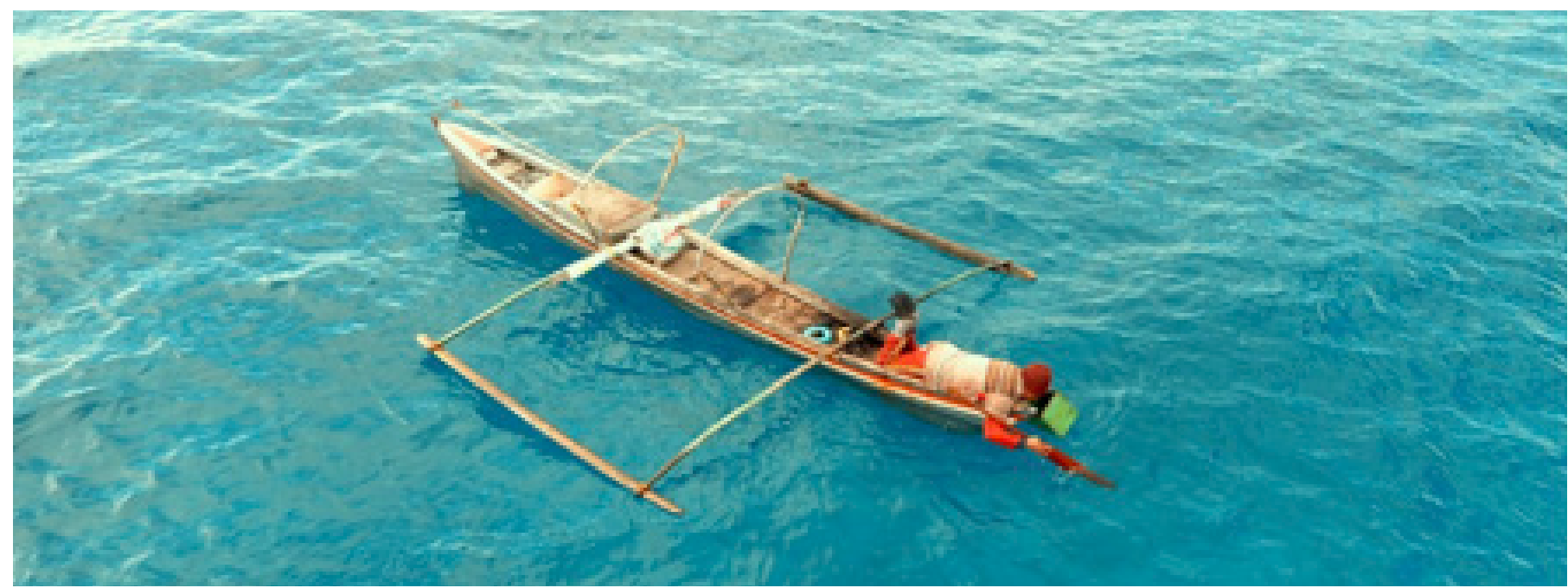

Figure 2: Fisher operating in Air Pinang traditional fishing waters on Simeulue Island, Aceh, Indonesia. Credit: Muhammad Zuhal/FFI

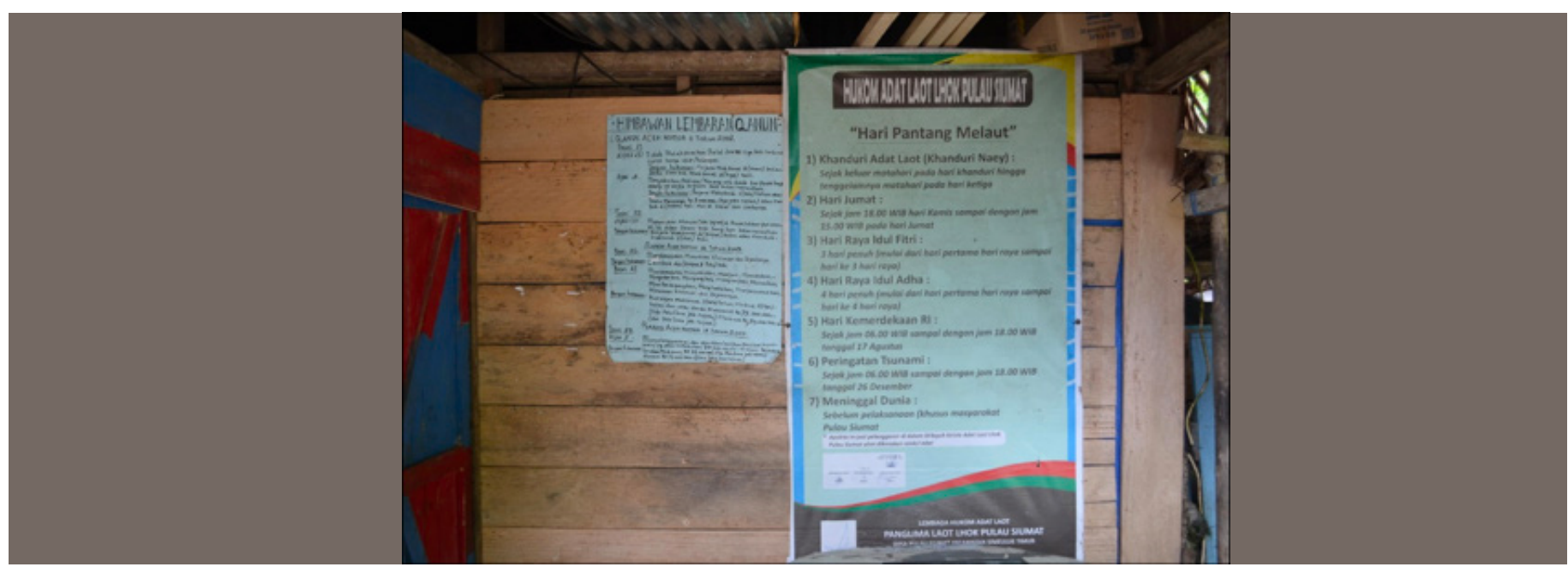

Figure 3: Marine customary law on display in Pulau Siumat, Simeulue Island. Credit: Rob Harris/FFI 


\section{Case study - United Arab Emirates, Middle East. \\ FK in policy, management planning, education and film}

This case study is a good example of integration of FK in policy, management planning and in educational use.

Fishery type: Marine. Small-scale commercial and recreational coastal.

No. of fishing communities: Thirteen, consisting of 6,332 commercial fishers and 16,000 recreational fishers.

Vessel types: $89 \%$ modern tarad (motor boat) and $11 \%$ traditional lansh (motored dhow).

Fishing methods and species: Traditional (Fish Traps, Netting, Longline, Hook \& Line, Spearfishing).

Method of obtaining FK: Focus Groups and Semi-structured interviews to obtain FK baseline.

Aichi Target achievement. Ongoing fisher engagement codified in legislation and policy (Targets 6 and 18).

Key findings:

- FK is embedded in policy, legislation and governance in the United Arab Emirates (UAE).

- This case study demonstrates the importance of how researching and including traditional fishing knowledge in fisheries management can be a fundamental data input for fisheries change management in a small-scale commercial and recreational fishing context.

- FK baseline established in 2015 with a UAE wide interview based approach with the most experienced fishers in each of the seven emirates.

- Interviews were recorded on film, with a key outcome being the development of a documentary on the state of the UAE fishery to support fisheries change management.

- The FK 2015 study supplemented previously completed archaeological and traditional maritime vessel studies with knowledge of cultural elements including historic societal living; species abundance and ecological knowledge and myths and folk systematics.

- Seventy eight percent of traditional UAE Arabian Gulf fishers and $76 \%$ of traditional UAE East Coast fishers agreed that significant resource depletion had occurred in these fisheries over the past 30 years due to fleet overcapacity, findings validated by empirical studies.

- Fishers identified applied uses for their knowledge which included application in environmental policy development and educating younger generations through books, films and practical vessel-based education

\section{References:}

- Abu Dhabi State of the Environment Report (2017).

www.soe.ae

- Federal Law No.7 of 2016 amending Federal Law of 1999 concerning the Exploitation, Protection and Development of the Living Aquatic Resources in the State of the United Arab
Emirates. Link: https://www.moccae.gov.ae/en/laws-andlegislations/federal-laws

FK programme contacts:

- Salah Al Rayssi. Acting Assistant Undersecretary for the Biodiversity and Marine Life Sector. Ministry of Climate Change and Environment.

- Halima Al Jassmi. Head of Fisheries. Ministry of Climate Change and Environment.

- Rumaitha Al Shehhi. Aquaculture Division. Ministry of Climate Change and Environment.

- Winston Cowie. Marine Policy Manager. Environment AgencyAbu Dhabi.

- Mohsin Al Ameri. Fisheries Scientist. Environment Agency-Abu Dhabi.

Contacts: saalrayssi@moccae.gov.ae / healjasmi@moccae. gov.ae / raalshehhi@moccae.gov.ae / winston.cowie@ead.ae / mohsin.alameri@ead.ae

Case study location: Landing sites and fishermen majlis (gathering halls) in the UAE where the interviews took place.

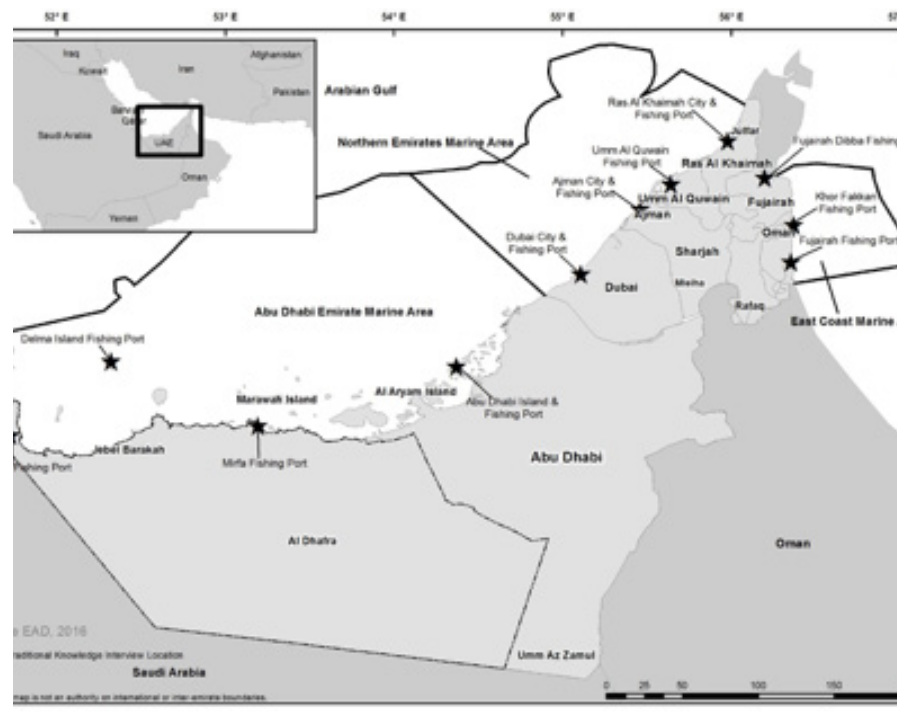

Figure 1: Map indicating FK survey locations within United Arab Emirates. 


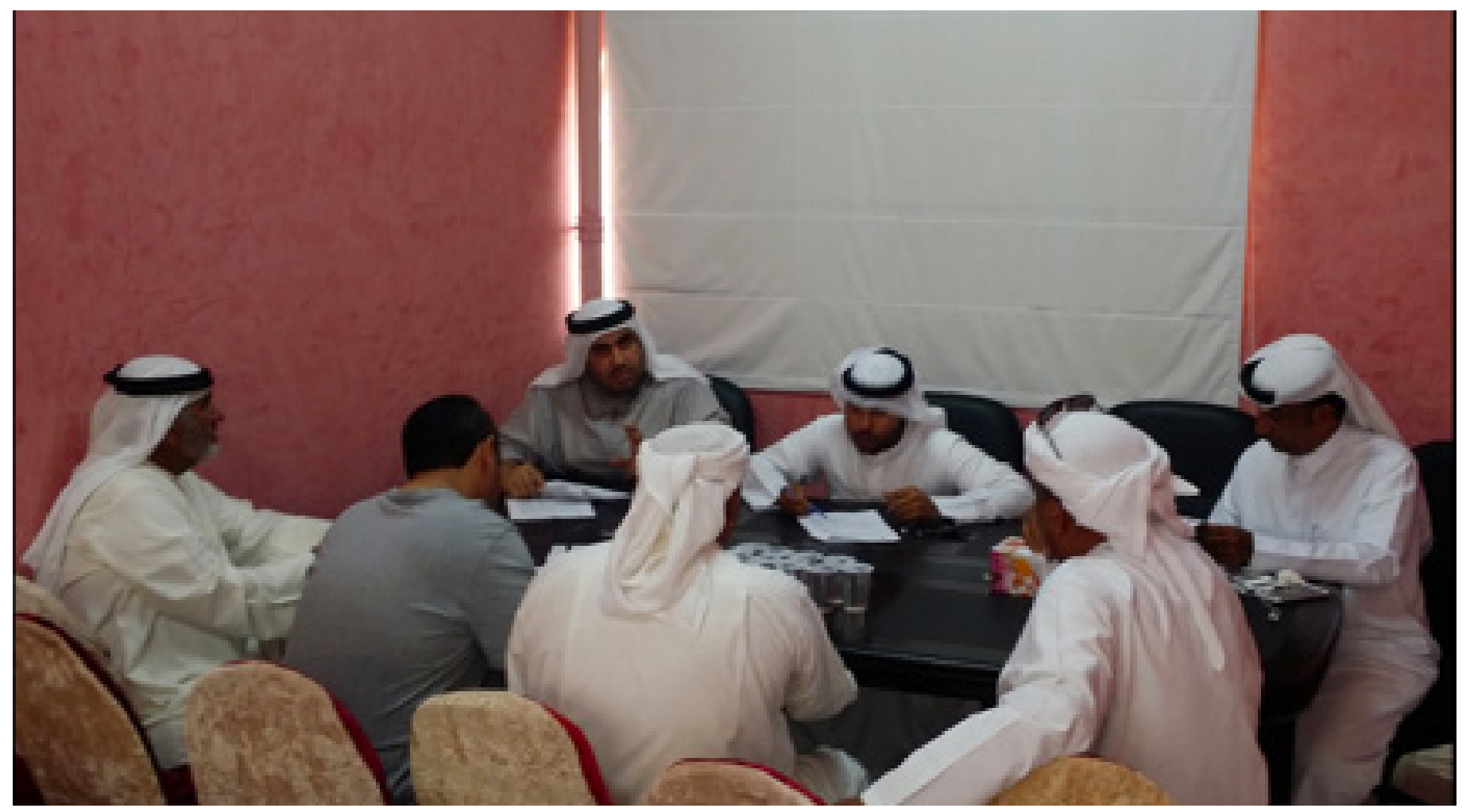

Figure 2: Gathering FK with video within the United Arab Emirates

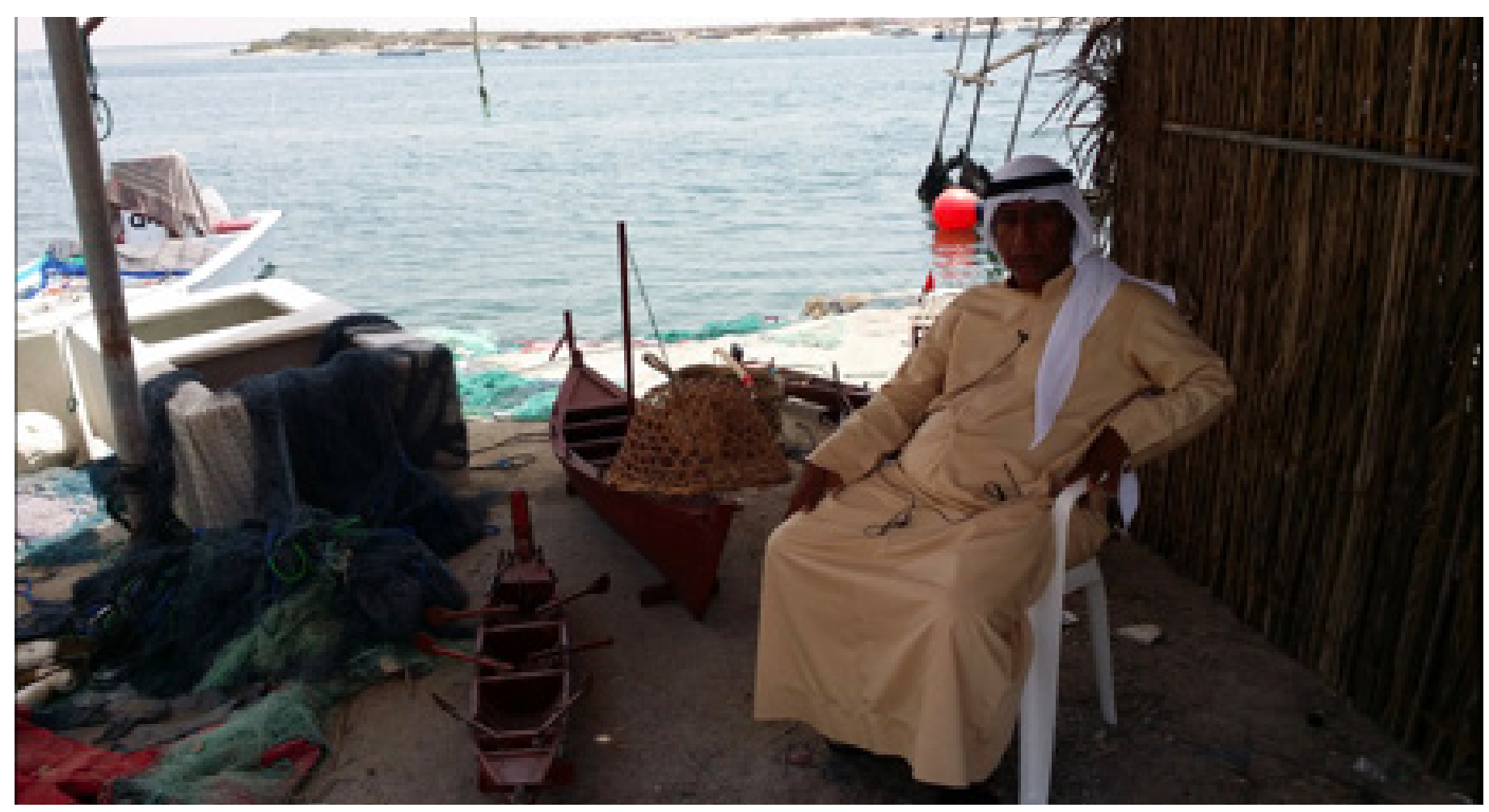

Figure 3: Gathering FK with video within the United Arab Emirates 


\section{CARIBBEAN}

\section{Regional experts}

FK experts in the Caribbean region are considered to include the following:

\begin{tabular}{|l|l|l|l|}
\hline Name & Country & Organisation & Contact Details \\
\hline Don DeMaria & $\begin{array}{l}\text { Florida Keys, } \\
\text { Caribbean region }\end{array}$ & Commercial fisher/diver & $\begin{array}{l}\text { Email: } \\
\text { dondemaria@aol.com }\end{array}$ \\
\hline Terry Gibson & $\begin{array}{l}\text { Florida, Caribbean } \\
\text { region }\end{array}$ & Northswell Media & $\begin{array}{l}\text { Email: } \\
\text { terry.gibson@ @orthswellmedia.com }\end{array}$ \\
\hline Dr. Will Heyman & Caribbean region & LGL Ecological Research Associates & $\begin{array}{l}\text { Email: } \\
\text { heymanwill@yahoo.com }\end{array}$ \\
\hline Mitchell Lay & $\begin{array}{l}\text { Antigua, Caribbean } \\
\text { region }\end{array}$ & $\begin{array}{l}\text { Caribbean Network of Fisherfolk } \\
\text { Organizations }\end{array}$ & $\begin{array}{l}\text { Email: } \\
\text { mitchlay@yahoo.co.uk }\end{array}$ \\
\hline Dr. Ken Lindeman & Caribbean region & $\begin{array}{l}\text { IUCN Snapper, Seabream and Grunt } \\
\text { Specialist Group }\end{array}$ & $\begin{array}{l}\text { Email: } \\
\text { lindeman@fit.edu }\end{array}$ \\
\hline Andres Maldonado & $\begin{array}{l}\text { Puerto Rico, } \\
\text { Caribbean region }\end{array}$ & $\begin{array}{l}\text { Commercial diver/fisher } \\
\text { Dr. Patrick McConney }\end{array}$ & Caribbean region \\
\hline Jaime Medina Flores & $\begin{array}{l}\text { Mexico, Caribbean } \\
\text { region }\end{array}$ & $\begin{array}{l}\text { Cooperativa de Langosteros y } \\
\text { Caracal }\end{array}$ & $\begin{array}{l}\text { Email: } \\
\text { Andres.scuba@gmail.com }\end{array}$ \\
\hline Dr. Hazel Oxenford & $\begin{array}{l}\text { Barbados, } \\
\text { Caribbean Region }\end{array}$ & University of West Indies & $\begin{array}{l}\text { Email: } \\
\text { patrick.mcconney@cavehill.uwi.edu }\end{array}$ \\
\hline
\end{tabular}




\section{Case study - Greater Caribbean. FK in Red List assessment}

This case study is a good example of FK being utilized in IUCN Red List assessment.

Fishery type: Marine; commercial, recreational, artisanal.

No. of fishing communities: Many hundreds around a region with over 35 countries.

Vessel types: All coastal vessel types used for fishing in estuaries or on reefs to the shelf edge and beyond.

Fishing methods: Traditional (Fish traps, Nets, Longlines, Hook \& Line, Spearfishing), Large commercial vessels in some subregions.

Method of obtaining FK: a) Identify and invite leading fishers to join the IUCN Snapper, Seabream and Grunt Species Group (SSG SG), and b) Obtain and apply their species-specific reviews to improve draft Red List species accounts during an assessment of snappers and grunts in the Caribbean.

Aichi Target achievement. Aichi Target 18.

Key findings:

- Placing multi-generational fishers onto an IUCN reef fish Specialist Group added value in measurable manners to the final Red List assessments for the Greater Caribbean.

- Species accounts were improved by fisher reviews that advised scientists working in very data-limited regions to not over-extrapolate geographically specific studies across broad insular regions when piecing-together larger patterns.

- Species accounts also were improved by fishers adding edits and additions on the little-acknowledged economic and ecological value that SG species have as baitfishes.

- The experience suggests that including leading fishers and FK in Red List assessments improved the review process.

- More fishing leaders will be added to the Snapper, Seabream and Grunt Species Group, with increased outreach as resources allow.

\section{References:}

- IUCN Red List account, Queen Snapper, Etelis oculatus

- IUCN Red List account, Pigfish, Orthopristis chrysoptera

- Linardich C. et al. 2018. Conservation status of greater Caribbean and Gulf of Mexico marine bony shorefishes. Aquatic Conservation: Marine \& Freshwater Ecosystems. 1-17. DOI: 10.1002/aqc.2959.

- Snapper, Seabream and Grunt Specialist Group Website: https://www.iucn.org/commissions/ssc-groups/fishes/snapperseabream-and-grunt-specialist-group

\section{Video:}

Click here to watch a video of Capt. Mitchell Lay of the Caribbean Network of Fisherfolk Organizations, that provides Antillean fisher knowledge and perspectives. Captain Lay is one of the winners of the Gladding Memorial Award, an honor given to fisherfolk who advance sustainable fishing by the Gulf and Caribbean Fisheries Institute since 2004.
FK programme contacts:

- Dr. Ken Lindeman, Co-chair, Snapper, Seabream and Grunt Specialist Group.

- Dr. Barry Russell, Co-chair, Snapper, Seabream and Grunt Specialist Group.

-Contacts: lindeman@fit.edu; Barry.Russell@magnt.net.au

Case study location: > 35 countries across the Greater Caribbean.

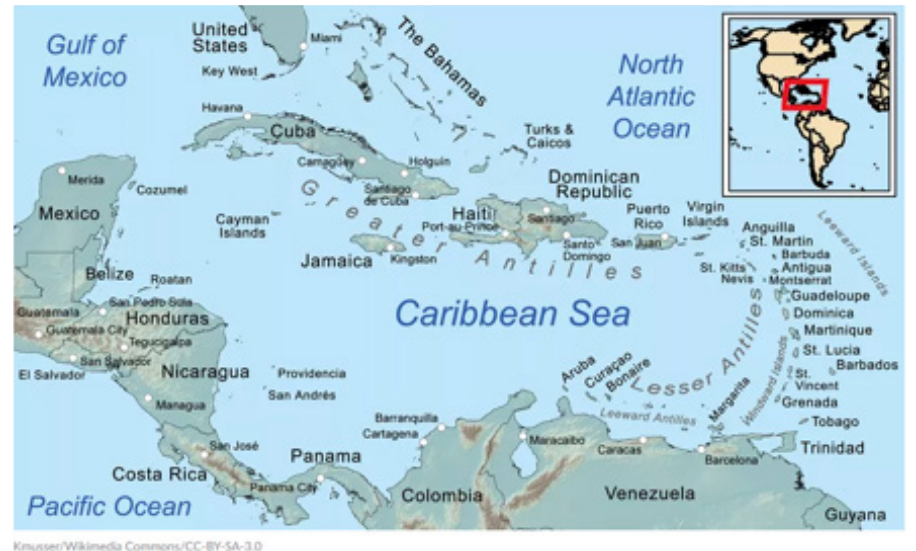

Figure 1: Map of Greater Caribbean region associated with the SSG SG Red List assessments. 

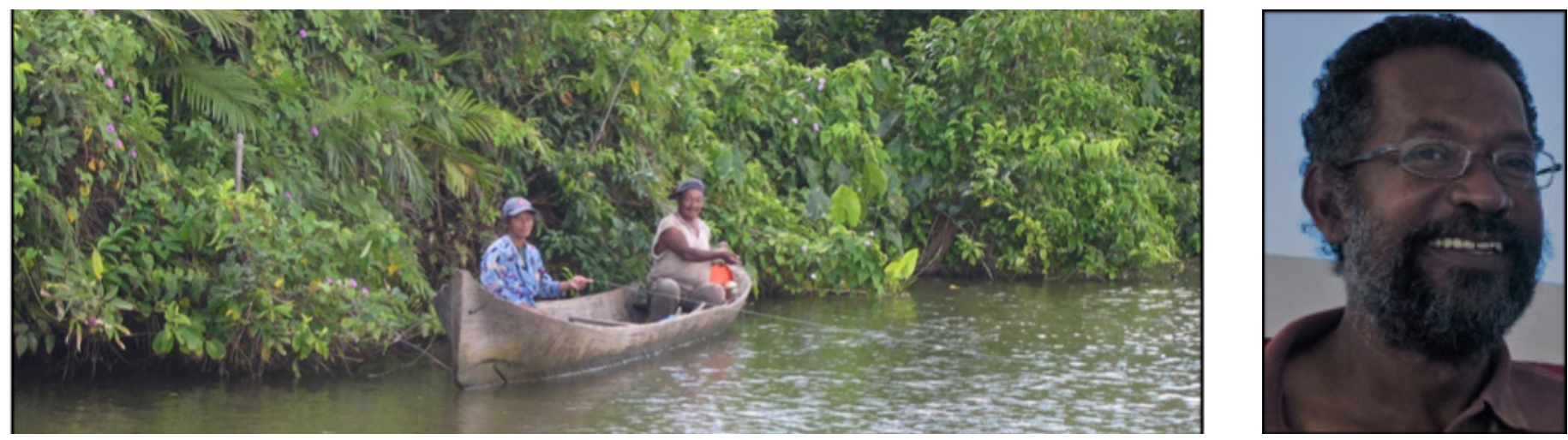

Figure 2: Left: Handline fishers at a high salinity river mouth, Laguna de Perlas, Nicaragua. Source: K. Lindeman. Right: Antiguan fisherman and SSG SG member, Capt. Mitchell Lay. Source: Caribbean Network of Fisherfolk Organizations
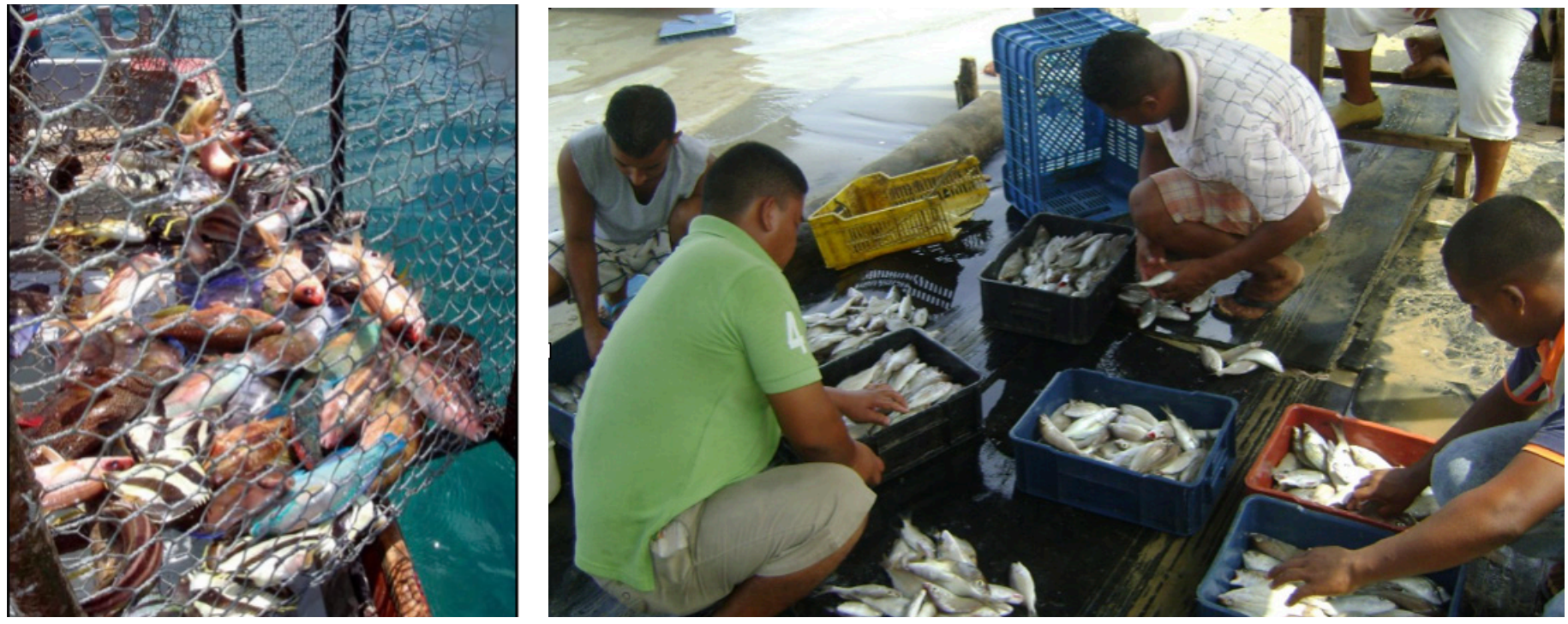

Figure 3: Left: Fish trap with multispecies catch including species from the SSG SG and other reef fish families, Barbados. Source: H. Oxenford. Right: Boxing tomtate grunts (Haemulon aurolineatum) caught by fish traps, beachside processing tent, near Cumana, Venezuela. Source: K. Lindeman. 


\section{CENTRAL AND SOUTH AMERICA}

\section{Regional experts}

FK experts in the Central and South American region are considered to include the following:

\begin{tabular}{|c|c|c|c|}
\hline Name & Country & Organization & Contact Details \\
\hline Claudio Baigún & $\begin{array}{l}\text { Argentina, South } \\
\text { America }\end{array}$ & $\begin{array}{l}\text { Laboratorio de Ecología Pesquera Aplica- } \\
\text { da, Instituto de Investigación e Ingeniería } \\
\text { Ambiental, Universidad Nacional de San } \\
\text { Martín- CONICET, Campus Miguelete -25 } \\
\text { de Mayo y Francia. San Martín, Provincia } \\
\text { de Buenos Aires (Argentina), CP } 1650 .\end{array}$ & $\begin{array}{l}\text { Email: } \\
\text { cbaigun@gmail.com }\end{array}$ \\
\hline $\begin{array}{l}\text { Marvin Fonseca } \\
\text { Borrás }\end{array}$ & $\begin{array}{l}\text { Costa Rica, Central } \\
\text { America }\end{array}$ & CoopeSoliDar R.L. & $\begin{array}{l}\text { Email: } \\
\text { mfonseca@coopesolidar.org }\end{array}$ \\
\hline Trilce Irupé Castillo & $\begin{array}{l}\text { Argentina, South } \\
\text { America }\end{array}$ & $\begin{array}{l}\text { Trilce Irupé Castillo, CONICET-Universi- } \\
\text { dad Nacional de Rosario, Rosario, Santa } \\
\text { Fe, Argentina. }\end{array}$ & $\begin{array}{l}\text { Email: } \\
\text { trilcecastillo@gmail.com }\end{array}$ \\
\hline Aracelly Jiménez & $\begin{array}{l}\text { Costa Rica, Central } \\
\text { America }\end{array}$ & $\begin{array}{l}\text { CoopeMolusChomes R.L, Mollusc gath- } \\
\text { erer. }\end{array}$ & $\begin{array}{l}\text { Email: } \\
\text { coopemoluscoschomes@gmail.com }\end{array}$ \\
\hline John Jorgensen & $\begin{array}{l}\text { Central and South } \\
\text { America }\end{array}$ & $\begin{array}{l}\text { Fisheries and Aquaculture Department, } \\
\text { Food and Agriculture Organization of the } \\
\text { United Nations }\end{array}$ & $\begin{array}{l}\text { Email: } \\
\text { John.Jorgensen@fao.org }\end{array}$ \\
\hline Daniela Kalikoski & $\begin{array}{l}\text { Central and South } \\
\text { America }\end{array}$ & $\begin{array}{l}\text { Fisheries and Aquaculture Department, } \\
\text { Food and Agriculture Organization of the } \\
\text { United Nations. }\end{array}$ & $\begin{array}{l}\text { Email: } \\
\text { Daniela.Kalikoski@fao.org }\end{array}$ \\
\hline David Chacón Rojas & $\begin{array}{l}\text { Costa Rica, Central } \\
\text { America }\end{array}$ & CoopeTárcoles R.L. Fisherman. & $\begin{array}{l}\text { Email: } \\
\text { dchacon19@yahoo.com }\end{array}$ \\
\hline Vivienne Solis Rivera & $\begin{array}{l}\text { Costa Rica, Central } \\
\text { America }\end{array}$ & $\begin{array}{l}\text { IUCN SULi, IUCN CEESP, CoopeSoliDar } \\
\text { R.L., Costa Rica. }\end{array}$ & $\begin{array}{l}\text { Email: } \\
\text { vsolis@coopesolidar.org }\end{array}$ \\
\hline
\end{tabular}




\section{Case study - Parana River Basin, Argentina. FK in policy and management planning}

This case study is a good example of FK being utilized to enhance knowledge in management planning.

Fishery type: Freshwater, small-scale artisanal/commercial.

No. of fishing communities: Two fishing communities located in San Pedro and Ramallo cities, with around 200 fishers.

Vessel types: Hand-powered \& motorized canoes.

Fishing methods: Gill-nets, trammel nets, and hook lines.

Method of obtaining FK: Semi-structured and structured questionnaires, personal interviews and participatory mapping.

Aichi Target achievement. Targets, 6, 18 and 19.

Key findings:

- FK research in the Parana river can provide a new and still little explored avenue for improving fisheries management and information not captured by traditional scientific and technical assessments

- FK results in the Parana Delta allowed getting novel information about environmental changes and the general status of the local fishing resources of which fishers depend on.

- FK represented a valuable tool to complement scientific information based on temporal and spatial species distribution and fish biodiversity using an ethnoichtylogical framework.

- Fishers showed awareness on current fisheries problems and concern about promoting new measures that ensure sustainable management based on stakeholders inclusion in the decisionmaking process.

- FK use represents a major step for moving toward the application of an ecosystem-based approach to fisheries in the Parana basin by highlighting the participative role of stakeholders.

- FK represents an excellent tool for gathering critical information related to the different capitals that contribute to fishers livelihood.

- FK assisted in the detection of fishers socio-economic conflicts and demands usually not tackled by a conventional management approach and translate them to a local spatial scale.

\section{References:}

- Baigún, C. 2015. Guidelines for use of fishers' ecological knowledge in the context of the fisheries ecosystem approach applied to small-scale fisheries in South America. Pages 6383 in Fischer, J., Jorgensen, J., Josupeit, H., Kalikoski, D. and Lucas, C.M., eds. Fishers' knowledge and the ecosystem approach to fisheries: applications, experiences and lessons in Latin America. FAO Fisheries and Aquaculture Technical Paper No. 591, FAO, Rome.

- Baigún, C., T. Castillo and P. Minotti. 2016. Fisheries governance in the 21 st century: barriers and opportunities in South American large rivers. Pages 301-310: In W.W. Taylor, D. M. Bartley, C. I. Goddard, N. J. Leonard and R. Welcomme, editors. Freshwater fish and the future: proceedings of the global cross-sectoral conference. FAO, Rome, Michigan State University, East Lansing and American Fisheries Society, Bethesda, Maryland, $351 \mathrm{p}$.

- Castillo, T., C. Baigún and P. Minotti. 2016. Assessment of fisheries legal framework for potential development of an ecosystem approach to fisheries management in large rivers. Fisheries Management and Ecology, 23: 510-518.

- Castillo, T., Brancolini, F., Saigo, M. Correa, J. and C. R.M. Baigún, C. 2018. Ethnoichthyology of artisanal fisheries from the lower La Plata River basin (Argentina). Journal of Ethnobiology, 38(3): 406-423 (accepted for publication)

- Castillo, T. and Baigun, C. 2020. Identification of artisanal fishing territories and associated conflicts in the middle and lower Paraná River (Argentina) through participatory mapping. Journal of Applied Geography (in press)

\section{FK programme contacts:}

- Trilce Irupé Castillo, CONICET-Universidad Nacional de Rosario, Rosario, Santa Fe, Argentina.

Contact: trilcecastillo@gmail.com

- Claudio Baigún, Laboratorio de Ecología Pesquera Aplicada, Instituto de Investigación e Ingeniería Ambiental, Universidad Nacional de San Martín- CONICET, Campus Miguelete -25 de Mayo y Francia. San Martín, Provincia de Buenos Aires (Argentina), CP 1650.

Contact: cbaigun@gmail.com

Case study location:Parana River, Argentina.

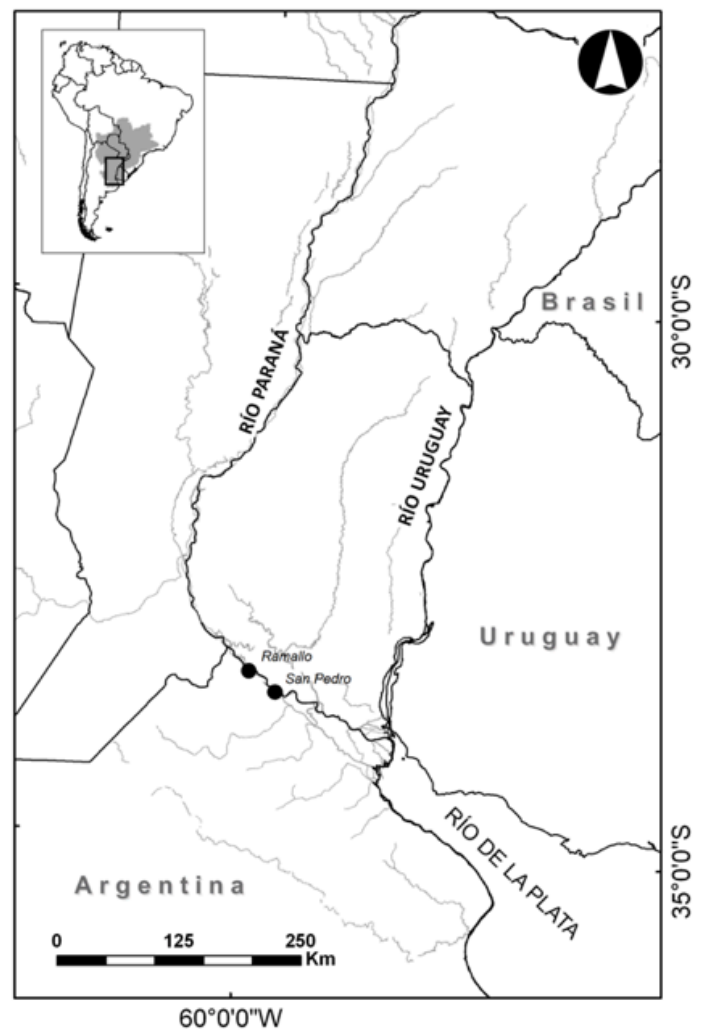

Figure 1: Map of Greater Caribbean region associated with the Red List assessments. 


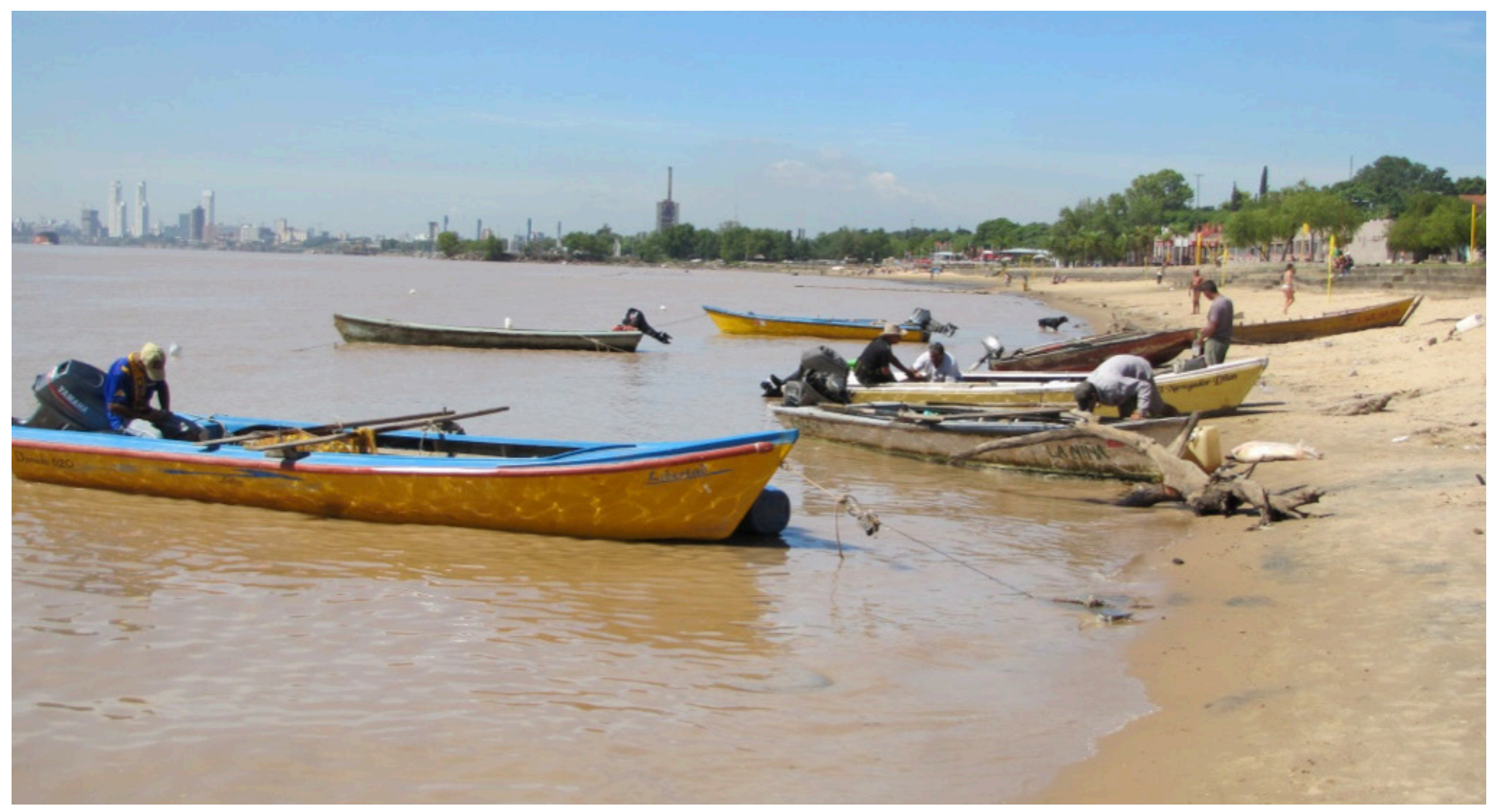

Figure 2: Fisher's boats in the Parana River.

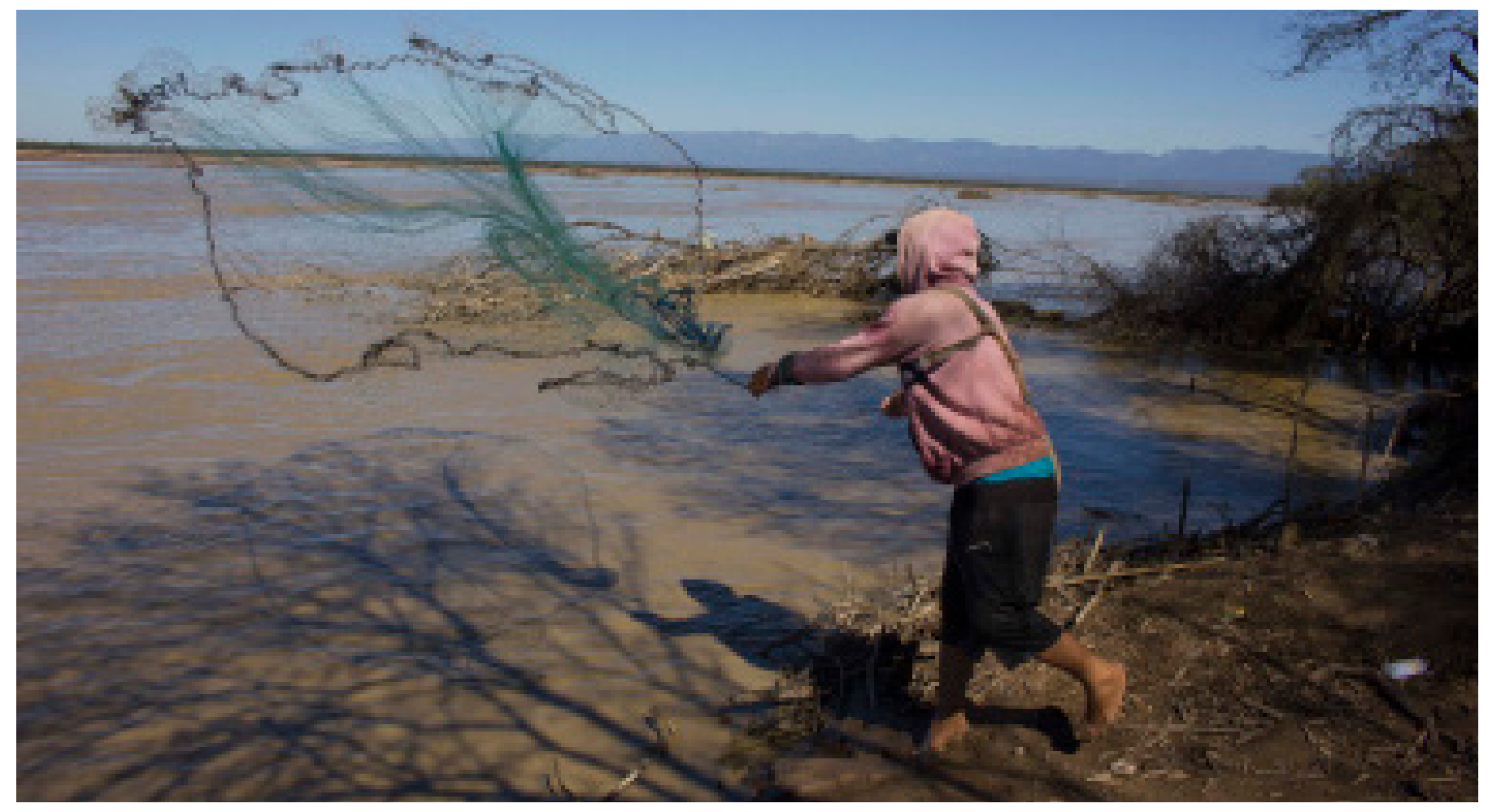

Figure 3: Pilcomayo River (Bolivia) @ Claudio Baigun 


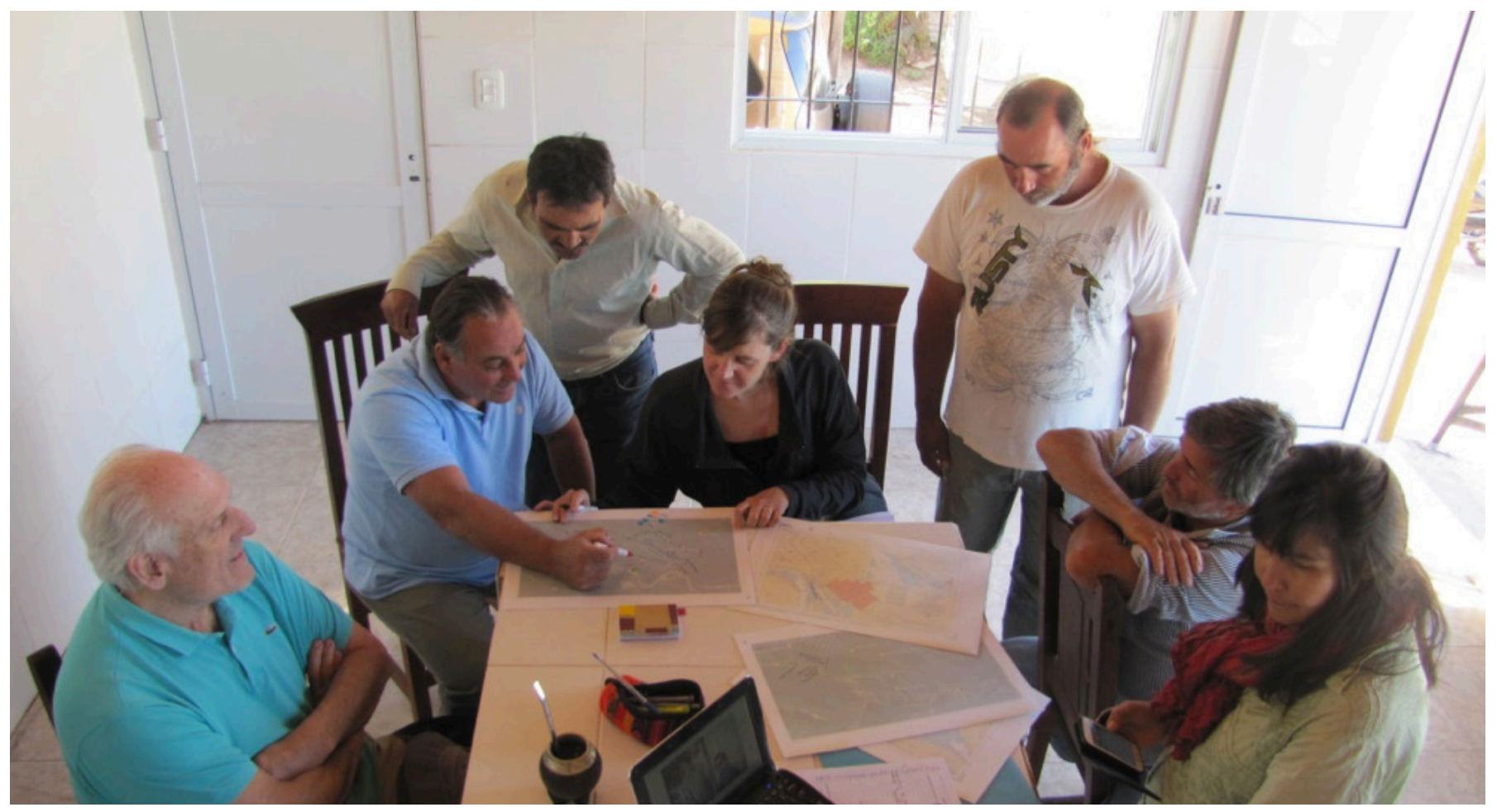

Figure 4: Gathering FK via participatory meetings, Parana River, Argentina.

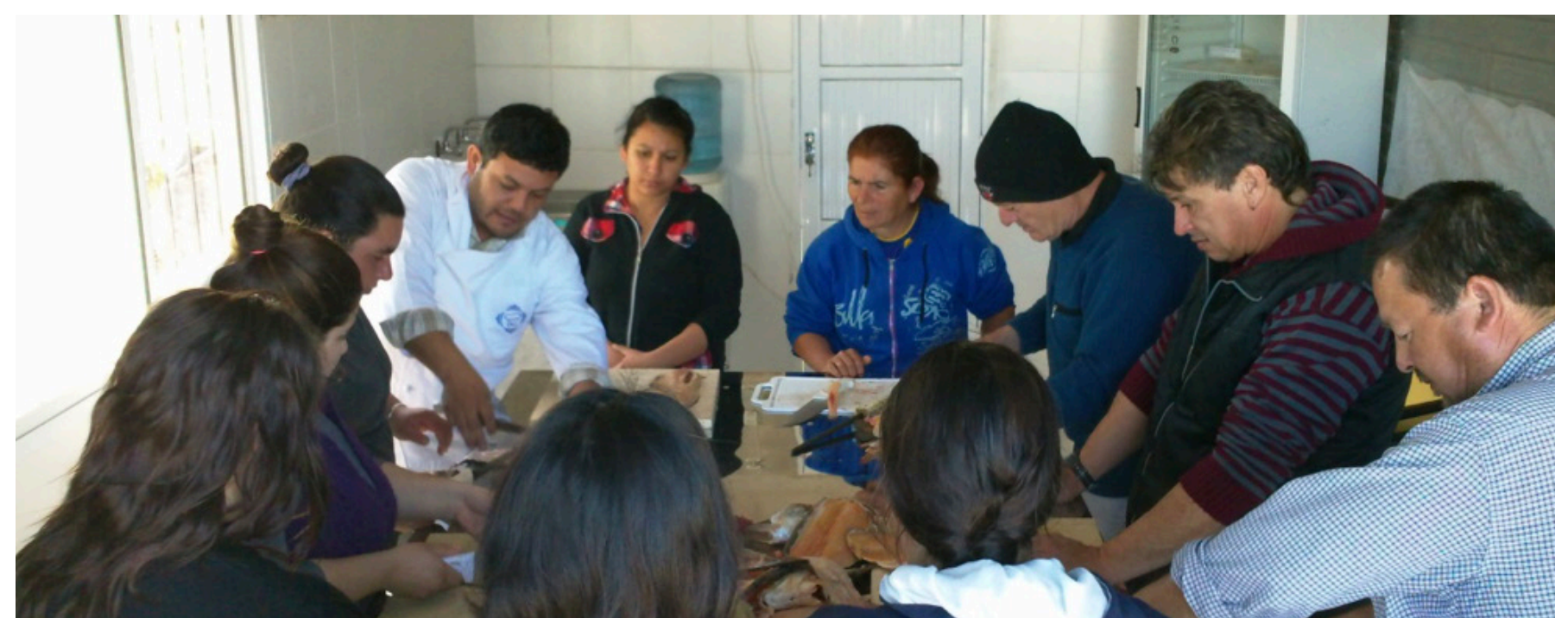

Figure 5: Learning how to fillet a fish, Parana River, Argentina. 


\section{Case study - Tárcoles, Pógeres, and La Pita, Costa Rica, Central America. FK in policy and management planning}

This case study is a good example of integration of FK in a database that informs policy and management planning.

Fishery type: Marine small-scale commercial and recreational coastal.

No. of fishing communities: Three communities (Tárcoles, Pógeres, and La Pita).

Vessel types: Panga (small boats with motor) travelling up to three miles.

Fishing methods and species: Hook and Line. ' $5 \times 7$ ' nets. Diving for lobster.

Method of obtaining FK: Development of a fishers stock assessment database supported by traditional knowledge and scientific analysis.

Aichi Target achievement. Targets 6 and 18. The fisher's territory is recognized as a Marine Responsible Fishing Area.

\section{Key findings:}

- Participatory research and innovative approaches to the generation of new knowledge with communities in Costa Rica was found to provide enormous value to reinforce the importance of conservation and food security for the populations of artisanal fishers.

- An ongoing and continuous database of FK has been developed, supporting stock assessment and allowing users to access valuable information and monitor the status of populations of target organisms. FK is one of the key indicators that enable fishers to evaluate the total fish catch obtained annually (Solis Rivera Vivienne et al, 2015).

- This initiative is the first of its kind conducted by an organization of artisanal fishermen in Costa Rica.

- The compiled information also permits the identification of fluctuation in the patterns of catch and effort in different marine and coastal locations over time, along with changes in perceived earnings from fishing.

- Through the database fishers are able to objectively compare variation in yield from year to year and to understand the potential causes for improvements or declines in productivity in a particular year (Solis Rivera, 2015).

- This supports with the understanding of the yield of fishing activities, which compares annual productivity, the effort invested in terms of time (number of fishing operations expressed as total hours spent fishing) and in terms of the amount of equipment used (number of nets used among fishers using seine nets or number of hooks for those using hook and line).

- FK goes beyond the commercial interest in species to become a real asset for the ecosystem management of their marine territory.

- The project includes recording of developmental data (e.g. juvenile or adult) of captured individuals of spotted rose snapper (Lutjanus guttatus, Lutjanidae), whitefin weakfish (Cynoscion albus, family Sciaenidae) and white snook (Centropomus viridis, family Centropomidae). (Solis Rivera, 2015).

- The process of processing and systematizing this enormous basket of knowledge requires time and adaptation to fisher's conditions and needs.

- Data analysis and registration in the hands of fishers' organizations provides them with a very strong negotiating power and enables fishers to compare and query government stock assessment data.

- Small-scale fisheries have a very heterogeneous base of species that are important not only for the commercial interest but also for food security in the communities; FK considers the diversity of the ecosystem.

- Accompanying agreements between organizations for the analysis of the data and improvement of the systematization methods is important and needs to be developed on a long term basis (CoopeSoliDar R.L and CoopeTárcoles R.L have now a relationship that goes back to 2000).

- Fishers' organizations can understand the economic and time value of the systematization of their knowledge, with their knowledge able to be used in the management of the fishery.

- Using FK in fisheries management has enabled fishers to find different species faster and in the right location through assessment of annual data.

- In the case of Tárcoles the type of information provided by the fishers included: Name of fisher, Location, type of fishing gear, Time fishing and added to this the moon phase and the date.

- Data gathering needs to be continuously adapted and improved through continuous discussions with fishers concerning fishing activities.

- Information of recreational fishing provided important evidence on the impact of fishing activities on ecosystems and also on the commercial fishing dynamics of the areas. This information was key to assessing the impacts of both recreational fishing and commercial fishing in development of small scale fisher's management plans.

- The information generated has opened up the possibility for sustainable use of fishery resources of this small fishery and for regular monitoring of the state of the resource based on the knowledge and effort of fishermen.

- As a result of the information generated by this database, it was included as a valuable data source in negotiations for the recognition of a Marine Responsible Fishing Area.

- The generation of knowledge is a continuous learning process that strengthens the power of those actors such as artisanal fishers that prior to this process had no voice or vote in management agencies .The information is rapidly transformed into power (given that the process occurs within an ethical framework and correct values), which strengthens local governance together with a fisheries management scheme oriented "in practice" towards a sustainable fishing model.

\section{References:}

- CoopeSoliDar R.L. 2005. Tárcoles: una comunidad de pescadores artesanales en Costa Rica, aportes a la conservación de los recursos marino costeros del golfo de Nicoya. San José, Costa Rica.

- CoopeSoliDar R.L. 2010. Plan de ordenamiento de la pequeña pesquería. Área marina de pesca responsable de Tárcoles. CoopeSoliDar R.L.; CoopeTárcoles R.L.; INCOPESCA. San Jose, Costa Rica.

- Coope SoliDar R.L.and CoopeTárcoles R.L..2011 Tárcoles +5. 
San Jose, Costa Rica.

- CoopeSoliDar R.L. 2016-2018. Paula Pérez, Omar Rodriguez. Estudio de la pesca recreativa en el area marina de pesca responsable. Informes de situación. San José, Costa Rica.

- Solis Rivera Vivienne, Alejandro Muñoz and Marvin Fonseca. Integrating Traditional and Scientific knowledge for the management of small-scale fisheries: an Example from Costa Rica. 2015. In Fisher's Knowledge and the ecosystem approach to fisheries Applications, experiences and lessons in Latin America. Edited by: Johanne Fisher, John Jorgensen, Helga Josupeit, Daniela Kalikosky and Christine M. Lucas. FAO Fisheries and aquaculture Technical 591 paper.

\section{Videos:}

- https://www.youtube.com/watch?v=YKmj6f2nU5w

- https://www.youtube.com/watch?v=hyRLuBJEdZA\&t=2s

- https://www.youtube.com/watch?v=jS0Q0J2X-D8

\section{FK programme contacts:}

- David Chacón Rojas. Fisherman. CoopeTárcoles R.L

Contact: dchacon19@yahoo.com

- Vivienne Solis Rivera. CoopeSoliDar R.L

Contact: vsolis@coopesolidar.org

Case study location: Three communities (Tárcoles, Pógeres, and La Pita), Costa Rica, Central America.

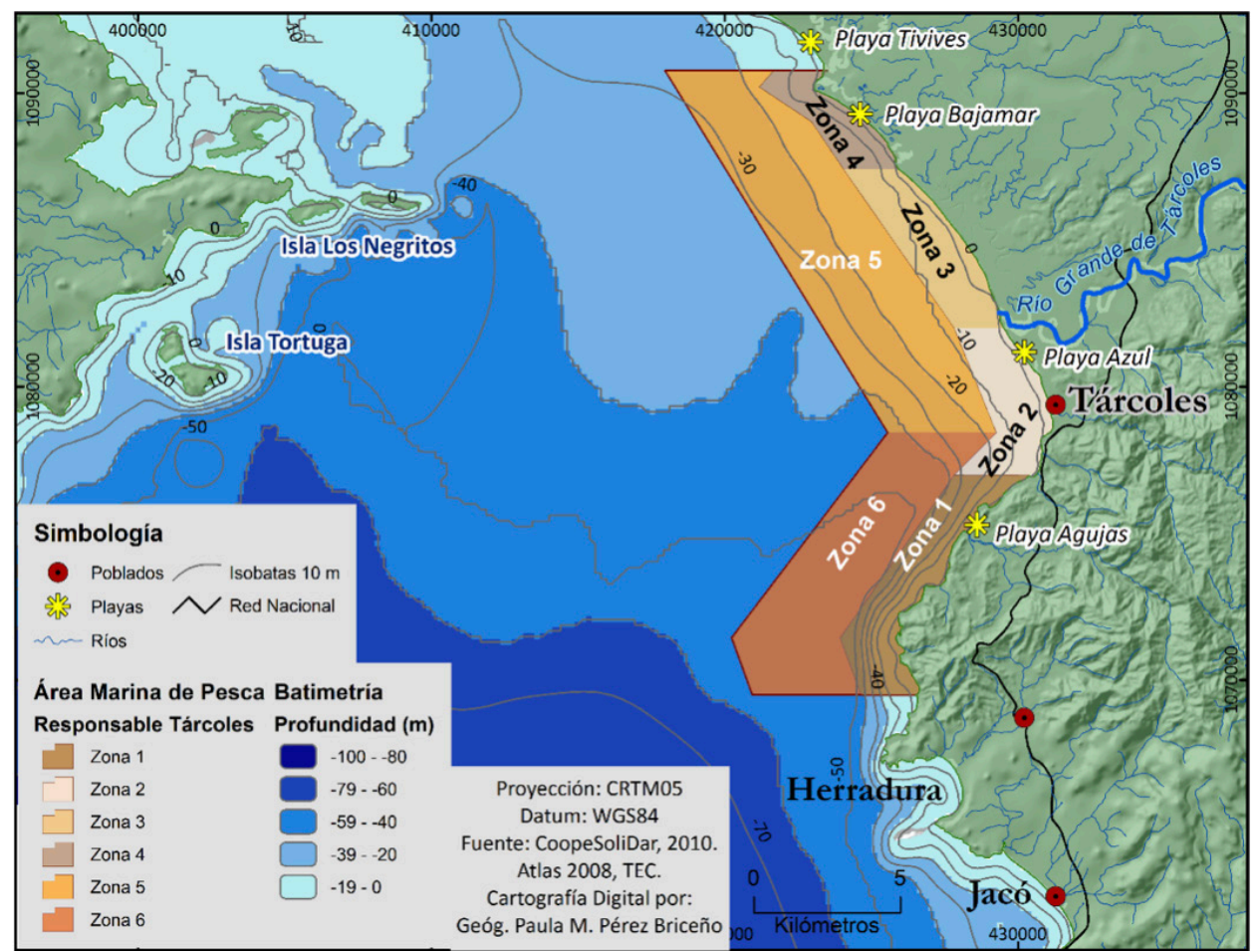

Figure 1: Map of Área Marina de Pesca Responsable de Tárcoles, Costa Rica.

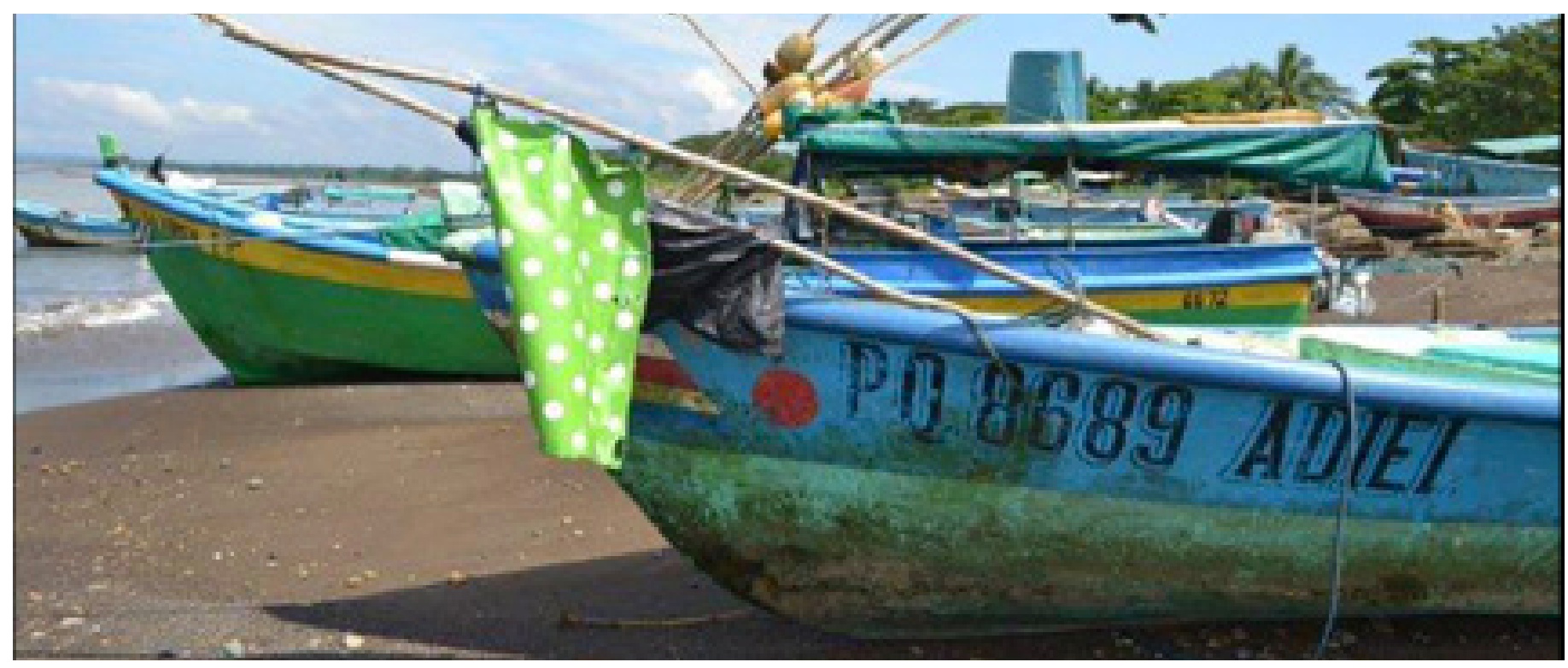

Figure 2: Fishing vessels within the Área Marina de Pesca Responsable de Tárcoles, Costa Rica. 


\section{Case study - Chomes, Puntarenas, Costa Rica, Central America Women FK enhancement}

This case study is a good example of women's FK being utilized in the sustainable management of a fishery resource.

Fishery type: Mollusc Gathering (traditionally done by hand).

No. of fishing communities: Three Chomes communities (Tárcoles, Pógeres, and La Pita).

Vessel types: Do not apply.

Fishing methods and species: Women Mollusc Gatherers.

Method of obtaining FK: Barefoot and barehand

Aichi Target achievement. Target 6 .

\section{Key findings:}

- The FK concerning molluscs has been gathered for the first time in Costa Rica, contributing to the development of a management plan and rights recognition of women as part of the small-scale fisher sector in Costa Rica.

- Women's knowledge was found to be highly rooted in their cultural identity and the link between their productive territory and the natural environment.

- The study indicates that in addition to molluscs, women's FK could support the gathering and enhancement of FK for the wider ecosystem (mangroves, the beach and estuaries) where the molluscs occur.

- The mangrove ecosystem in Chomes is of extreme value for the wellbeing of communities and their food security. The ecosystem could be more sustainably managed based on the knowledge of women.

- CoopeMolus-Chomes, R.L., has pursued the inclusion of traditional knowledge of its women at the national level in Costa
Rica through the elaboration of a participatory management plan. - It is considered that there is still a need for the totality of institutions, specially academy and the protected area system to recognized the women's knowledge related to mollusc gathering. - It was recognised that women work what is considered to be 'triple time,' which is not currently identified appropriately through social security.

-Women have recognized other threats to the ecosystem coming from pollutants from big factories and aquaculture activities.

- Technical and scientific respectful support from CoopeSoliDar R.L has been of great importance for the trust and collective work necessary to share knowledge and information.

\section{References:}

- CoopeMolusChomes R.L. 2017. Plan participativo de aprovechamiento de moluscos en el manglar de Chomes, Puntarenas. Costa Rica.

\section{Videos:}

- https://www.youtube.com/watch?v=TnbjQ1A3RJ4

- https://www.youtube.com/watch?v=XADSvQMYmr8\&t=9s

- https://www.youtube.com/watch?v=QordFK8F5uU\&t=41s

- https://www.youtube.com/watch?v=e6NOH4EEXOQ

\section{FK programme contacts:}

- Marvin Fonseca Borras. CoopeSoliDar R.L Contact: mfonseca@ coopesolidar.org

- Aracelly Jiménez. Mollusc Gathering Woman.

Contact: coopemoluscoschomes@gmail.com

- Vivienne Solis Rivera. CoopeSoliDar R.L

Contact: vsolis@coopesolidar.org

Case study location: One mollusc gathering community at Ubicación de Chomes, Puntarenas, Costa Rica.

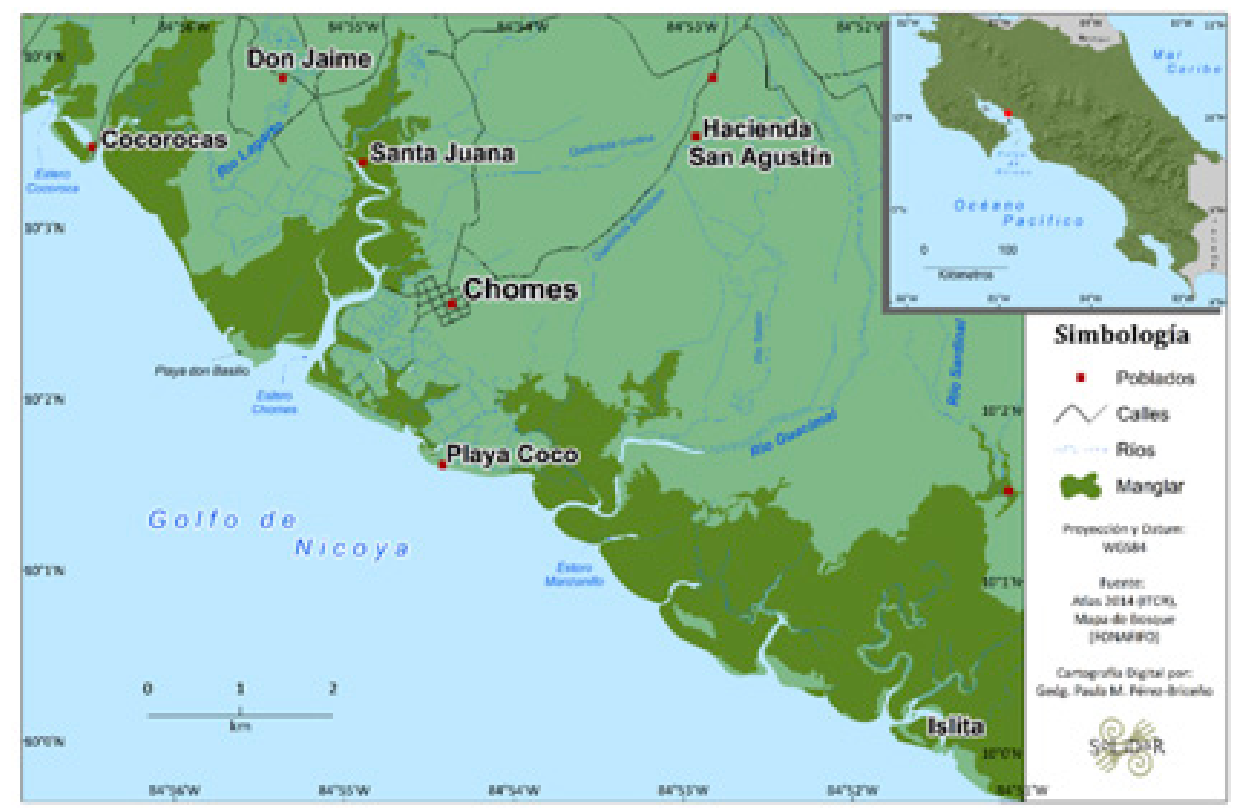

Figure 1: Mollusc gathering community at Chomes, Puntarenas, Costa Rica. 


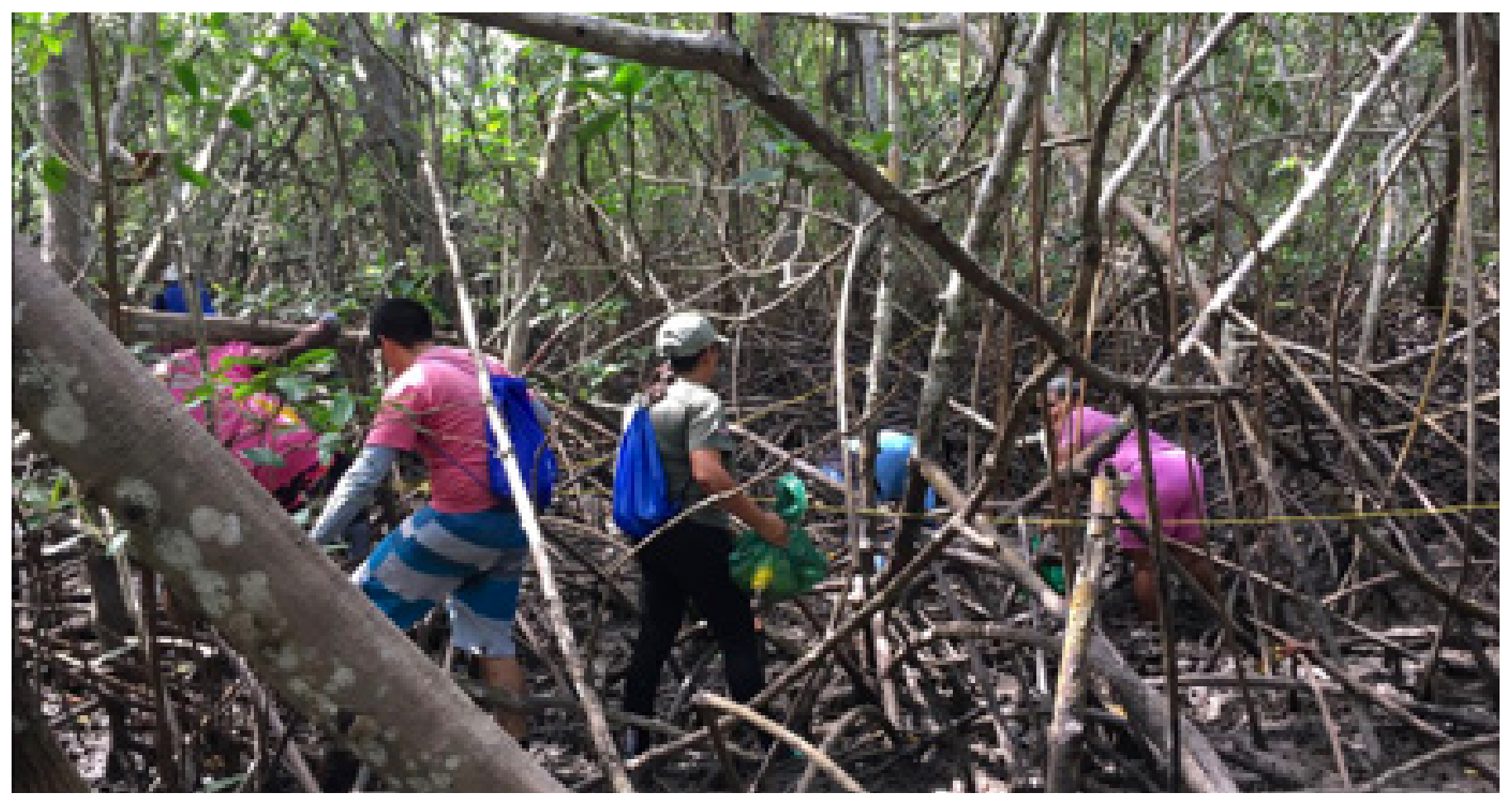

Figure 2: Gathering of molluscs, Ubicación de Chomes, Puntarenas, Costa Rica.

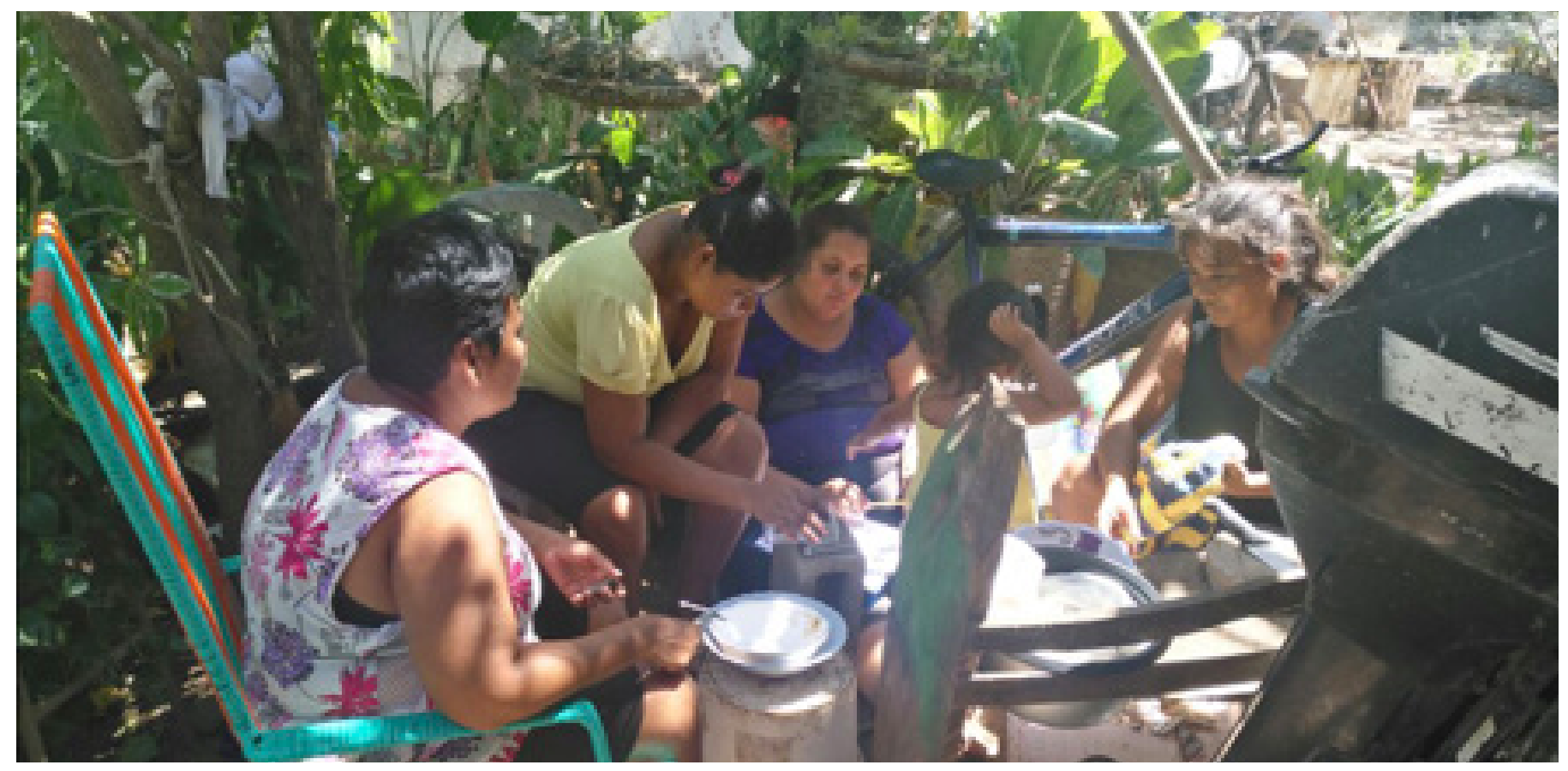

Figure 3: Women from CoopeMolusChomes R.L measuring the molluscs as part of the participatory management plan developed. 


\section{PACIFIC}

\section{Regional experts}

FK experts in the Pacific region are considered to include the following:

\begin{tabular}{|c|c|c|c|}
\hline Name & Country & Organisation & Contact Details \\
\hline Kevin Chang & Hawai'i & $\begin{array}{l}\text { Co-Director } \\
\text { Kua'āina Ulu ‘Auamo }\end{array}$ & $\begin{array}{l}\text { Cell: (808) 672-2545 } \\
\text { Email: kevin@kuahawaii.org } \\
\text { www.kuahawaii.org }\end{array}$ \\
\hline Dr Rosie Cooney & Australia & $\begin{array}{l}\text { Honorary Senior Fellow, Fen- } \\
\text { ner School of Environment and } \\
\text { Society, Australian National } \\
\text { University. Former Chair of } \\
\text { IUCN SULI }\end{array}$ & $\begin{array}{l}\text { Email: } \\
\text { Rosie.Cooney@anu.edu.au }\end{array}$ \\
\hline Winston Cowie & $\begin{array}{l}\text { New Zealand / United } \\
\text { Arab Emirates }\end{array}$ & $\begin{array}{l}\text { Marine Policy Manager } \\
\text { Environment Agency - Abu } \\
\text { Dhabi, } \\
\text { United Arab Emirates }\end{array}$ & $\begin{array}{l}\text { Email: } \\
\text { winston.cowie@ead.gov.ae }\end{array}$ \\
\hline Simon Foale & Australia & $\begin{array}{l}\text { Associate Professor, Depart- } \\
\text { ment of Anthropology, Archae- } \\
\text { ology and Sociology, School } \\
\text { of Arts and Social Sciences, } \\
\text { James Cook University, } \\
\text { Townsville, Queensland 4811, } \\
\text { Australia. }\end{array}$ & $\begin{array}{l}\text { Email: } \\
\text { simon.foale@jcu.edu.au }\end{array}$ \\
\hline Dr Hugh Govan & Fiji & $\begin{array}{l}\text { Senior Adjunct Fellow } \\
\text { University of the South Pacific } \\
\text { Independent Researcher }\end{array}$ & $\begin{array}{l}\text { Email: } \\
\text { hgovan@gmail.com }\end{array}$ \\
\hline Doug Jones & New Zealand & $\begin{array}{l}\text { General Manager - Kaupapa } \\
\text { Kura Taiao } \\
\text { Manahautū } \\
\text { Environmental Protection } \\
\text { Authority } \\
\text { New Zealand }\end{array}$ & $\begin{array}{l}\text { Phone: +64 } 44745412 \\
\text { Email: Doug.Jones@epa.govt.nz }\end{array}$ \\
\hline Shaelene Kamakaala & Hawai'i & $\begin{array}{l}\text { Coordinator Hawai'i State } \\
\text { Community Based Fisheries } \\
\text { (Previous Role). }\end{array}$ & $\begin{array}{l}\text { Email: } \\
\text { skamakaala@gmail.com }\end{array}$ \\
\hline Solomon Kaho'ohalahala & Hawai'i & Kua'āina Ulu ‘Auamo & Email: maunalei.ahupuaa@gmail.com \\
\hline Jeff Kinch & Papua New Guinea & $\begin{array}{l}\text { Principal of the National } \\
\text { Fisheries Authority's Nation- } \\
\text { al Fisheries College and the } \\
\text { Nago Island Mariculture and } \\
\text { Research Facility in the New } \\
\text { Ireland Province. }\end{array}$ & $\begin{array}{l}\text { Email: } \\
\text { jkinch@fisheries.gov.pg }\end{array}$ \\
\hline Te Taiawatea Moko-Mead & New Zealand & $\begin{array}{l}\text { Senior Policy Analyst } \\
\text { Te Ohu Kaimoana } \\
\text { New Zealand }\end{array}$ & $\begin{array}{l}\text { Email: } \\
\text { TeTaiawatea.Moko-Mead@teohu.maori.nz }\end{array}$ \\
\hline Mehana Vaughan & Hawai'i & $\begin{array}{l}\text { Associate Professor Depart- } \\
\text { ment of Natural Resources and } \\
\text { Environmental Management } \\
\text { University of Hawai'i }\end{array}$ & $\begin{array}{l}\text { Email: } \\
\text { mehana@hawaii.edu }\end{array}$ \\
\hline Charles Young & Hawai'i & Kua'āina Ulu ‘Auamo & $\begin{array}{l}\text { Email: } \\
\text { youngc042@hawaii.rr.com }\end{array}$ \\
\hline
\end{tabular}




\section{Case study - Mo'omomi, Moloka'i, Hawai'i, United States of America FK in policy and management planning}

This case study is a good example of FK being utilized in policy development and management planning - management measures for fish, limpet, crustacean, and seaweed species.

Fishery type: Nearshore subsistence fishery.

No. of fishing communities: One.

Vessel types: Small motorised vessels.

Fishing methods and species: Gathering by hand. Hook and line. Spearfishing. Net fishing. Species include: a'ama crab (Rock Crabs, Grapsus tenuicrustatus, Pachygrapsus plicatus), 'a'laihi (menpachi/Squirrel fish, Holocentidae spp.), akule (Bigeye Scad, Selar crumenopthalmus), enenue, nenue (Gray Chub/ Rudderfish, Kyphosus biggibus), he'e (octopuses, Octopoda spp.), kole (Goldenring surgeonfish, Ctenochaetus strigosus), kumu (Whitesaddle Goatfish, Parupeneus porphyreus), limu (Varieties of seaweeds), moi (Pacific Threadfin, Polydactylus sexfilis), 'opihi (Limpets, Patellidae spp.), pa'akai (sea salt), pāpio (Jacks, Carangids), uhu (Parrotfishes, Scarids), wekea (White Goatfish, Mulloidichthy flavolineatus), weke'ula (Yellowfin Goatfish, Mulloidichthys vanicoensis), other Goatfishes (Mullidae spp.), ula (Lobster, Panulirus penicillatus), variety of Surgeonfishes (Acanthuridae spp.), and variety of Wrasses (Labridae spp.).

Method of obtaining FK: The Hui Mālama o Mo'omomi (Hui) community group and subsistence fishing families holds generational FK and has been the catalyst in the creation of a de-facto Community Based Subsistence Fishing Area (CBSFA) on the island of Moloka'i, Hawai'i. At a fundamental level, FK is obtained and passed down by holding true to thinking like our ancestor's -- maintaining relationships with each species; understanding interconnectivities of other species, the environment, etc.; understanding how you use/gather/treat a resource will dictate what and in what quantities a food species will be available now and into future generations of each species; and understanding other factors of elimination such as natural death, predators, disease, etc. At the next level of FK is having an ability to develop formulas to assess population sustainability for each species, based upon the fundamental knowledge known of a species and its connectivities. The Hui's proposed management plan is pending public hearings and adoption. Their practices and efforts catalyzed the State of Hawai'i law that created CBSFAs and a movement for community-based natural resource management in the early $90 \mathrm{~s}$. This movement is part of a greater effort to document and enliven traditional Hawaiian practices, governance, fishing knowledge and values. It inspired the first de jure CBSFA in Hawaiian history in Hā'ena, Kaua'i and inspired the efforts of many rural Native Hawaiian communities across the state. In Mo'omomi FK is held by subsistence fishers in the community who have assisted in setting a Code of Conduct informed by cultural practice, setting the take and size limits for important subsistence species in need of management, among other things such as dive programs for the next generation of lawai'a pono (fishers who understand and practice cultural management as part of their gathering practices).
Aichi Target achievement. Target 6 .

Key findings:

- Fisheries rules for the CBSFA have been informed by the Hui Mālama o Mo'omomi's generational observations and scientific studies they continue to conduct on species life cycles and population health, as well as by the practices, understandings, and FK of Mo'omomi's fishing families.

- Recent baseline surveys led by government agencies (which utilized independent randomly selected survey points), showed high abundance of total biomass in relation to other similar coastlines on other islands, with lower abundance for FK identified species that require management solutions such as Kole, Kumu, and Uhu.

- The scientific data corroborated the FK and observations that three additional species (in addition to lobster, moi, and opihi) were overexploited and required management solutions.

- These two key data streams - FK and scientific study - were key in setting size and take limits for the Mo'omomi community on the island of Moloka'i, Hawai'i.

\section{References:}

- Mac Poepoe. Hui Mālama o Mo'omomi.

- Presentation. Shaelene Kamakaala. Solomon Kaho'ohalahala. Kevin Chang. Mehana Vaughan. Charles Young. IUCN Conference: Communities Conservation \& Livelihoods. Halifax, Canada.

- The Hui Mālama o Mo‘omomi Community Based Subsistence Fishing Webpage:

https://www.mauinui.net/hui-malama-o-moomomi.html

- Kua'āina Ulu 'Auamo (KUA), a US 501c3 non-profit organization that facilitates networks of community-based natural resource management efforts in Hawai' $i$ www.kuahawaii.org

- Friedlander AM, Donovan MK, Stamoulis KA, et al. Humaninduced gradients of reef fish declines in the Hawaiian archipelago viewed through the lens of traditional management boundaries. Aquatic Conserv: MarFreshw Ecosyst. 2017;1-12. https://doi. org/10.1002/aqc.2832

\section{FK programme contributors:}

- Kevin Chang, Co-Director, Kua'āina Ulu ‘Auamo (KUA).

Contact: kevin@kuahawaii.org

- Shaelene Kamaka'ala, Community Based Subsistence Fisheries Coordinator, State of Hawai'i (Previous). Contact: skamakaala@gmail.com

- Solomon Kaho'ohalahala, Maunalei Ahupua'a Restoration Project, E Alu Pū Network Council, Kua'āina Ulu 'Auamo. Contact: maunalei.ahupuaa@gmail.com

- Mehana Vaughan, Associate Professor, University of Hawai'i.

Contact: mehana@hawaii.edu

Charles Young, Kama'āina United to Protect the 'Āina (KUPA), E

Alu Pū Council Member,

- Kua'āina Ulu ‘Auamo.

Contact: youngc042@hawaii.rr.com

Case study location: Mo'omomi, Moloka'i Island, Hawai'i, United States of America. 


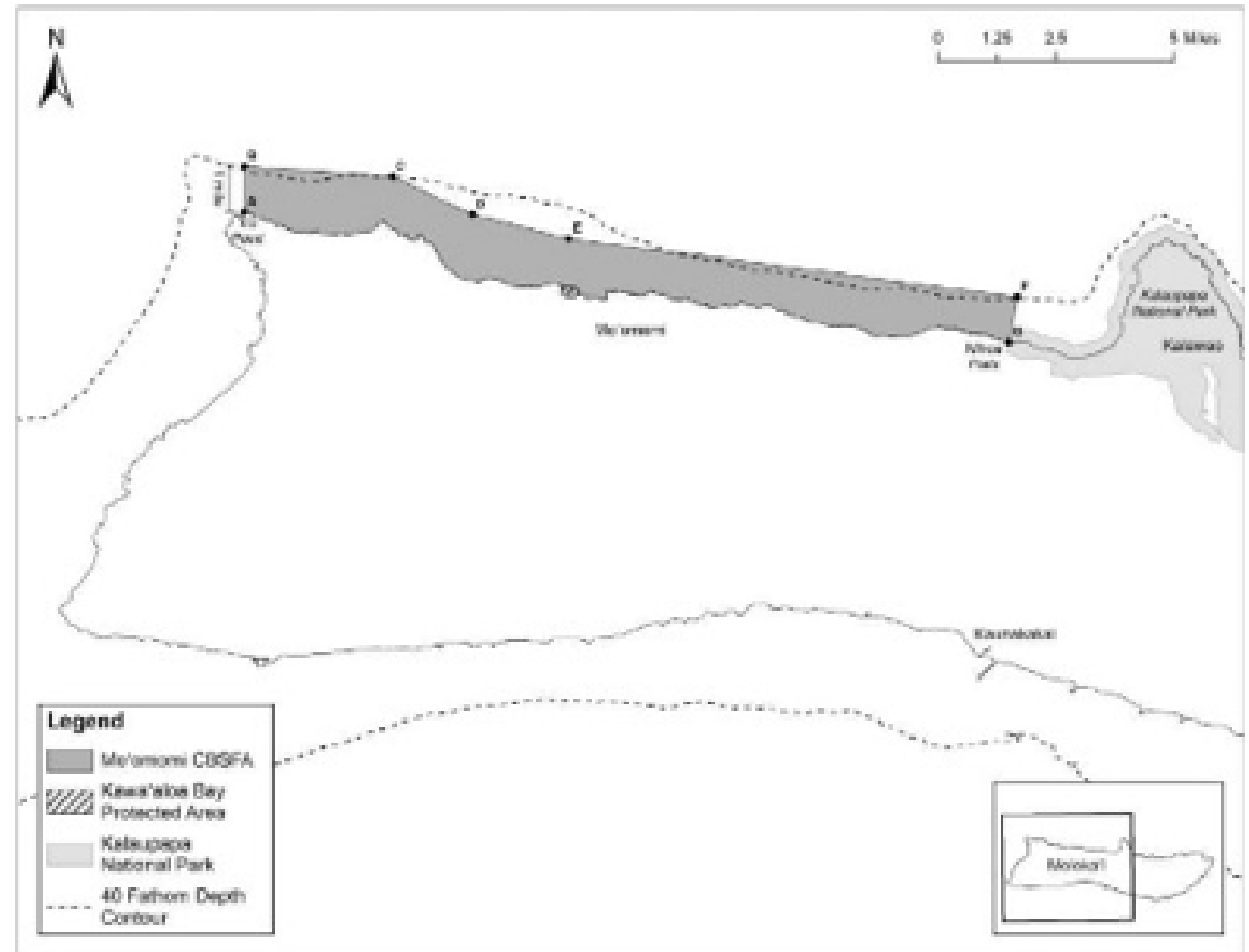

Figure 1: Proposed Boundary for the Mo'omomi, Moloka'i CBSFA by Hui Mālama o Mo'omomi and Department of Land and Natural Resources, Division of Aquatic Resources (April 2018).

\section{FISHERS' KNOWLEDGE}

$\checkmark$ General Declines in certain species

$\checkmark$ Majority local fishers agreements for 2 bag limit

Identified unsustainable method using lobster nets
TRADITIONAL SCIENCE

Hui Mălama o Mo'omomi Traditional Science
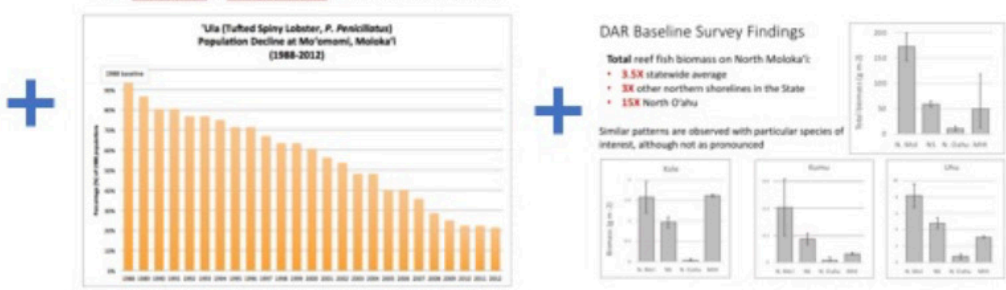

EFFECTIVE FISHERIES MANAGEMENT STRATEGIES

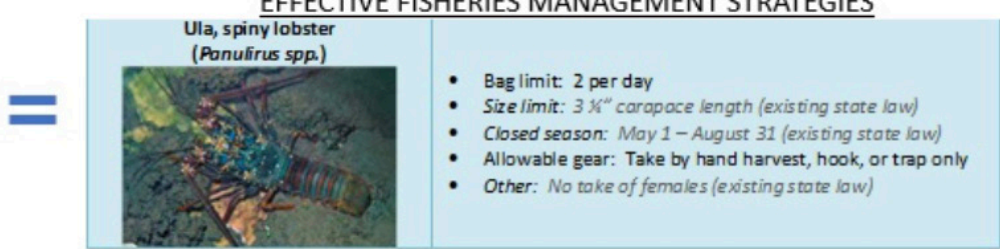

Figure 2: How FK, traditional science \& state government studies 'modern science' have informed effective fisheries management strategies (Mo'omomi, Moloka'i, Hawai'i). 


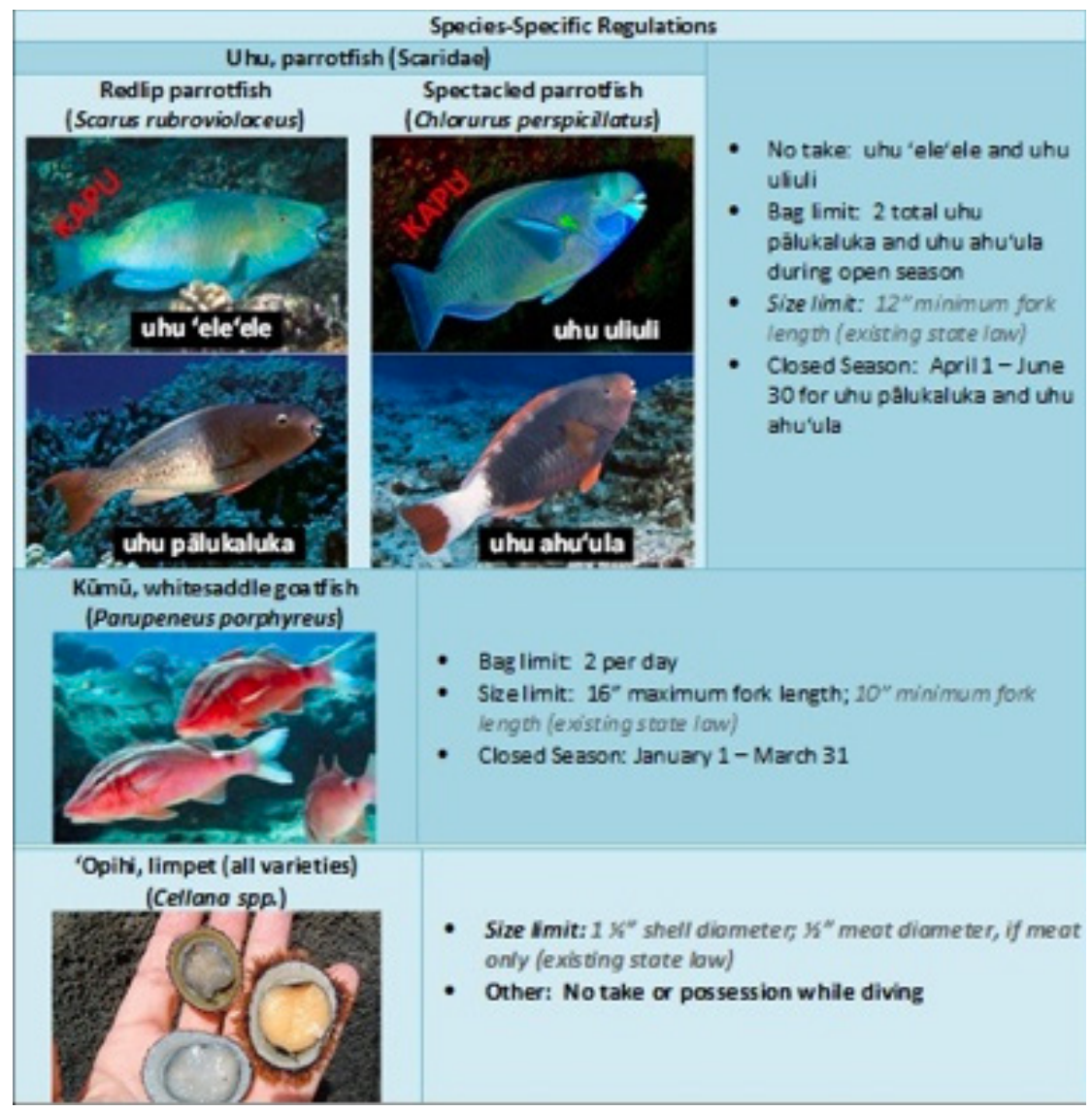

Figure 3: FK and traditional science incorporated in the development of take limits (Mo'omomi, Moloka'i, Hawai'i).

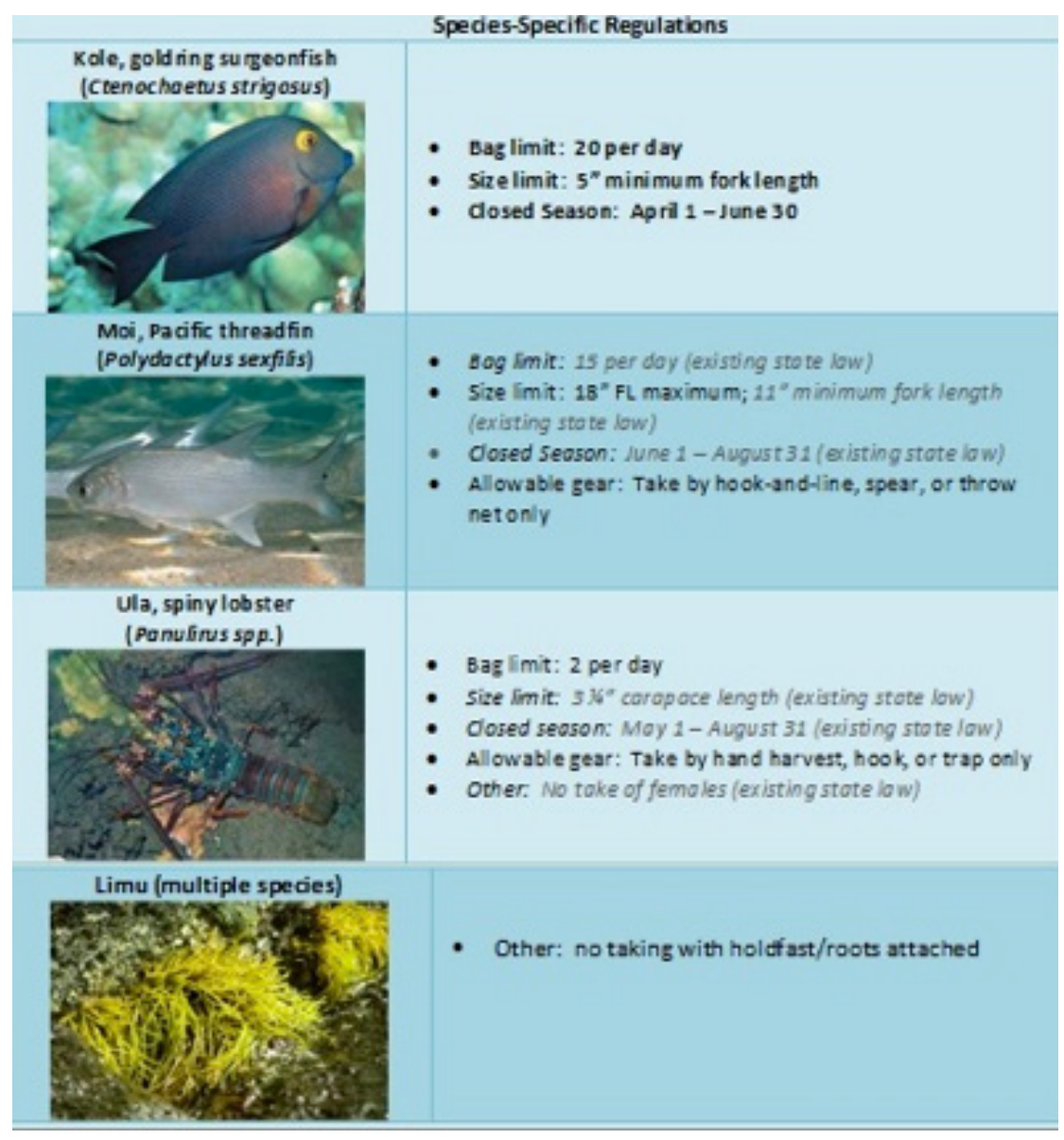

Figure 4: FK and traditional science informed the development of take limits (Mo'omomi, Moloka'i, Hawai'i). 


\section{Case study - Local Managed Marine Areas Guidelines, Melanesia FK in Local Marine Area Management - Guidelines}

This case study presents Guidelines developed for the Pacific and South East Asia (with universal application) on FK in the development of Local Managed Marine Areas (LMMA).

Fishery type: Small scale recreational fisheries

No. of fishing communities: Many across the Pacific and South East Asia: Cook Islands; Fiji; Hawaii; Indonesia; Malaysia; Palau; Papua New Guinea; Philippines; Solomon Islands; Vietnam.

Vessel types: Small canoe powered and motorised vessels.

Fishing methods and species: Multiple methods and multiple species across 10 countries.

Method of obtaining FK: The authors' experience in assisting in setting up multiple Local Managed Marine Areas across the Pacific and South-east Asia.

Aichi Target achievement. Target 6 and 18.

Key findings:

- This Guideline presents step-by-step guidelines for setting up an LMMA and provides simple and discrete community organizing activities and 'tools' that are used to facilitate and guide communities, local leaders, and their conservation partners through the process of creating and managing an LMMA.

- While there is considerable literature on setting up community marine resource management plans, methods to assist communities develop monitoring plans and techniques are less well-developed. This guideline attempts to begin to address this.

- These activities and tools are generally used in some sort of sequence as part of community resource management process, which usually requires a partnership of some five to ten years before significant and long-term results are expected.

- The guideline has been written principally with coastal community members and leaders in mind, as well as the partner organizations that support them and their local management efforts. Partners can include government agencies, nongovernment organizations, universities and other interested parties.

- The guideline may also be useful for national decision makers who are considering using LMMAs, conservation scientists and researchers who are working to learn how to improve the practice of marine conservation, donor organizations who support LMMAs and marine conservation work, and students, professors or others in academia.

- There is also detailed and useful information on how to set up no-take areas, followed by information on biological monitoring. This manual is helpful to anyone wishing a better understanding of how to carry out effective community-based management of the coastal area and many of the activities could also be adapted for different situations.

- The guideline is structured around four general phases taken along the path of LMMA establishment and use:

o Phase One - Initial Assessment;

o Phase Two - LMMA Design and Planning;

o Phase Three - Implementation of Community-Based Adaptive Management; and

o Phase Four - Ongoing Community Based Adaptive Management.

\section{References:}

- Govan, H., Aalbersberg, W., Tawake, A., and Parks, J. (2008). Locally-Managed Marine Areas: A guide for practitioners. The Locally-Managed Marine Area Network.

- http://Immanetwork.org/resources/tools/

- Govan, H. et al. 2009. Status and potential of locally-managed marine areas in the South Pacific: meeting nature conservation and sustainable livelihood targets through wide-spread implementation of LMMAs.

- Govan, H., Alifereti Tawake, Kesaia Tabunakawai, Aaron Jenkins, Antoine Lasgorceix, Erika Techera, Hugo Tafea, Jeff Kinch, Jess Feehely, Pulea Ifopo, Roy Hills, Semese Alefaio, Semisi Meo, Shauna Troniak, Siola'a Malimali, Sylvia George, Talavou Tauaefa, Tevi Obed. 2009. Community Conserved Areas: A review of status \& needs in Melanesia and Polynesia. ICCA regional review for CENESTA /TILCEPA /TGER/IUCN/ GEF-SGP.

- Local Managed Marine Area Network Website: http://lmmanetwork.org/

FK programme contributors:

- Dr Hugh Govan, Senior Fellow, University of the South Pacific

- Email: hgovan@gmail.com

- Jeff Kinch, Principal - National Fisheries Authority, Papua New Guinea.

•Email: jkinch@fisheries.gov.pg

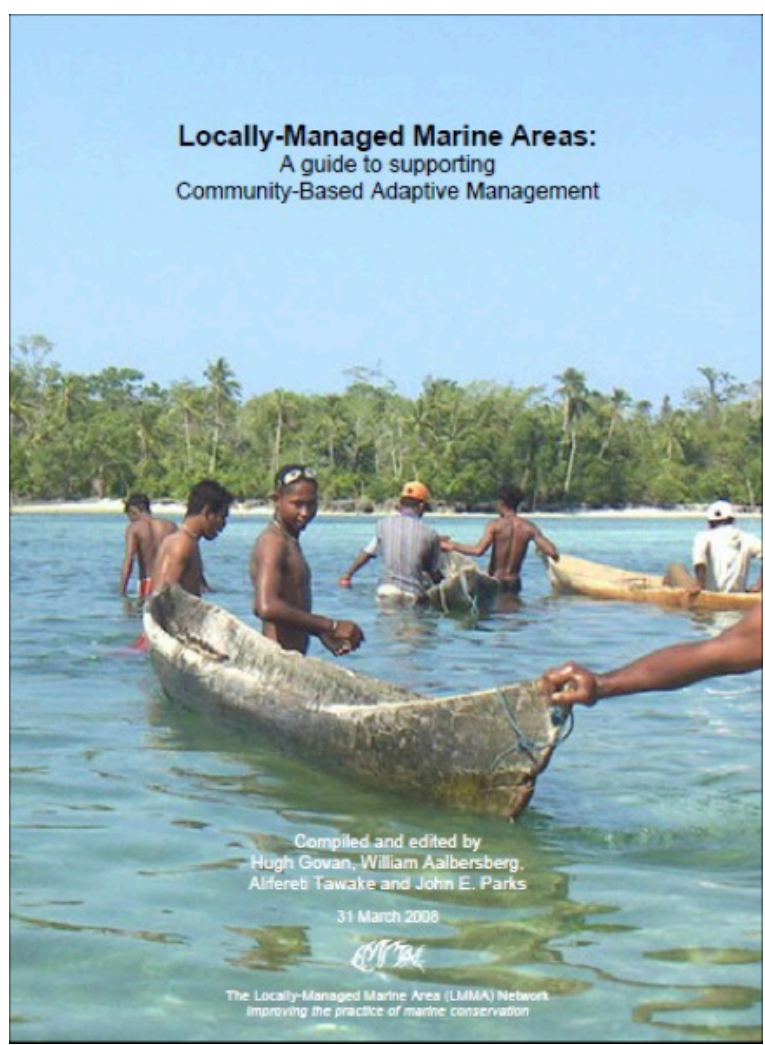

Figure 1: LMMA Guideline Cover (2008) 


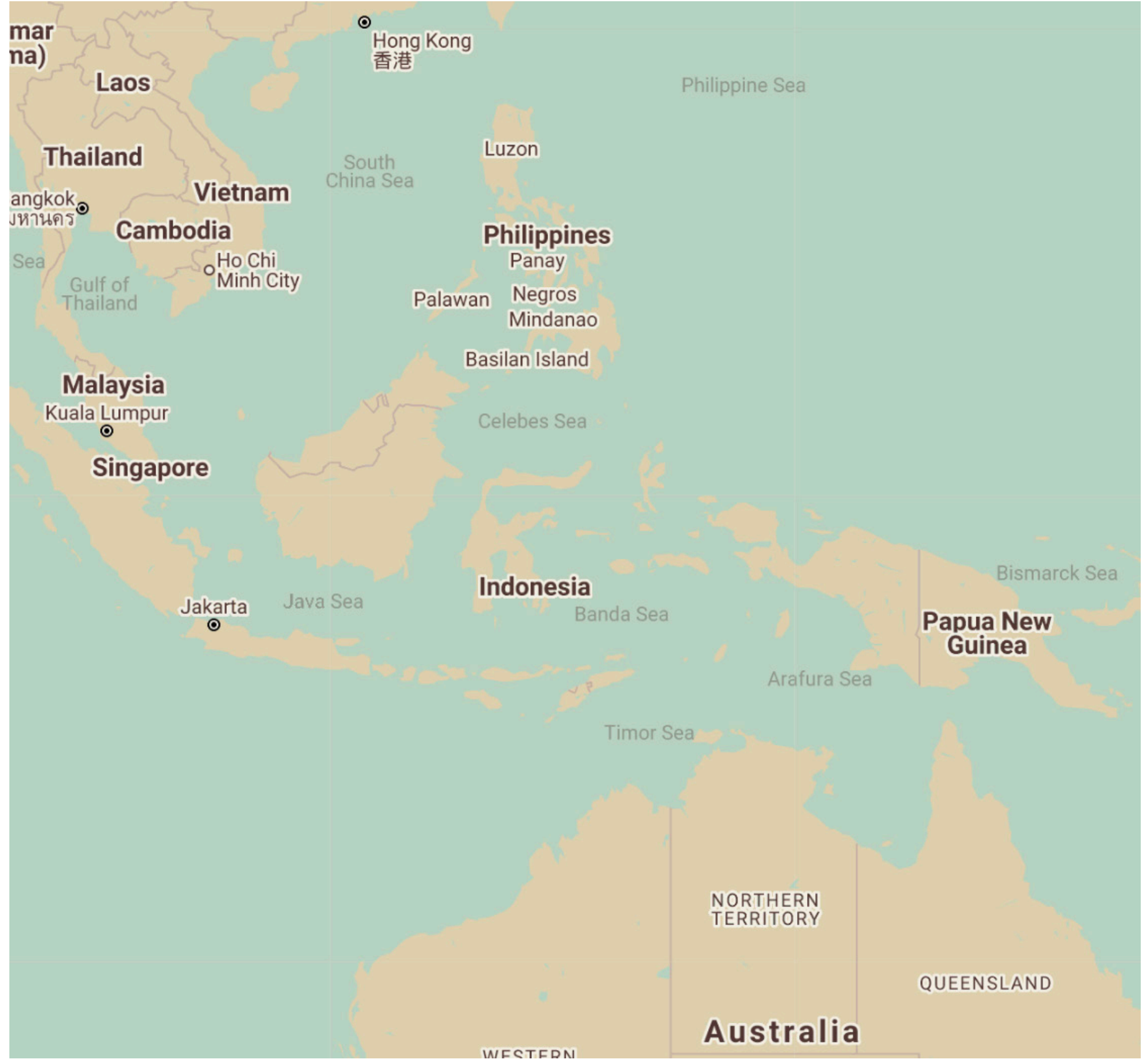

Figure 2: Map of Melanesia, Pacific. 


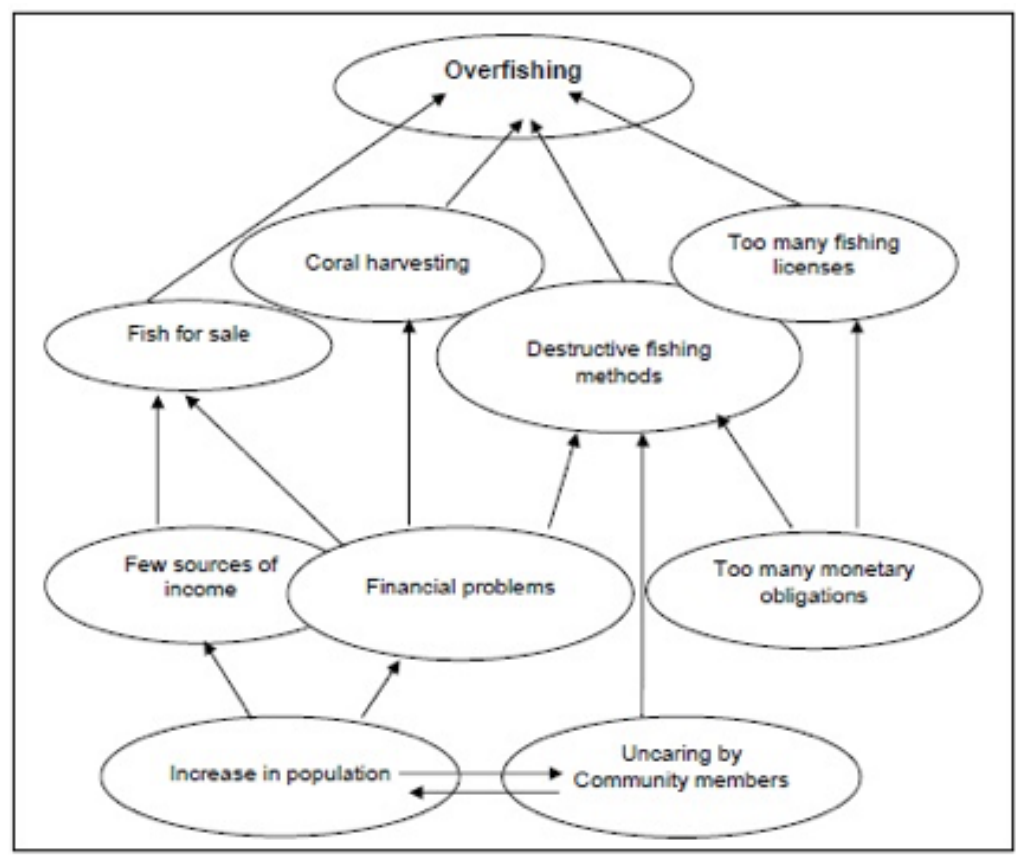

Figure 3: An example of a Problem Tree from Fiji, LMMA Guideline.

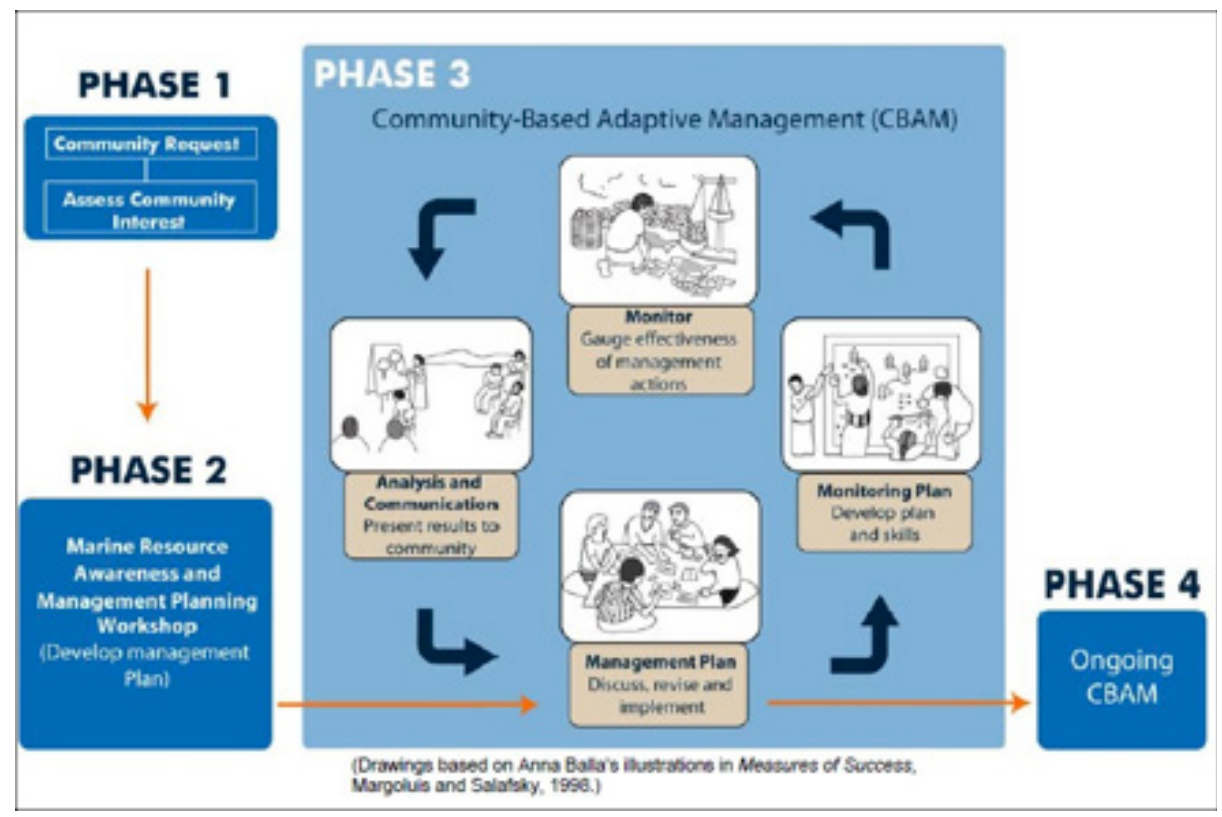

Figure 4: The four phases of LMMA establishment; LMMA Guideline. 


\section{Case study - Aotearoa / New Zealand FK in policy and management planning}

This case study is a good example of FK being utilized in successful community based management, policy development and management planning - take limits for fish species in localized areas.

Fishery type: Small scale recreational fishery.

No. of fishing communities: Many.

Vessel types: Small motorised vessels.

Fishing methods and species: Hook and line. Spearfishing. Diving. Multiple species.

Method of obtaining FK: The tangata whenua (Maori people of the land with historic authority in a particular place) manage their fisheries under customary fishing regulations and the New Zealand Fisheries Act in a way that best fits their local practices. The knowledge is held by the community and assisted in setting the take and size limits for certain species.

Aichi Target achievement. Target 6 and Target 18.

\section{Key findings:}

- The rights and interests of tangata whenua (Maori people of the land) are provided for under the Fisheries Act 1996 (Fisheries Act) and the Treaty of Waitangi (Fisheries Claims) Settlement Act 1992 (Settlement Act).

- The Settlement Act requires the Minister to recognise and provide for non-commercial customary food gathering by Māori and the special relationship between tangata whenua and important customary food gathering areas.

- The Minister has the ability to make provisions to provide for customary fishing. These include the establishment of mataitai reserves and taiapure, which are areas in which tangata whenua can undertake management of fisheries resources.

- The Māori Fisheries Act 2004 sets in place a framework to allocate the 1992 Treaty of Waitangi Deed of Settlement to Mandated Iwi Organisations. This allows fisher knowledge of individual Mandated Iwi Organisations to influence decisions of commercial activity and policy settings,and take a multi-generational approach to management.

- Forty-two mataitai reserves and 10 taiapure have been established.

- To date, over 200 kaitiaki have been appointed by tangata whenua to manage customary food gathering.

- In addition, commercial fishing has been prohibited in some areas of Stewart Island and Chatham Islands to provide for customary fishing.

- Under the New Zealand Fisheries Act there are a number of ways in which FK can be utilised to establish different types of management areas and reserves. These include: o Mātaitai reserves - recognise and provide for traditional fishing through local management. They allow customary and recreational fishing but usually don't allow commercial fishing.

o Taiāpure (local fisheries) - estuarine or coastal areas that are significant for food, spiritual, or cultural reasons. They allow all types of fishing and are managed by local communities.

o Temporary closures and restrictions on fishing methods
(Sections 186A and 186B closures) - areas that are temporarily closed to fishing or certain fishing methods.

o Fisheries bylaws - changes to fisheries management rules made by tangata whenua or tangata kaitiaki/tiaki (guardians) for their Crown settlement area or mātaitai reserve.

Under the Fisheries Act, the Minister is required to recognise and provide for the input and participation of tangata whenua into a range of fisheries management processes, and to have particular regard to kaitiakitanga when making decisions.

- Once a taiāpure is established, for example, the local Māori community nominates people for the management committee. The committee is appointed by the Minister of Fisheries, after consultation with the Minister for Māori Development. The management committee can provide recommendations to the Minister of Fisheries for regulations (under the Fisheries Act) to manage taiāpure fisheries, relating to:

o Species fished;

o Fishing seasons;

o Sizes and amounts of fish;

o Fishing areas;

\section{References:}

- New Zealand Ministry of Primary Industries - Law and Policy

o https://www.mpi.govt.nz/law-and-policy/legislation/

- New Zealand Ministry of Primary Industries o https://www.mpi.govt.nz/law-and-policy/maoricustomary-fishing/managing-customary-fisheries/

- New Zealand Ministry of Primary Industries National Aquatic Biodiversity Information System o https://maps.mpi.govt.nz/templates/ MPIViewer/?appid=96f54e1918554ebbaf17f965f0d961e1 o https://www.fisheries.govt.nz/law-and-policy/maoricustomary-fishing/managing-customary-fisheries/ customary-fisheries-management-areas/

- New Zealand Ministry of Primary Industries, Guidelines for mataitai reserve applications. Download the guidelines for mātaitai reserve applications

- Tauranga City Council. Mauao Reserve Management Plan. o https://www.tauranga.govt.nz/Portals/0/data/council/ plans/files/mauao_reserve_management.pdf

\section{FK programme contributors:}

- Doug Jones, General Manager, Kaupapa Kura Taiao Mana Manahautū, Environmental Protection Authority, New Zealand

- Contact: Doug.Jones@epa.govt.nz

- Te Taiawatea Moko-Mead, Senior Policy Analyst, Te Ohu Kaimoana, New Zealand.

- Contact: TeTaiawatea.Moko-Mead@epa.govt.nz

- Winston Cowie. Marine Policy Manager. Environment Agency-Abu Dhabi. Contacts: winston.cowie@ead.gov.ae

Case study location: Forty-two mataitai reserves and 10 taiapure areas across New Zealand. These can be accessed at the New Zealand Ministry of Primary Industries National Aquatic Biodiversity Information System. 


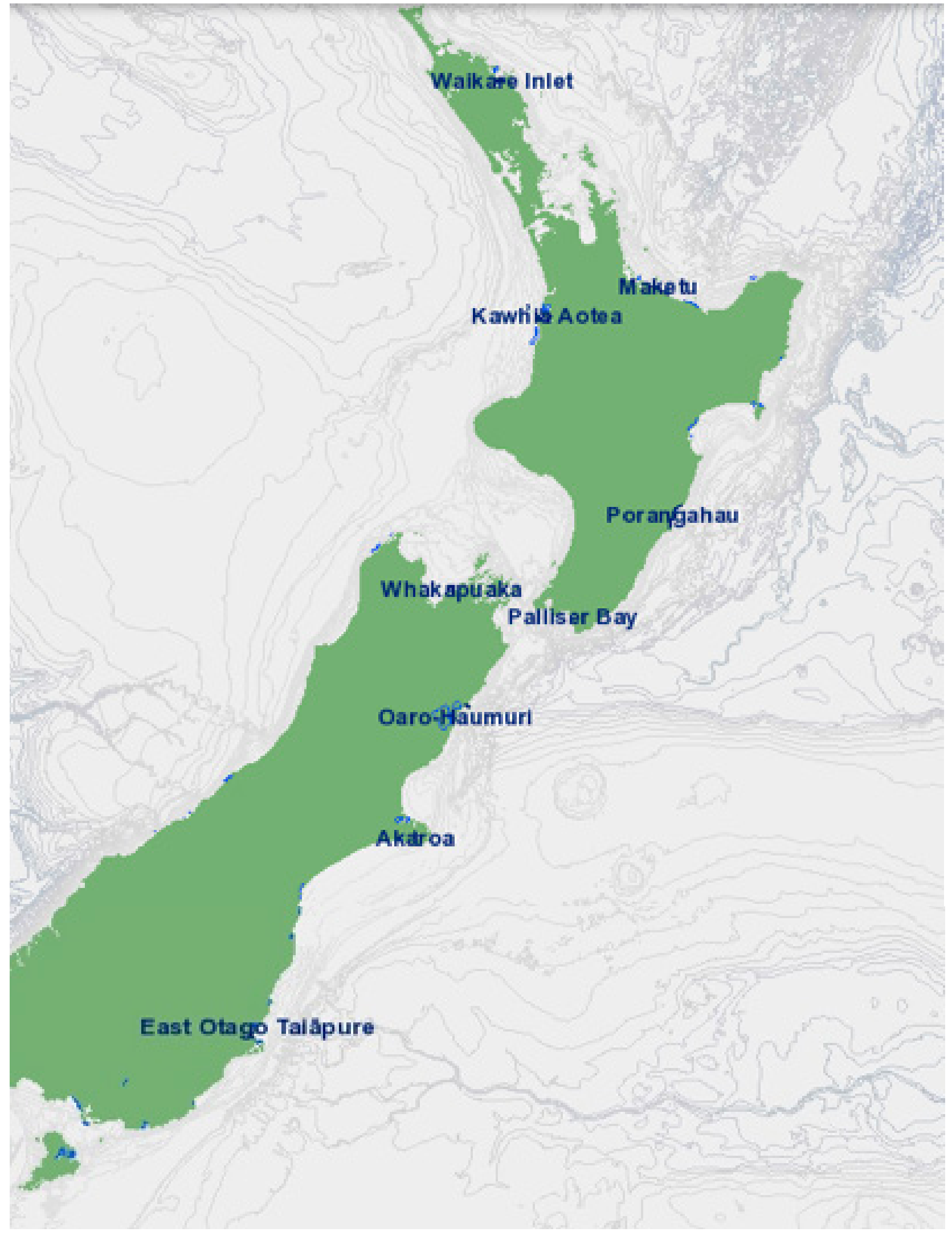

Figure 1: Map of mataitai and taiapure reserves in New Zealand (presented in blue). 


\section{Case study - Southern North Island, Aotearoa / New Zealand FK in non-governmental organisation policy lobbying}

This case study is a good example of FK being utilized in policy development to impact the Total Allowable Commerical Catch of Crayfish / Rock lobster in a regional fishery.

Fishery type: Commercial and recreational fishery for Crayfish / Rock lobster.

No. of fishing communities: Numerous communities in the Hawkes Bay, Wairarapa, Wellington, Kapiti and Taranaki regions. Vessel types: Motorised vessels - fishing commercially and recreationally.

Fishing methods and species: Crayfish pots in the commercial fishery.

Method of obtaining FK: FK was freely given by Tangata Whenua, fishers and lobster exporters. This information was used by over a third of the commercial sector to reject a proposed $20 \%$ increase to the Total Allowable Commercial Catch. Instead Tangata Whenua (the indigenous people of the region) and fishers chose to maintain the status quo based on what they were seeing in the fishery and not on model outputs.

Aichi Target achievement. Target 6 and 18 .

Key findings:

- The CRA4 fishery is managed using a management procedure which uses fishers Catch Per Unit of Effort (CPUE) to drive management decision making.

- Based on model outputs it was recommended that the Total Allowable Commerical Catch be increased by $20 \%$.

- Tangata Whenua and fishers along with exporters compared their experiences and aspirations to the management procedure and thought that agreeing with the $20 \%$ increase was not in the best interests of the fishery and Tangaroa (the god of the sea in Māori culture). Essentially, tangata whenua wanted the Minister to sideline the 'best available scientific information' in favour of their experiences and aspirations for the fishery.

- This was reflected in supplementary advice and lobbying to the Minister of Fisheries.
- The result was that the Minister of Fisheries rejected the proposed $20 \%$ increase in favour of maintaining status quo.

- This Case Study is an example of how FK was used to ground truth management procedures and demonstrates that local knowledge can be used as a key input to fisheries policy change.

References:

- Te Ohu Kaimoana / The Māori Fisheries Trust: https://teohu.maori.nz/ikanet/

FK programme contributors:

- Kim Drummond, Kurae Moana, Te Ohu Kaimoana, The Māori Fisheries Trust, Aotearoa / New Zealand:

Contact: Kim.Drummond@teohu.maori.nz

- Monique Holmes, Tai Pari, Te Ohu Kaimoana, The Māori Fisheries Trust, Aotearoa / New Zealand. Contact: monique.holmes@teohu.maori.nz

- Te Taiawatea Moko-Mead, Senior Policy Analyst, Te Ohu Kaimoana (The Māori Fisheries Trust), Aotearoa / New Zealand

Contact: TeTaiawatea.Moko-Mead@teohu.maori.nz

Case study location: Southern North Island, Aotearoa / New Zealand. This includes: Hawkes Bay, Wairarapa, Wellington, Kapiti and Taranaki regions. 


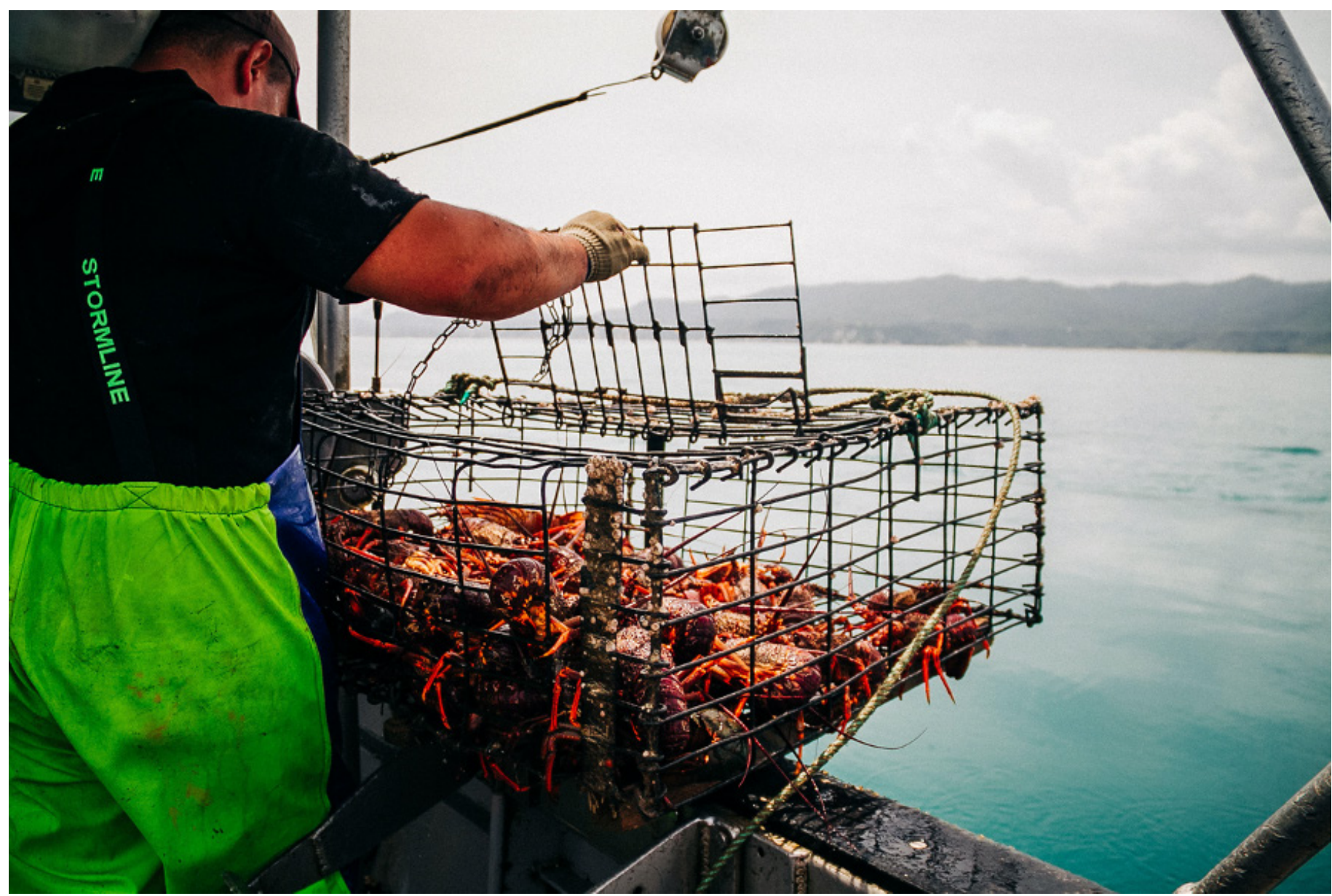

Figure 1: Map of Crayfish Fishery Area 2, Auckland and Northland, New Zealand

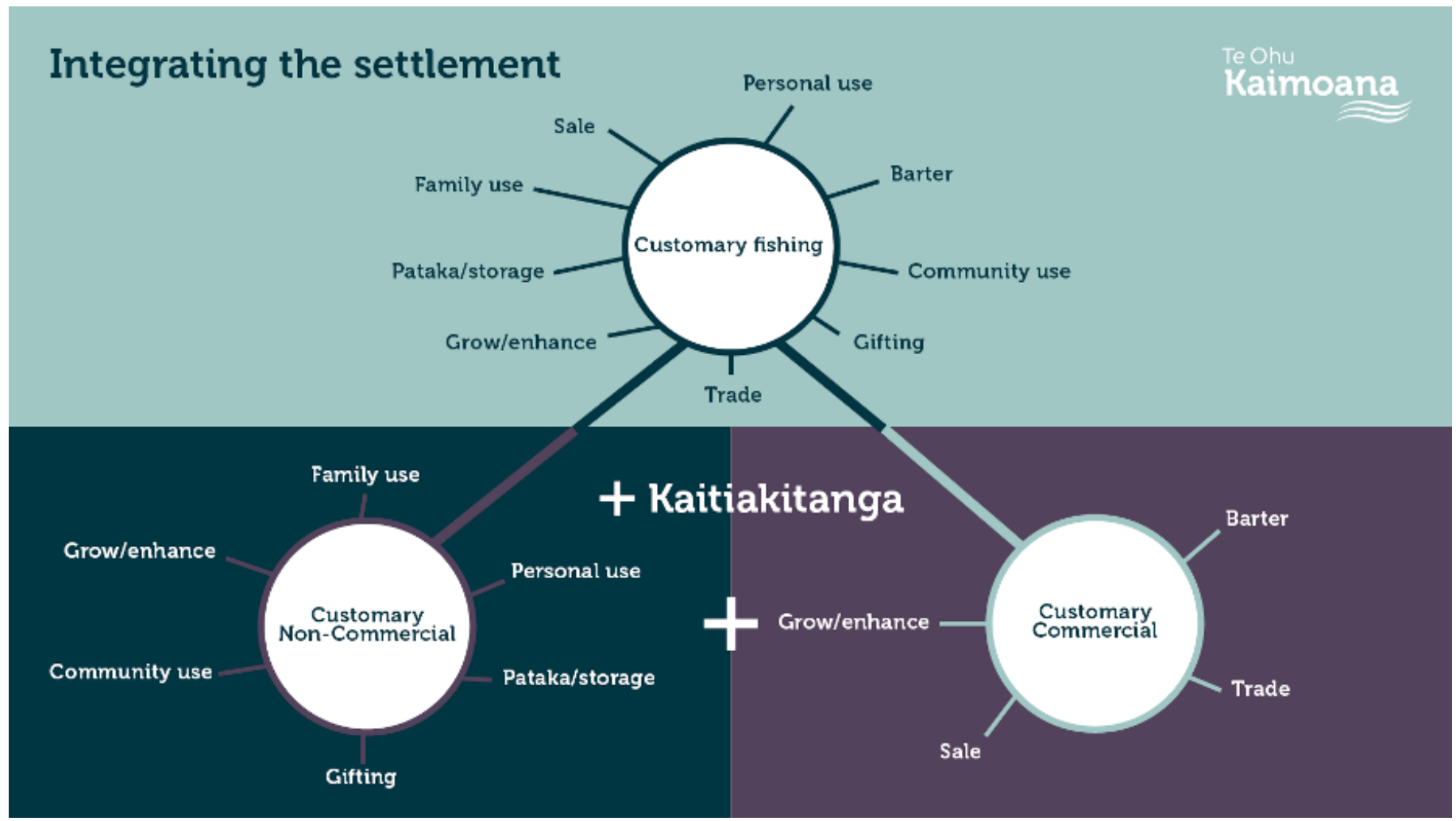

Figure 2: How the Fisheries Settlement has been integrated in Aotearoa /New Zealand. 
Case study - Aotearoa / New Zealand

FK of Māori (Indigenous peoples in

Aotearoa) used to enhance fisheries

management

and exercise customary rights

This case study is a good example of how fisher knowledge of indigenous peoples and technological innovation has been used to enhance fisheries management while enabling indigenous peoples to exercise their customary (traditional) fishing rights.

Fishery type: Customary fishing

- Customary fisheries are recognised fishing rights of Māori for traditional and customary practices - for example, traditional management of a fishery. Customary fisheries can include the following:

- non-commercial food gathering, including for personal and community use.

- commercial food gathering through exercise of customary fishing rights through the quota management system

- harvest and storage for community use, using modern technology through pātaka kai arrangements with commercial fishing companies

- These rights have been given expression through New Zealand's Fisheries Act 1996 as a result of the the Fisheries Deed of Settlement, which resolved Treaty claims to customary fisheries in 1992.

No. of fishing communities: All Māori communities in Aotearoa/ New Zealand

Vessel types: All vessels - fishing customary non-commercial.

Fishing methods and species: All methods and species.

Method of obtaining FK: Māori communities manage their non-commercial fisheries under legislation and regulations administered by Fisheries New Zealand, the central government agency responsible for fisheries. Specifically the:

- Fisheries Act 1996;

- Fisheries (Kaimoana Customary Fishing) Regulations 1998;

- South Island Customary Fishing Regulations 1999;

- Te Arawa Lakes (fisheries) Regulations 2006; and

- Waikato-Tainui (Waikato River Fisheries) Regulations 2011.

In practice, customary fishing carried out under these provisions is consistent with the tikanga and kawa (protocols) of the people of that place. The mātauranga (knowledge) is held by the community and assisted in setting the take and size limits for certain species.

Aichi Target achievement. Target 6, 18 and 19.

\section{Key findings:}

- Customary fishing is the practice of collecting and providing kai (food). These practices are based on traditional and contemporary knowledge unique to people and place. The ability to gather kai (food) in this way is based on generations-old rights established by the fishing practices of one's ancestors. Most recently these practices have been provided for in New Zealand law through legislation, regulation and case law.

- Today, customary non-commercial fishing in Aotearoa New Zealand must be subject to a customary fishing permit. These permits may be issued to individuals and groups of Māori to collect and provide kai to their whānau (family) for personal purposes or to the wider community for tangihanga (funerals), for hui (meetings) and celebrations.

- Customary permits are issued by representatives appointed as 'Tangata Kaitiaki/Tiaki' under the Kaimoana Customary Fishing regulations 1998, being a member of the tangata whenua, tangata whenua organisation or their notified representative.

- The Maori Fisheries Deed of Settlement (1992) and the subsequent Maori Fisheries Act 2004 established Te Ohu Kaimoana, a charitable Trust whose purpose is to advance and protect the interests of all Māori and their tribal groupings. Amongst many other important functions, Te Ohu Kaimoana created a customary fisheries management tool in 2009 known as lkaNet. This tool has been developed to enhance the capability of Tangata Kaitiaki/Tiaki and Iwi to manage their fisheries and exercise their non-commercial customary fishing rights.

- Tangata Kaitiaki/Tiaki identified a knowledge gap in that each was issuing authorisations (permits to fish) to the same body of water but were potentially unaware of what species and quantities others were permitting. Thus risking inadvertently putting pressure on the resources within their rohe (traditional area of interest).

- With the input of Tangata Kaitiaki/Tiaki, Iwi from Tauranga Moana - Te Ohu Kaimoana and WakaDigital developed IkaNet (and later redeveloped by FINNZ) to meet their needs consistent the regulatory requirements set out in legislation.

- IkaNet provides kaitiaki with the platform to generate digital harvest permits to allow people to fish for customary purposes, with catch effort information from within their iwi/ hapū (tribal/sub-tribal) boundaries (rohe). This information assists with fisheries management.

- IkaNet enables Tangata Kaitiaki/Tiaki to generate digital customary permits which can be emailed to community members via mobile, tablet or computer devices.

- This online system supports sustainability by providing real-time electronic reporting - based on permits granted over the rohe, kaitiaki can make informed decisions about what, where and how much they authorise. The information can also be used to respond to government policy on sustainability initiatives. All information is $100 \%$ Iwi owned.

- IkaNet provides kaitiaki with a facility to fill, manage and distribute pātaka kai with the help of a commercial fishing partner.

- IkaNet is a Fisheries New Zealand-approved platform. It's compliant with the regulations that provide for customary non-commercial fishing.

- IkaNet demonstrates how indigenous peoples can innovate to allow their communities to better exercise their customary rights, including through their commercial fishing partners. 
Acknowledgements:

No reira, ma tini ma mano kua rapa te wha (By many the work was accomplished). Therefore, we would like to acknowledge those who were instrumental in the development of IkaNet including; the past and present team at Te Ohu Kaimoana including Laws Lawson, Tania McPherson, John Willmer, Peter Van Kampen, as well as FINNZ (Mark Jones, Dan Martin and the team), WakaDigital (Aaron McCallion and Mark Berry) and Sam Tamarapa (Iwi innovator).

\section{Key contacts:}

- Peter van Kampen, Kairuruku Whakahaumanu Kaimoana (Shellfish Restoration Coordinator) at The Nature Conservancy.

- Te Taiawatea Moko-Mead, Senior Policy Analyst, Te Ohu Kaimoana (The Māori Fisheries Trust), Aotearoa / New Zealand.

Contact: TeTaiawatea.Moko-Mead@teohu.maori.nz

- Kim Drummond, Kurae Moana, Te Ohu Kaimoana, The Māori Fisheries Trust, Aotearoa / New Zealand:

Contact: Kim.Drummond@teohu.maori.nz
References:

- IkaNet Video: https://www.youtube.com/watch?v=wgMt8o4GavE

- IkaNet Video: https://www.youtube.com/watch?v=ntY2G6htSC4

- Te Ohu Kaimoana: https://teohu.maori.nz/ikanet/

- Deepwater Pataka: https://www.sealord.com/nz/newsroom/ sealord-iwi-collaborations-to-see-increased-returns/

- Fisheries (Kaimoana Customary Fishing) Regulations 1998, Aotearoa/New Zealand

- The South Island Customary Fishing Regulations 1999, Aotearoa/New Zealand

- Te Arawa Lakes (fisheries) Regulations 2006, Aotearoa/ New Zealand

- Waikato-Tainui (Waikato River Fisheries) Regulations 2011, Aotearoa/New Zealand

- Fisheries Act 1997, Aotearoa/New Zealand

- Ministry for Primary Industries: www.mpi.govt.nz/law-andpolicy/maori-customary-fishing/

- Te Hāo Tangaroa: https://teohu.maori.nz/te-ha-o-tangaroakia-ora-ai-taua/

- Māori Fisheries Deed of Settlement 1992 


\section{Case study - Solomon Islands \\ FK in an educational video series to raise awareness of overfishing in communities}

This case study is a good example of FK being captured using film and utilized in education, policy development and management planning.

Fishery type: Small scale commercial and recreational.

No. of fishing communities: Numerous communities in Solomon Islands and Papua New Guinea.

Vessel types: Small scale paddle powered canoes and motorised vessels.

Fishing methods and species: Multiple methods across multiple fisheries.

Method of obtaining FK: Interviews using film.

Aichi Target achievement. Target 6 and 18.

Key findings:

- A collaboration between James Cook University and documentary makers developed a fisheries science education DVD, called "Fish and People". Its main target audience is high school students in Solomon Islands and Papua New Guinea, with the principle of the tool being able to be used universally, tailored to fit species of a particular locality.

- The program is divided into five 12-minute episodes, each dealing with a different topic and all cohesively aligned to achieving greater educational awareness. A Teacher's Guide for each episode is part or the package.

- The scientific material covers a range of economically important local marine species, from highly resilient to highly vulnerable, and explains their life cycles and stock dynamics under conditions varying from over-fishing to sound management.

- The program clearly and graphically explains the science of fish stock dynamics using a combination of cutting-edge animations, world-class underwater photography, and carefully selected interviews with local marine scientists, conservation workers and village-based fishers.

- The work draws on a combination of the most recent anthropological research on local environmental knowledge in the target countries as well as the latest marine science - much of it produced at James Cook University - on the fishery biology and population connectivity of the relevant species.

\section{References:}

- Foale, Simon. Fish and People: An innovative fisheries science learning tool for the Pacific. SPC Traditional Marine Resource Management and Knowledge Information Bulletin \#31 (May 2013).

- Oceans IQ website:

https://www.oceansiq.org.au

- Fish and People Video:

https://www.oceansiq.org.au/fish-and-people
FK programme contributors:

-Simon Foale. Associate Professor. Department of Anthropology, Archaeology and Sociology, School of Arts and Social Sciences, Building DA4, James Cook University, Townsville, Queensland 4811, Australia.

Email: simon.foale@jcu.edu.au

- Brett Shorthouse, Oceans IQ Film.

Email: brett.shorthouse@oceansiq.com.au

Case study location: Solomon Islands.

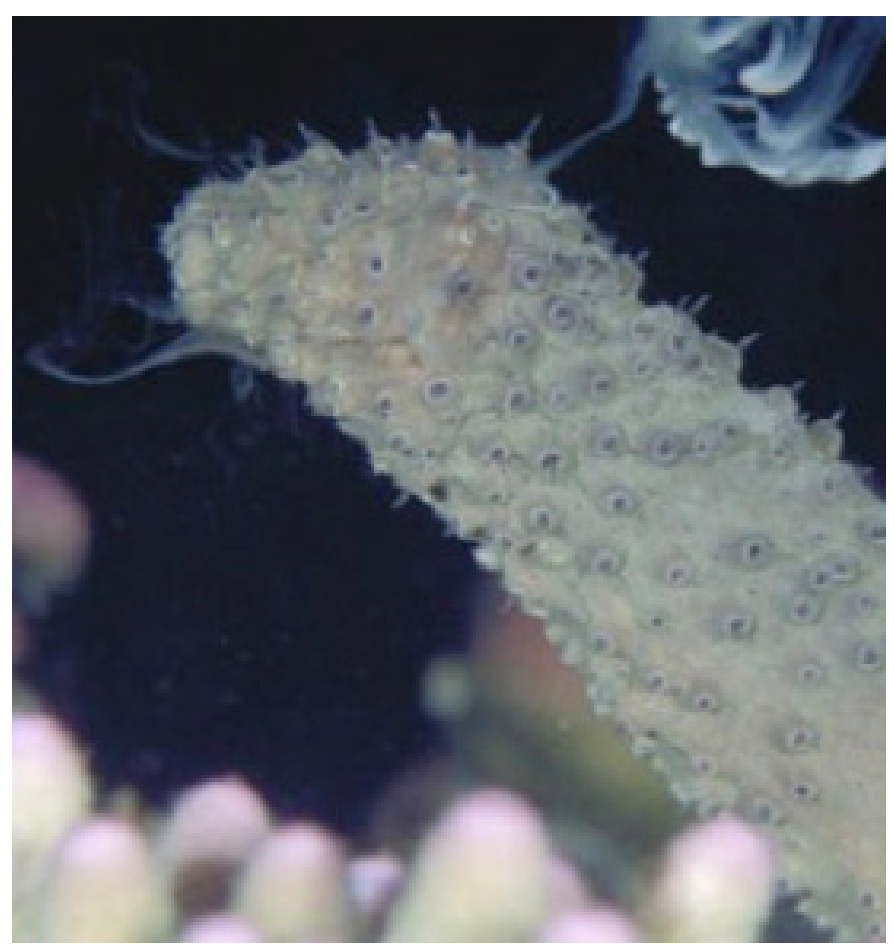

Figure 1: Spawning sea cucumber. One of a variety of images supplied in the supplementary material on the Fish and People DVD. 
Munda

Segie

Bolomon Sea inla

Isaju

\section{suki}

Malalta

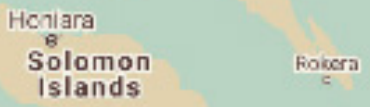

Solomon

oweria

Ari's

Potes

Sin Cristckial

Natiogs

Figure 2: Map of Solomon Islands, Pacific.

\section{FISH AND PEOPLE}

Module 1 Plenty more fish in the sea?

Module 2 where do fish come from?

Module 3 How to make fish

Module 4 Larval lifeboats near and far

Module 5 Fish and people today and tomonow

Figure 3: Opening frame of the 'Fish and People' DVD. 


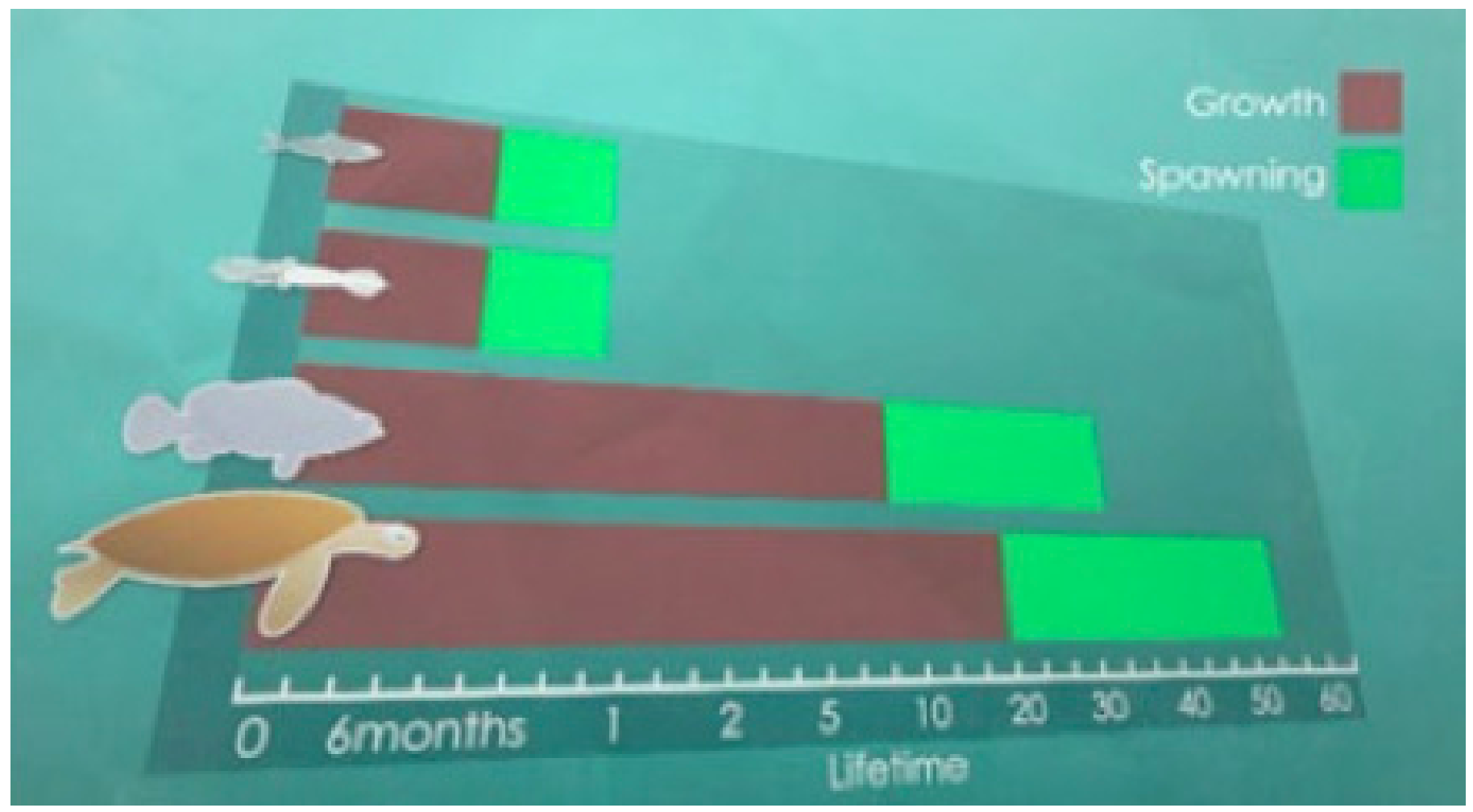

Figure 4: A graphic in Module 3 of Fish and People, demonstrating why knowledge of lifespan and age-at-maturity matters in fishery management.

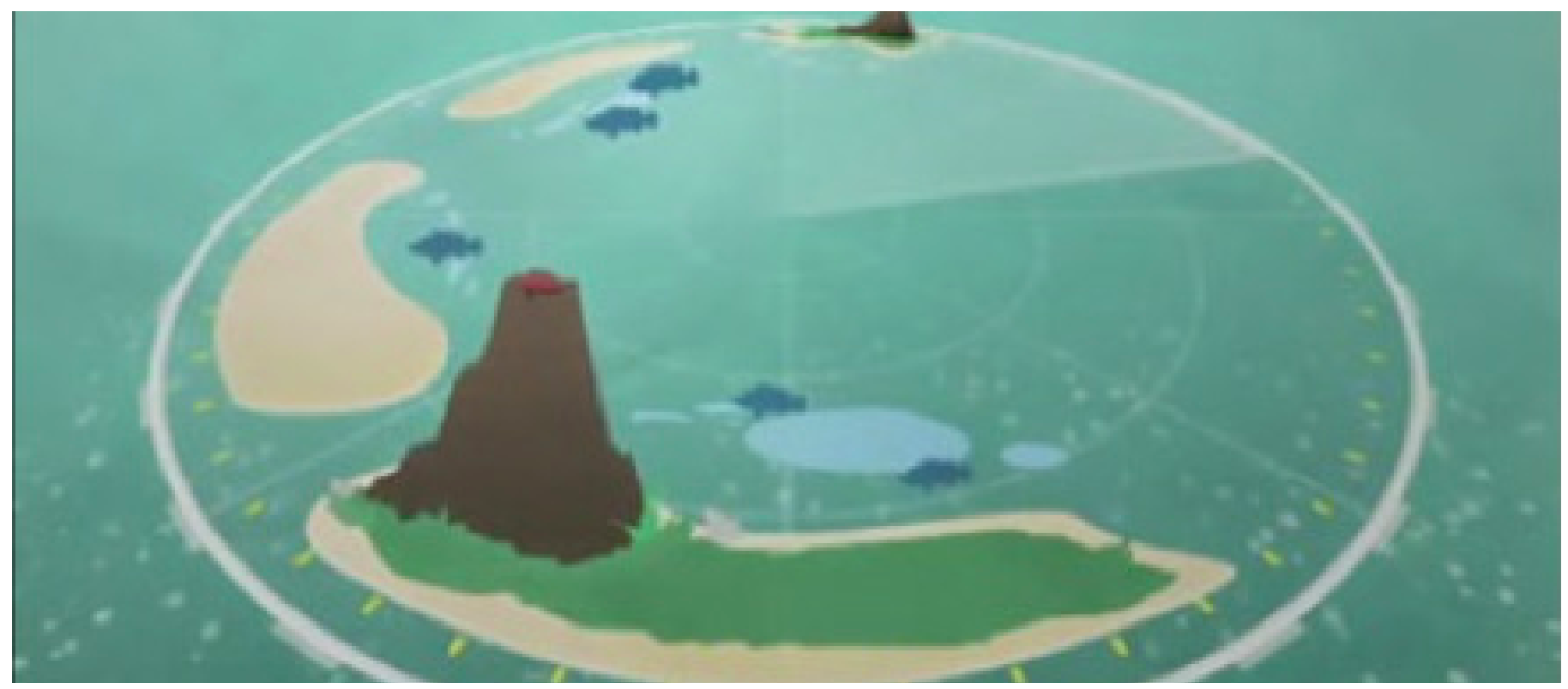

Figure 5: A graphic used throughout the show to illustrate larval dispersal and connectivity processes at the ecosystem scale. 



\section{IUCN}

INTERNATIONAL UNION FOR CONSERVATION OF NATURE

Rue Mauverney 28

1196 Gland, Switzerland

mail@iucn.org

Tel +41229990000

Fax +41229990002

www.iucn.org 